\title{
Characterization and durability evaluation of recycled FRP composites and sandwich specimens
}

\author{
Siddalingesh K. Kalligudd \\ West Virginia University
}

Follow this and additional works at: https://researchrepository.wvu.edu/etd

\section{Recommended Citation}

Kalligudd, Siddalingesh K., "Characterization and durability evaluation of recycled FRP composites and sandwich specimens" (2010). Graduate Theses, Dissertations, and Problem Reports. 4611.

https://researchrepository.wvu.edu/etd/4611

This Thesis is protected by copyright and/or related rights. It has been brought to you by the The Research Repository @ WVU with permission from the rights-holder(s). You are free to use this Thesis in any way that is permitted by the copyright and related rights legislation that applies to your use. For other uses you must obtain permission from the rights-holder(s) directly, unless additional rights are indicated by a Creative Commons license in the record and/ or on the work itself. This Thesis has been accepted for inclusion in WVU Graduate Theses, Dissertations, and Problem Reports collection by an authorized administrator of The Research Repository @ WVU. For more information, please contact researchrepository@mail.wvu.edu. 


\title{
CHARACTERIZATION AND DURABILITY EVALUATION OF RECYCLED FRP COMPOSITES AND SANDWICH SPECIMENS
}

Siddalingesh K. Kalligudd

\author{
Thesis Submitted to the \\ College of Engineering and Mineral Resources at \\ West Virginia University in \\ Partial fulfillment of the requirements \\ For the degree of
}

\author{
Master of Science \\ in \\ Civil Engineering
}

\author{
P.V. Vijay, Ph.D., Chair \\ Hota V. S. GangaRao, Ph.D. \\ Ruifeng Liang Ph.D.
}

Department of Civil and Environmental Engineering

\author{
Morgantown, West Virginia
}

2010

Keywords: Recycled ABS, durability, aging, thermoplastic, thermoset, sandwich composite, salt aging, alkaline aging, SEM 


\section{ABSTRACT \\ CHARACTERIZATION AND DURABILITY EVALUATION OF RECYCLED FRP COMPOSITES AND SANDWICH SPECIMENS}

\section{Siddalingesh K. Kalligudd}

In this research, use of recycled thermoplastic polymer composites for manufacturing and evaluation of structural products is investigated. Durability (aging) evaluations of those polymers have been carried out to predict their service life. Durability studies were initiated coupon levels to evaluate material performance of recycled ABS polymer at under salt and alkaline aging. ABS polymers were reinforced with $4 \%, 7 \%$ and $12 \%$ fiber volume fractions of bi-directional glass fabric (fabric density: $12 \mathrm{oz} / \mathrm{yd}^{2}$ ). Alkaline solution was prepared by mixing $1.4 \%$ of potassium hydroxide $(\mathrm{KOH}), 1 \%$ of sodium hydroxide $(\mathrm{NaOH})$ and $0.2 \%$ of calcium hydroxide $\left(\mathrm{Ca}(\mathrm{OH})_{2}\right)$ salts by weight, which resulted in a $\mathrm{pH}$ of 13.0. Salt solution was prepared by adding $3 \%$ sodium chloride $(\mathrm{NaCl})$ by weight to the standard water which measured a $\mathrm{pH}$ of 7.0. Temperature and humidity were controlled by choosing different freeze-thaw cycles programmed in an environmental chamber for specific humidity and temperature. In this research, the coupon specimens with and without glass fiber reinforced polymers (GFRP) conforming to ASTM standards were conditioned in salt and alkaline solution at room temperature and under freezethaw variations (in environmental chamber), before testing them at regular intervals of $1,4,8$ and 12 months.

The maximum tensile strength reductions were $20 \%, 33.15 \%, 61.46 \%$, and $75.07 \%$ for 0 , 1, 3 and 5 GFRP layered coupon specimens, respectively (with a corresponding fiber volume fraction of $0 \%, 4 \%, 7 \%$ and $12 \%$ ). The maximum bending strength reductions were $13.31 \%$, $13.78 \%, 31.33 \%$, and $52.23 \%$ for $0,1,3$ and 5 layer coupon samples, respectively. The maximum strength reductions in compression test were $11.82 \%, 30 \%, 29.44 \%$, and $45.75 \%$ for $0,1,3$ and 5 layer coupon specimens, respectively. The impact strength reductions were $17 \%$, $70.87 \%, 83.42 \%$, and $93.29 \%$ for corresponding $0,1,3$ and 5 layer coupon specimens. Images were taken for both control and aged samples through Scanning Electron Microscope (SEM) to note the FRP surface texture, variation in fabric pattern, fabric matrix interface, and potential delamination due to salt and alkaline aging.

Thermoplastic (TP)-thermoset (TS) sandwich composites were manufactured to evaluate their behavior and feasibility for structural applications. The mechanical properties of composite products can be optimized by combining thermosets and thermoplastics to minimize the costs. Six different combinations of TS/TP sandwich specimens were manufactured with and without surface roughening. TS/TP/TS roughened specimen (16\% FVF) showed a maximum tensile strength of $11.4 \mathrm{ksi}$, among six types of sandwich specimens. Similarly, maximum tensile modulus of $0.723 \times 10^{6}$ psi was noted.

Research results indicate the significant potential of recycled polymer composites for different applications with the use of continuous glass fabrics (e.g., bidirectional fabrics). Durability evaluations including SEM results indicate that the strength reductions depend on fiber volume fraction and exposed fabric at the cut edges of coupon specimens. The thermoplastic FRP composite must be designed and manufactured such that fabrics are well protected from direct environmental exposure, and proper fiber wet-out is achieved during manufacturing. 


\section{I am dedicating this thesis work to my grandparents Mrs. Prabhawati S. Itagi and Sanganna B. Itagi}




\section{Acknowledgement}

It gives me an immense pleasure to thank the sponsors of this project: MARCEE and NETLDOE.

My honest and heartfelt thanks to Dr. P V. Vijay and Dr. Hota GangaRao for offering me an opportunity to work with the Constructed Facilities Center, WVU.

I heartily thank my committee chair and advisor, Dr. Vijay, whose guidance, encouragement, direction and support right from the day one to last day of thesis completion at WVU. Dr. Vijay was more than advisor for me during my stay in Morgantown. His way of guiding me both academically and personally made me feel that he is my greatest well wisher. Dr. Vijay is the person I would think of approaching if I needed any suggestion. I have learnt being patient from Dr. Vijay.

Working with Dr. Hota was one of the best learning experiences for me. Each time I visited his office I learnt something new, both technically and non-technically. I really like his approach towards solving problems, the way he elaborates and analyzes them; this is something I would like to learn from him. My best time during masters is the time I spent with Dr. Hota in his office working on ASCE LRFD Pultruded manual. I am a big fan of Dr. Hota.

I would like to thank Dr. Ruifeng Liang for being in my committee. Dr. Liang has a helping nature.

Right from the beginning of masters program at WVU and also my work with the Constructed Facilities Center, I have worked on most of the projects from 2006 to 2010. Working with different projects at $\mathrm{CFC}$ has helped me grow stronger technically. I have learnt to plan and organize work.

I feel affection for my noble grandparents Mrs. Prabhawati S. Itagi and Mr. Sanganna B. Itagi; my loving parents Savita and Karabasappa Kalligudd; my caring brothers Parappa and Harish; and all my relatives and cousins for their love, encouragement and support throughout my education, I love you all.

I would like to thank all my friends: Aneesh, Amarnath, Avinash, Manohar, Abhijit, Srinath, Manab, Vamsi, Nagasree, Praveen, Lavanya, Niranjan, Saurabh, Raj, and Sridhar who helped me directly or indirectly during my work at WVU and stay in Morgantown. I would like to thank Mark Skidmore for helping me with experimentation and Lynne Jacobs for paper work. I also would like to thank Mr. Jerry Nestor and Mr. David Turner, who helped me during manufacturing and machining of specimens required for my thesis work.

Siddalingesh K. Kalligudd 


\section{Table of contents}

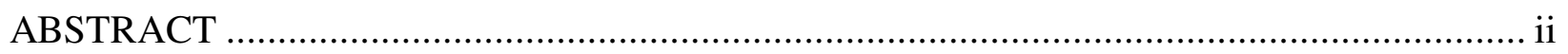

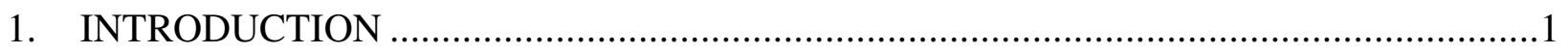

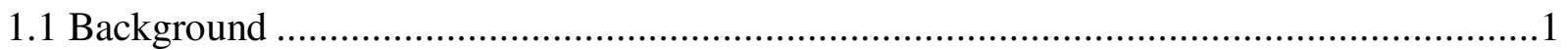

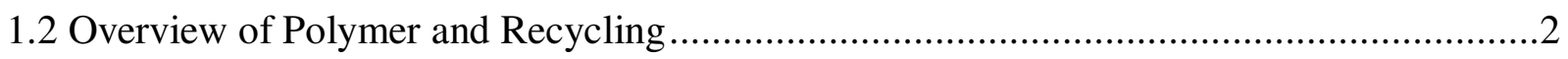

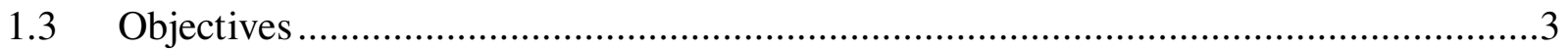

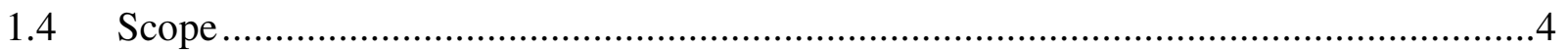

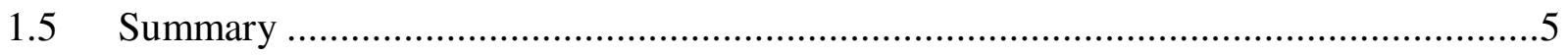

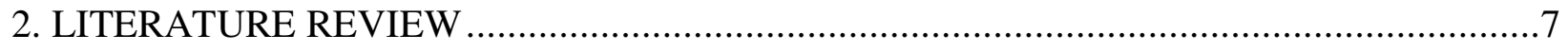

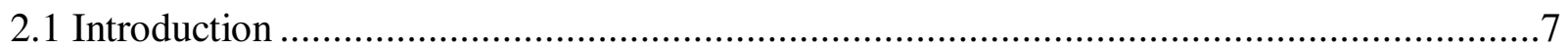

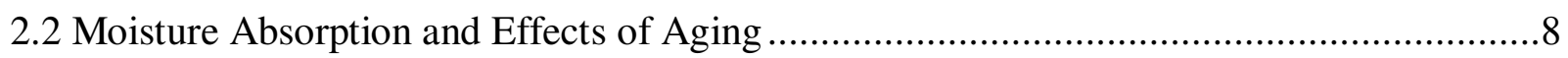

3. MATERIALS, MOLDING PROCESS and AGING SCHEMES ......................................11

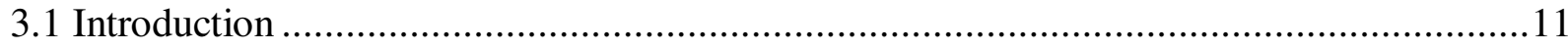

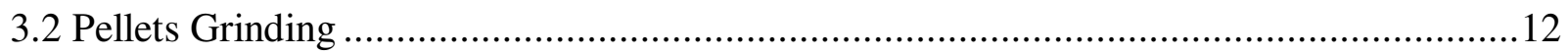

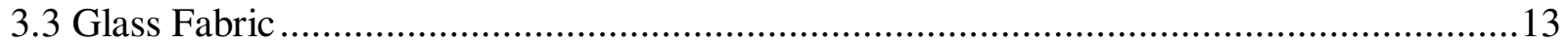

3.3.1 Fiber Weight Fraction.......................................................................................13

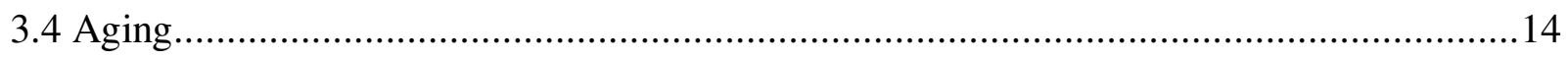

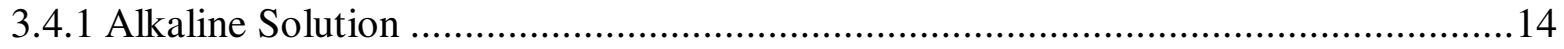

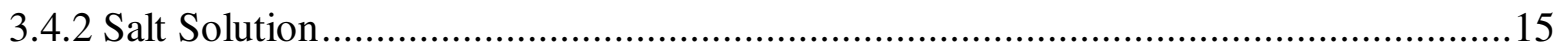

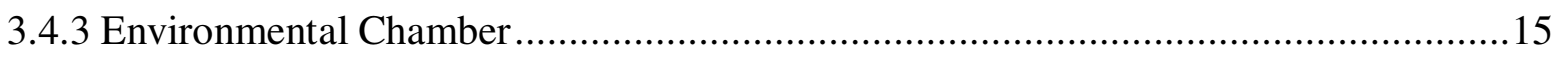

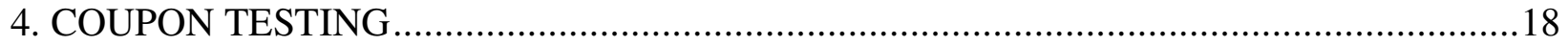

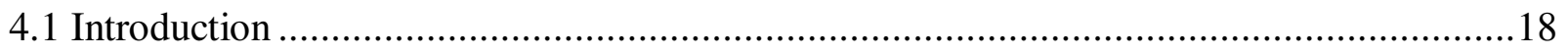

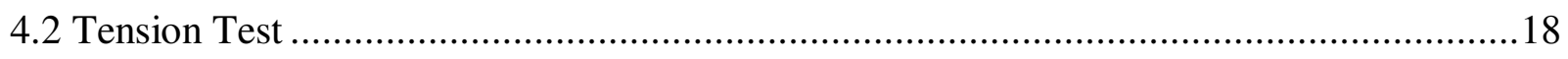

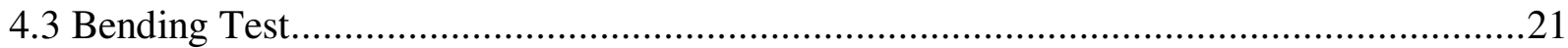

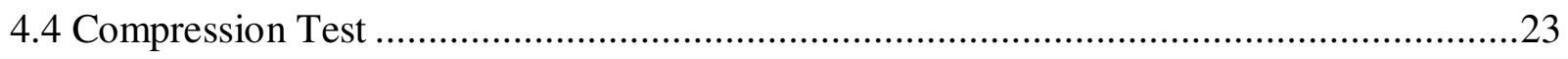

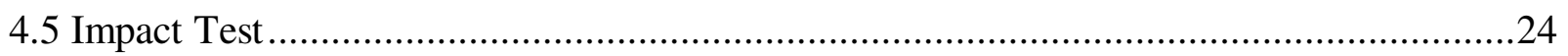

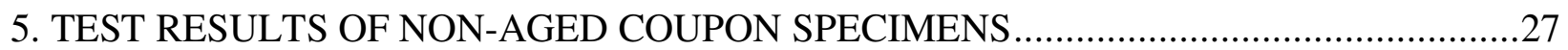

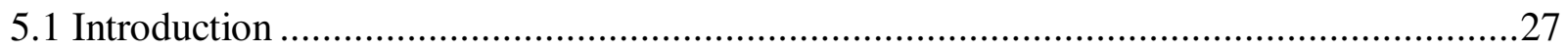

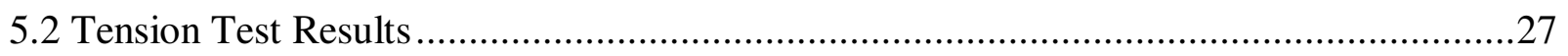

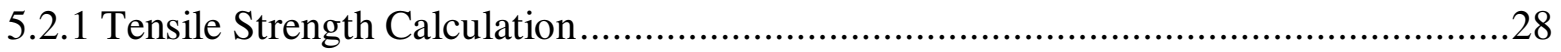

Note: Tensile Modulus data is in line with Rule of Mixture (Refer: Appendix E) ...............29 


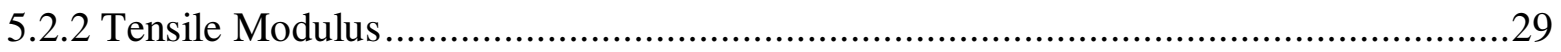

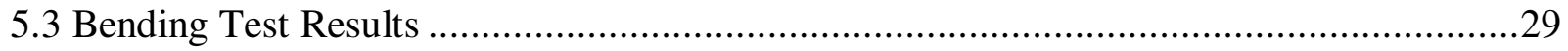

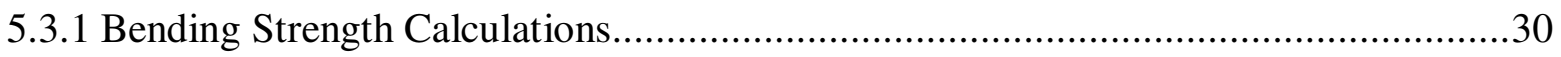

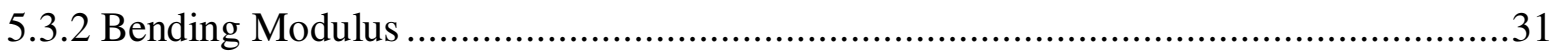

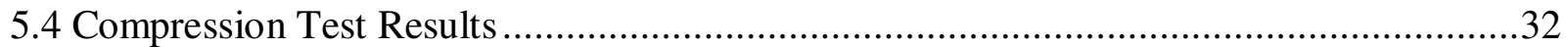

5.4.1 Compressive Strength Calculations …………….................................................. 32

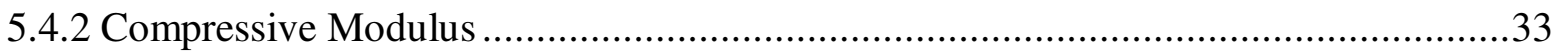

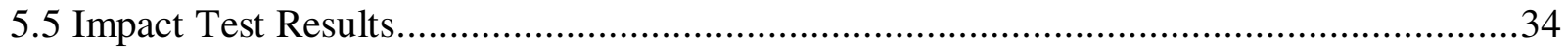

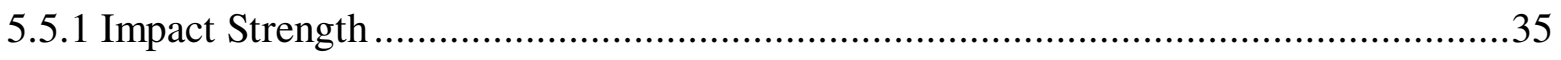

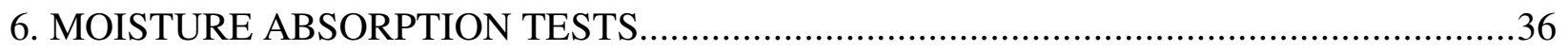

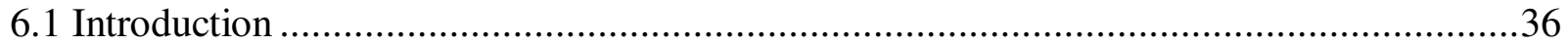

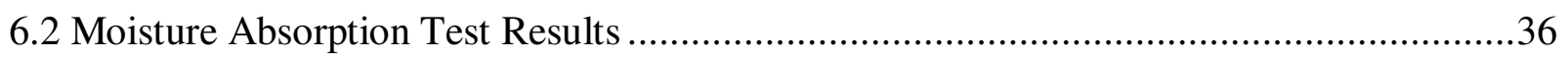

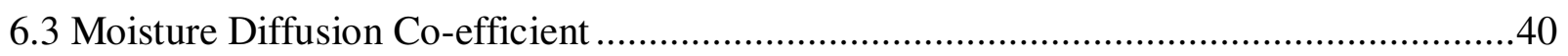

7. DURABILITY EVALUATION OF RECYCLED POLYMERS.........................................4

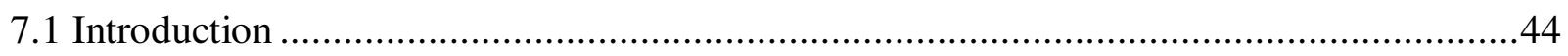

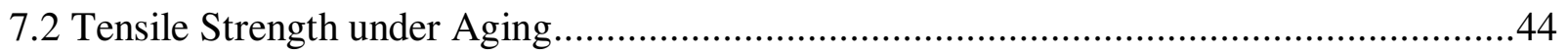

7.2.1 Alkaline solution under room temperature and freeze-thaw (Tension)........................45

7.2.2 Salt solution under room temperature and freeze-thaw (Tension) ...............................4

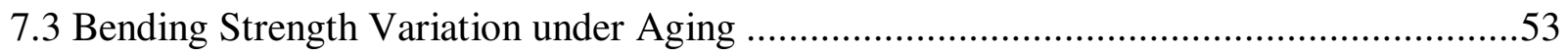

7.3.1 Alkaline aging under room temperature and freeze-thaw (Bending).........................53

7.3.2 Salt aging under room temperature and freeze-thaw (Bending) ..................................56

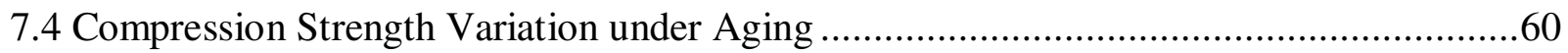

7.4.1 Alkaline aging under room temperature and freeze-thaw (Compression) ...................60

7.4.2 Salt aging under room temperature and freeze-thaw (Compression) ..........................63

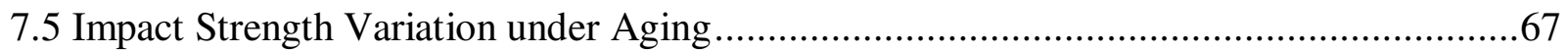

7.5.1 Alkaline aging under room temperature and freeze-thaw (Impact) ............................67

7.5.2 Salt aging under room temperature and freeze-thaw (Impact) ...................................68

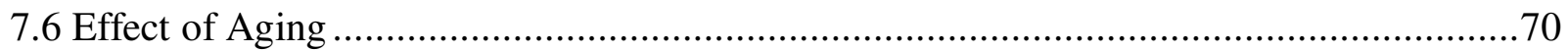

7.6.1 Effects of Alkaline Conditioning …………….......................................................

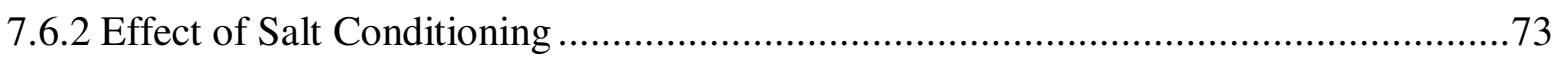

7.7 Recycled Polymer Composition Effects on Mechanical Properties ..................................78 
8. Scanning Electron Microscope (SEM) and Discussion of Durability Test Results................80

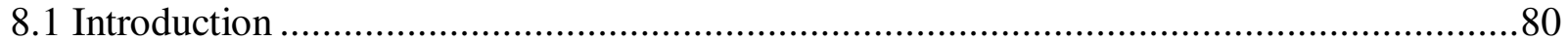

8.2 Scanning Electron Microscopy...................................................................... 80

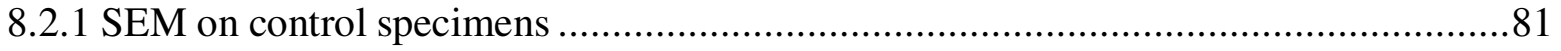

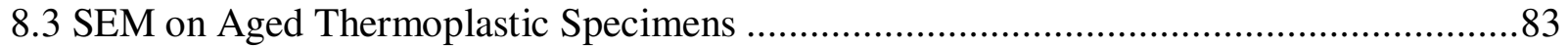

8.3.1 SEM on specimens in alkaline solution (one month) ..........................................84

8.3.2 SEM on specimens in alkaline solution (four months) .......................................86

8.3.3 SEM on specimens in salt solution (one month) ............................................89

8.3.4 SEM of specimens in salt solution (four months) ..............................................91

8.3.5 SEM of specimens in salt solution (eight months) .......................................92

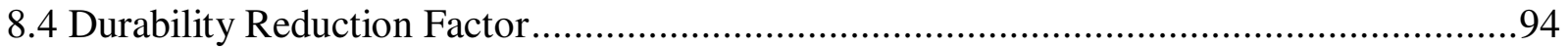

9. THERMOPLASTIC THERMOSET SANDWICH SPECIMENS ....................................96

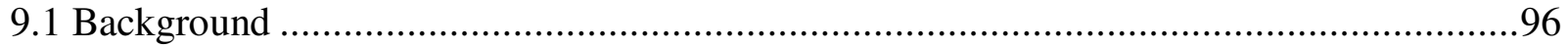

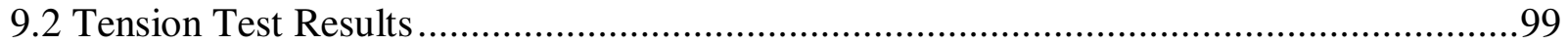

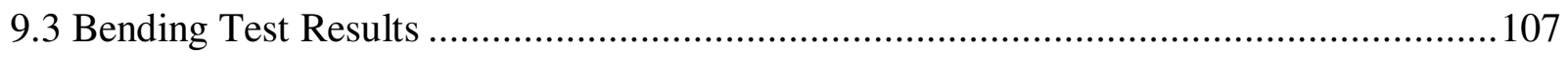

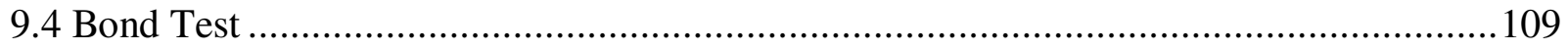

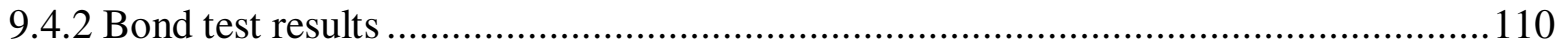

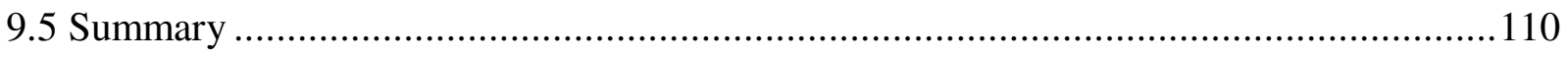

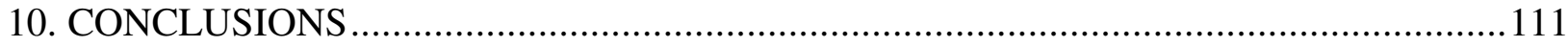

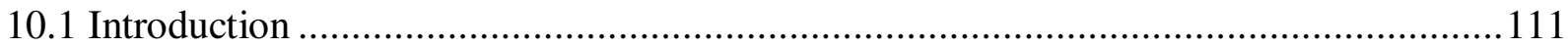

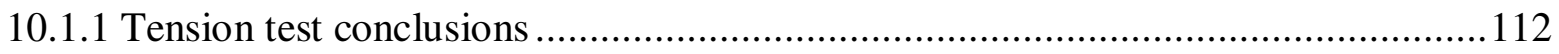

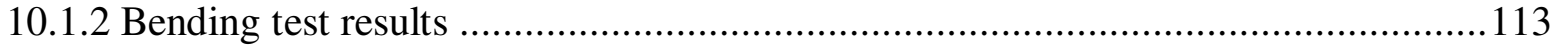

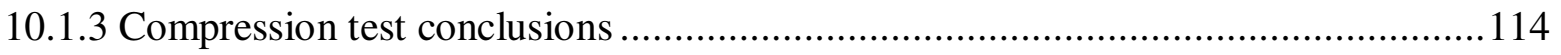

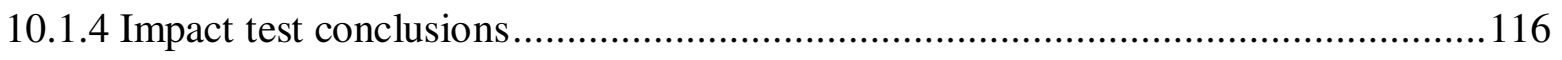

10.2 Conclusions for Moisture Absorption Test ......................................................... 116

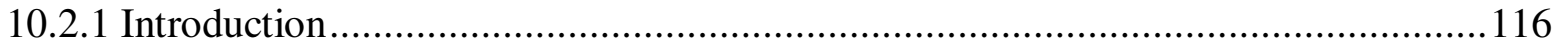

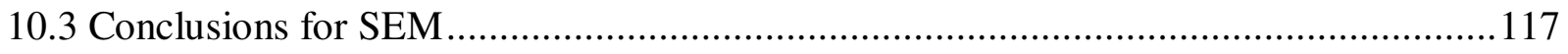

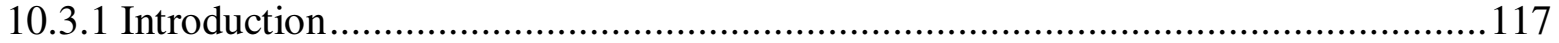

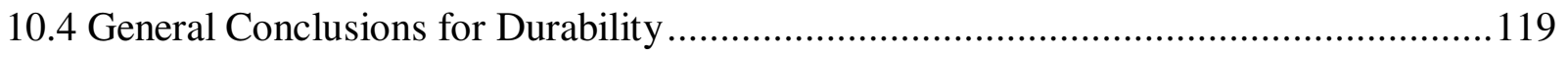

10.5 Conclusions for Thermoplastic and Thermoset Sandwich Composites .......................119

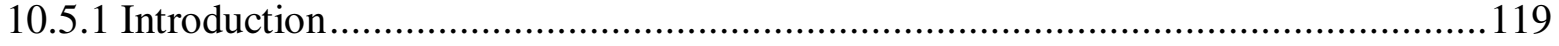




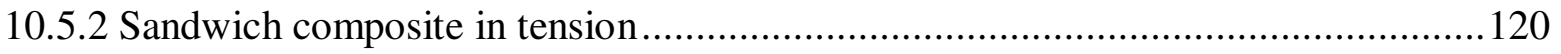

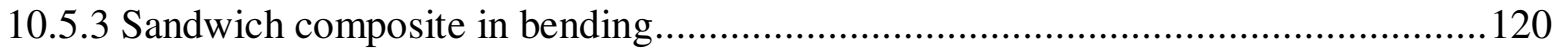

10.5.4 General conclusions for TS and TP sandwich composites ...................................121

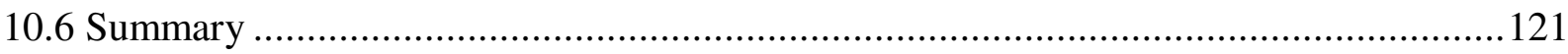

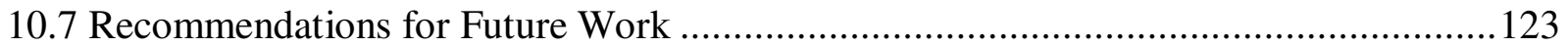

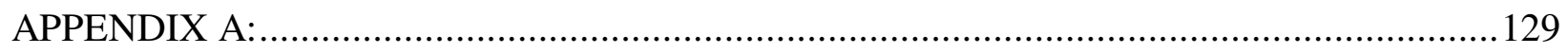

A.1 Earlier Research at CFC-WVU ……….................................................................129

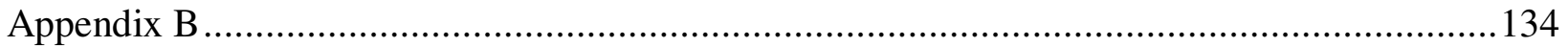

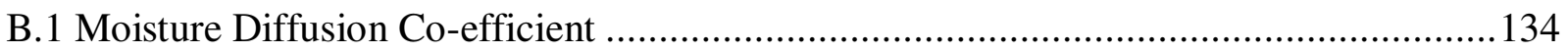

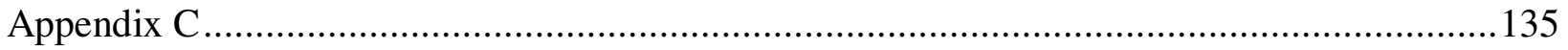

Summary of Coupon Strength Variations under Salt and Alkaline Aging at Room Temperature

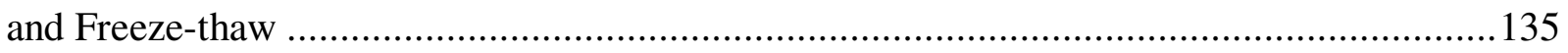

C.1 Summary for tension strength under aging ..............................................................135

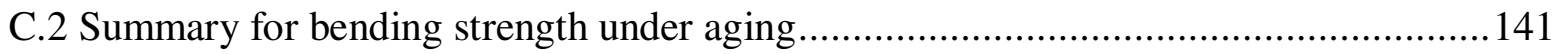

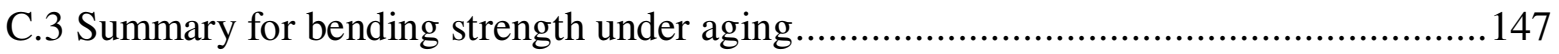

C.3.1 Bar graph for compressive strength variation for aged specimens............................150

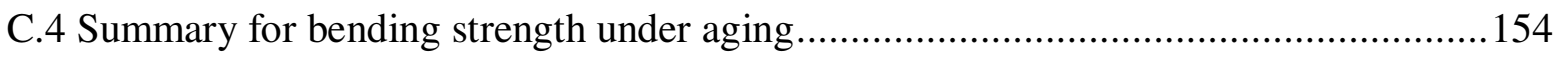

C.4.1 Bar graph for impact strength variation for aged specimens ..................................156

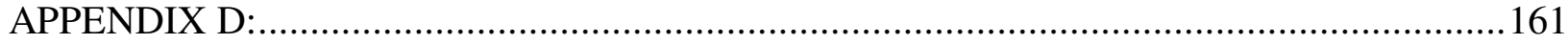

D.1 Hand Lay-Up Method Sandwich Composites Thermoplastic/Thermoset (TP/TS)..........161

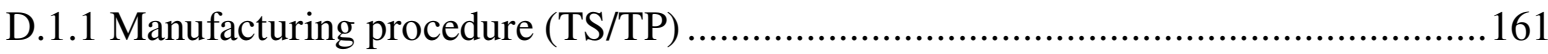

D.1.2 Procedure for manufacturing thermoplastics/thermoset/thermoplastics (TP/TS/TP) 163

D.1.3 Procedure for manufacturing thermoset/thermoplastics/thermoset (TS/TP/TS)........164

D.2 Bonding between Thermoplastic and Thermoset (TS/TP/TS) with End Tabs..................164

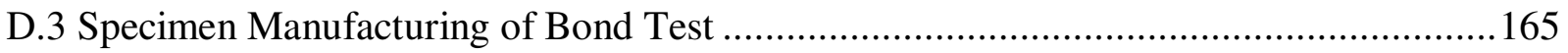

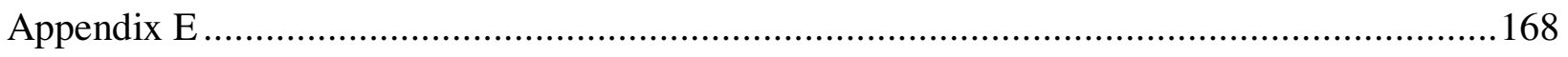

Rule of Mixtures for non-aged Tension and Bending test results:.........................................168 


\section{List of Figures}

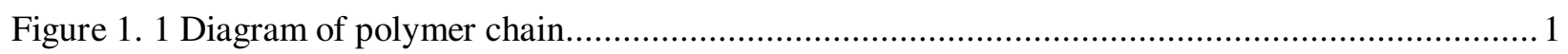

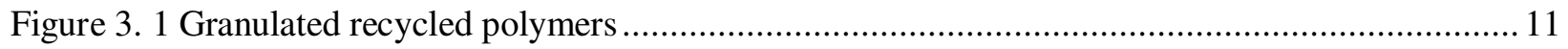

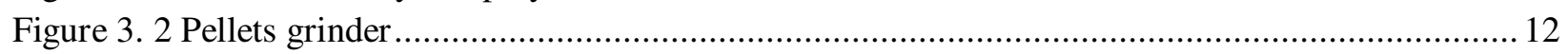

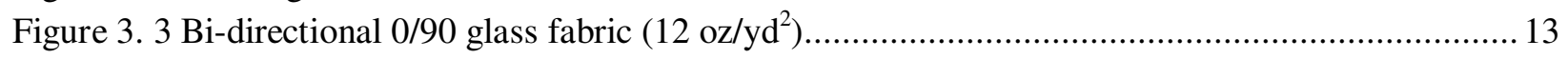

Figure 3. 4 Tension, bending, impact and compression specimen .................................................... 14

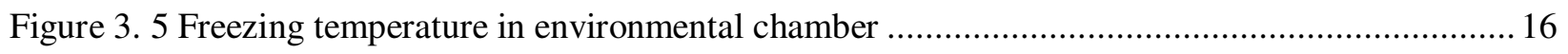

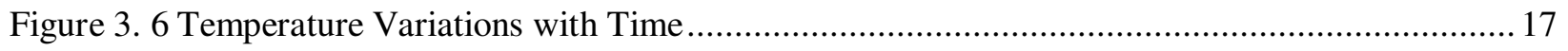

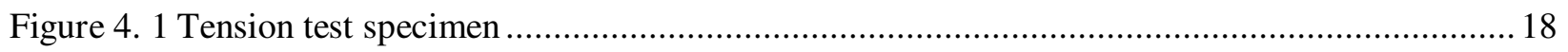

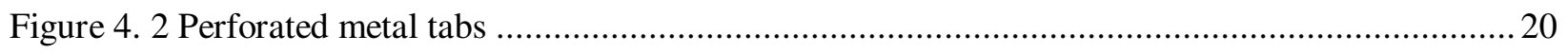

Figure 4. 3 Tension test setup with data Acquisition................................................................ 20

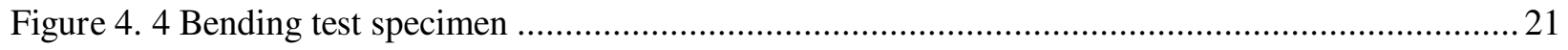

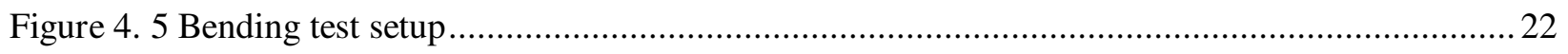

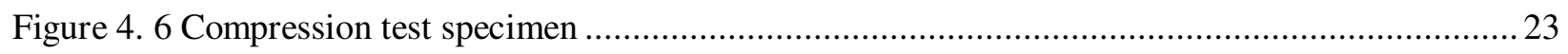

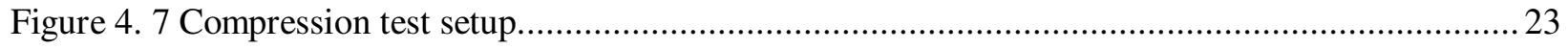

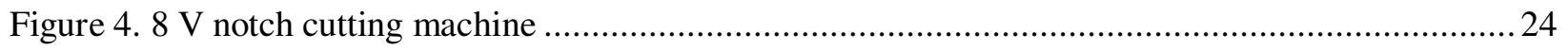

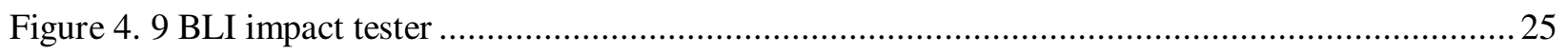

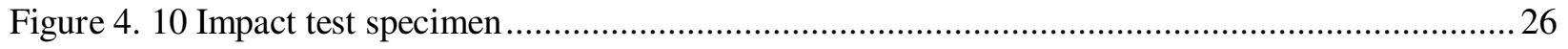

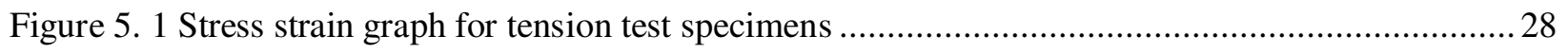

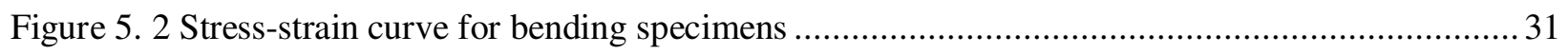

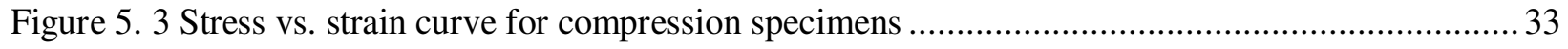

Figure 5. 4 Impact strengths with increasing number of fabrics .................................................... 35

Figure 6. 1 Moisture absorption test at room temperature ......................................................... 36

Figure 6. 2 Water, salt and alkali absorption vs. fabric layer plot.................................................... 37

Figure 6. 3 Salt and alkaline solution diffusion pattern ............................................................. 38

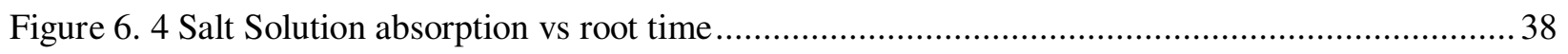

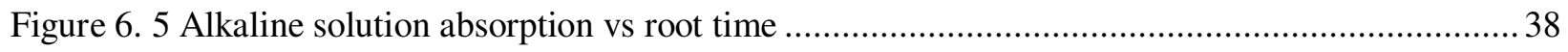

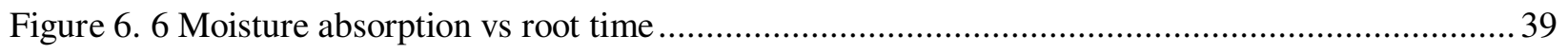

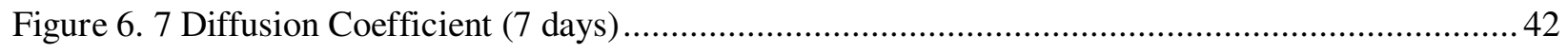

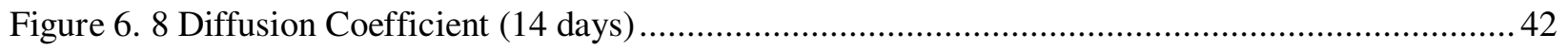

Figure 7. 1 Stress strain curves for specimens in alkaline solution environmental chamber for one month

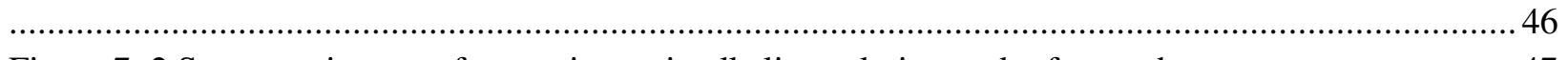

Figure 7. 2 Stress strain curve for specimens in alkaline solution under freeze-thaw ............................47

Figure 7. 3 Tension modulus in alkaline solution under freeze-thaw variations...................................4 47

Figure 7. 4 Tensile stress-strain in salt solution under freeze-thaw (environmental chamber) for one month

Figure 7. 5 Tensile stress-strain in salt solution under freeze-thaw (environmental chamber) for eight months

Figure 7. 6 Tension modulus variation of thermoplastic specimens in alkaline solution with freeze-thaw

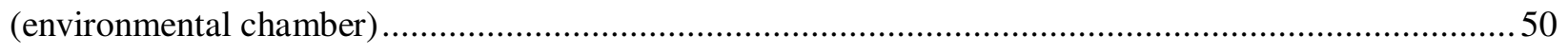

Figure 7. 7 Failure modes in thermoplastic tension test coupon specimens ........................................52 
Figure 7. 8 Bending stress-strain in alkaline solution under freeze-thaw (environmental chamber) for one

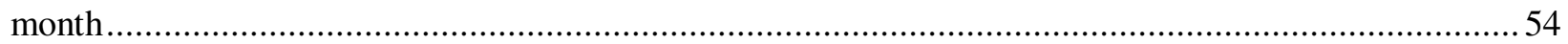

Figure 7. 9 Bending stress-strain conditioned in alkaline solution under freeze-thaw (environmental

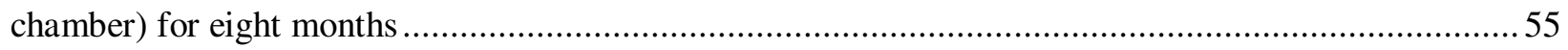

Figure 7. 10 Bending modulus in alkaline solution under freeze-thaw for one and eight months ............55

Figure 7. 11 Bending stress-strain in salt solution under freeze-thaw for one month .........................5 57

Figure 7. 12 Bending stress-strain in salt solution underfreeze-thaw (environmental chamber) for eight

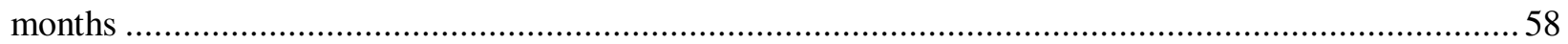

Figure 7. 13 Bending modulus in salt solution under freeze-thaw ..............................................5

Figure 7. 14 Failure modes conditioned in salt/alkaline solution and freeze-thaw (environmental chamber)

Figure 7. 15 Compressive stress-strain in alkaline solution under freeze-thaw for one month

61

Figure 7. 16 Compressive stress-strain curve in alkaline solution under freeze-thaw (environmental

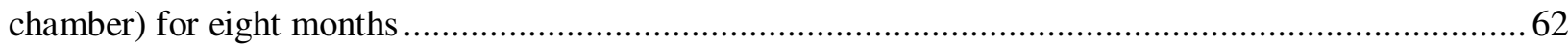

Figure 7. 17 Compression modulus in alkaline solution under freeze-thaw for one and eight months...... 63

Figure 7. 18 Compression stress-strain in salt solution under freeze-thaw conditioning for one month.... 64

Figure 7. 19 Compression stress-strain in salt solution under freeze-thaw conditions for eight months.... 65

Figure 7. 20 Compression modulus in salt solution under freeze-thaw chamber after one and eight months

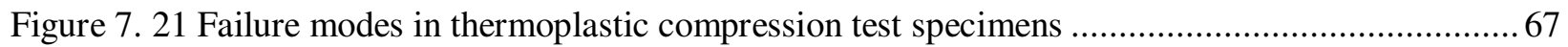

Figure 7. 22 Failure modes in thermoplastic impact test specimens .............................................. 70

Figure 7. 23 Visual absence of fabric at rupture location (alkaline solution conditioning under freeze-

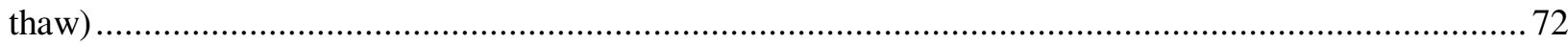

Figure 7. 24 Rupturing of fabric was noted after eight months of aging in alkaline solution at room

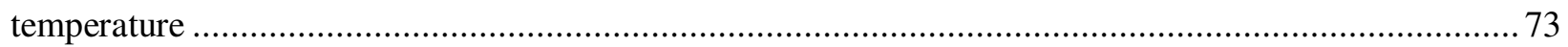

Figure 7. 25 Fabric were not ruptured in specimens subjected to salt solution under freeze-thaw ............73

Figure 7. 26 Fabric were not ruptured in specimens subjected to salt solution at room temperature......... 74

Figure 7. 27 Absence of fabric (alkaline conditioning, left) and presence of fabric (salt conditioning, right)

Figure 7. 28 Complete rupturing of fabric and delamination at the fabric-matrix interface for specimens in

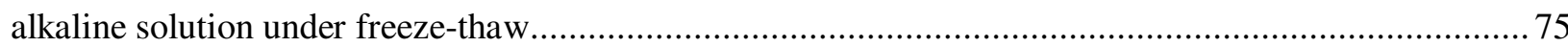

Figure 7. 29 Crack formation in tension zone for specimens in salt solution under freeze-thaw ..............76

Figure 7. 30 Crack formation in tension zone for specimens in alkaline solution at room temperature .... 77

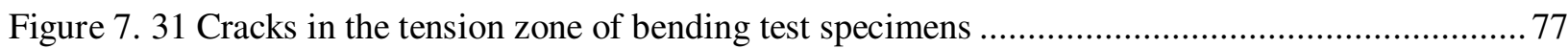

Figure 7. 32 Crack formation and delamination for specimens in alkaline solution under freeze-thaw .... 78

Figure 7. 33 Presence of different pellet grades and voids might alter the strength of polymer .............. 79

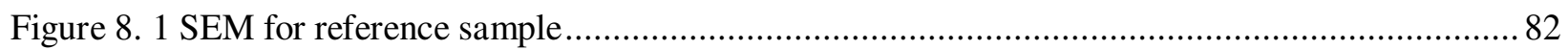

Figure 8. 2 SEM sample aged for 1 month alkaline solution environmental chamber (Axial Direction) .. 85

Figure 8. 3 SEM sample aged for 1 month alkaline solution environmental chamber (Transverse

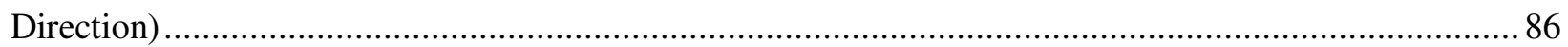

Figure 8. 4 SEM Sample Aged for 4 Month Alkaline Solution Freeze-thaw (Axial Direction) ................ 87

Figure 8. 5 SEM sample aged for 4 month alkaline solution environmental chamber (Transverse

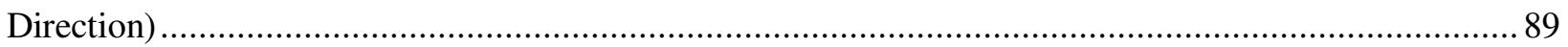

Figure 8. 6 SEM sample aged for 1 month salt solution environmental chamber (Axial Direction) .........90 
Figure 8. 7 SEM Sample Aged for one Month Salt Solution Freeze-thaw (Transverse Direction) ...........91

Figure 8. 8 SEM sample aged for 4 month salt solution environmental chamber (Axial Direction) .........91

Figure 8. 9 SEM sample aged for 4 month salt solution environment chamber (Transverse Direction).... 92

Figure 8. 10 SEM sample aged for 8 month salt solution environmental chamber (Transverse Direction) 93

Figure 9. 1 Six types of thermoplastic and thermoset composite plates .......................................... 98

Figure 9. 2 Tensile stress-strain for vinyl ester and virgin ABS tension test specimen.......................... 100

Figure 9. 3 Stress strain graph for TP/TS/TP roughened tension test specimen ................................. 101

Figure 9. 4 Stress strain graph for TP/TS/TP roughened specimen ............................................... 101

Figure 9. 5 Thermoplastic/Thermoset/Thermoplastic tension test .............................................. 103

Figure 9. 6 Stress strain graph for TS/TP roughened tension test specimen....................................... 104

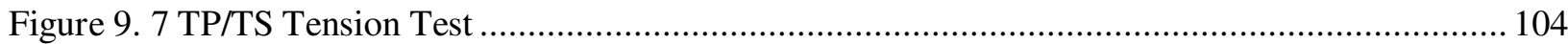

Figure 9. 8 Stress strain graph for TS/TP/TS roughened tension test specimen ................................. 106

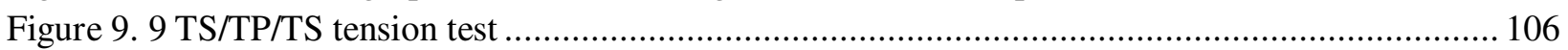

Figure 9.10 Delamination of thermoplastic and thermoset sandwich composite ............................... 108

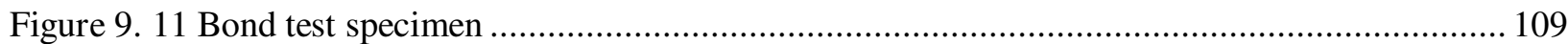

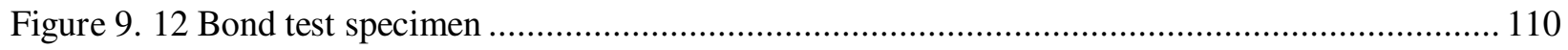

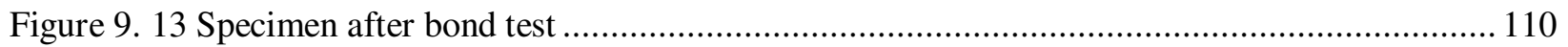

Figure C. 1 Strength reductions in alkaline solution at room temperature ...................................... 137

Figure C. 2 Percentage strength reductions in alkaline solution at room temperature .......................... 138

Figure C. 3 Strength reductions in alkaline solution under freeze-thaw......................................... 138

Figure C. 4 Percentage strength reductions in alkaline solution under freeze-thaw............................. 139

Figure C. 5 Strength reductions in salt solution at room temperature ................................................ 139

Figure C. 6 Percentage strength reductions in salt solution at room temperature ................................. 140

Figure C. 7 Strength reductions in salt solution under freeze-thaw ............................................... 140

Figure C. 8 Percentage strength reductions in salt solution under freeze-thaw ................................... 141

Figure C. 9 Strength reductions in alkaline solution at room temperature ........................................ 144

Figure C. 10 Percentage strength reductions in alkaline solution at room temperature ........................ 144

Figure C. 11 Strength reductions in alkaline solution under freeze-thaw ........................................... 145

Figure C. 12 Percentage strength reductions in alkaline solution under freeze-thaw........................... 145

Figure C. 13 Strength reductions in salt solution at room temperature ........................................... 146

Figure C. 14 Percentage strength reductions in salt solution at room temperature ............................. 146

Figure C. 15 Strength reductions in salt solution under freeze-thaw............................................... 147

Figure C. 16 Percentage strength reductions in salt solution under freeze-thaw ................................ 147

Figure C. 17 Strength reductions in alkaline solution at room temperature ...................................... 150

Figure C. 18 Percentage strength reductions in alkaline solution at room temperature ....................... 151

Figure C. 19 Strength reduction in alkaline solution under freeze-thaw ......................................... 151

Figure C. 20 Percentage strength reductions in alkaline solution under freeze-thaw........................... 152

Figure C. 21 Strength reductions in salt solution at room temperature ............................................ 152

Figure C. 22 Percentage Strength reductions in salt solution at room temperature.............................. 153

Figure C. 23 Strength reductions in salt solution under freeze-thaw............................................. 153

Figure C. 24 Percentage strength reductions in salt solution under freeze-thaw ................................ 154

Figure C. 25 Strength reductions in alkaline solution at room temperature ...................................... 157

Figure C. 26 Percentage strength reductions in alkaline solution at room temperature ........................ 157

Figure C. 27 Strength reductions in alkaline solution under freeze-thaw .......................................... 158 
Figure C. 28 Percentage strength reductions in alkaline solution under freeze-thaw........................... 158

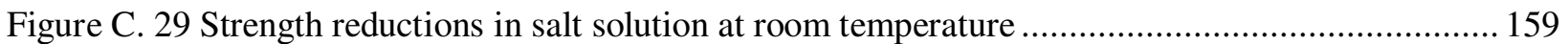

Figure C. 30 Percentage strength reductions in salt solution at room temperature .............................. 159

Figure C. 31 Strength reductions in salt solution under freeze-thaw............................................... 160

Figure C. 32 Percentage strength in salt solution under freeze-thaw ............................................... 160

Figure D. 1 DeWALT Heavy-Duty 7"/ 9" Large Angle Sander.......................................................... 161

Figure D. 2 Manufacturing of TP/TS composite sandwich plate ..................................................... 163

Figure D. 3 Bonding of composite sandwich plate components (TP/TS/TP) ..................................... 164

Figure D. 4 Application of tabs for sandwich specimens ............................................................. 165

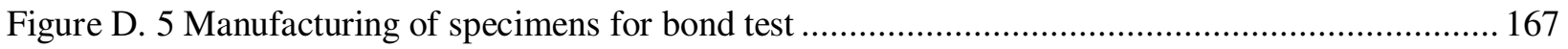




\section{List of Tables}

Table 1. 1 Recycled polymer specimens for durability test ...................................................... 4

Table 1. 2 Summary of test for TS/TP sandwich composites ........................................................... 5

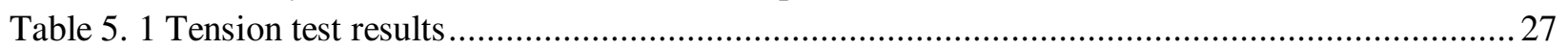

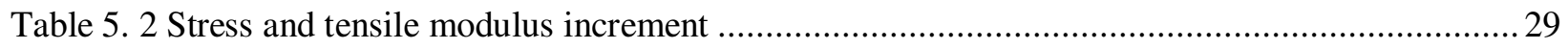

Table 5. 3 Bending test results of non-aged samples............................................................................. 30

Table 5. 4 Percentage stress and modulus increment for bending test ............................................ 31

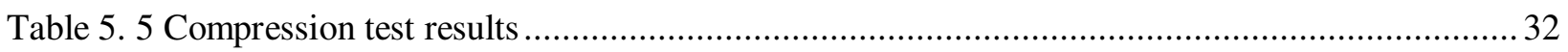

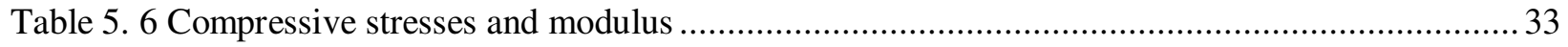

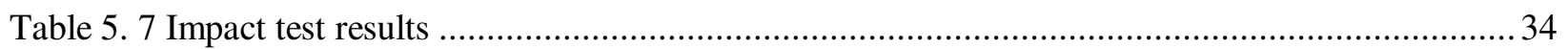

Table 5. 8 Impact strength increment with fiber volume fraction ...................................................... 35

Table 6. $1 \mathrm{Mt} / \mathrm{M} \infty$ values for various solutions and fabric layers for 48 days ..................................... 40

Table 6. 2 Diffusion Coefficient .......................................................................................... 41

Table 7. 1 Tensile strength reductions for non-fabric specimens under 12 months in salt and alkaline

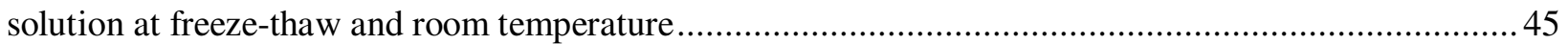

Table 7. 2 Tension test results in alkaline solution at room temperature................................................. 45

Table 7. 3 Tension test results in alkaline solution under freeze-thaw ................................................. 46

Table 7. 4 Tension modulus in alkaline solution under freeze-thaw for one and eight months ............... 47

Table 7. 5 Tension strength in salt solution at room temperature ....................................................... 48

Table 7. 6 Tension strength in salt solution under freeze-thaw variations......................................... 48

Table 7. 7 Tension modulus in salt solution under freeze-thaw for one and eight months......................50

Table 7. 8 Bending strength reductions for non-fabric specimens under 12 months in salt and alkaline

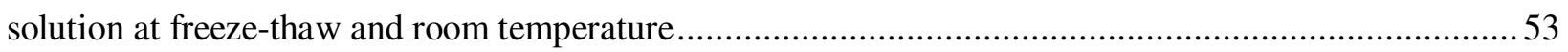

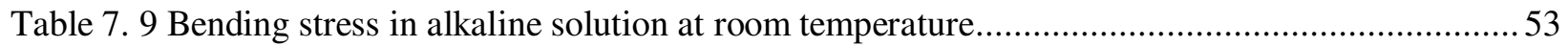

Table 7. 10 Bending stress under freeze-thaw conditions (environmental chamber) ..............................54

Table 7. 11 Bending modulus in alkaline solution under freeze-thaw for one and eight months .............55

Table 7. 12 Bending stress in salt solution at room temperature.....................................................56

Table 7. 13 Bending stress in salt solution with freeze-thaw (environmental chamber) ........................57

Table 7. 14 Bending modulus in salt solution under freeze-thaw variations aged for one and eight months

Table 7. 15 Compressive strength reductions for non-fabric specimens under 12 months in salt and alkaline solution at freeze-thaw and room temperature.

Table 7. 16 Compression test results of specimens conditioned in alkaline solution at room temperature 61 Table 7. 17 Compression test results of thermoplastic specimens conditioned in alkaline solution with freeze-thaw (environmental chamber)

Table 7. 18 Compression modulus variations of thermoplastic specimens conditioned for one and eight

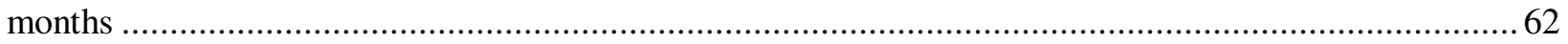

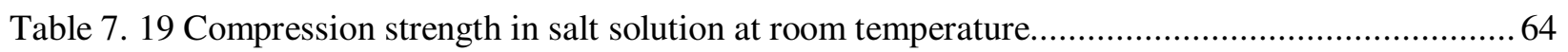

Table 7. 20 Compression strength in salt solution with freeze-thaw conditioning .................................64

Table 7. 21 Modulus variations for one and eight months aged compression specimens ...................... 65

Table 7. 22 Impact strength reductions for non-fabric specimens under 12 months in salt and alkaline

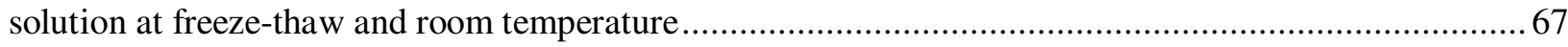

Table 7. 23 Impact energy in alkaline solution at room temperature ............................................... 68 
Table 7. 24 Impact energy in alkaline solution under freeze-thaw

Table 7. 25 Impact test results of thermoplastic specimens conditioned in salt solution at room temperature

Table 7. 26 Impact energy in salt solution under freeze-thaw variations (environmental chamber).....

Table 8. 1 Maximum percentage strength reduction of tension, bending comp and impact specimens..... 81

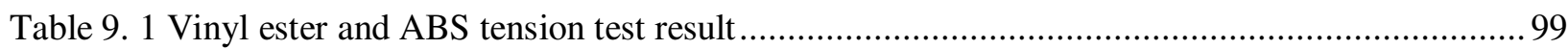

Table 9. 2 Thermoplastic thermoset (TP/TS/TP) tension test result ................................................... 102

Table 9. 3 Thermoplastic thermoset (TP/TS) tension test results ................................................... 103

Table 9. 4 Thermoplastic thermoset (TS/TP/TS) tension test results ............................................ 105

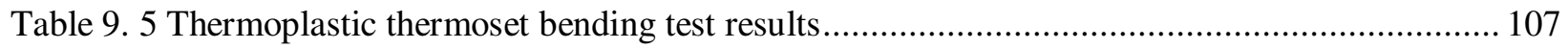

Table 9. 6 Thermoplastic thermoset (TP/TS) bending test results ................................................. 108

Table 9. 7 Bond test summary................................................................................................. 110

Table A. 1 Samples tested, resin type, and type of fibers (Bargo, 2000).......................................... 129

Table A. 2 Types of coupon specimens from conditioned recycled thermoplastics (Basto, 2002).......... 130

Table A. 3 Guardrail post, rail and offset block specimens tested times (Basto, 2002) ....................... 130

Table A. 4 Types of bending specimens for guardrail systems (Basto, 2002) ................................... 130

Table A. 5 Structural components manufactured with different fiber volume fractions (Amarnath, 2006)

Table A. 6 Bending tests on structural components (Amarnath, 2006) ........................................... 132

Table C. 1 Strength variations for non-fabric tension test specimens subjected to aging for 1, 4, 8 and 12 months

Table C. 2 Strength variations for tension test specimens subjected to aging for 1, 4, 8 and 12 months . 135 Table C. 3 Strength variations for non-fabric bending test specimens subjected to aging for 1, 4, 8 and 12 months

Table C. 4 Strength variations for thermoplastic bending test specimens subjected to aging for 1, 4, 8 and 12 months.

Table C. 5 Strength variations for non-fabric compression test specimens after 1, 4, 8 and 12 months of aging

Table C. 6 Strength variations for compression test specimens subjected to aging for 1, 4, 8 and 12 months

Table C. 7 Strength variations for non-fabric impact test specimens subjected to aging for 1, 4, 8 and 12 months

Table C. 8 Strength variations for impact test specimens subjected to aging for 1, 4, 8 and 12 months.. 155 


\section{INTRODUCTION}

\subsection{Background}

Glass fibers reinforced polymer (GFRP) composites are replacing the metallic components because of recycling capability, non-corrosiveness, and high strength to weight ratio (Chin et al., 1997). When fibers are incorporated in polymers they are commonly referred to as Fiber Reinforced Polymer (FRP) composites. Polymers in general are giant molecules (compared to hydrocarbon molecules) formed by the long chain of carbon atoms which forms the spine of polymer chain. The polymer properties mainly depend on polymer array and degree of polymerization. The atomic chains of thermoplastic are linear (Figure 1.1 (a)) and those of thermoset are cross linked (Figure 1.1 (b)). Atoms of linear and cross linked polymer chains are held together by Van der waal and covalent bonds, respectively. Cross-linking in plastics is due to presence of additive atoms and molecules. This research focuses on characterization and durability evaluation of recycled thermoplastic FRP composites with emphasis on Acrylonitrile Butadiene Styrene (ABS) because our objective is to evaluate recycled polymers as per the sponsor. Pelletized Acrylonitrile-butadiene styrene (ABS) polymer used in this research was received from Star Plastics Inc, Ravenswood, WV.

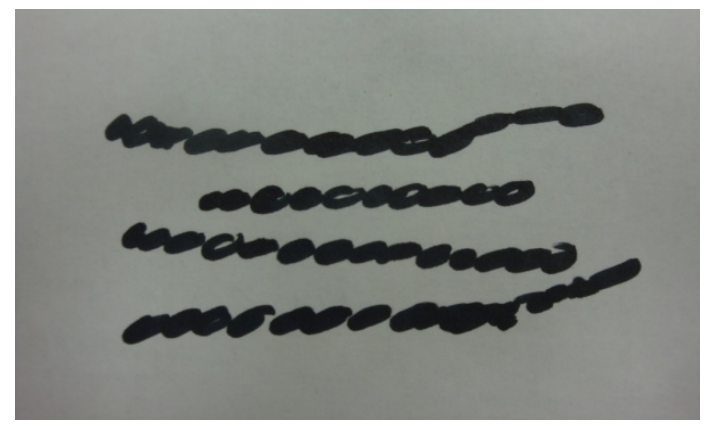

(a) Linear polymer chain (thermoplastic)

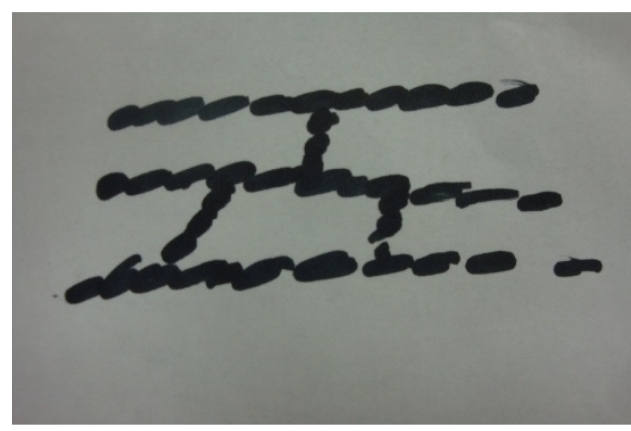

(b) Cross linked polymer chain (thermoset)

Figure 1. 1 Diagram of polymer chain 


\subsection{Overview of Polymer and Recycling}

ABS is a two phase polymer blend, where the continuous phase of styrene-acrylonitrile copolymer gives rigidity, hardness and heat resistance. However, toughness of ABS is derived from sub-microscopically fine poly-butadiene rubber particles uniformly distributed in the polymer. In addition to strength and stiffness, shape and finish requirement are equally important for composite products. Most rubber contains poly-butadiene cross-linked S atoms. Mechanical and thermal properties mainly depend on molecular structure, where increase in mechanical and thermal properties is due to increased strength of connecting links. In addition, polymer exhibits wide range of characteristics like strength and resistance to electricity, alkalinity and acids etc. Hygroscopic resins such as ABS, PET, PC, PS etc. are more susceptible to moisture absorbed and need to be properly dried for better quality finish of products. Poor drying might lead to low mechanical properties and other moisture related deficiencies. Strength of polymers in specific applications depends on degree of curing. Increase in consumption, shorter shelf-life, and resistance to biodegradability have greatly advanced the recycling of plastics. A schematic representation of recycling of thermoplastic is shown in Figure 1.2. Some of the common recyclable plastics are polyethylene, polypropylene, polyester and polyvinyl chloride. Recycling of plastic includes collection of scrap from domestic, industrial, and commercial sources. Impurities are separated before providing recycling stream of polymers to manufacturers. Recycling of plastic has become difficult due to presence of additives and impurities found in range of wide applications, increased cost of labor, collection and transportation of recyclable polymers. Recycled ABS polymers are used in automobile dashboard, conduits, pipelines, cell phones, toys, electronic appliances, medical equipments (where they do not produce magnetic field), window panels, sign posts, spacer blocks in guard rails etc. 
Previously research focus at CFC-WVU was on the development and evaluation of reduced scale reinforced recycled polymer components such as hexagonal panel, rectangular grid, sign board, and sign post etc. Generally, in-service building and highway structural components experience harsh environmental effects such as thermal cycling, fatigue, UV radiations etc. Hence it is important to study and understand the mechanical performance of FRPs under the influence of detrimental environmental conditions.

In this research, a continuous glass fabric with density of $12 \mathrm{oz} / \mathrm{yd}^{2}$ was used for manufacturing of recycled polymer composites to evaluate their mechanical properties and durability. In addition, the thermoplastic (TP) and thermoset (TS) sandwich composites were manufactured through combination of compression molding process and hand lay-up method and tested in tension and bending to explore their applications.

\subsection{Objectives}

Objectives of this research work are to:

- Manufacture and evaluate mechanical properties (e.g: compression, bending, tension, and impact as per ASTM) of recycled thermoplastic polymers reinforced with continuous bidirectional glass fabrics (previous research focused on short-discontinuous fibers).

- Evaluate aging effects on recycled and reinforced ABS polymer composites (coupon level) with $0,4 \%, 7 \%$ and $12 \%$ fiber volume fractions.

- Manufacture by compression molding process and hand lay-up method and evaluate the mechanical properties of glass fabric reinforced Thermoplastic (TP)/Thermoset(TS) sandwich composites specimens (coupon level). 


\subsection{Scope}

- Compression molding process was used to manufacture the tension, bending, compression, and impact coupon specimens (conforming to ASTM standards) using recycled ABS polymers and reinforced with $0,1,3$ and 5 layers of glass fabrics. Altogether 48 non-aged specimens were tested to evaluate their mechanical properties as reference data.

- Over 700 additional coupon specimens were manufactured through compression molding process and subjected to salt solution $(\mathrm{pH}-7.0)$ and alkaline solution (13.0) aging, under room temperature and with freeze thaw conditions to evaluate their long term (durability) behavior (Table 1.1).

- Moisture diffusion coefficients were established and Scanning Electron Microscopy (SEM) was carried out on coupon specimens subjected to salt and alkaline aging with freeze-thaw variations to examine the fiber/resin interface degradations.

- A total of 90 roughened and un-roughened thermoplastic (TP) and thermoset (TS) sandwich composite specimens were manufactured using hand layup method and were tested under tension and bending (Table 1.2).

Table 1. 1 Recycled polymer specimens for durability test

\begin{tabular}{|c|c|c|c|c|c|c|c|c|c|c|}
\hline \multirow{6}{*}{$\begin{array}{c}\text { Months } \\
\\
\begin{array}{c}1,4,8 \\
\text { and } 12\end{array}\end{array}$} & \multirow{6}{*}{$\begin{array}{c}\text { Test } \\
\text { Tension } \\
\text { Bending } \\
\text { Comp. } \\
\text { Impact }\end{array}$} & \multirow{6}{*}{$\begin{array}{c}\text { FVF } \\
\\
0 \% \\
4 \% \\
7 \% \\
12 \% \\
\end{array}$} & \multicolumn{4}{|c|}{ Room temperature } & \multicolumn{4}{|c|}{ E- chamber } \\
\hline & & & \multicolumn{2}{|c|}{ Salt soln. } & \multicolumn{2}{|c|}{ Akln. soln. } & \multicolumn{2}{|c|}{ Salt soln. } & \multicolumn{2}{|c|}{ Akln. soln. } \\
\hline & & & $2+1$ & $2+1$ & $2+1$ & $2+1$ & $2+1$ & $2+1$ & $2+1$ & $2+1$ \\
\hline & & & 3 & 3 & 3 & 3 & 3 & 3 & 3 & 3 \\
\hline & & & 3 & 3 & 3 & 3 & 3 & 3 & 3 & 3 \\
\hline & & & 3 & 3 & 3 & 3 & 3 & 3 & 3 & 3 \\
\hline $\begin{array}{c}\mathrm{T}=4 \\
\text { Months }\end{array}$ & $\begin{array}{l}\mathrm{T}=4 \\
\text { Tests }\end{array}$ & $\mathrm{T}=4$ & $\mathrm{~T}=12$ & $\mathrm{~T}=12$ & $\mathrm{~T}=12$ & $\mathrm{~T}=12$ & $\mathrm{~T}=12$ & $\mathrm{~T}=12$ & $\mathrm{~T}=12$ & $\mathrm{~T}=12$ \\
\hline
\end{tabular}


T $=$ Total numbers, FVF $=$ Fiber Volume Fraction

Table 1. 2 Summary of test for TS/TP sandwich composites

\begin{tabular}{|c|c|c|c|c|c|c|c|c|}
\hline $\begin{array}{c}\text { Test } \\
\text { type }\end{array}$ & ABS & VE & \multicolumn{2}{|c|}{ TP/TS/TP } & \multicolumn{2}{|c|}{ TS/TP/TS } & \multicolumn{2}{|c|}{ TS/TP } \\
\hline & $\begin{array}{c}\text { (With } \\
\text { and } \\
\text { without } \\
\text { fabric) }\end{array}$ & $\begin{array}{c}\text { (With } \\
\text { and } \\
\text { without } \\
\text { fabric) }\end{array}$ & Rough & $\begin{array}{c}\text { Un- } \\
\text { Rough }\end{array}$ & Rough & $\begin{array}{c}\text { Un- } \\
\text { Rough }\end{array}$ & Rough & $\begin{array}{c}\text { Un- } \\
\text { Rough }\end{array}$ \\
\hline Tension & 10 & 10 & 5 & 5 & 5 & 5 & 5 & 5 \\
\hline Bending & -- & -- & 5 & 5 & 5 & 5 & 5 & 10 \\
\hline Total & \multicolumn{8}{c|}{$85+5$ (Bond Test) =90 } \\
\hline
\end{tabular}

Note: TS-thermoset, TP-thermoplastic

\subsection{Summary}

This research work and results are organized into nine chapters. Chapter 1 comprises of introduction to polymers, objective and scope. In chapter 2, based on the objective and scope, literature review on previous work at CFC-WVU and by other researchers, moisture absorption and durability are carried out. Polymer and fiber glass materials, manufacturing methods and procedures of thermoplastic FRPs are presented in chapter 3. Descriptions of alkaline and salt solutions (conditioners) used in this research and aging scheme in an environmental chamber are provided in chapter 4 . In chapter 5 , test setup, specimen specification, procedure to test tension, bending, compression and impact coupon specimens conforming to ASTM standards are presented. In chapter 6 , results of tension, bending, compression, and impact tests including moisture absorption test and moisture diffusion coefficients are presented. In chapter 7, the strength reductions due to salt and alkaline solution conditioning at room temperature and with freeze-thaw (environmental chamber) are presented. Summary aging test results and bar graphs representing strength reductions are reported in Appendix C. Scanning Electron Microscopy (SEM) and discussions on strength reduction mechanisms has been reported in Chapter 8. In 
chapter 9, the tension and bending test results of thermoplastic (TP)/thermoset (TS) sandwich composites are presented. The hand layup method of manufacturing of TP/TS composite plates and TP/TS bond test specimens has been reported in Appendix D. Conclusions from mechanical property characterization, aging (durability), moisture absorption, SEM and thermoplastic/thermoset sandwich specimens are provided in chapter 10 . 


\section{LITERATURE REVIEW}

\subsection{Introduction}

Literature review was conducted on the research done by CFC-WVU and other research organizations regarding thermoplastic and thermoset composites including product development, mechanical property characterization and product implementation. Literature review regarding thermoplastics composites research between 1999 and 2006 at CFC-WVU has been summarized in Appendix A of this report. Durability studies on reinforced thermoplastics were sparse. This might be due to lack of applications of thermoplastics in the field of structural composites of long (> 25 years) service life. Hence, literature review on durability of composites related to infrastructure applications discussed herein is mostly limited to glass reinforced thermoset composites. In the same fashion, some comparison of results from thermoplastic FRP composites manufactured and tested under this project is carried out with respect to results of thermoset FRP composites.

Polymer matrix is susceptible to deterioration which could be instigated by UV radiation, moisture, temperature, and high $\mathrm{pH}$ environment (Vijay and GangaRao, 1999). Literature suggests that the mechanical properties of FRPs are impressive compared to general construction materials such as steel and concrete. However, comprehensive durability data and knowledge are still incomplete. Due to incomplete research and lack of governing specification in the field of civil engineering, FRPs are not considered as automatic choice for many major load carrying structural members. With the current knowledge and experience, CFRPs and GFRPs are generally being used to strengthen concrete and steel structures by reinforcing and/or wrapping. Proper bonding between FRPs and steel and/or concrete ensures effective strengthening and guarantees better stress transfer in the system. Fibers are the main strength carrying elements in 
FRP system and are need to be properly protected from harsh environmental effects. Different types of thermoplastic or thermoset resins offer different degree of protection to fibers. Vijay et

al. (2006) have presented some of the environmental conditions that affect durability of composite materials under accelerated/natural conditions including salt, alkaline and acid solution, freeze-thaw cycles, elevated temperature, creep and relaxation, fatigue, and others.

The aging scheme used in this research is based on the work by Vijay and GangaRao (1999). Authors have compared their alkaline solution with freeze-thaw conditioning test results with GFRP bars extracted from tension side of concrete beams. Authors noted an excellent correlation between natural and accelerated aged specimens that are investigated using Litherland's accelerated aging methodology.

The deterioration of bare glass fibers exposed to alkaline environmental would be from combined action of pitting, hydroxylation, hydrolysis and leaching (Karbhari, et al., (2003). Durability test of FRPs can be conducted by subjecting them to dry freeze-thaw or a combination of freeze-thaw with humidity, which is harsher. In this research, the specimens were immersed in salt and alkaline solution causing $100 \%$ humidity with freeze-thaw effects. Moisture studies on polymers provide information regarding molecular weight, heat conduction, copolymer composition, degree of crystalinity and crosslink density (Lee and Peppas, 1993).

\subsection{Moisture Absorption and Effects of Aging}

Compared to thermosetting composites, thermoplastics have more applications due to their low cost and recyclability. However, thermoset composites have better resistance for moisture absorption compared to thermoplastics. Diffusion of moisture mainly depends on composite matrix properties as moisture cannot diffuse in to fabric (Lee and Peppas, 1993). 
The moisture diffusion in all organic polymers results in changes to thermophysical, mechanical, and chemical properties. Moisture absorption by resin leads to hydrolysis, plasticization, saponification and other mechanisms, which can cause reversible and irreversible changes in polymer structure (karbhari et al., 2003).

Lee and Peppas, (1993) have reported that due to moisture diffusion in FRPs, the changes in properties of composites could be reversible or irreversible. These properties may be mechanical, chemical, and physical or such as change in volume, weight and surface texture. The absorbed water on graphite/epoxy composites had damaging effects on their high temperature properties such as, moisture induced micromechanical damages, internal stresses, relaxation of mechanical properties and plasticization. Amongst these damages, micromechanical damage is irreversible. Kajorncheappungam et al. (2003) reported that moisture can encourage chemical change in resin. If the resin is not completely cured, water can plasticize a polymer and lower its $\mathrm{T}_{\mathrm{g}}$. Reduction in $\mathrm{T}_{\mathrm{g}}$ can make the polymer soft and promote creep related deformations

Al-Zahrani et al. (2002) and several authors have reported that increase in temperature is an efficient way to accelerate aging. The weight increased due to moisture absorption by various FRP specimens is reflected in tension test results, and higher the diffusion rate, higher is the strength loss (Vijay and GangaRao, 1999; Khelifi and Nanni, 2004).

In section 3.5 of ACI $440.2 \mathrm{R}-02$, the factors influencing the mechanical properties of FRP are the type of exposure environment, time of exposure, resin type and formulation, fiber type and resin curing method. From section 8.3.1 of ACI 440.2R-02, the mechanical properties of some FRPs degrade under certain exposures like, alkalinity, salt water, chemicals, UV light, elevated temperature, humidity and freeze-thaw cycling. In section 8.3 .3 of $\mathrm{ACI} 440.2 \mathrm{R}-02$, it is stated that, "The engineer should select such an FRP system that has undergone durability testing 
consistent with application environment. Durability test may include hot-wet cycling, alkaline immersion, freeze-thaw cycling, and ultraviolet exposure”. As suggested from ACI 440, alkaline solution was selected as one of the aging parameter in this research for the durability test of recycled thermoplastic, along with salt solution at room temperature and freeze thaw conditioning. In this research, different chemicals were used to reach a $\mathrm{pH}$ of 13 , which would replicate the typical exposure and aging effect resulting from concrete pore solution as suggested by several authors. In section 8.4 of ACI 440-02, unless otherwise stated, material properties provided from manufacturer like ultimate tensile strength, generally does not account for long term environmental exposure of FRPs, which should be considered, because can reduce the tensile properties, creep rupture and fatigue performance. The material properties used in design equation should be reduced based on environmental exposure conditions. Durability and reliability are requested as design inputs for specific applications, and in load bearing structural components, long term strengths are required to complete the design of structure (Hartman et al., 1996). Feasibility of using TP/TS sandwich specimens for product development is investigated in this research. Scanning Electron Microscopy (SEM) is also considered to evaluate the fabricmatrix interface properties. 


\section{MATERIALS, MOLDING PROCESS and AGING SCHEMES}

\subsection{Introduction}

Recycled Acrylonitrile Butadiene Styrene (ABS polymer, Figure 3.1) used in this research (Chemical formula $\left.\left(\mathrm{C}_{8} \mathrm{H}_{8} \cdot \mathrm{C}_{4} \mathrm{H}_{6} \cdot \mathrm{C}_{3} \mathrm{H}_{3} \mathrm{~N}\right)_{\mathrm{n}}\right)$ is typically manufactured from polymerization of the basic monomers acrylonitrile, butadiene and styrene using a common process adopted for ABS polymer, which was batch type emulsion graft polymerization process. Acrylonitrile (represented as $\mathrm{C}_{3} \mathrm{H}_{3} \mathrm{~N}$ ), a pale yellow liquid in changeable state, has pungent smell, and polymerizes quickly when heated. This material would be flammable when exposed to fire. Butadiene (1, 3-butadiene represented as $\mathrm{C}_{4} \mathrm{H}_{6}$ ) can be listed under dienes (hydrocarbons which can hold two double bonds) and is a monomer used for production of the rubber copolymer. Styrene (represented as $\mathrm{C}_{8} \mathrm{H}_{8}$ ), styrol, ethenyl benzene, vinyl benzene, and phenetylene, etc is generally an oily material. Styrene is a volatile material and offers the material with shining property and which makes the surface impermeable.

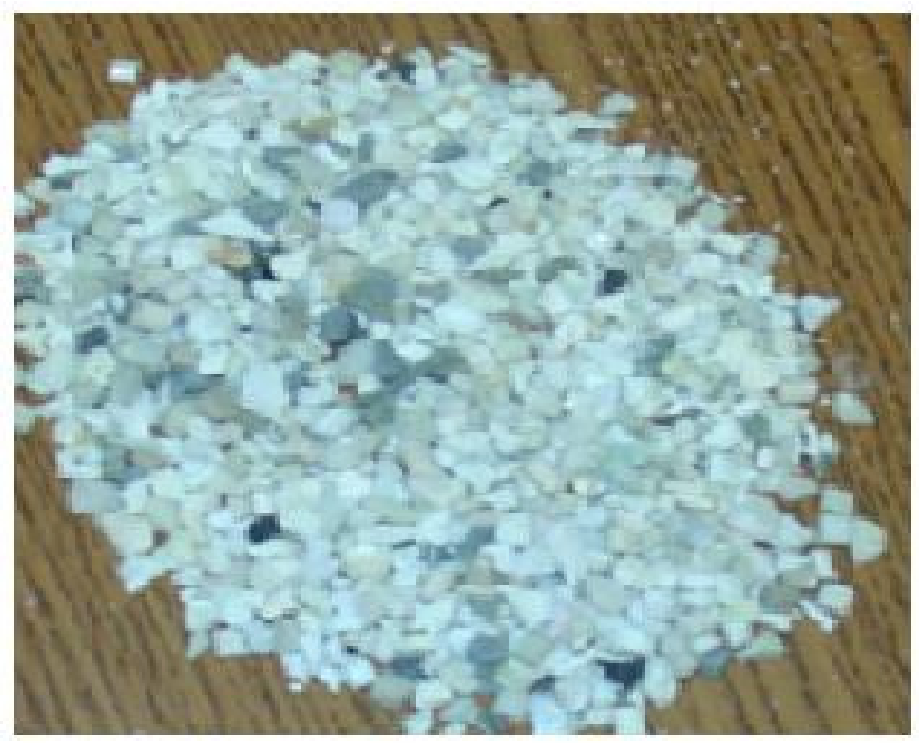

Figure 3. 1 Granulated recycled polymers 
A blend of acrylonitrile and styrene provides superior mechanical properties and toughness. In addition, butadiene in the form of rubber has increased its application. ABS polymers have resistance to liquid acids like concentrated hydrochloric and phosphoric acid and mineral oils. However, these get dissolved in esters and ketones. Quality of ABS resin can be controlled by maintaining the diameter of rubber material used during manufacturing process. Optimum diameter of rubber would be 0.2 micron to 0.5 micron for better shock resistance and surface luster. (Wikipedia.org)

\subsection{Pellets Grinding}

In this research, recycled ABS polymer pellets were received from Star Plastics Inc. and were subjected prior to manufacturing GFRP plates. Pellets received from the manufacturer were $1 / 4$ " in size with irregular shape. Grinding of pellets to smaller size (Figure 3.1) was achieved by using a granulator (Figure 3.2). ABS polymer was ground to manufacture a quarter inch thick GFRP plate with 1, 3 and 5 layers of glass fabric. Grinding of pellets resulted in lower voids and enhanced strength of composites.

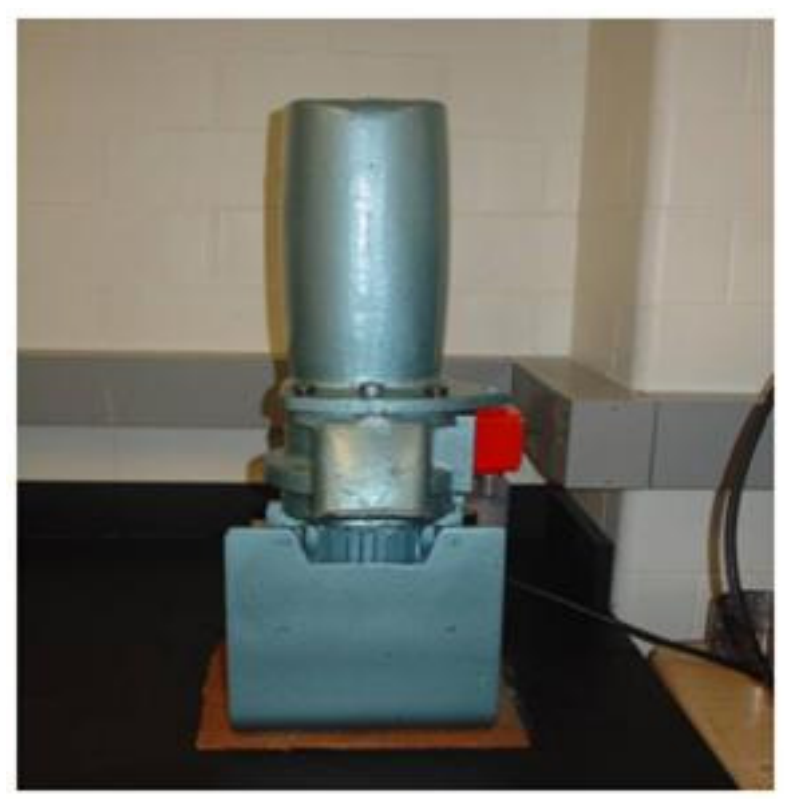

Figure 3. 2 Pellets grinder 


\subsection{Glass Fabric}

Glass fabric reinforcement in polymers enhances strength and stiffness of the composites. Glass fabrics are preferred as reinforcement based on their good strength, stiffness, heat and corrosion resistance characteristics, and feasibility for different environment, and low cost (Vijay et al, 2006). In addition, glass fabrics have good electrical insulation, lower moisture absorption and fire resistant. These fabrics are available in wide variety of architecture and densities and can be chosen depending upon respective applications. In this research, bi-directional (0,90 degrees) glass fabrics (Figure 3.3) with a density of $12 \mathrm{oz} / \mathrm{yd}^{2}$ was used.

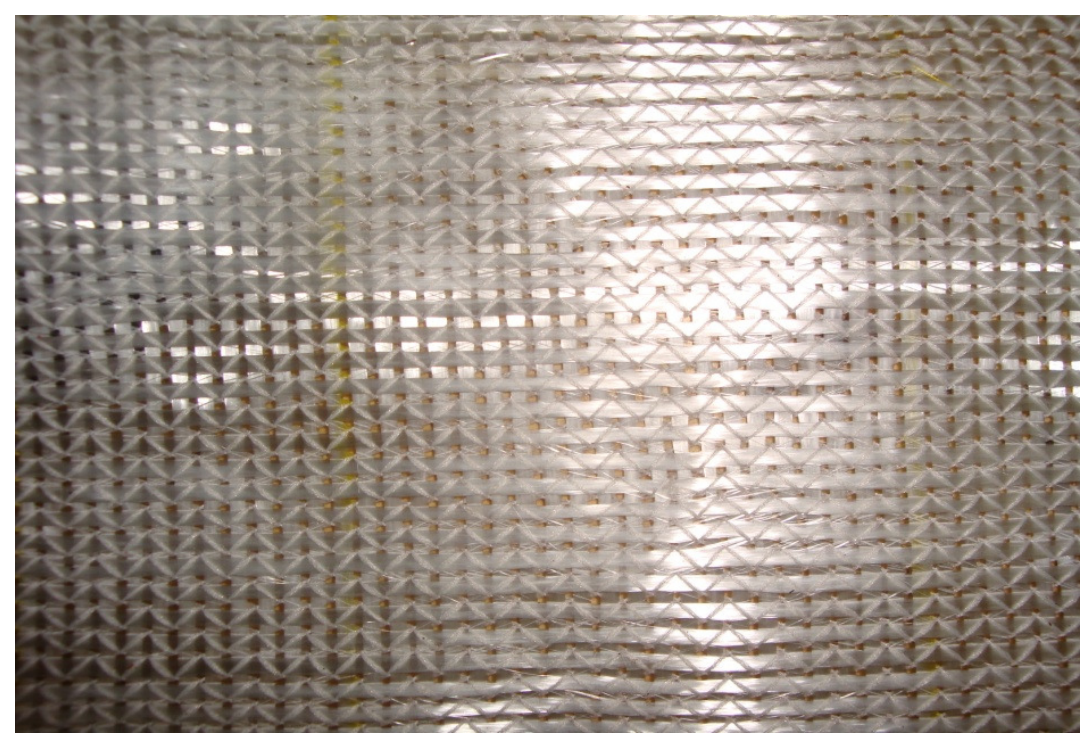

Figure 3. 3 Bi-directional 0/90 glass fabric $\left(12 \mathrm{oz} / \mathrm{yd}^{2}\right)$

\subsubsection{Fiber Weight Fraction}

Fiber volume fraction was evaluated by placing recycled composite specimens $\left(\mathrm{w}_{1}\right)$ in an oven. They were burnt to remove matrix and the mass of left out was glass fiber $\left(\mathrm{w}_{2}\right)$. Fiber volume fraction can be calculated using Eqn. 3.1:

Fiber Volume Fraction $=\left[1-\left(\mathrm{w}_{1}-\mathrm{w}_{2}\right) / \mathrm{w} 1\right]^{*} 100$ 


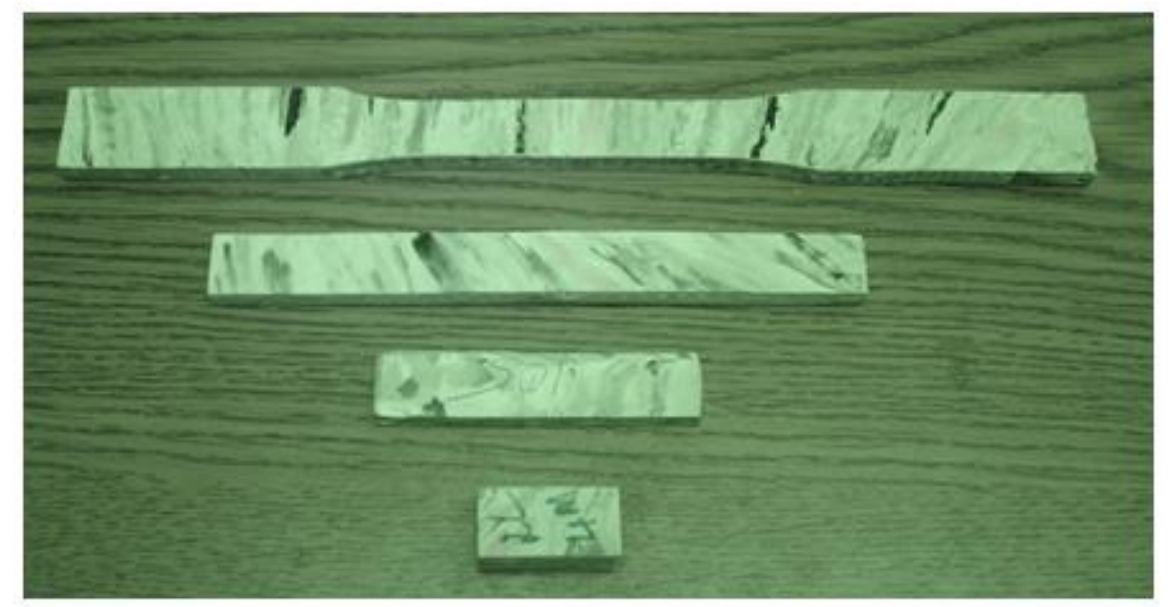

Figure 3. 4 Tension, bending, impact and compression specimen

\subsection{Aging}

Industries are continuing to introduce and study the behavior of FRP materials in combination with steel and concrete. In this research, to evaluate the durability performance of thermoplastic FRPs, coupon specimens were manufactured as per ASTM standards (Figure 3.4) and were subjected to salt and alkaline aging with freeze-thaw and room temperatures variations. The aging solution used in this research were as follows

\subsubsection{Alkaline Solution}

Alkaline solution used in this research was prepared by mixing $1.4 \%$ of potassium hydroxide $(\mathrm{KOH}), 1 \%$ of sodium hydroxide $(\mathrm{NaOH})$ and $0.2 \%$ of calcium hydroxide $\left(\mathrm{Ca}(\mathrm{OH})_{2}\right)$ salts by weight in standard water. This resulted in a $\mathrm{pH}$ of 13.0 and produces an effect of environment typical of wet Portland cement.

Several authors have used similar salts with same or slightly different proportions for the durability test of FRPs. Micelli et al. (2001) has used $0.16 \% \mathrm{Ca}(\mathrm{OH})_{2}+1 \% \mathrm{NaOH}+1.4 \% \mathrm{KOH}$ by weight in distilled water with the $\mathrm{pH}$ of 12.6. Khelifi and Nanni (2004) used $0.16 \% \mathrm{Ca}(\mathrm{OH})_{2}$ $+1 \% \mathrm{NaOH}+1.4 \% \mathrm{KOH}$ combination of salts for accelerated conditioning in an alkaline solution. Al-Zahrani et al. (2002) has used $0.6 \mathrm{~N} \mathrm{KOH}+0.2 \mathrm{~N} \mathrm{NaOH}+$ Saturated $\mathrm{Ca}(\mathrm{OH})_{2}$ to 
produce a $\mathrm{pH}$ of 13.5 to represent concrete environment. Tannous and Saadatmanesh (1999) have used different salts and salt combinations of $\mathrm{Ca}(\mathrm{OH})_{2}, \mathrm{NaCl}, \mathrm{CaCl}_{2}, \mathrm{HCl}$, and $\mathrm{MgCl}_{2}$ at different temperatures to replicate hydrating cement (also at higher temperature), acid environment, sea water, $\mathrm{NaCl}$ and TETRA94 deicing salts, $\mathrm{NaCl}$ and Ice-stop deicing salts, and used ultraviolet radiation to simulate sunlight in a desert region. Gotou et al. (2005) has used 30 wt $\% \mathrm{NaOH}$ at $50 \mathrm{C}$ in water for the corrosion test. Tavakkolizadeh and Saadatmanesh, (2004) prepared saturated $\mathrm{Ca}(\mathrm{OH})_{2}$ solutions with $\mathrm{pH} 10$ and 12.5 (authors used $\mathrm{NaOH}$ to control $\mathrm{pH}$ ) to reproduce hydrating cement and other alkaline environment.

\subsubsection{Salt Solution}

Salt solution used in this research for the durability test was prepared by mixing $3 \%$ sodium chloride $(\mathrm{NaCl})$ by weight to the standard water. This measured a $\mathrm{pH}$ of 7.0 . The $3 \% \mathrm{NaCl}$ solution was selected in order to replicates the typical effect of sea water or deicing chemicals (Dohnalek, 2006), 3\% NaCl would create a typical deicing effect for roads and highways during winter (Basto, 2002), and ocean water with $\mathrm{pH} 7.25$ was used to simulate the marine environment by authors Tavakkolizadeh and Saadatmanesh, (2004). 3.5\% NaCl by weight in distilled water was used by Chin et al., (1997) to replicate marine or offshore environment.

In this research, the coupon specimens conditioned in salt and alkaline solutions were further exposed to freeze thaw variations and room temperature. Freeze-thaw was achieved by placing coupon specimens in Thermotron environmental chamber.

\subsubsection{Environmental Chamber}

Environmental chamber simulates the accelerated aging effects. In an environmental chamber, temperature and humidity can be controlled by choosing various cycles programmed for specific humidity and temperature variations. In this research, specimens were directly exposed to 
alkaline and salt solution (100\% humidity), and placed in an environmental chamber in addition to room temperature. Specimens were subjected to freeze-thaw cycles, which magnify the influence of dry freeze-thaw as reported by Wu et al. (2006) and others.

In this study, temperature variations inside an environmental chamber were between $-20.2 \mathrm{~F}$ (Figure 4.1 (a) and (b)) to $120 \mathrm{~F}$ ( $-29 \mathrm{C}$ to $49 \mathrm{C}$ ). Average temperature was evaluated to be $88.8 \mathrm{~F}$ (31.6 C), which is calculated by considering the duration of each temperature. Higher temperature in the environmental chamber would certainly influence the moisture absorption rate in conditioned coupon specimens. One day of chamber conditioning is equivalent to 34 days of natural aging in Morgantown, WV or 36 days of UK weathering (Vijay and GangaRao, 1999). Complete freezing of salt and alkaline solution was noted in environmental chamber at $-29 \mathrm{C}$ as shown in Figure 3.5.

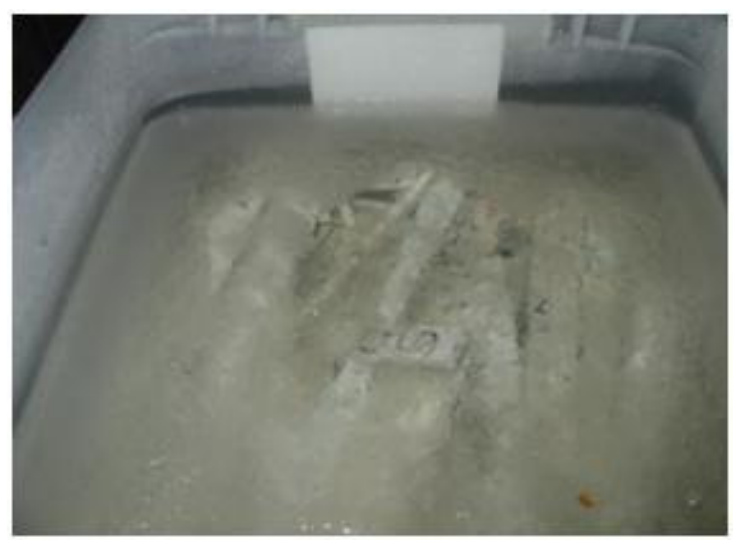

(a) $-29 \mathrm{C}$ in E Chamber

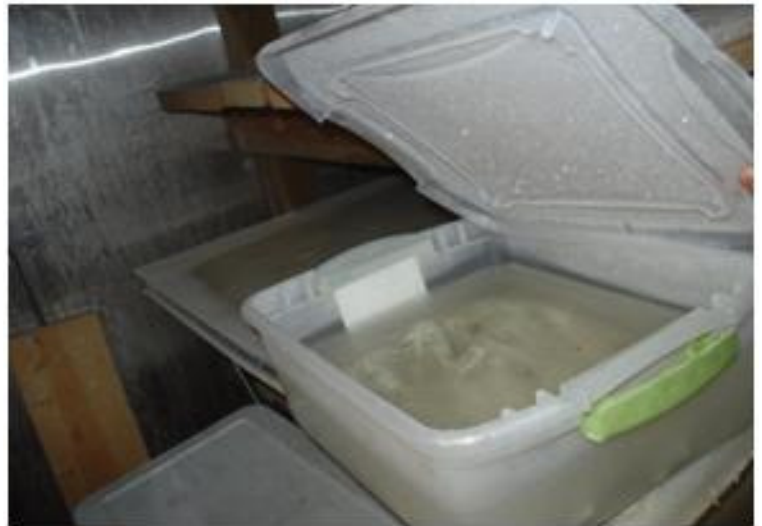

(b) $-29 \mathrm{C}$ in E Chamber

Figure 3. 5 Freezing temperature in environmental chamber

Temperature variation as shown in Figure 3.6 corresponding to the environmental chamber being operational at CFC-WVU was selected in this research. One day of this environmental chamber conditioning is equivalent to 34 days of natural aging in Morgantown, WV or 36 days of UK weathering (Vijay and GangaRao, 1999). The cycle starts with a temperature $20 \mathrm{C}$ and then 
increases to $50 \mathrm{C}$ in about 48 hours, which then comes down to $-29 \mathrm{C}$ in next 24 hours and continues there for around 10 hours. Later it increases to mid 40s and then comes back to $20 \mathrm{C}$. The humidity for salt and alkaline conditioned specimens remains $100 \%$ as specimens were completely immersed in aging solutions.

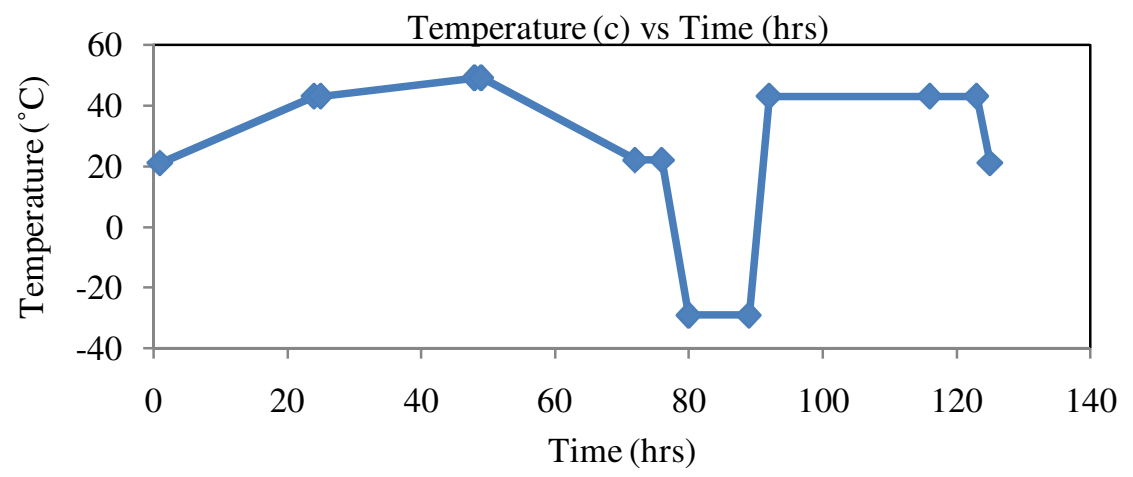

Figure 3. 6 Temperature Variations with Time

The conditioned and non-conditioned specimens were mechanically tested as per ASTM standards. In the next chapter mechanical testing set-up and procedure of coupon specimens has been described. 


\section{COUPON TESTING}

\subsection{Introduction}

Testing of aged and non-aged coupon specimens was carried out as per ASTM standards was carried out. Mechanical properties of coupon specimens might be requested during design of structures. In this research, tension, bending, compression and impact tests were carried out on coupon specimens as described below.

\subsection{Tension Test}

Test Setup: Tension test was carried out using Inston 8501 universal testing machine. The test was computer controlled using 'Wave Runner' and 'Wave Maker Editor' software. ABS tension test coupon specimens were $1 / 4$ " thick with $0,1,3$ and 5 layers of bi directional glass fibers (i.e. 4\%, 7\% and 12\% fiber volume fraction, respectively). Dog bone (Figure 4.1) and rectangular shape specimens' were machined and dimensions were as follows

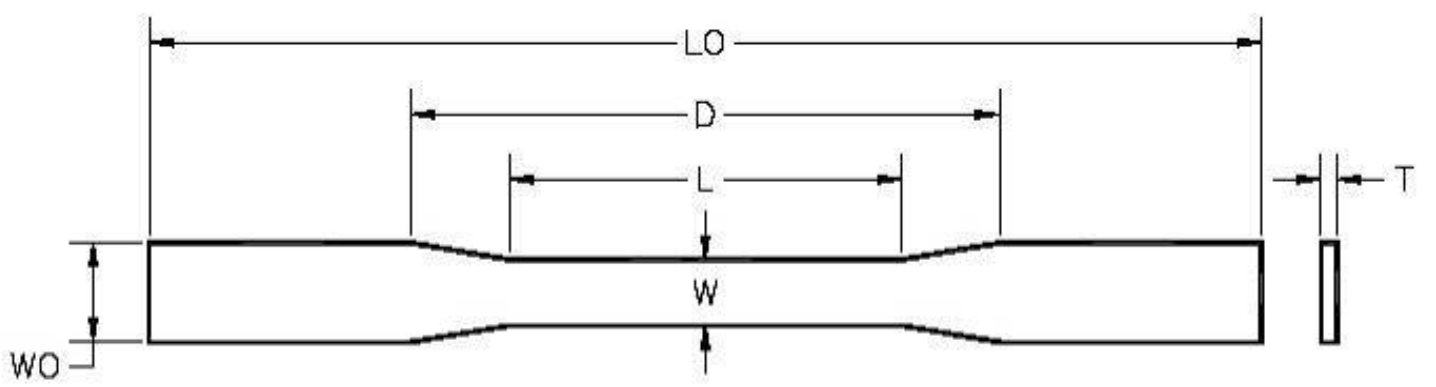

Figure 4. 1 Tension test specimen

Dog bone: Overall length $(\mathrm{Lo})=9$ ", Gage length $(\mathrm{L})=3.0$ ", Length between fixture $(\mathrm{D})=4.5$ "

Specimen thickness $(\mathrm{T})=0.25$ ”.

Rectangular: Overall Length $=9.5 "$, Gage length $=3.5 "$, Tab length $=3 "$.

Specimen specification: Dog bone and rectangular shaped coupon specimens were machined from a quarter inch thick recycled FRP plate. The length of dog bone specimen was 9" with 4.5" 
gage length. In the case of rectangular specimen, the overall length was 9.5" with 3.5" gage length. Perforated metal tabs (3" long, 3/4" wide and 1/16" thick) (Figure 4.2) were developed and used for the rectangular tension test samples to ensure proper gripping of the specimens in the Instron's fixture. Metal tabs were widely used at CFC-WVU, however, due to successive failure of tension specimens in the grip area, drilling of holes (1/8" diameter) in tabs was decided and perforated tabs were manufactured. Each tab was drilled with uniformly distributed 6 pairs of holes (1/8" diameter) throughout the tab area. The objective of drilling holes was to squeeze out the excess adhesive used to stick the tabs to specimen, which reduces stress concentrations with uniform layer of the adhesive.

Test procedure:

1. Both dog bone and rectangular specimens were held exactly at the center of tension test fixtures of Instron machine (Figure 4.3).

2. Strain gage and extensometer were used to record the strain at regular load interval. The test readings were recorded at the rate of 10 readings per second using data acquisition.

3. Wave maker runner and wave maker editor settings were changed to US customary units and strain values were monitored in microstrains in computer connected to Instron UTM.

4. The loading rate was set to $0.05 \mathrm{in} / \mathrm{min}$ as suggested by ASTM D638. The load and strain values were calibrated before the start of test and maximum load was noted down for the calculation of the strength.

Note: The tension test procedure above was followed for testing of Thermoplastic/Thermoset sandwich composite specimens and also for bond test specimens. 


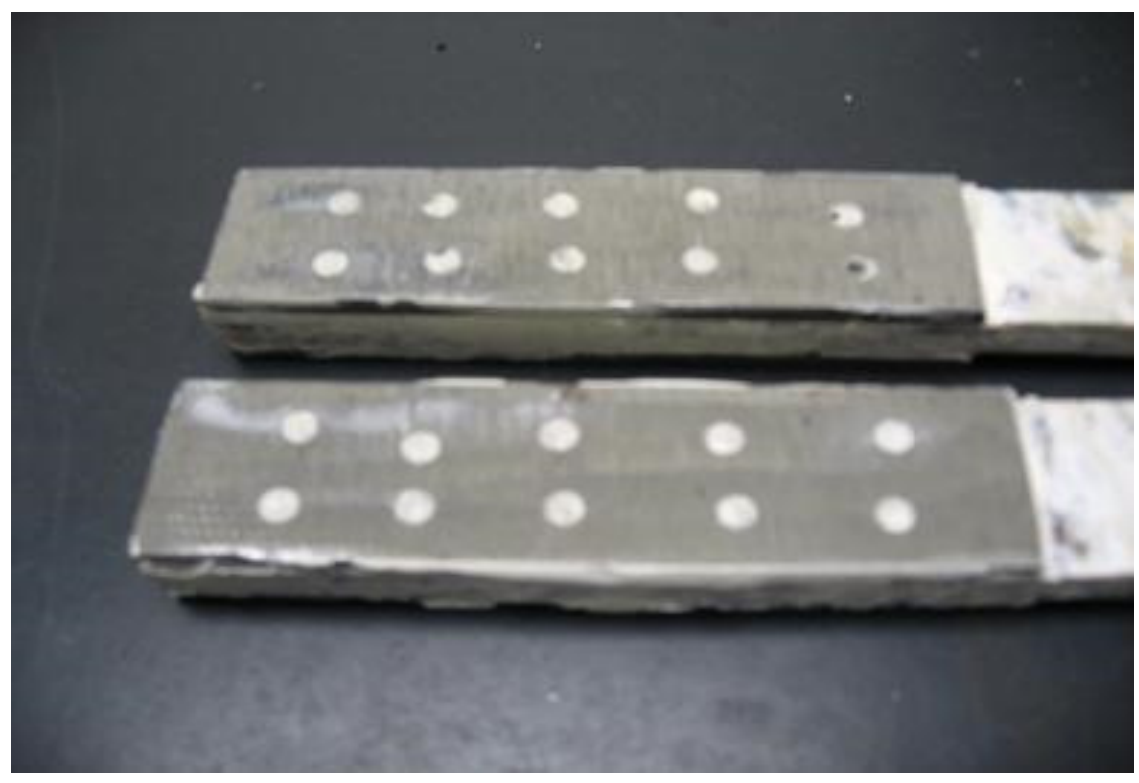

Figure 4. 2 Perforated metal tabs

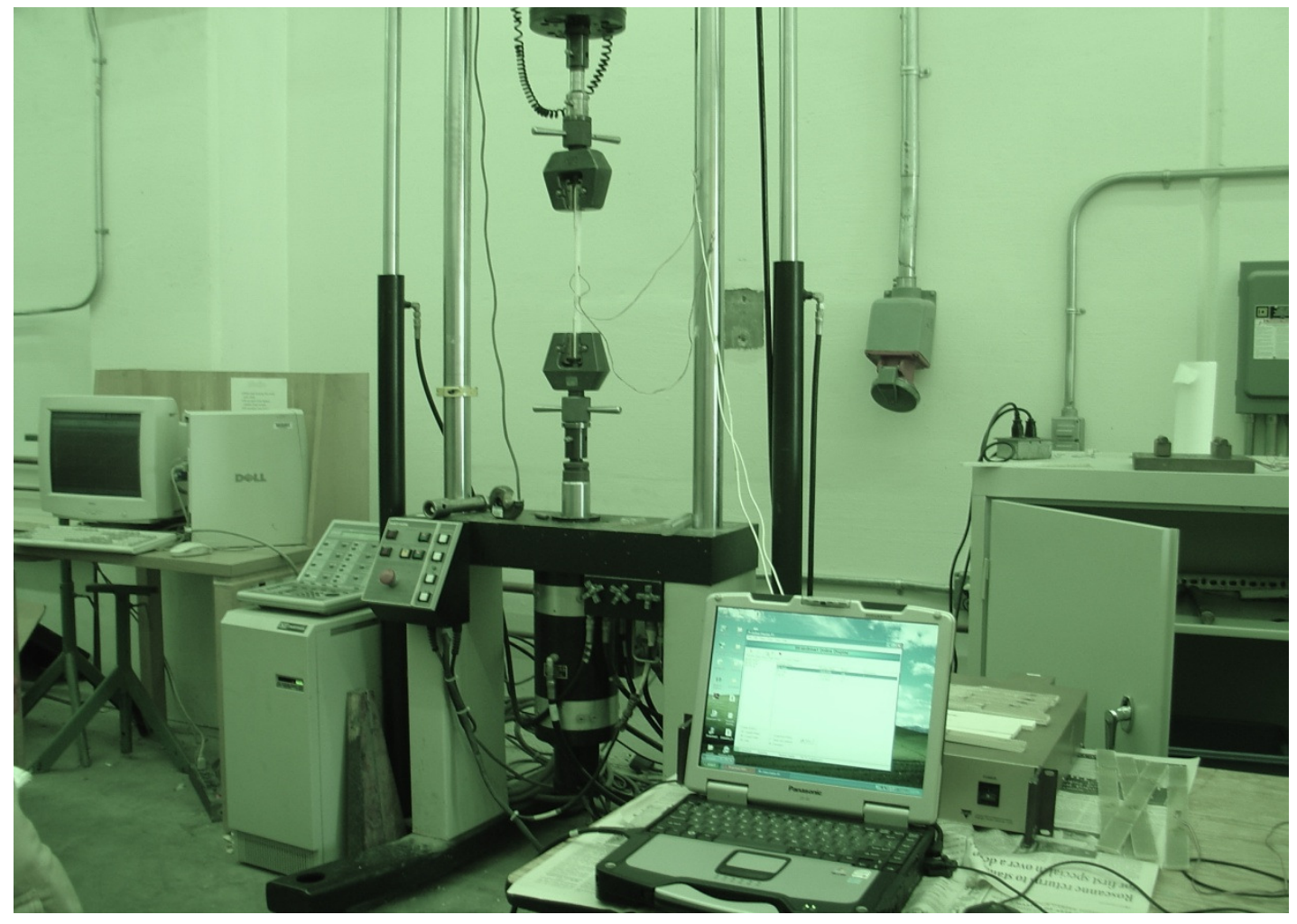

Figure 4. 3 Tension test setup with data Acquisition 


\subsection{Bending Test}

Test Setup: Bending test coupon specimens were evaluated in 3-point bending. Bending specimens were marked at the center span of test specimens, and placed exactly over the supports coinciding with the effective span (4 in center to center of supports) points. Specimens were jacked until the Instron's cross head is in contact with specimens. Strain and load values are calibrated before the load application.

Specimen specification: The specimens were machined to dimensions 5.0 in. $x 0.5$ in. $x 0.25$ in (Figure 4.4) suggested by ASTM D790 for 3 point bending test. ASTM D790-03 also suggests Eqn.1 from article 10.1.4 to calculate the loading rate, which was evaluated to be $0.1 \mathrm{in} / \mathrm{min}$ for the 0.25 in. thick bending specimen. Deflection can be calculated using the Eqn. 2 from article 10.1.7 suggested by ASTM (D790-03).

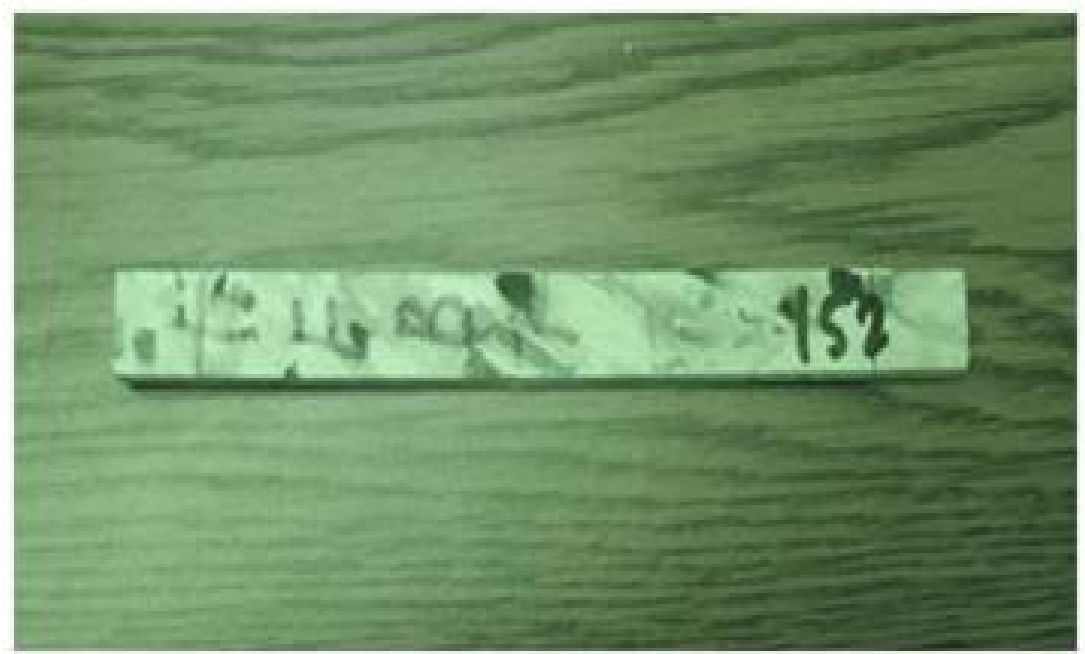

Figure 4. 4 Bending test specimen 


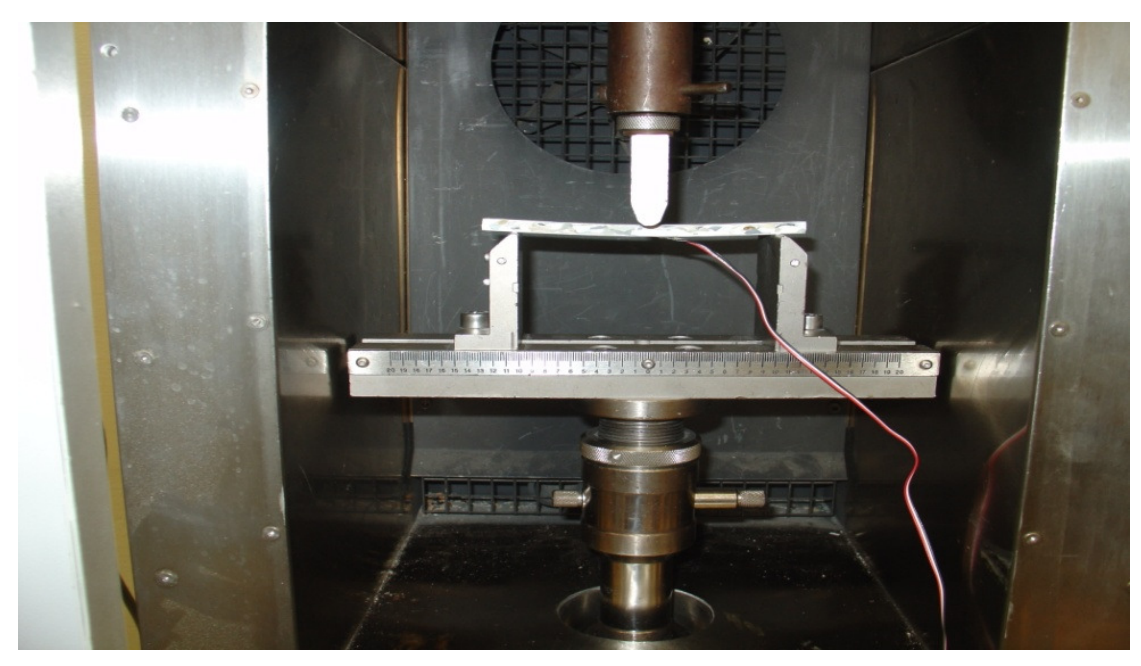

Figure 4. 5 Bending test setup

Test Procedure:

1. Instron 8501 Universal testing machine was used to carry out bending test. Supporting fixture was adjusted by providing a span of 4 in. for a three point bending test.

2. Test was organized by wave maker editor and wave maker runner with the invariable loading rate of $0.1 \mathrm{in} / \mathrm{min}$ (the loading rate was calculated using eqn. 1 from section 10.1.3 of ASTM D 790-03).

3. Uni-axial Strain gages were installed on tension zone of coupon specimen to measure the strain. Strain smart equipment and software was used to measure the load and strain.

4. Load at failure was recorded and stress was being calculated using eqn. 3 from article 12.2 of ASTM D790-03 (load and corresponding strains were recorded at the rate of 10 readings per second).

Note: The bending test procedure above was followed for bending test of Thermoplastic/Thermoset sandwich composite specimens. 


\subsection{Compression Test}

Test Setup: Test was carried out in Instron 8501 universal testing machine which was computer controlled, using 'Wave Runner' and 'Wave Maker Editor' software. In case of specimens with strain gages, strain smart equipment and software were used to record the test. Compression test samples were reinforced with $0,2,6$, and 10 layers of bi-directional glass fibers (with 4\%, 7\% and $12 \%$ fiber volume fraction, respectively) were tested in compression with force being along parallel to fabric.

Specimen specification: Compression specimens were machined from $1 / 2$ " thick GFRP plate was manufactured using compression molding process. The dimensions of compression test specimens were 0.5 in. $x 0.5$ in. $x 1$ in. (Figure 4.6) as specified by ASTM D695.

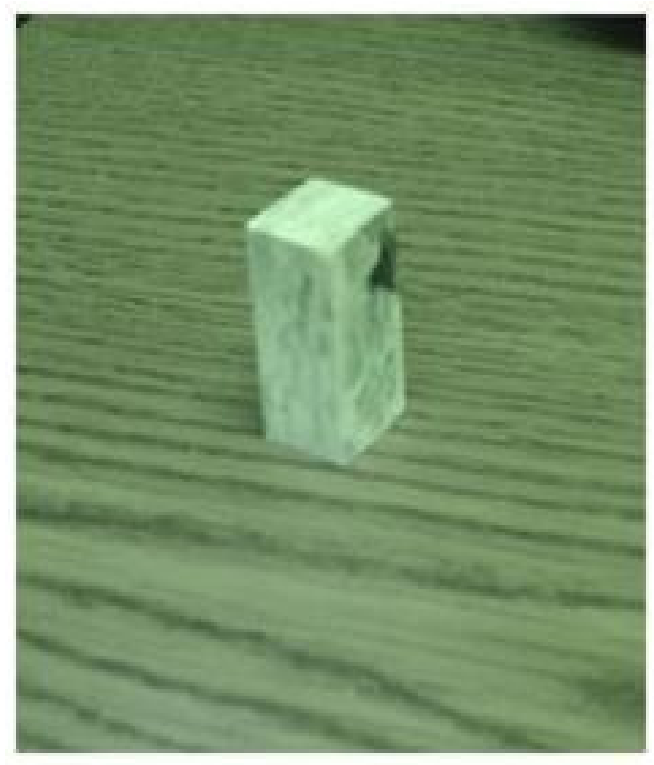

Figure 4. 6 Compression test specimen

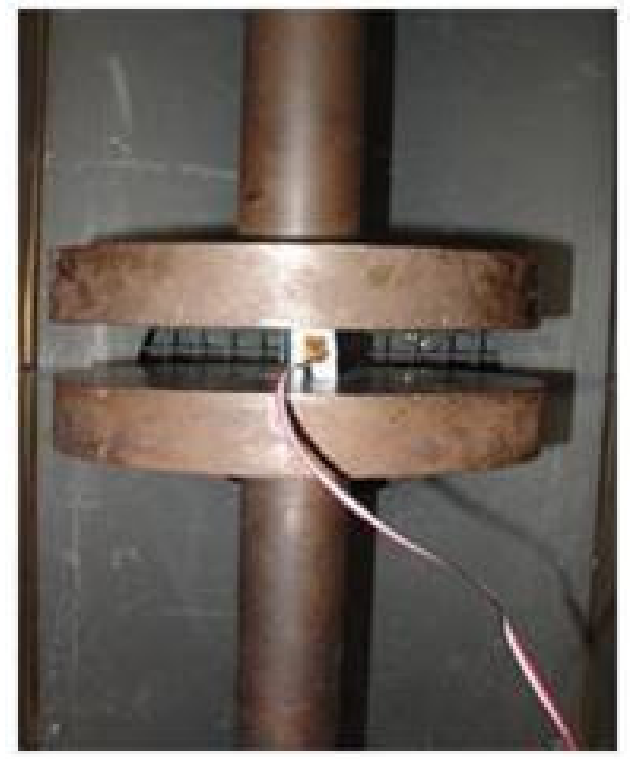

Figure 4. 7 Compression test setup

Test procedure:

1. Compression test specimens conforming to ASTM D695 standards were placed exactly at the geometric center between the fixtures (Figure 4.7), such that the center of gravity of the fixtures and compression specimens must coincide for the proper 
strength evaluation and failure (compression load was applied along the length parallel to fiber of specimen).

2. The wave maker runner and wave maker editor setting controls the entire test (computer load recording standards were changed to US customary) and loading rate was set to $0.05 \mathrm{in} / \mathrm{min}$ as specified in ASTM D695.

3. Strains and load were calibrated before the start of the test (load and corresponding strains were recorded at the rate of 10 reading per second).

4. Loading with constant rate continued till the specimen failed and ultimate load was noted to calculate the strength.

\subsection{Impact Test}

V notch impact test is suggested by ASTM D256 specification for GFRPs. Impact test specimens were notched using a CEAST V-notch machine (Figure 4.8), the notching sensitivity of the machine was up to three decimal points.

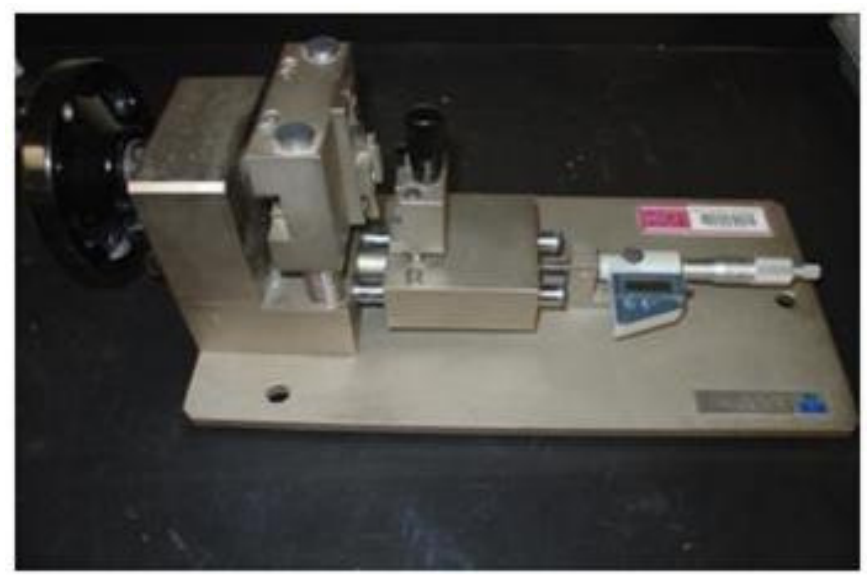

Figure 4. $8 \mathrm{~V}$ notch cutting machine

Specimen specification: ASTM D256 suggested the following dimensions

Overall length: 2.5 in", thickness: 0.25 ", depth of notch: 0.125 ", width: 0.5 " 
Test Setup: Impact test specimen (Figure 4.10) is fixed into the BLI impact tester (Figure 4.9) using a tool such that the V-notch facing hammer. The pointer is set to zero and hammer is released to measure the impact strength.

Test Procedure:

1. Correction factor was noted by allowing free fall of impact hammer.

2. The specimen was held at the center of the fixture, where v-notch in impact specimen facing towards hammer.

3. Impact strength readings were noted after the failure of the specimen from the pointer on BLI tester scale (additional weights were added on the impact hammer as the number of glass fiber layers increased).

4. The specimen failures in impact were classified into different categories as ' $\mathrm{C}$ ' complete break, ' $\mathrm{H}$ ' hinge break, 'P' partial breaks and NB non break as suggested by ASTM D256.

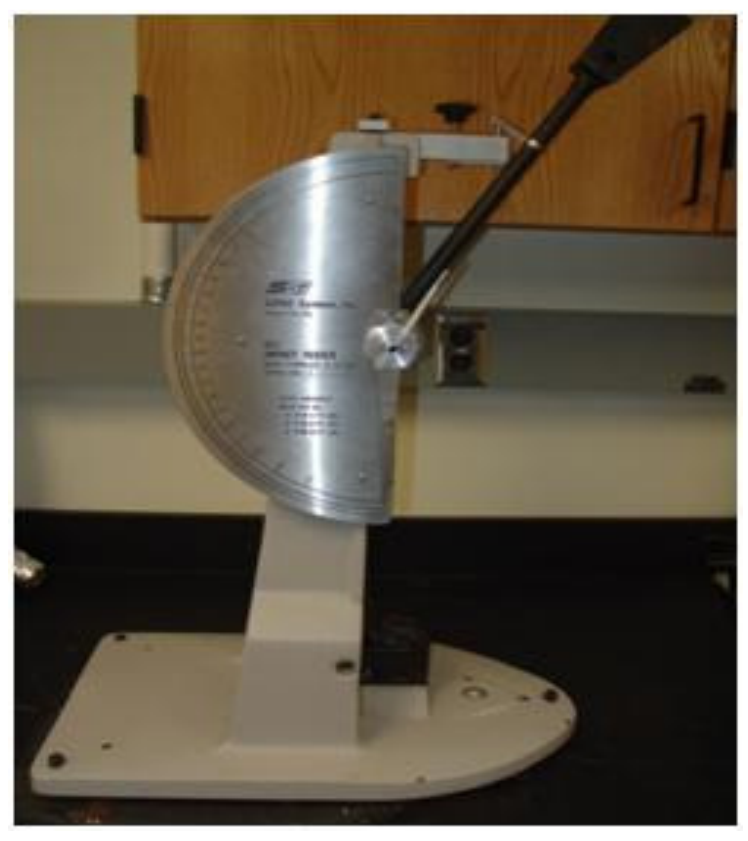

Figure 4. 9 BLI impact tester 


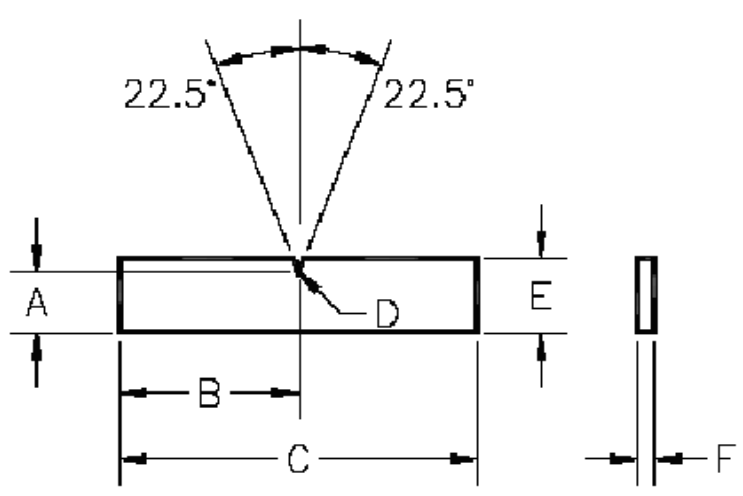

Figure 4. 10 Impact test specimen

Mechanical test results of coupon specimens under tension, bending, compression and impact are provided in chapter 5 . 


\section{TEST RESULTS OF NON-AGED COUPON SPECIMENS}

\subsection{Introduction}

Tension, bending, compression and impact test coupon specimens (as per ASTM standards) manufactured in this study were tested and evaluated with and without aging. In order to understand the strength and stiffness variations due to salt and alkaline aging at room temperature and environmental chamber, it is necessary to evaluate the mechanical properties of control coupon specimens. The test results of coupon specimens are as follows:

\subsection{Tension Test Results}

Tension test results of recycled thermoplastic specimens without aging for $0,1,3$ and 5 layers of glass fabric reinforcement are presented in Table 5.1.

Table 5. 1 Tension test results

\begin{tabular}{|c|c|c|c|c|c|c|}
\hline Layers & $\begin{array}{c}\text { Fiber } \\
\text { Volume } \\
\text { Fraction }\end{array}$ & Sample \# & Load & Area & Stress & $\begin{array}{c}\text { Average } \\
\text { stress }\end{array}$ \\
\hline & & & lbs. & in $^{2}$ & psi. & psi. \\
\hline \multirow{3}{*}{0} & \multirow{3}{*}{0} & 2 & 736 & 0.19 & 3873.68 & \multirow{3}{*}{4112} \\
\hline & & 5 & 493 & 0.1176 & 4192.17 & \\
\hline & & 6 & 534 & 0.125 & 4272 & \\
\hline \multirow{3}{*}{1} & \multirow{3}{*}{$4 \%$} & 1 & 913 & 0.195 & 4682.05 & \multirow{3}{*}{5010} \\
\hline & & 7 & 601 & 0.11086 & 5421.25 & \\
\hline & & 8 & 565 & 0.11466 & 4927.61 & \\
\hline \multirow{3}{*}{3} & \multirow{3}{*}{$7 \%$} & 3 & 1001 & 0.1875 & $* 5338.66$ & \multirow{3}{*}{8563} \\
\hline & & 9 & 1062 & 0.11564 & 9183.67 & \\
\hline & & 10 & 914 & 0.115668 & 7901.92 & \\
\hline \multirow{3}{*}{5} & \multirow{3}{*}{$12 \%$} & 4 & 2007 & 0.19 & 10563.16 & \multirow{3}{*}{10484} \\
\hline & & 11 & 1128 & 0.12642 & 8922.63 & \\
\hline & & 12 & 1459 & 0.12192 & 11966.86 & \\
\hline
\end{tabular}

*Not considered for averaging of stresses due to improper (grip) failure mode 


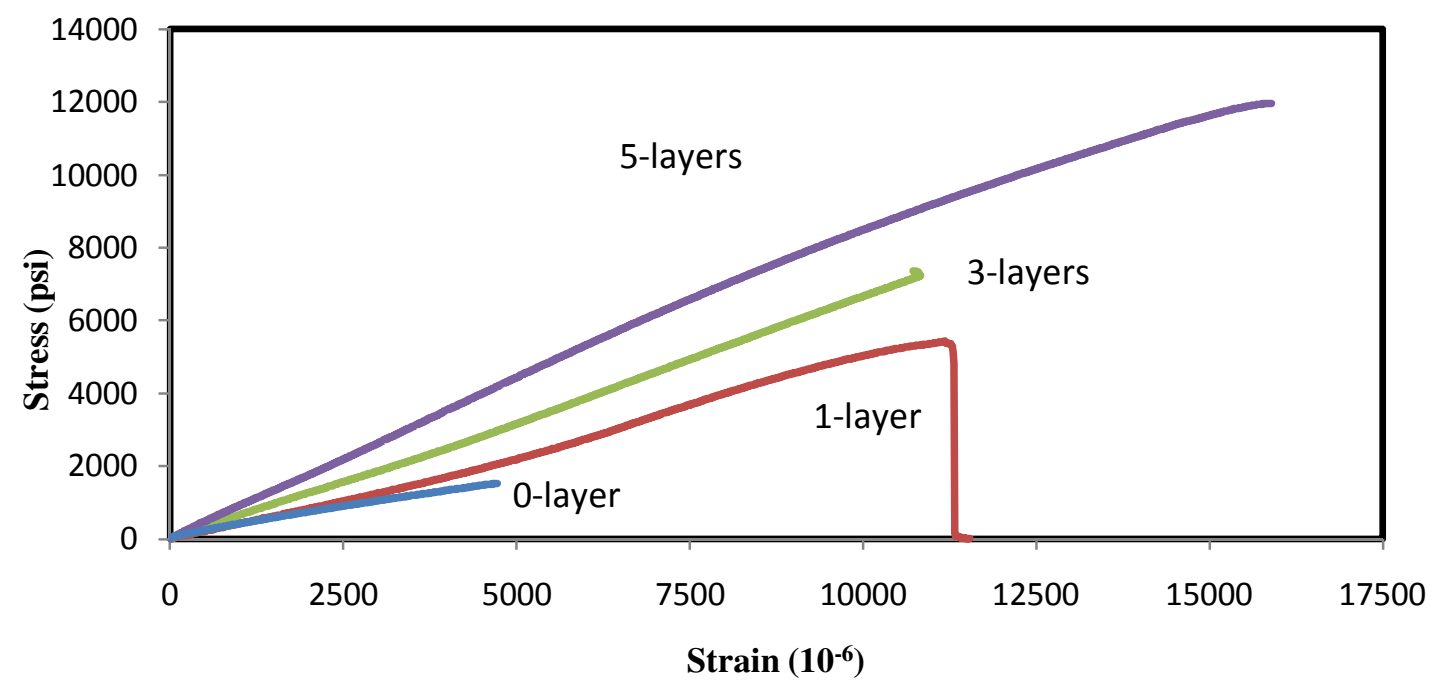

Figure 5. 1 Stress strain graph for tension test specimens

\subsubsection{Tensile Strength Calculation}

Tensile modulus was calculated from initial slope of stress vs. strain curve for $0,1,3$ and 5 layer specimens (Figure 5.1). Average tensile strength of coupon specimens without glass fabrics (Table 5.1) was evaluated to be 4112 psi and the average strengths with 1, 3 and 5 layers of glass fabrics were 5010 psi, 8563 psi and 10484 psi, respectively. Stress increases with increasing glass fabric layers by 22\%, $108 \%$ and $155 \%$ was noted (Table 5.2) for tension test specimens.

$\sigma($ stress $)=\frac{P}{A}(\mathrm{psi}), \mathrm{P}$ is load $(\mathrm{lbs})$ and $\mathrm{A}$ is area $\left(\mathrm{in}^{2}\right)$

Tensile stress calculation for specimen \#10 and 12

For specimen \#10, Stress $=$ Load $/$ Area $=914(\mathrm{lbs}) / 0.115668\left(\mathrm{in}^{2}\right)=7901.9 \mathrm{psi}$.

For specimen \#12, Stress = Load $/$ Area $=1459(\mathrm{lbs}) / 0.12192\left(\mathrm{in}^{2}\right)=11966.86$ psi. 
Table 5. 2 Stress and tensile modulus increment

\begin{tabular}{|c|c|c|c|c|c|c|c|c|}
\hline $\begin{array}{c}\text { Fabric } \\
\text { layers }\end{array}$ & $\begin{array}{c}\text { Average } \\
\text { stress }\end{array}$ & $\begin{array}{c}\text { Per } \\
\text { layer } \\
\text { average } \\
\text { stress } \\
\text { increase }\end{array}$ & $\begin{array}{c}\% \\
\text { increase } \\
\text { in stress }\end{array}$ & $\begin{array}{c}\text { Per } \\
\text { layer } \\
\text { increase } \\
\text { in } \\
\text { strength }\end{array}$ & $\begin{array}{c}\text { Tensile } \\
\text { modulus }\end{array}$ & $\begin{array}{c}\text { Per } \\
\text { layer } \\
\text { modulus } \\
\text { increase }\end{array}$ & $\begin{array}{c}\% \\
\text { increase } \\
\text { in } \\
\text { modulus }\end{array}$ & $\begin{array}{c}\text { Per } \\
\text { layer } \\
\text { modulus } \\
\text { increase }\end{array}$ \\
\hline 0 & psi & psi & & & msi & msi & & $\%$ \\
\hline 1 & 5112 & ----- & ---- & ---- & 0.31 & ---- & ---- & ---- \\
\hline 3 & 8563 & 1483 & $108 \%$ & $36 \%$ & 0.675 & 0.121 & $117 \%$ & $39 \%$ \\
\hline 5 & 10484 & 1274 & $155 \%$ & $31 \%$ & 0.774 & 0.092 & $149 \%$ & $30 \%$ \\
\hline
\end{tabular}

Note: Tensile Modulus data is in line with Rule of Mixture (Refer: Appendix E)

\subsubsection{Tensile Modulus}

Average tensile modulus without fibers was $0.31 \times 10^{6} \mathrm{psi}$, and with 1,3 and 5 layers, the moduli were evaluated to be $0.463 \times 10^{6} \mathrm{psi}, 0.675 \times 10^{6} \mathrm{psi}$, and $0.774 \times 10^{6} \mathrm{psi}$, respectively. Tensile modulus increased by $49 \%, 117 \%$ and $149 \%$ for 1,3 and 5 layers, respectively. This resulted in per layer tensile modulus increment of 49\%, 39\%, and 30\% for 1, 3 and 5 layers of glass fabrics, respectively.

\subsection{Bending Test Results}

Bending test results of recycled thermoplastic specimens (non-aged) with and without fabric are presented in Table 5.3. 
Table 5. 3 Bending test results of non-aged samples

\begin{tabular}{|c|c|c|c|c|c|c|}
\hline Layers & Sample & Load & Width & Depth & Stress & Average \\
\hline & \# & lbs & in. & in. & psi. & psi. \\
\hline \multirow{3}{*}{0} & 1 & 40 & 0.51 & 0.233 & 8668.2 & \multirow{3}{*}{8516} \\
\hline & 2 & 43 & 0.508 & 0.24 & 8817.2 & \\
\hline & 3 & 38 & 0.512 & 0.235 & 8063.6 & \\
\hline \multirow{3}{*}{1} & 4 & 44 & 0.508 & 0.254 & 8055.1 & \multirow{3}{*}{8587} \\
\hline & 5 & 44 & 0.51 & 0.246 & 8553.8 & \\
\hline & 6 & 53 & 0.514 & 0.26 & 9152.0 & \\
\hline \multirow{3}{*}{3} & 7 & 60 & 0.511 & 0.252 & 11093.8 & \multirow{3}{*}{11045} \\
\hline & 8 & 58 & 0.503 & 0.251 & 10981.5 & \\
\hline & 9 & 61 & 0.501 & 0.257 & 11060.5 & \\
\hline \multirow{3}{*}{5} & 10 & 75 & 0.514 & 0.258 & 13152.5 & \multirow{3}{*}{13044} \\
\hline & 11 & 81 & 0.506 & 0.267 & 13473 & \\
\hline & 12 & 72 & 0.511 & 0.26 & 12506 & \\
\hline
\end{tabular}

\subsubsection{Bending Strength Calculations}

The average bending strength without fabric was 8516 psi. Average bending strength with 1,3 and 5 layers of bi-directional glass fabrics were 8587 psi, 11045 psi and 13044 psi, respectively. Percentage increase in bending strength for 1, 3 and 5 layers (having 4\%, 7\% and $12 \%$ fiber volume fraction, respectively) compared to non-fabric were $1 \%, 30 \%$ and $53 \%$, respectively. Bending strength was calculated using eqn. 3 from ASTM D790-03.

$\sigma=\frac{3 P L}{2 b d^{2}}$

Calculations for sample \#8 and \#10:

Stress (sample\#8) $=\sigma=\frac{3 P L}{2 b d^{2}}=\frac{3 \times 58 \times 4}{2 \times 0.503 \times 0.251^{2}}=10981.5 \mathrm{psi}$.

Stress (sample\#10) $=\sigma=\frac{3 P L}{2 b d^{2}}=\frac{3 \times 75 \times 4}{2 \times 0.514 \times 0.258^{2}}=13152.5$ psi. 


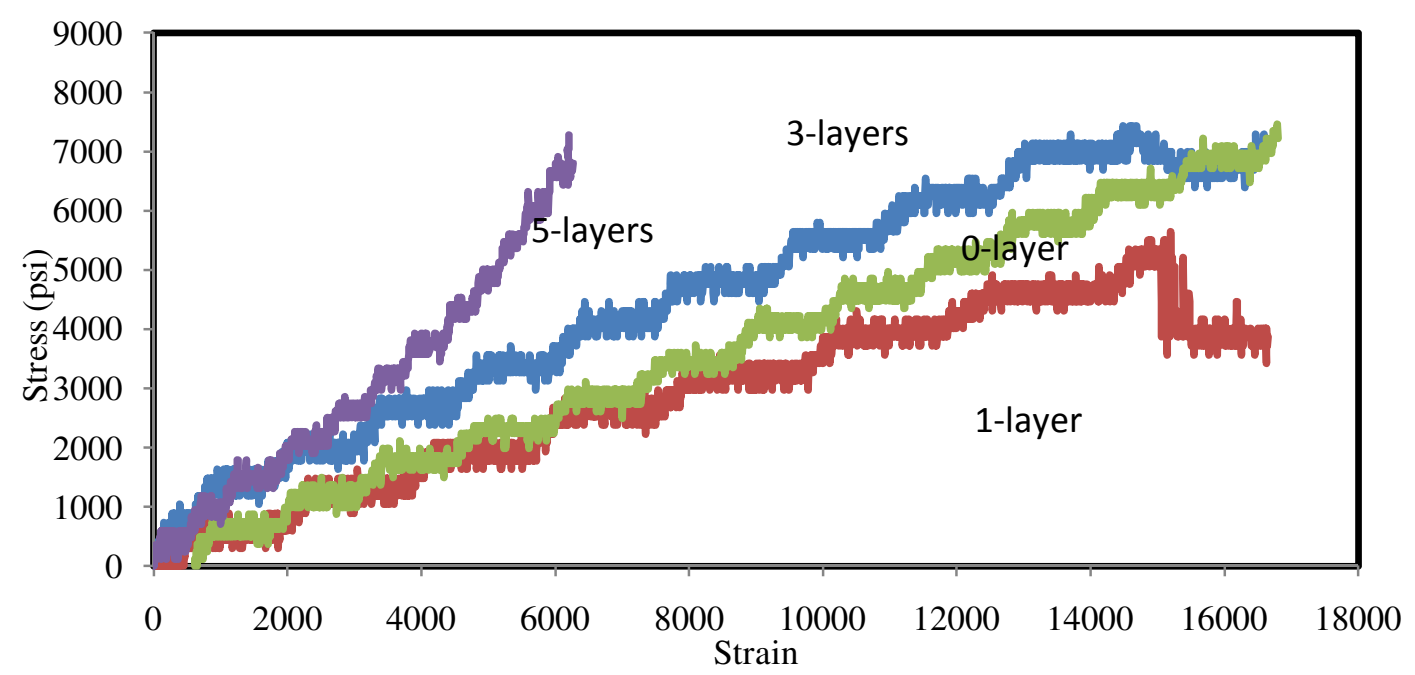

Figure 5. 2 Stress-strain curve for bending specimens

The increase in bending strength was $1 \%$ for specimens with $4 \%$ fiber volume fraction compared to non-fabric specimens, because the location of the glass fabric was at the neutral axis of the bending test specimen, which might not contribute to resist bending force.

Table 5. 4 Percentage stress and modulus increment for bending test

\begin{tabular}{|c|c|c|c|c|c|c|c|c|}
\hline Layers & $\begin{array}{c}\text { Average } \\
\text { stress }\end{array}$ & $\begin{array}{c}\text { Per layer } \\
\text { average } \\
\text { stress } \\
\text { increase }\end{array}$ & $\begin{array}{c}\% \\
\text { increase } \\
\text { in stress }\end{array}$ & $\begin{array}{c}\text { Per layer } \\
\text { increase }\end{array}$ & $\begin{array}{c}\text { Bending } \\
\text { modulus }\end{array}$ & $\begin{array}{c}\text { Per layer } \\
\text { modulus } \\
\text { increase }\end{array}$ & $\begin{array}{c}\% \\
\text { increase } \\
\text { in } \\
\text { modulus }\end{array}$ & $\begin{array}{c}\text { Per layer } \\
\text { modulus } \\
\text { increase }\end{array}$ \\
\hline & $\mathrm{psi}$ & $\mathrm{psi}$ & & & $\mathrm{msi}$ & $\mathrm{msi}$ & & \\
\hline 0 & 8516 & ----- & ---- & ----- & 0.304 & ---- & ---- & ----- \\
\hline 1 & 8587 & 71 & $1 \%$ & $1 \%$ & 0.447 & 0.143 & $47 \%$ & $47 \%$ \\
\hline 3 & 11045 & 843 & $30 \%$ & $10 \%$ & 0.447 & 0.047 & $47 \%$ & $16 \%$ \\
\hline 5 & 13044 & 905 & $53 \%$ & $11 \%$ & 0.994 & 0.138 & $227 \%$ & $45 \%$ \\
\hline
\end{tabular}

\subsubsection{Bending Modulus}

Bending modulus was calculated from initial slope of stress vs. strain curve (Figure 5.1) for 0,1 , 3 and 5 layer specimens from Figure 5.2. Average bending strength of coupon specimens without glass fabrics (Table 5.4) was evaluated to be 8516 psi and the average strengths with 1,3 and 5 
layers of glass fabrics were 8587 psi, 11045 psi and 13044 psi, respectively. Stress increases with increasing glass fabric layers by $1 \%, 30 \%$ and $53 \%$ was noted (Table 5.4) for bending test specimens.

\subsection{Compression Test Results}

Compression test results of recycled composite specimens (non-aged) with and without fabric are presented in Table 5.5.

Table 5. 5 Compression test results

\begin{tabular}{|c|c|c|c|c|c|}
\hline Layers & Sample & Load & Area & Stress & $\begin{array}{c}\text { Average } \\
\text { stress }\end{array}$ \\
\hline & $\#$ & lbs & in $^{2}$ & Psi & psi \\
\hline \multirow{3}{*}{0} & 1 & 2013 & 0.250 & 8030.6 & \multirow{3}{*}{8278} \\
\cline { 2 - 5 } & 2 & 1989 & 0.249 & 7977 & \\
\cline { 2 - 5 } & 3 & 2179 & 0.246 & 8827.6 & \\
\hline \multirow{3}{*}{2} & 4 & 2034 & 0.251 & 8087 & \multirow{3}{*}{8172} \\
\cline { 2 - 5 } & 5 & 1953 & 0.251 & 7777 & \\
\cline { 2 - 5 } & 6 & 2221 & 0.256 & 8652 & \\
\hline \multirow{3}{*}{6} & 7 & 1803 & 0.252 & 7141.0 & \multirow{3}{*}{6404} \\
\cline { 2 - 5 } & 8 & 1860 & 0.253 & 7332.2 & \\
\cline { 2 - 5 } 10 & 9 & 1976 & 0.255 & 7738.5 & \\
\hline & 10 & 1749 & 0.255 & 6849.3 & \\
\cline { 2 - 5 } & 11 & 1724 & 0.252 & 6818.6 & \\
\cline { 2 - 5 } & 12 & 1827 & 0.252 & 7240.3 & \\
\hline
\end{tabular}

\subsubsection{Compressive Strength Calculations}

Average compressive strength of specimens without fabric was 8278 psi and the strength decreased with the increase in number of fabrics layers. The average strength of 2-layers compression specimens was 8172 psi which was $1 \%$ lower than the specimen without fabric. Similarly, the average compressive strengths of 6 and 10 layers specimens were noted to be 7404 psi and 6969 psi, respectively. The compressive strength of 6 and 10 layers were $11 \%$ and $16 \%$, respectively, lower compared to non-fabric specimens (Table 5.6). 
$\sigma($ stress $)=\frac{P}{A}(\mathrm{psi})$ where $\mathrm{P}$ is load (lbs) and $\mathrm{A}$ is area $\left(\mathrm{in}^{2}\right)$

Tensile stress calculation for specimen \# 4 and 8

For specimen \#4, Stress $=$ Load $/$ Area $=2034(\mathrm{lbs}) / 0.251\left(\mathrm{in}^{2}\right)=8087$ psi.

For specimen $\# 8$, Stress $=$ Load $/$ Area $=1860(\mathrm{lbs}) / 0.253\left(\mathrm{in}^{2}\right)=7332.2$ psi.

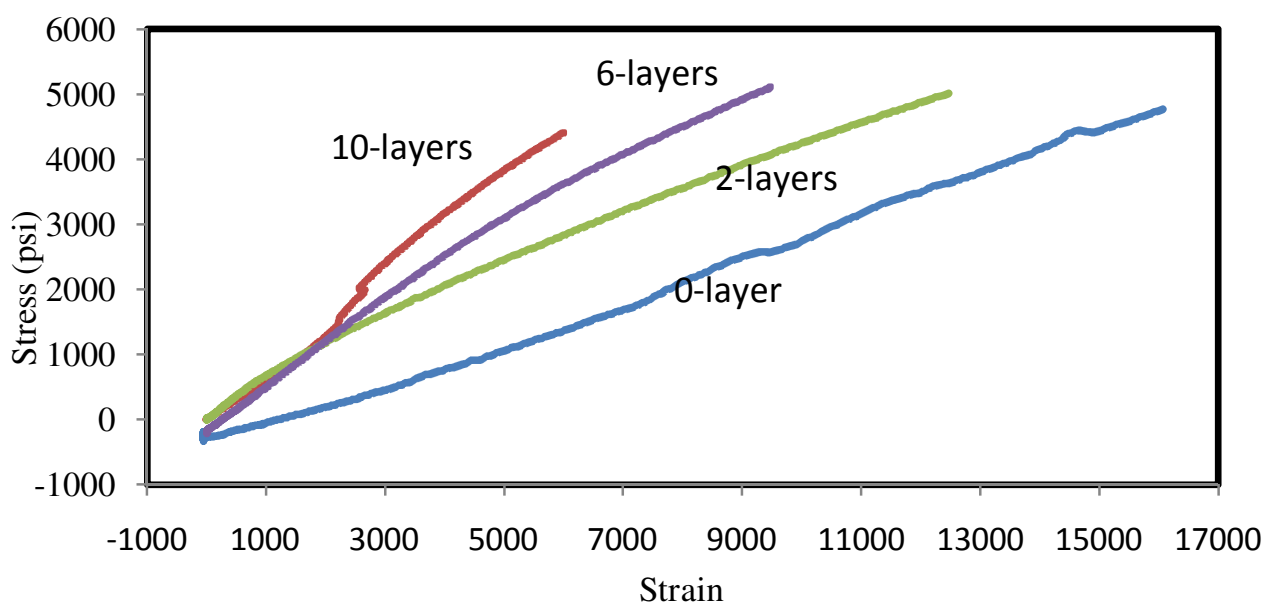

Figure 5. 3 Stress vs. strain curve for compression specimens

Table 5. 6 Compressive stresses and modulus

\begin{tabular}{|c|c|c|c|c|c|c|c|c|}
\hline Layers & $\begin{array}{c}\text { Avg. } \\
\text { stress }\end{array}$ & $\begin{array}{c}\text { Per } \\
\text { layer } \\
\text { stress } \\
\text { decrease }\end{array}$ & $\begin{array}{c}\text { Stress } \\
\text { decrease }\end{array}$ & $\begin{array}{c}\text { Per } \\
\text { layer } \\
\text { decrease } \\
\text { in stress }\end{array}$ & $\begin{array}{c}\text { Comp. } \\
\text { modulus }\end{array}$ & $\begin{array}{c}\text { Per layer } \\
\text { increase } \\
\text { in comp. } \\
\text { modulus }\end{array}$ & $\begin{array}{c}\% \\
\text { modulus } \\
\text { increase }\end{array}$ & $\begin{array}{c}\text { Per layer } \\
\text { modulus } \\
\text { increase }\end{array}$ \\
\hline 0 & 8278 & ---- & ---- & ---- & 0.312 & ---- & ---- & $\%$ \\
\hline 2 & 8172 & 52.2 & $1 \%$ & $0.5 \%$ & 0.419 & 0.053 & $34 \%$ & $17 \%$ \\
\hline 6 & 7404 & 145 & $11 \%$ & $2 \%$ & 0.598 & 0.047 & $91 \%$ & $15 \%$ \\
\hline 10 & 6969 & 130 & $16 \%$ & $2 \%$ & 0.678 & 0.036 & $117 \%$ & $12 \%$ \\
\hline
\end{tabular}

\subsubsection{Compressive Modulus}

Compressive moduli were calculated from initial slope of stress vs. strain curve of various FVF specimens (Figure 5.3). Average compressive modulus for specimens without fiber was $0.312 \mathrm{x}$ $10^{6}$ psi. Addition of 2 layers of bi-directional glass fabric increased the modulus by $34 \%$, and 
average modulus was found to be $0.419 \times 10^{6}$ psi. Similarly, the average compressive modulus for 3 and 5 layers compressive specimens were $0.598 \times 10^{6}$ and $0.678 \times 10^{6}$, respectively. The compressive modulus increased by $91 \%$ and $117 \%$, for 6 and 10 layers respectively, compared to modulus of non fabric specimen. The per layer decrease in compressive stress were $52.2 \mathrm{psi}, 145$ psi and $130 \mathrm{psi}$, and per layer compressive modulus increase was $0.053 \times 10^{6} \mathrm{psi}, 0.047 \times 10^{6} \mathrm{psi}$ and $0.036 \times 10^{6}$ psi for 2, 6 and 10 layers, respectively. Reduction in bending strength was noted for increasing fabric layers. This is mainly due to weak interlaminar shear transfer resulted in delamination, splitting and buckling kind of failure mode during loading. Also, lower degree of fabric wetting during manufacturing was due to high viscosity of thermoplastic (Amarnath, 2006).

\subsection{Impact Test Results}

Impact test results of recycled thermoplastics specimens (non-aged) with and without fabric are provided in Table 5.7

Table 5. 7 Impact test results

\begin{tabular}{|c|c|c|c|c|c|c|c|}
\hline $\begin{array}{c}\text { Sample } \\
\text { no. }\end{array}$ & $\begin{array}{l}\text { Fabric } \\
\text { layers }\end{array}$ & $\begin{array}{l}\text { Correction } \\
\text { factor } \\
\text { weight } \\
\text { (2lbs)(4 lbs) }\end{array}$ & $\begin{array}{l}\text { Impact } \\
\text { strength } \\
\text { (ft.lbs) }\end{array}$ & $\begin{array}{l}\text { Failure } \\
\text { type }\end{array}$ & $\begin{array}{l}\text { Strength } \\
\text { after } \\
\text { correction }\end{array}$ & $\begin{array}{l}\text { Strength after } \\
\text { weight correction } \\
\text { factor (ft.lbs.) }\end{array}$ & $\begin{array}{l}\text { Average } \\
\text { Strength } \\
\text { (ft.lbs.) }\end{array}$ \\
\hline 1 & \multirow{4}{*}{0} & 0.04 & 0.38 & $\bar{C}$ & 0.34 & 0.34 & \multirow{4}{*}{0.36} \\
\hline 2 & & 0.04 & 0.36 & $\mathrm{C}$ & 0.32 & 0.32 & \\
\hline 3 & & 0.04 & 0.46 & $\mathrm{C}$ & 0.42 & 0.42 & \\
\hline 13 & & 0.04 & 0.4 & $\mathrm{C}$ & 0.36 & 0.36 & \\
\hline 4 & \multirow{3}{*}{1} & 0.04 & 1.16 & $\mathrm{H}$ & 1.115 & 1.115 & \multirow{3}{*}{1.19} \\
\hline 5 & & 0.04 & 1.09 & $\mathrm{C}$ & 1.045 & 1.045 & \\
\hline 6 & & 0.04 & 1.46 & $\mathrm{H}$ & 1.415 & 1.415 & \\
\hline 7 & \multirow{3}{*}{3} & 0.045 & 1.98 & $\bar{P}$ & 1.935 & 1.935 & \multirow{3}{*}{2.21} \\
\hline 8 & & $0.045(2)$ & 1.21 & $\mathrm{H}$ & 1.165 & 2.33 & \\
\hline 9 & & $0.045(2)$ & 1.23 & $\mathrm{H}$ & 1.185 & 2.37 & \\
\hline 10 & \multirow{3}{*}{5} & $0.035(4)$ & 1.31 & $\mathrm{H}$ & 1.275 & 5.1 & \multirow{3}{*}{5.36} \\
\hline 11 & & $0.035(4)$ & 1.49 & $\mathrm{H}$ & 1.455 & 5.82 & \\
\hline 12 & & $0.035(4)$ & 1.33 & $\mathrm{H}$ & 1.295 & 5.18 & \\
\hline
\end{tabular}

ASTM (D256-03) defines the failure modes as C-complete break, H-Hinge break, and P-Partial break. 


\subsubsection{Impact Strength}

Average impact strength (Figure 5.4) of specimens without fabrics was $0.36 \mathrm{ft} . \mathrm{lbs}$. The average impact strengths increased to $1.19 \mathrm{ft} .1 \mathrm{bs}, 2.21 \mathrm{ft} .1 \mathrm{bs}$ and $5.36 \mathrm{ft} . \mathrm{lbs}$, for 1 , 3, and 5 layers, respectively, when compared to non-fabric layer specimens. The percentage increase in impact strength was $230 \%, 516 \%$ and $1388 \%$ in 1,3 , and 5 layers, respectively, when compared to specimens without fabric (Table 5.8).

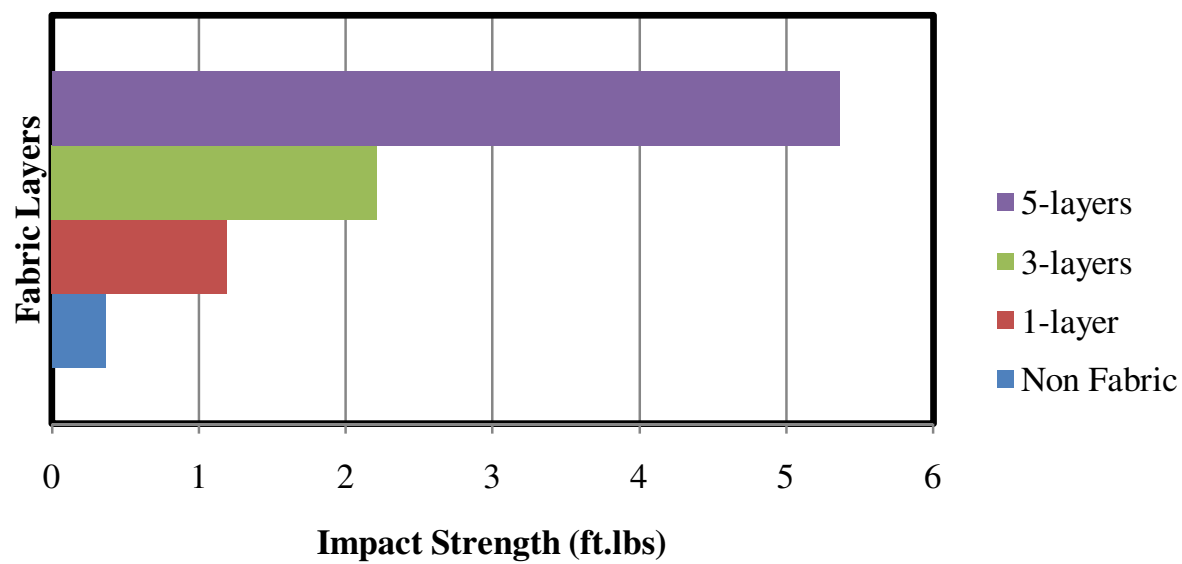

Figure 5. 4 Impact strengths with increasing number of fabrics

Table 5. 8 Impact strength increment with fiber volume fraction

\begin{tabular}{|c|c|c|c|c|}
\hline Layers & $\begin{array}{c}\text { Fiber volume } \\
\text { fraction }\end{array}$ & $\begin{array}{c}\text { Average } \\
\text { strength ft.lbs. }\end{array}$ & $\%$ increase & $\begin{array}{c}\text { Per layer impact } \\
\text { strength ft.lbs. }\end{array}$ \\
\hline 0 & 0 & 0.36 & ---- & ---- \\
\hline 1 & 4 & 1.19 & $230 \%$ & 0.83 \\
\hline 3 & 7 & 2.22 & $516 \%$ & 0.62 \\
\hline 5 & 12 & 5.36 & $1388 \%$ & 1.0 \\
\hline
\end{tabular}

Following the evaluation of coupon mechanical properties, some of these coupons were subjected to evaluate moisture diffusion that indicates the amount of voids in the composites, which is also an indication of durability as described in chapter 6. Following moisture absorption tests, testing of aged composites coupons was carried out as explained in chapter 7. 


\section{MOISTURE ABSORPTION TESTS}

\subsection{Introduction}

In this research, coupon specimens (tension, bending, compression and impact specimens be conventional to ASTM standards) were subjected to alkaline and salt solution aging with $100 \%$ humidity (immersed in ionic solutions) for the durability evaluation. In order to evaluate the rate of moisture absorption and diffusion coefficient, coupon specimens were immersed in distilled water, salt solution (with $3 \% \mathrm{NaCl}$ by weight in standard water) and alkaline solution (1.4\% $\mathrm{KOH}, 1 \% \mathrm{NaOH}$ and $0.2 \% \mathrm{Ca}(\mathrm{OH})_{2}$ salts by weight in standard water) at room temperature (Figure 6.1). The weights of specimens were monitored continuously for first 3 day and then later every week using high precision digital weighing scale. Specimens that were taken out periodically were wiped and dried surface moisture using a tissue paper before weighing.

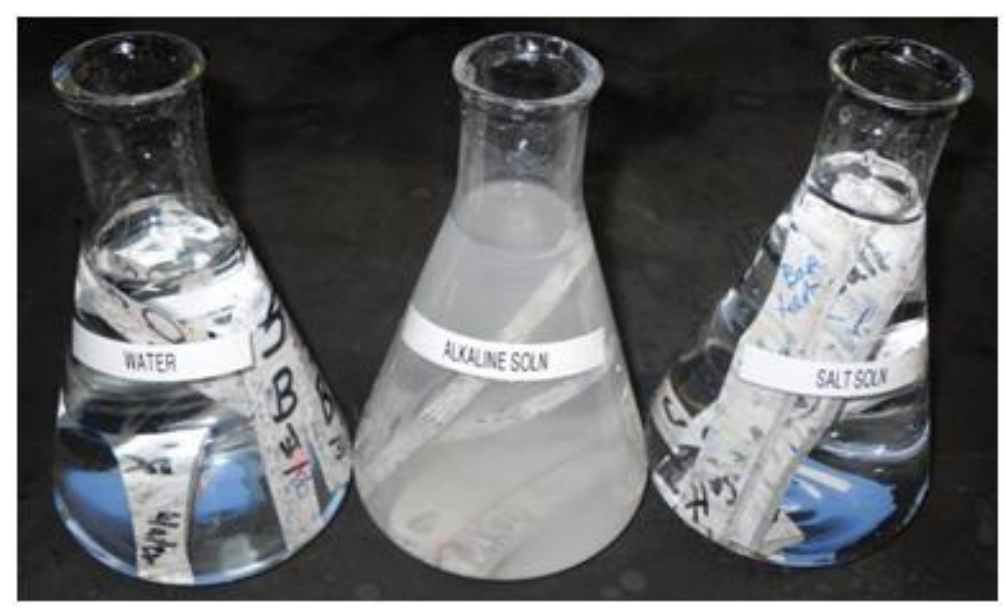

Figure 6. 1 Moisture absorption test at room temperature

\subsection{Moisture Absorption Test Results}

In this research, to understand the moisture absorption pattern in coupon specimens and to evaluate the moisture diffusion coefficient, coupon specimens were subjected to water, salt and alkaline solution at room temperature. Water, salt and alkali solution absorption after 3, 14, 28 
and 42 days are plotted for 0, 1, 3 and 5 layers of fabric specimens (Figure 6.2). Water, salt and alkaline solution absorption patterns was fairly uniform for specimens. From the moisture absorption test, it was noted that the moisture absorption by coupon specimens depends on presence of electrolytes, and protection of fiber from environmental exposure and fiber volume fraction.

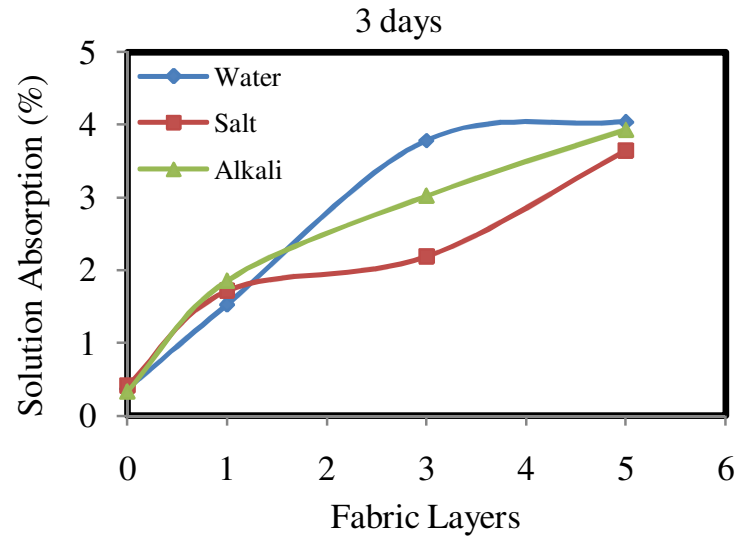

(a) Moisture absorption after 3 days

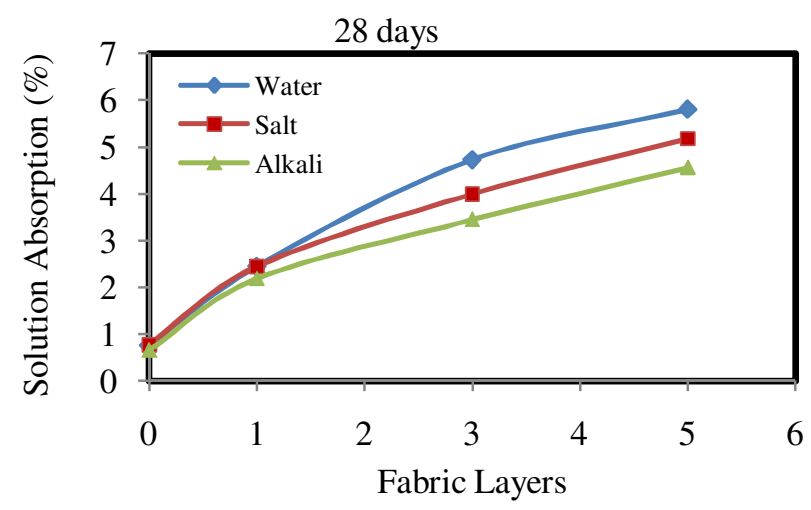

(c) Moisture absorption after 28 days

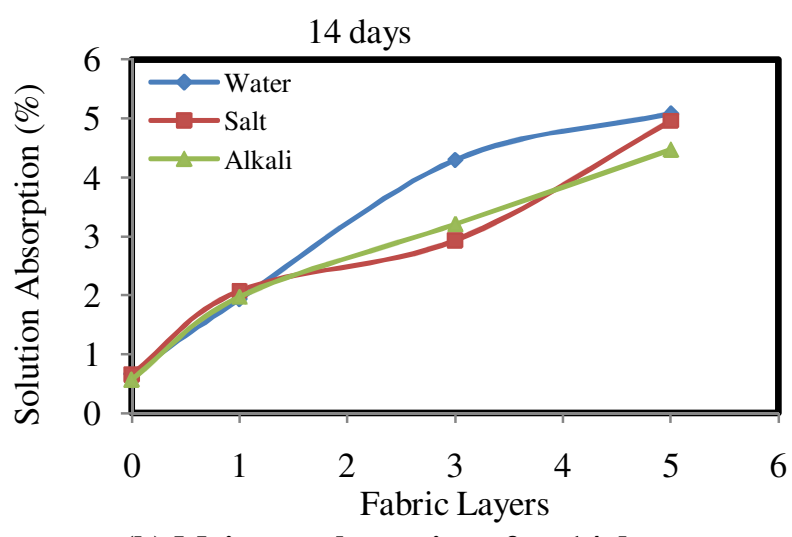

(b) Moisture absorption after 14 days

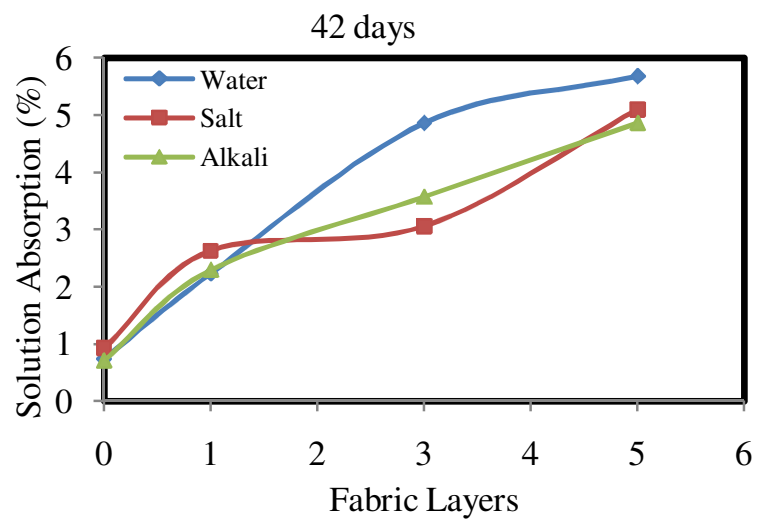

(d) Moisture absorption after 42 days

Figure 6. 2 Water, salt and alkali absorption vs. fabric layer plot 


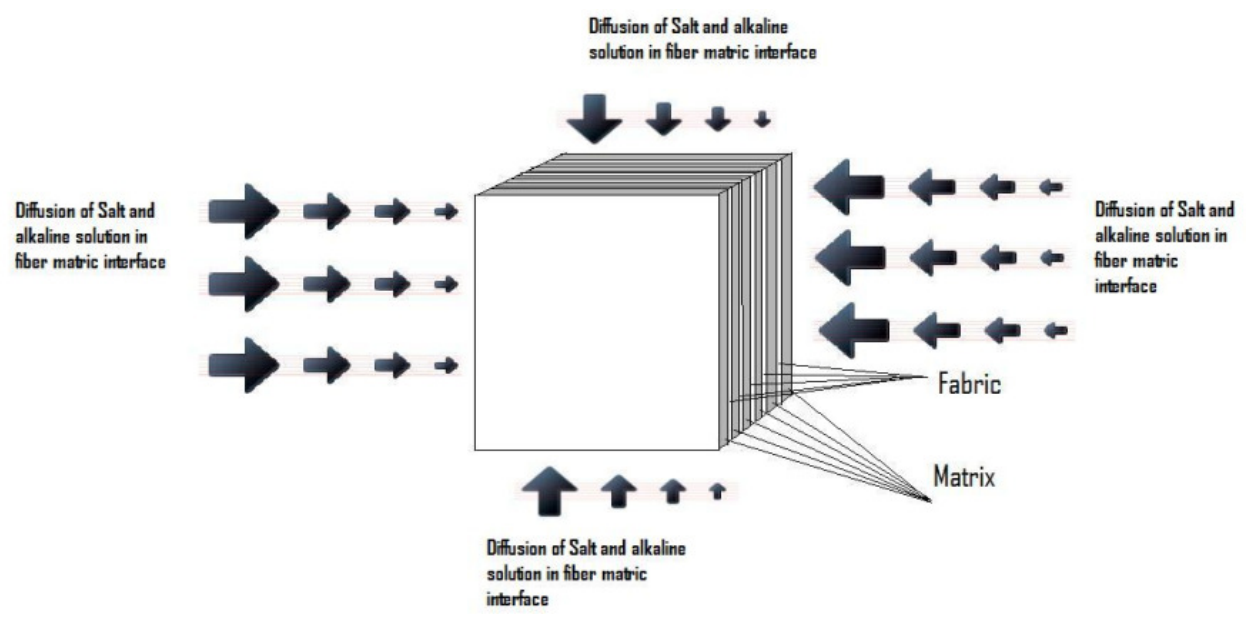

Figure 6. 3 Salt and alkaline solution diffusion pattern

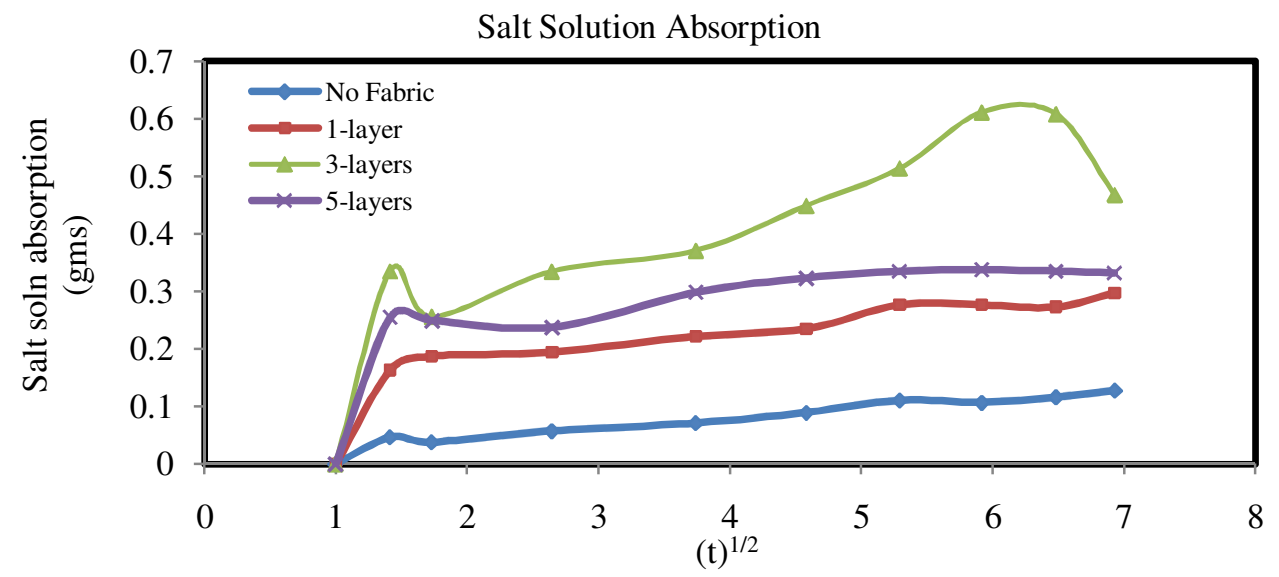

Figure 6. 4 Salt Solution absorption vs root time

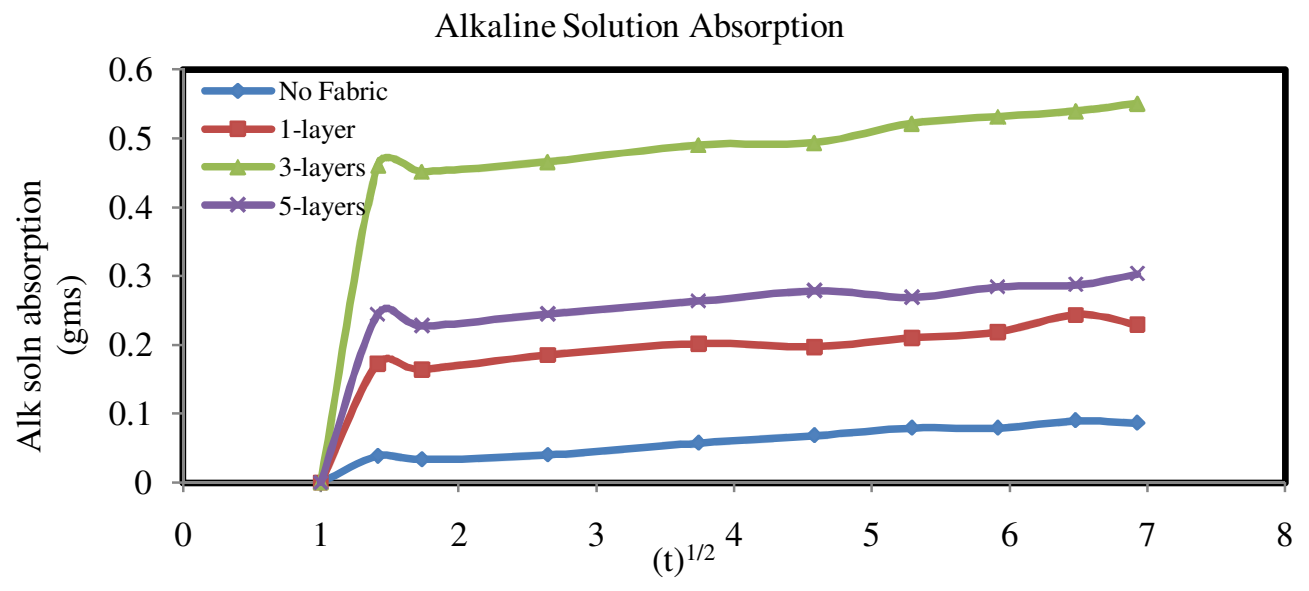

Figure 6. 5 Alkaline solution absorption vs root time 
Water Absorption

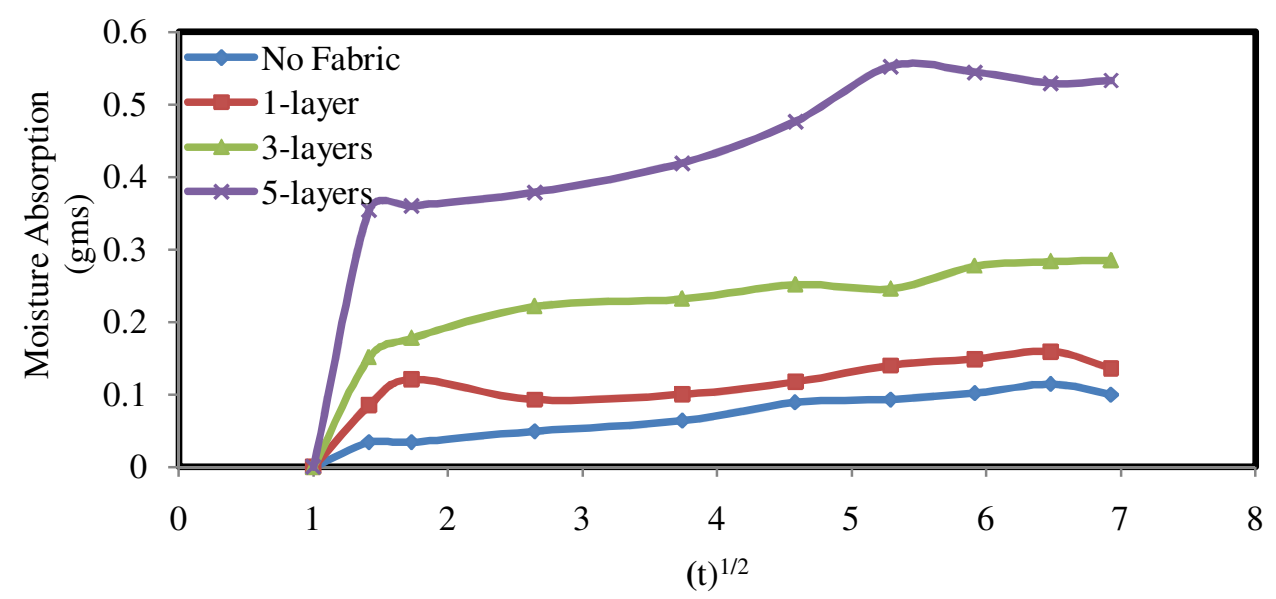

Figure 6. 6 Moisture absorption vs root time

Alkaline, salt and water absorption was noted to be non-linear for specimens with various fiber volume fractions. The non-linear moisture absorption might have occurred due to diffusion through exposed fabric at the specimen's edge (Figure 6.3). Researchers (Khelifi and Nanni, 2004) have noted nonlinear moisture absorption due to voids and imperfections in FRP cross sections specimens. The solution absorption by specimens in environmental chamber is expected to be higher than the absorption in room temperature, due to thermal cycling.

Addition of aqueous environment increases the effect of dry freeze-thaw through coming together and forming of interfacial cracks/debonds, eventually leading to higher diffusion of water through cracks during freeze-thaw cycle (Wu et al., 2006).

Following moisture absorption tests, salt, alkaline solution and water absorption vs root time graphs were plotted for recycled thermoplastic specimens (Figure 6.4, 6.5 and 6.6). It was noted that the solution absorption was higher for 3 layered specimens compared to 5, 1 and No fabric specimens (Figure 6.4 and 6.5). Solution infusion was higher for 3 layered specimens, which might be due to voids at the fabric matrix interface. However, for 5 layered specimens, the matrix and fabric layer were densely packed during manufacturing resulting in better quality 
FRP. Chin et al., (1997) noted the weight loss of specimens conditioned in alkaline solution initiated at $100 \mathrm{hrs}$ and were equivalent to the specimens conditioned in salt solution at $200 \mathrm{hrs}$; this indicates the chances of polymer collapse followed by leaching of soluble degradation or hydrolysis products. Elevated temperature used in this research might change water, salt and alkaline solution absorption patterns. Several researchers have noted that the salt and alkaline solution absorption would increase at higher temperature.

\subsection{Moisture Diffusion Co-efficient}

Fickian theory and Moisture Diffusion Coefficient equations for one dimensional and unsteady diffusion has been reported in Appendix B of this report. In this research, $M_{t} / M_{\infty}$ versus $\mathrm{t}^{1 / 2} / 2 l$ graphs were not plotted due to insufficient data (moisture absorption) points (however, trials graphs $M_{t} / M_{\infty}$ versus $\mathrm{t}^{1 / 2} / 2 l$ were plotted in order to note the saturation point, which was noted to be reached at around 35 days).

Table 6. $1 \mathrm{Mt} / \mathrm{M} \infty$ values for various solutions and fabric layers for 48 days

\begin{tabular}{|c|c|c|c|c|c|c|c|c|c|c|c|c|}
\hline 1 & 2 & 3 & 4 & 5 & 6 & $* 7$ & $* 8$ & 9 & 10 & 11 & 12 & 13 \\
\hline & & & $\begin{array}{c}1 \\
\text { day }\end{array}$ & $\begin{array}{c}2 \\
\text { days }\end{array}$ & $\begin{array}{c}3 \\
\text { days }\end{array}$ & $\begin{array}{c}7 \\
\text { days }\end{array}$ & $\begin{array}{c}14 \\
\text { days }\end{array}$ & $\begin{array}{c}21 \\
\text { days }\end{array}$ & $\begin{array}{c}28 \\
\text { days }\end{array}$ & $\begin{array}{c}35 \\
\text { days }\end{array}$ & $\begin{array}{c}42 \\
\text { days }\end{array}$ & $\begin{array}{c}48 \\
\text { days }\end{array}$ \\
\hline $\begin{array}{l}\text { Time } \\
\text { (hrs) }\end{array}$ & $\begin{array}{l}\text { Fabric } \\
\text { Layers }\end{array}$ & Egn. & $\begin{array}{c}24 \\
\text { (hrs) }\end{array}$ & $\begin{array}{c}48 \\
\text { (hrs) }\end{array}$ & $\begin{array}{c}72 \\
\text { (hrs) }\end{array}$ & $\begin{array}{c}168 \\
(\mathrm{hrs})\end{array}$ & $\begin{array}{c}336 \\
\text { (hrs) }\end{array}$ & $\begin{array}{c}504 \\
(\mathrm{hrs})\end{array}$ & $\begin{array}{c}672 \\
\text { (hrs) }\end{array}$ & $\begin{array}{c}840 \\
\text { (hrs) }\end{array}$ & $\begin{array}{l}1008 \\
\text { (hrs) }\end{array}$ & $\begin{array}{l}1152 \\
\text { (hrs) }\end{array}$ \\
\hline \multirow{4}{*}{ Water } & $\mathbf{0}$ & \multirow{4}{*}{$\begin{array}{c}\mathbf{M}_{\mathbf{t}} \\
/ \mathbf{M}_{\infty}\end{array}$} & 0.314 & 0.314 & 0.451 & 0.5831 & 0.8153 & 0.851 & 0.931 & 1.045 & 0.912 & 1 \\
\hline & 1 & & 0.575 & 0.818 & 0.629 & 0.6775 & 0.7956 & 0.947 & 1.00 & 1.079 & 0.919 & 1 \\
\hline & 3 & & 0.539 & 0.633 & 0.790 & 0.8269 & 0.8979 & 0.877 & 0.988 & 1.010 & 1.016 & 1 \\
\hline & 5 & & 0.691 & 0.702 & 0.739 & 0.8178 & 0.9301 & 1.078 & 1.062 & 1.032 & 1.039 & 1 \\
\hline \multirow{4}{*}{$\begin{array}{l}\text { Salt } \\
\text { Soln. }\end{array}$} & 0 & \multirow{4}{*}{$\begin{array}{c}\mathbf{M}_{\mathbf{t}} \\
/ \mathbf{M}_{\infty}\end{array}$} & 0.383 & 0.310 & 0.470 & 0.5829 & 0.7318 & 0.907 & 0.874 & 0.953 & 1.044 & 1 \\
\hline & 1 & & 0.539 & 0.619 & 0.643 & 0.7343 & 0.7777 & 0.916 & 0.915 & 0.903 & 0.984 & 1 \\
\hline & 3 & & 0.694 & 0.530 & 0.694 & 0.7695 & 0.9309 & 1.064 & 1.061 & 1.078 & 1.097 & 1 \\
\hline & 5 & & 0.753 & 0.737 & 0.702 & 0.8824 & 0.9564 & 0.991 & 0.998 & 0.991 & 0.982 & 1 \\
\hline \multirow{4}{*}{$\begin{array}{l}\text { Alkl. } \\
\text { Soln. }\end{array}$} & $\overline{0}$ & \multirow{4}{*}{$\begin{array}{c}\mathbf{M}_{\mathbf{t}} \\
/ \mathbf{M}_{\infty}\end{array}$} & 0.431 & 0.373 & 0.448 & 0.6406 & 0.7645 & 0.886 & 0.886 & 1.00 & 0.966 & 1 \\
\hline & 1 & & 0.646 & 0.615 & 0.694 & 0.7560 & 0.7384 & 0.786 & 0.819 & 0.913 & 0.860 & 1 \\
\hline & 3 & & 0.746 & 0.731 & 0.754 & 0.7939 & 0.7992 & 0.844 & 0.860 & 0.873 & 0.891 & 1 \\
\hline & 5 & & 0.761 & 0.709 & 0.764 & 0.8218 & 0.8682 & 0.839 & 0.885 & 0.894 & 0.944 & 1 \\
\hline
\end{tabular}

*Diffusion coefficients were calculated for $M_{t} / M_{\infty}$ values of column 7 and 8 (Highlighted), $M_{t} / M_{\infty}>1$ is an indication of saturation in specimens. 
Due to small number (insufficient) of data points, $M_{t}$ and $M_{\infty}$ were calculated manually. $M_{t}$ would be the difference between moisture absorption and dry weight of samples subjected to water, salt and alkaline solution. $M_{\infty}$ would be difference between saturated weight and moisture absorbed at regular interval of samples subjected to water, salt and alkaline solution. Some of $\mathrm{M}_{\mathrm{t}} / \mathrm{M}_{\infty}$ values might be higher than one after 21 days; reason being the saturation might have been reached any time after 21days of moisture exposure in coupon specimens. Eqn. (6.3) was used to evaluate the moisture diffusion co-efficient, D. $M_{t} / M_{\infty}$ values were calculated (Table 6.1) from moisture absorption data.

To evaluate moisture diffusion co-efficient, D, eqn. (B.3) was rearranged to eqn. (6.1).

$D=\left(\frac{M_{t}}{M_{\infty}} \frac{\pi^{1 / 2} 2 l}{4 t^{1 / 2}}\right)^{2}$

$D$ - Diffusion co-efficient, $c$ - concentration, $t$ - time (sec), $x$ - is the position in the Diffusion direction, $M_{\infty}$ - equilibrium increase in specimen mass, $M_{t}-$ moisture uptake, $2 l$ - thickness of sample.

Table 6. 2 Diffusion Coefficient

\begin{tabular}{|c|c|c|c|c|}
\hline $\begin{array}{c}\text { Solution } \\
\text { Type }\end{array}$ & $\begin{array}{c}\text { Fabric } \\
\text { Layers }\end{array}$ & $\begin{array}{c}\text { Average } \\
\text { depth }\end{array}$ & $\begin{array}{c}\text { Diffusion Coefficient } \\
\text { day 7 }\end{array}$ & $\begin{array}{c}\text { Diffusion Coefficient } \\
\text { day 14 }\end{array}$ \\
\hline & & (in) & sq.in/sec & sq.in/sec \\
\hline \multirow{4}{*}{ Water } & No Fabric & 0.236 & $6.150 \mathrm{E}-09$ & $6.011 \mathrm{E}-09$ \\
\cline { 2 - 5 } & $\mathbf{1}$ & 0.253 & $9.565 \mathrm{E}-09$ & $6.595 \mathrm{E}-09$ \\
\cline { 2 - 5 } & $\mathbf{3}$ & 0.253 & $1.425 \mathrm{E}-08$ & $8.401 \mathrm{E}-09$ \\
\cline { 2 - 5 } & $\mathbf{5}$ & 0.261 & $1.487 \mathrm{E}-08$ & $9.616 \mathrm{E}-09$ \\
\hline \multirow{4}{*}{$\begin{array}{c}\text { Salt } \\
\text { Solution }\end{array}$} & No Fabric & 0.236 & $6.146 \mathrm{E}-09$ & $4.842 \mathrm{E}-09$ \\
\cline { 2 - 5 } & $\mathbf{1}$ & 0.253 & $1.123 \mathrm{E}-08$ & $6.3017 \mathrm{E}-09$ \\
\cline { 2 - 5 } & $\mathbf{3}$ & 0.253 & $1.234 \mathrm{E}-08$ & $9.0305 \mathrm{E}-09$ \\
\hline \multirow{4}{*}{$\begin{array}{c}\text { Alkaline } \\
\text { solution }\end{array}$} & $\mathbf{5}$ & 0.261 & $1.731 \mathrm{E}-08$ & $1.0168 \mathrm{E}-08$ \\
\cline { 2 - 5 } & $\mathbf{N o}$ Fabric & 0.236 & $7.421 \mathrm{E}-09$ & $5.284 \mathrm{E}-09$ \\
\cline { 2 - 5 } & $\mathbf{1}$ & 0.253 & $1.191 \mathrm{E}-08$ & $5.681 \mathrm{E}-09$ \\
\cline { 2 - 5 } & $\mathbf{3}$ & 0.253 & $1.313 \mathrm{E}-08$ & $6.656 \mathrm{E}-09$ \\
\hline \multirow{4}{*}{} & $\mathbf{5}$ & 0.261 & $1.501 \mathrm{E}-08$ & $8.379 \mathrm{E}-09$ \\
\hline
\end{tabular}

*Diffusion coefficient for neat vinylester resin was noted to be $1.424 \times 10^{-9} \mathrm{in}^{2} / \mathrm{s}\left(9.19 \times 10^{-7}\left(\mathrm{~mm}^{2} / \mathrm{s}\right)\right.$ in a previous study by Shah et al, (2002) 
Moisture diffusion coefficients were manually calculated (Table 6.2) because of inadequate data points to plot $\mathrm{M}_{t} / \mathrm{M}_{\infty}$ vs $\mathrm{t}^{1 / 2} / 2 l$. Trial $\mathrm{M}_{\mathrm{t}} / \mathrm{M}_{\infty}$ vs $\mathrm{t}^{1 / 2} / 2 l$ graphs were plotted and based on the stabilized weight, gain saturation of samples was assumed to be reached after 28 days of immersions in water salt and alkaline solution. Hence, 7 and 14 days of moisture absorption data were selected to compute the $\mathrm{M}_{\mathrm{t}} / \mathrm{M}_{\infty}$ and evaluate moisture diffusion coefficient.

Moisture diffusion coefficient was calculated using Eqn. 6.1 (Table 6.2) and was noted to be higher for 7 days when compared to 14 days. Moisture diffusion coefficient increased with increasing number of fabric layer, which might be due to fabric acting as a medium for solution to penetrate in FRPs and presence of voids at fabric matrix interface.

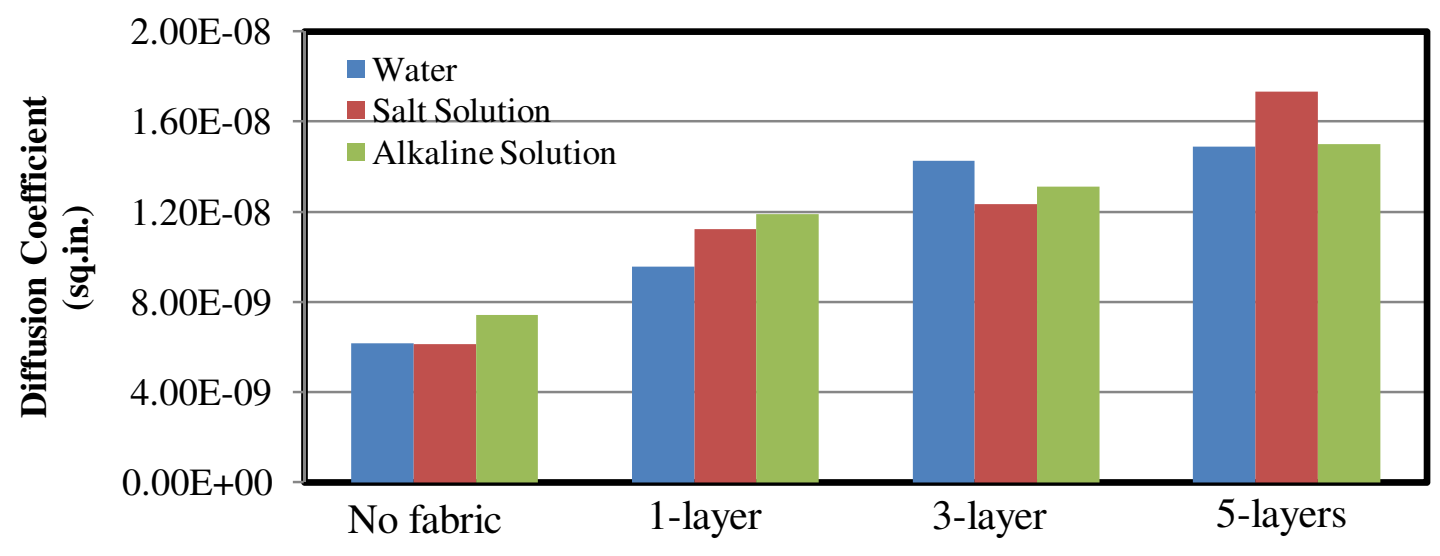

Figure 6. 7 Diffusion Coefficient (7 days)

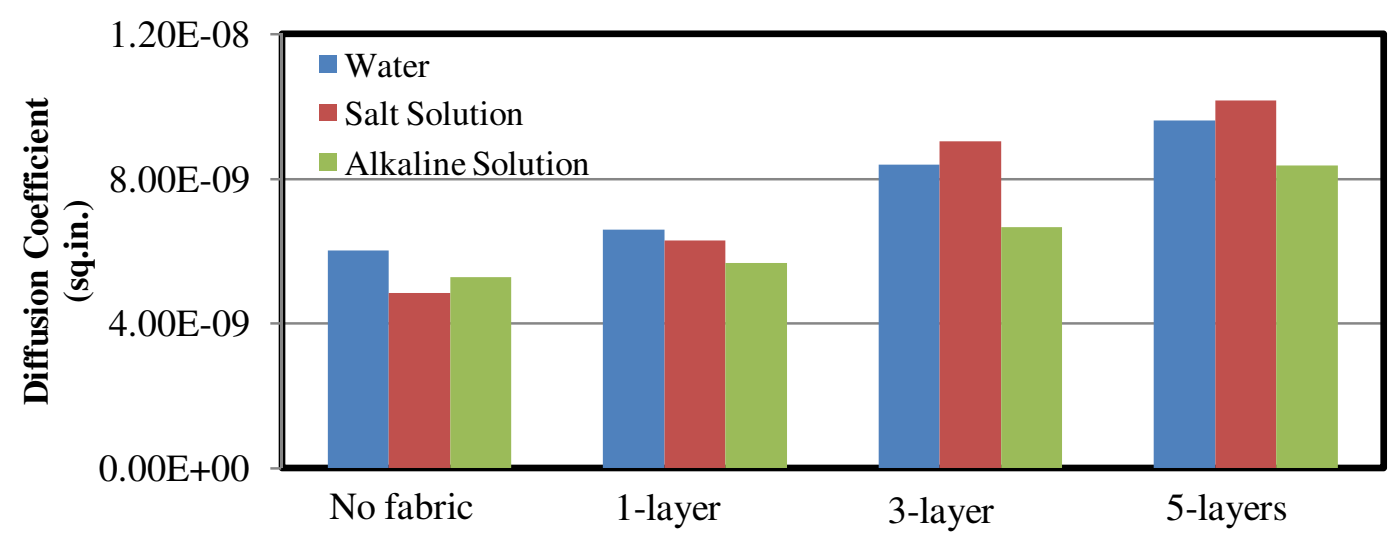

Figure 6. 8 Diffusion Coefficient (14 days) 
In this research, the moisture diffusion coefficients were higher compared to Shah et al. (2002). This may be due to use of thermoplastics in this research vs. use of nano-particles with thermoset vinyl-ester resin in their research (Shah et al. 2002). The presence of nano-particles reduces the moisture absorption and the diffusion coefficient as explained by Shah et al. (2002) and Krishnaswamy (2006).

In this research, higher diffusion coefficient was due to voids in thermoplastic FRPs and exposed fabric at specimen edges when compared to vinyl-ester FRP. The diffusion coefficient in specimens was noted to be lower at 14 days when compared to 7 days (Figure 6.7 and Figure 6.8) which is attributed to decrease in moisture saturation rate. 


\section{DURABILITY EVALUATION OF RECYCLED POLYMERS}

\subsection{Introduction}

In this research, durability of recycled polymers is evaluated by testing mechanical properties of coupon specimens subjected to alkaline and salt solution conditioning at room temperature and freeze-thaw temperature in an environmental chamber. Strength and stiffness of coupon specimens are evaluated under varying $\mathrm{pH}$, temperature and $\mathrm{H}_{2} \mathrm{O}$ conditions and compared with those of control specimens (non-aged). To account for durability of FRPs in structural design, strength reduction factors have been developed for structural design of specific applications (e.g., ACI 440). The average maximum percentage coupon strength reductions evaluated in this research are compared with the ACI 440 specified values. It was noted in this research that the coupon strength variations were mainly dependent on the fiber volume fraction and exposed fabric at specimen edges in accelerated aging environments.

\subsection{Tensile Strength under Aging}

Thermoplastic coupon specimens, compression molded with $0,1,3$, and 5 layers of bidirectional glass fabric were subjected to different conditioning schemes for $1,4,8$ and 12 months. Conditioning schemes involves immersion of coupon specimens in both the salt and alkaline solutions at room temperature and also under freeze-thaw variations. After conditioning coupon specimens for various durations, they were tested under tension, bending, compression, and impact, which were followed by Scanning Electron Microscopy (SEM). Results of durability tests are provided in following sections: 


\subsubsection{Alkaline solution under room temperature and freeze-thaw (Tension)}

In this section, average tensile strength of thermoplastic coupons aged in alkaline solution at room temperature was evaluated through mechanical testing. The strength reductions of nonfabric aged tensile specimens are reported in Table 7.1.

Table 7. 1 Tensile strength reductions for non-fabric specimens under 12 months in salt and alkaline solution at freeze-thaw and room temperature

\begin{tabular}{|c|c|c|c|c|c|c|c|c|c|c|}
\hline \multicolumn{11}{|c|}{ Tension } \\
\hline \multirow{2}{*}{$\begin{array}{l}\text { Aging } \\
\text { Scheme }\end{array}$} & \multirow[b]{2}{*}{ Layers } & \multirow{2}{*}{$\begin{array}{c}\text { Base } \\
\text { test } \\
\text { (psi) }\end{array}$} & \multicolumn{2}{|c|}{$1 \mathrm{M}$} & \multicolumn{2}{|c|}{$4 \mathrm{M}$} & \multicolumn{2}{|c|}{$8 \mathrm{M}$} & \multicolumn{2}{|c|}{$12 \mathrm{M}$} \\
\hline & & & $\begin{array}{c}\text { Stress } \\
\text { (psi) }\end{array}$ & $\begin{array}{c}\% \\
\text { change }\end{array}$ & $\begin{array}{c}\text { Stress } \\
\text { (psi) }\end{array}$ & $\begin{array}{c}\% \\
\text { change }\end{array}$ & $\begin{array}{c}\text { stress } \\
\text { (psi) }\end{array}$ & $\begin{array}{c}\% \\
\text { change }\end{array}$ & $\begin{array}{c}\text { Stress } \\
\text { (psi) }\end{array}$ & $\begin{array}{c}\% \\
\text { change }\end{array}$ \\
\hline ASRT & \multirow{4}{*}{$\begin{array}{l}\text { No } \\
\text { fiber }\end{array}$} & \multirow{4}{*}{4112} & 3660 & -11 & -- & -- & 3570 & -13 & 3633 & -12 \\
\hline ASFT & & & 3862 & -6 & -- & -- & 3855 & -6 & 3692 & -10 \\
\hline SSRT & & & 4325 & 5 & -- & -- & -- & -- & 3331 & -19 \\
\hline SSFT & & & 3778 & -8 & -- & -- & 3309 & -20 & 4140 & 1 \\
\hline
\end{tabular}

Note: AS: Alkaline solution, SS: Salt solution, RT: Room temperature, FT: Freeze-thaw

Average tensile strengths of specimens with $0,1,3$ and 5 layers of glass fabric were evaluated after 1, 4, 8 and 12 months of conditioning in alkaline solution at room temperature and the corresponding maximum stress reductions were found to be $-13 \%,-24 \%,-54 \%$, and $-65 \%$, respectively as given in, Table 7.2.

Table 7. 2 Tension test results in alkaline solution at room temperature

\begin{tabular}{|c|c|c|c|c|c|c|}
\hline \multicolumn{7}{|c|}{ Alkaline solution room temperature } \\
\cline { 1 - 5 } Months & \multirow{2}{*}{$\begin{array}{c}\text { Base test } \\
(\mathrm{psi})\end{array}$} & $1 \mathrm{M}$ & $4 \mathrm{M}$ & $8 \mathrm{M}$ & $12 \mathrm{M}$ & $\begin{array}{c}\text { Max stress } \\
\text { gain(+)/reduction(-)* }\end{array}$ \\
\cline { 3 - 7 } Layers & $\begin{array}{c}\text { Stress } \\
(\mathrm{psi})\end{array}$ & $\begin{array}{c}\text { Stress } \\
(\mathrm{psi})\end{array}$ & $\begin{array}{c}\text { Stress } \\
(\mathrm{psi})\end{array}$ & $\begin{array}{c}\text { Stress } \\
(\mathrm{psi})\end{array}$ & $\%$ \\
\hline No fiber & 4112 & 3660 & -- & $3569^{*}$ & 3632 & $-13 \%$ \\
\hline 1-layer & 5010 & 5140 & 4621 & $3789^{*}$ & 3891 & $-24 \%$ \\
\hline 3-layers & 8563 & 6999 & 6381 & 4309 & $3916^{*}$ & $-54 \%$ \\
\hline 5-layers & 10484 & 7623 & 8382 & 4106 & $3589^{*}$ & $-65 \%$ \\
\hline
\end{tabular}

Similar to Table 7.2, the average tensile strengths of coupon specimens with $0,1,3$ and 5 layers of glass fabric were evaluated after 1, 4, 8 and 12 months of alkaline solution conditioning in an 
environmental chamber (freeze-thaw variation) and the corresponding maximum stress reductions were found to be $-10 \%,-33 \%,-61 \%$, and $-75 \%$, respectively, Table 7.3 .

Table 7.3 Tension test results in alkaline solution under freeze-thaw

\begin{tabular}{|c|c|c|c|c|c|c|}
\hline \multicolumn{7}{|c|}{ Alkaline solution under freeze-thaw variation } \\
\hline Months & \multirow{2}{*}{$\begin{array}{c}\text { Base test } \\
\text { (psi) }\end{array}$} & $1 \mathrm{M}$ & $4 \mathrm{M}$ & $8 \mathrm{M}$ & $12 \mathrm{M}$ & $\begin{array}{c}\text { Max stress } \\
\text { gain }(+) / \text { reduction(-)* }\end{array}$ \\
\hline Layers & & $\begin{array}{l}\text { Stress } \\
(\mathrm{psi})\end{array}$ & $\begin{array}{l}\text { Stress } \\
\text { (psi) }\end{array}$ & $\begin{array}{l}\text { Stress } \\
\text { (psi) }\end{array}$ & $\begin{array}{l}\text { Stress } \\
\text { (psi) }\end{array}$ & $\%$ \\
\hline No fiber & 4112 & 3862 & -- & 3855 & $3692 *$ & $-10 \%$ \\
\hline 1-layer & 5010 & 3790 & 3683 & 4126 & $3349 *$ & $-33 \%$ \\
\hline 3-layers & 8563 & 4267 & 3685 & 4114 & $3299 *$ & $-61 \%$ \\
\hline 5-layers & 10484 & 4198 & 3645 & 3642 & $2613^{*}$ & $-75 \%$ \\
\hline
\end{tabular}

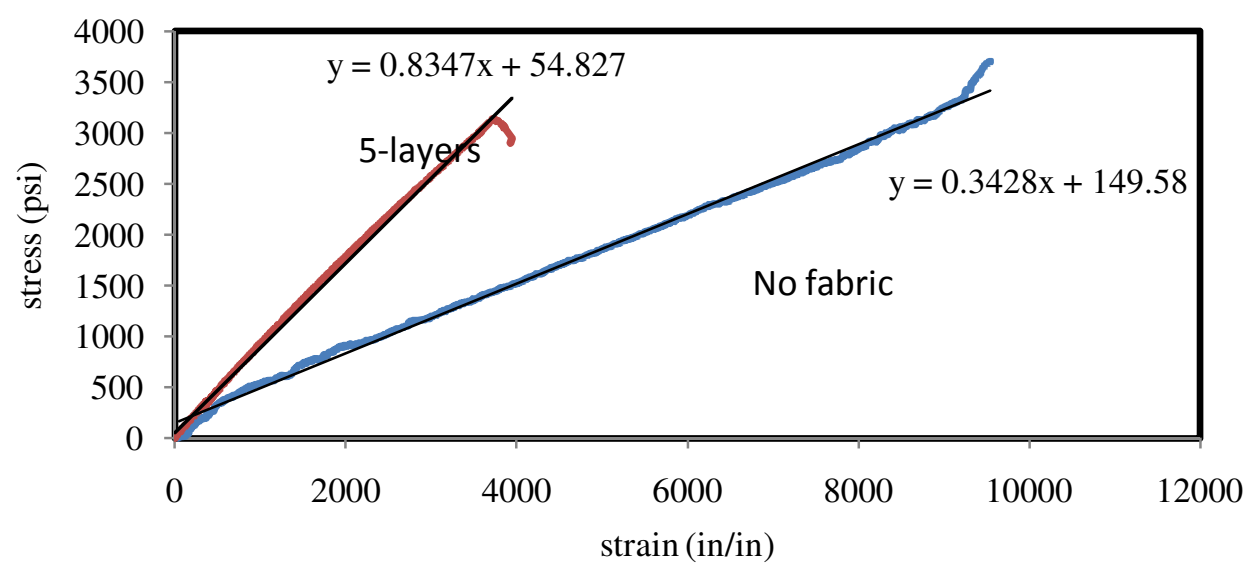

Figure 7. 1 Stress strain curves for specimens in alkaline solution environmental chamber for one month Maximum change in modulus of coupons under tension aged in alkaline solution at freeze thaw chamber for up to one month was noted to be $10 \%$ and $23 \%$ and figure 7.1 for specimens without fibers and with 5-layers (12\% fiber volume fraction), respectively (Table 7.4 and Figure 7.1). 


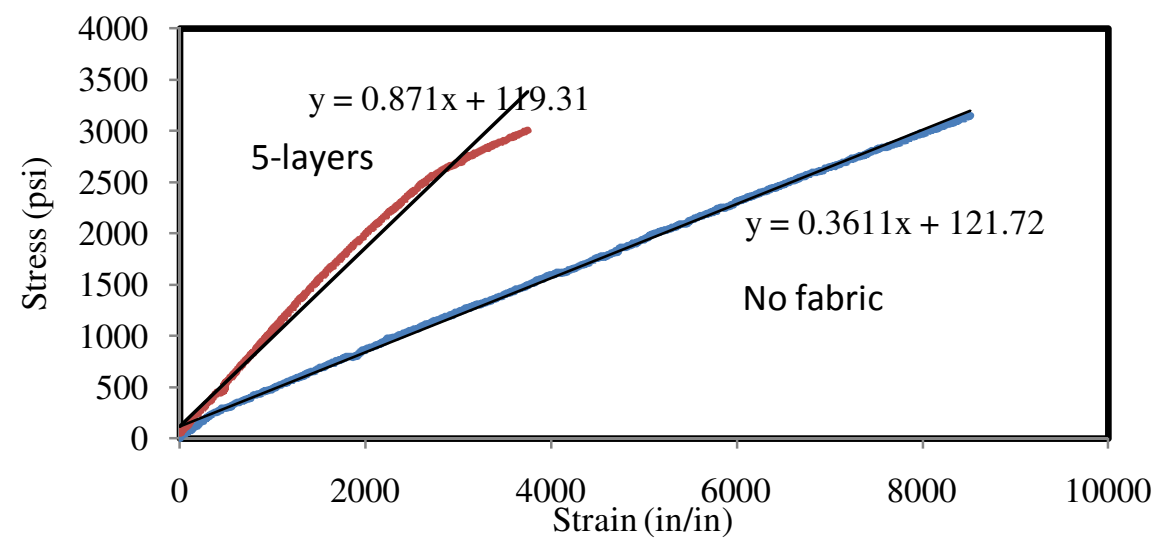

Figure 7. 2 Stress strain curve for specimens in alkaline solution under freeze-thaw

Maximum changes in tensile modulus for coupon specimens placed in alkaline solution with freeze thaw variations (in an environmental chamber) for up to eight months were 16\% and 28\% for specimens without fabric and 5-layers of fabric (12\% fiber volume fraction), respectively (Table 7.4 and Figure 7.2). From Figure 7.3, it was noted that the modulus of elasticity increased for alkaline conditioned specimens in alkaline solution with freeze-thaw (environmental chamber) compared to those of control specimens.

Table 7. 4 Tension modulus in alkaline solution under freeze-thaw for one and eight months

\begin{tabular}{|c|c|c|c|c|c|}
\hline \multirow{2}{*}{$\begin{array}{c}\text { No of } \\
\text { layers }\end{array}$} & \multirow{2}{*}{$\begin{array}{c}\text { Modulus } \\
\text { Base }\end{array}$} & $\begin{array}{c}\text { AM aged tensile } \\
\text { modulus }\end{array}$ & $\begin{array}{c}\text { \% } \\
\text { change }\end{array}$ & $\begin{array}{c}\text { 8M aged tensile } \\
\text { modulus }\end{array}$ & $\begin{array}{c}\text { \% } \\
\text { change }\end{array}$ \\
\cline { 3 - 6 } & $\mathrm{msi}$ & $\mathrm{msi}$ & $\%$ & $\mathrm{msi}$ & $\%$ \\
\hline No fibers & 0.312 & 0.342 & $10 \%$ & 0.361 & $16 \%$ \\
\hline 5-layers & 0.678 & 0.834 & $23 \%$ & 0.871 & $28 \%$ \\
\hline
\end{tabular}

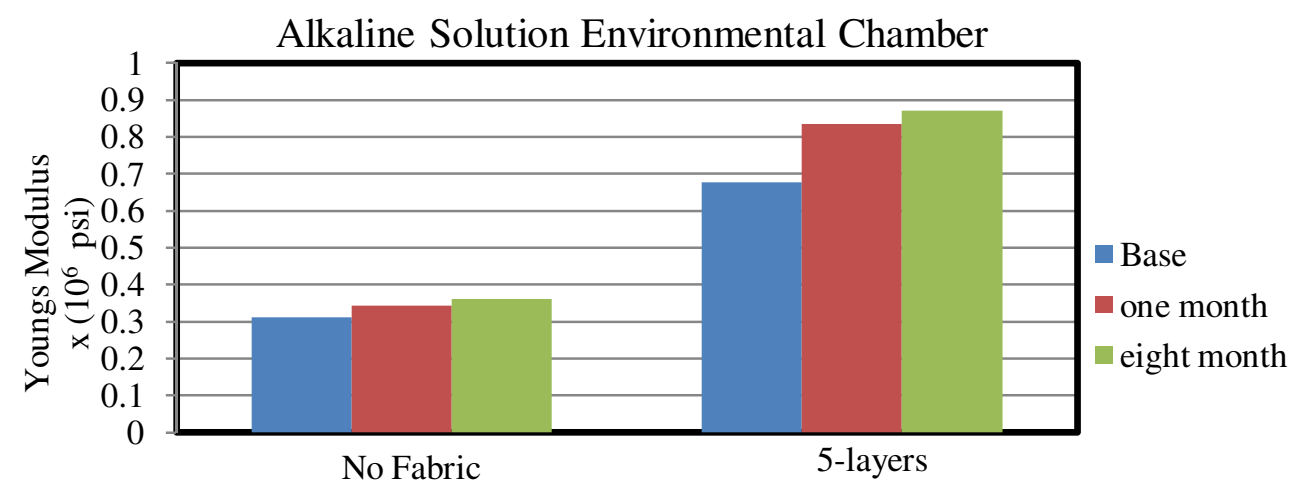

Figure 7. 3 Tension modulus in alkaline solution under freeze-thaw variations 


\subsubsection{Salt solution under room temperature and freeze-thaw (Tension)}

Similar to specimens under alkaline solution, average tensile strength of thermoplastic coupons aged in salt solution at room temperature was evaluated through mechanical testing. Average tensile strengths of specimens with $0,1,3$ and 5 layers were evaluated after 1, 4, 8 and 12 months of salt solution conditioning at room temperature and the corresponding maximum stress reductions were found to be $-19 \%,-7 \%,-14 \%$, and $-17 \%$, respectively, Table 7.5 .

Table 7. 5 Tension strength in salt solution at room temperature

\begin{tabular}{|c|c|c|c|c|c|c|}
\hline \multicolumn{7}{|c|}{ Salt solution room temperature } \\
\hline Months & \multirow{2}{*}{$\begin{array}{l}\text { Base test } \\
\text { (psi) }\end{array}$} & $1 \mathrm{M}$ & $4 \mathrm{M}$ & $8 \mathrm{M}$ & $12 \mathrm{M}$ & $\begin{array}{c}\text { Max stress } \\
\text { gain }(+) / \text { reduction(-)* }\end{array}$ \\
\hline Layers & & $\begin{array}{c}\text { Stress } \\
(\mathrm{psi})\end{array}$ & $\begin{array}{c}\text { Stress } \\
(\mathrm{psi})\end{array}$ & $\begin{array}{c}\text { Stress } \\
(\mathrm{psi})\end{array}$ & $\begin{array}{c}\text { Stress } \\
(\mathrm{psi})\end{array}$ & $\%$ \\
\hline No fiber & 4112 & 4325 & -- & -- & $3331 *$ & $-19 \%$ \\
\hline 1-layer & 5010 & 5350 & $4657 *$ & 5486 & 4970 & $-7 \%$ \\
\hline 3-layers & 8563 & 8004 & 7731 & 8290 & $7349 *$ & $-14 \%$ \\
\hline 5-layers & 10484 & $8720 *$ & 10097 & 11078 & 8954 & $-17 \%$ \\
\hline
\end{tabular}

The average tensile strengths of coupon specimens with $0,1,3$ and 5 layers of glass fabric are evaluated after 1, 4, 8 and 12 months of salt solution conditioning with freeze-thaw (environmental chamber) environmental chamber and the corresponding maximum stress reductions were found to be $-20 \%,-16 \%,-20 \%$, and $-41 \%$, respectively, as given in Table 7.6.

Table 7. 6 Tension strength in salt solution under freeze-thaw variations

\begin{tabular}{|c|c|c|c|c|c|c|}
\hline \multicolumn{7}{|c|}{ Salt solution under freeze-thaw variation } \\
\hline Months & \multirow{2}{*}{$\begin{array}{l}\text { Base test } \\
\text { (psi) }\end{array}$} & $1 \mathrm{M}$ & $4 \mathrm{M}$ & $8 \mathrm{M}$ & $12 \mathrm{M}$ & $\begin{array}{c}\text { Max stress } \\
\text { gain }(+) / \text { reduction(-)* }\end{array}$ \\
\hline Layers & & $\begin{array}{c}\text { Stress } \\
(\mathrm{psi})\end{array}$ & $\begin{array}{c}\text { Stress } \\
(\mathrm{psi})\end{array}$ & $\begin{array}{c}\text { Stress } \\
\text { (psi) }\end{array}$ & $\begin{array}{c}\text { Stress } \\
(\mathrm{psi})\end{array}$ & $\%$ \\
\hline No fiber & 4112 & 3778 & - & $3308 *$ & 4140 & $-20 \%$ \\
\hline 1-layer & 5010 & $4180^{*}$ & 4500 & 5203 & 4514 & $-16 \%$ \\
\hline 3-layers & 8563 & $6871^{*}$ & 7169 & 7633 & 6914 & $-20 \%$ \\
\hline 5-layers & 10484 & $6183^{*}$ & 10206 & 9878 & 8079 & $-41 \%$ \\
\hline
\end{tabular}




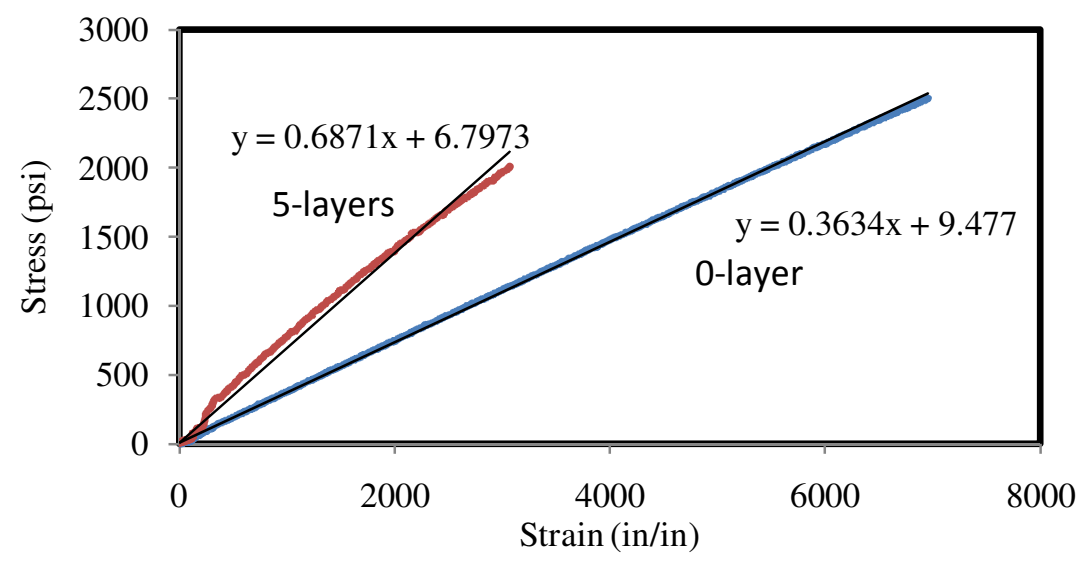

Figure 7. 4 Tensile stress-strain in salt solution under freeze-thaw (environmental chamber) for one month Maximum percentage change in tensile modulus of specimens in salt solution at room temperature variations (in an environmental chamber) for up to one month was $12 \%$ and $1.5 \%$ higher for specimens without fibers and 5-layers of fabric (12\% fiber volume fraction), respectively (Table 7.7 and Figure 7.4).

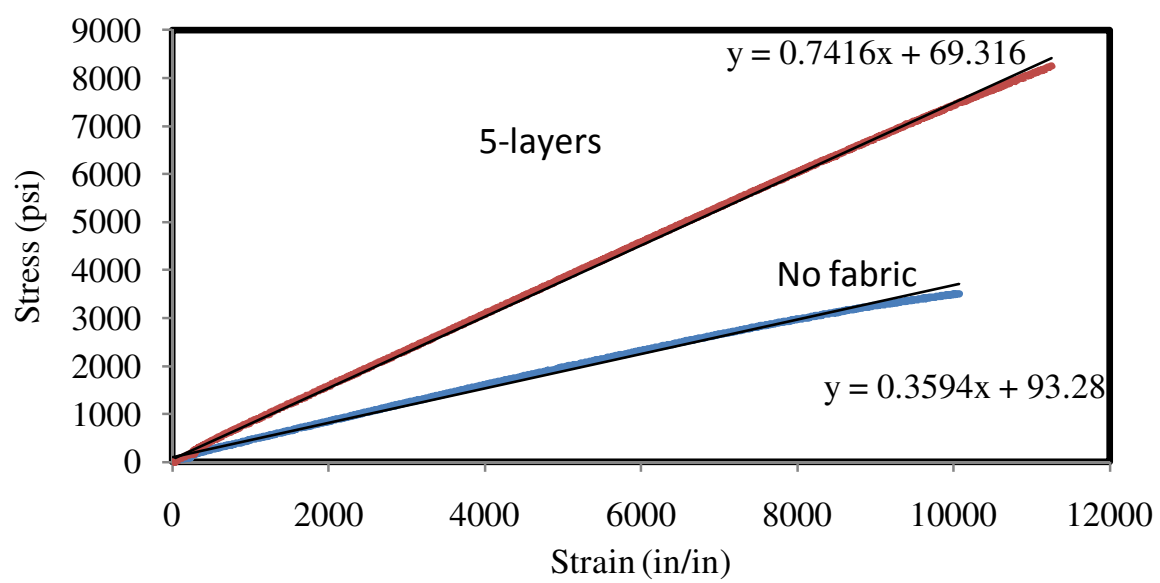

Figure 7. 5 Tensile stress-strain in salt solution under freeze-thaw (environmental chamber) for eight months Tension modulus of thermoplastic coupon specimens was evaluated from the initial slope of stress-strain curve. The tensile modulus of specimens aged in salt solution with freeze-thaw (environmental chamber) under one and eight months are presented in Table 7.7. 
Percentage gain in tensile modulus of thermoplastic coupon specimens in salt solution with freeze-thaw (environmental chamber) conditioning for eight months was $15 \%$ and $37 \%$ with no fabric and 5-layers of fabric (12\% fiber volume fraction), respectively (Table 7.7 and Figure 7.6).

Table 7. 7 Tension modulus in salt solution under freeze-thaw for one and eight months

\begin{tabular}{|c|c|c|c|c|c|}
\hline \multirow{2}{*}{$\begin{array}{c}\text { No of } \\
\text { layers }\end{array}$} & \multirow{2}{*}{$\begin{array}{c}\text { Modulus } \\
\text { Base }\end{array}$} & $\begin{array}{c}\text { 1M aged tensile } \\
\text { modulus }\end{array}$ & \% change & $\begin{array}{c}\text { 8M aged tensile } \\
\text { modulus }\end{array}$ & \% Change \\
\hline & $\mathrm{msi}$ & $\mathrm{msi}$ & $\%$ & $\mathrm{msi}$ & $\%$ \\
\hline No fibers & 0.312 & 0.348 & $12 \%$ & 0.359 & $15 \%$ \\
\hline 5-layers & 0.678 & 0.687 & $1.5 \%$ & 0.927 & $37 \%$ \\
\hline
\end{tabular}

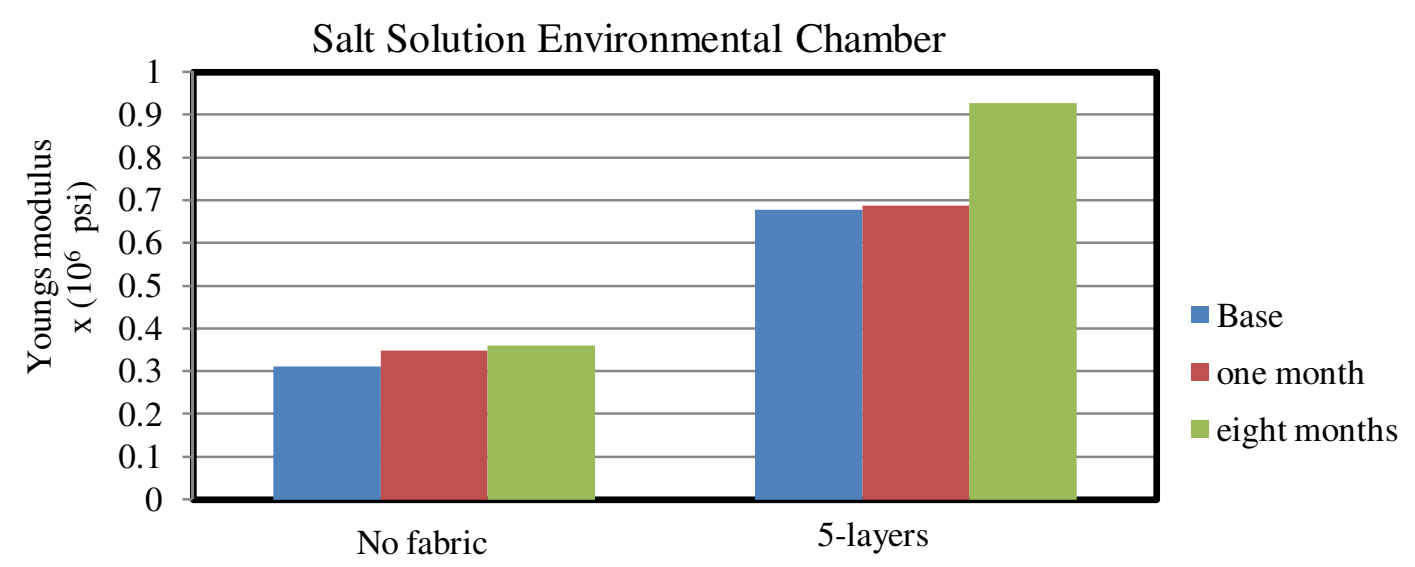

Figure 7. 6 Tension modulus variation of thermoplastic specimens in alkaline solution with freeze-thaw (environmental chamber)

In this research, tensile modulus increased for all specimens in alkaline and salt solution under freeze-thaw variations (Figures 7.3 and 7.7). Lower strains were noted for salt and alkaline solution aged samples compared to non-aged tension test specimens at corresponding stresses, which was an indication of brittle behavior leading to increased in modulus and reduced strength. The brittle behavior of glass fabric due to nucleation of calcium hydroxide on the fiber surface is noted by Zhang and Karbhari, (1999). 


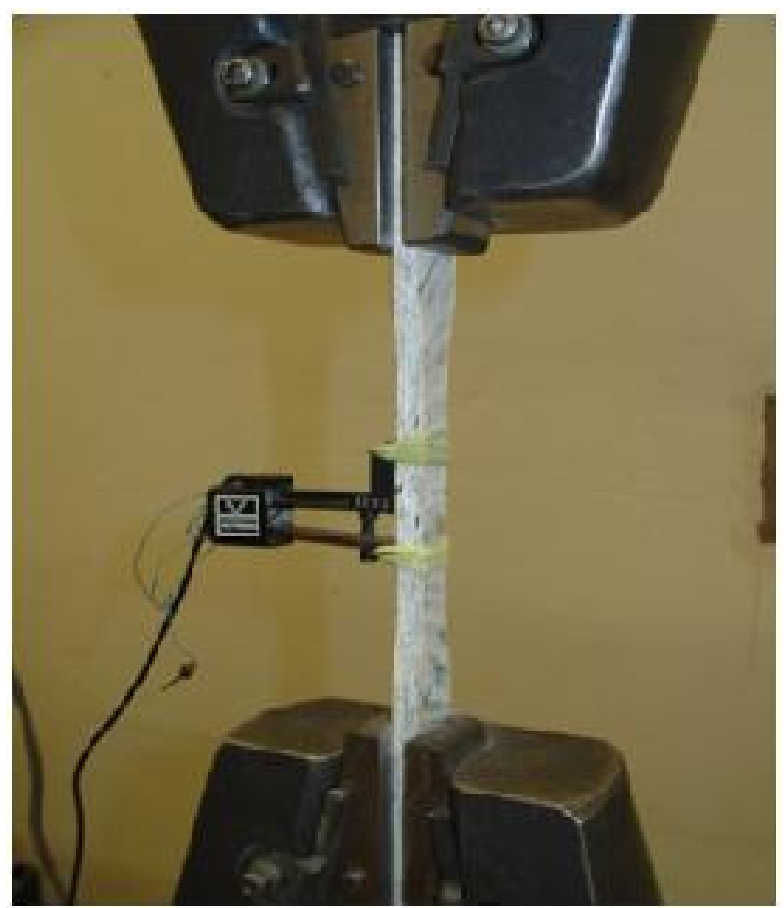

(a) Failure modes of control tension test specimen

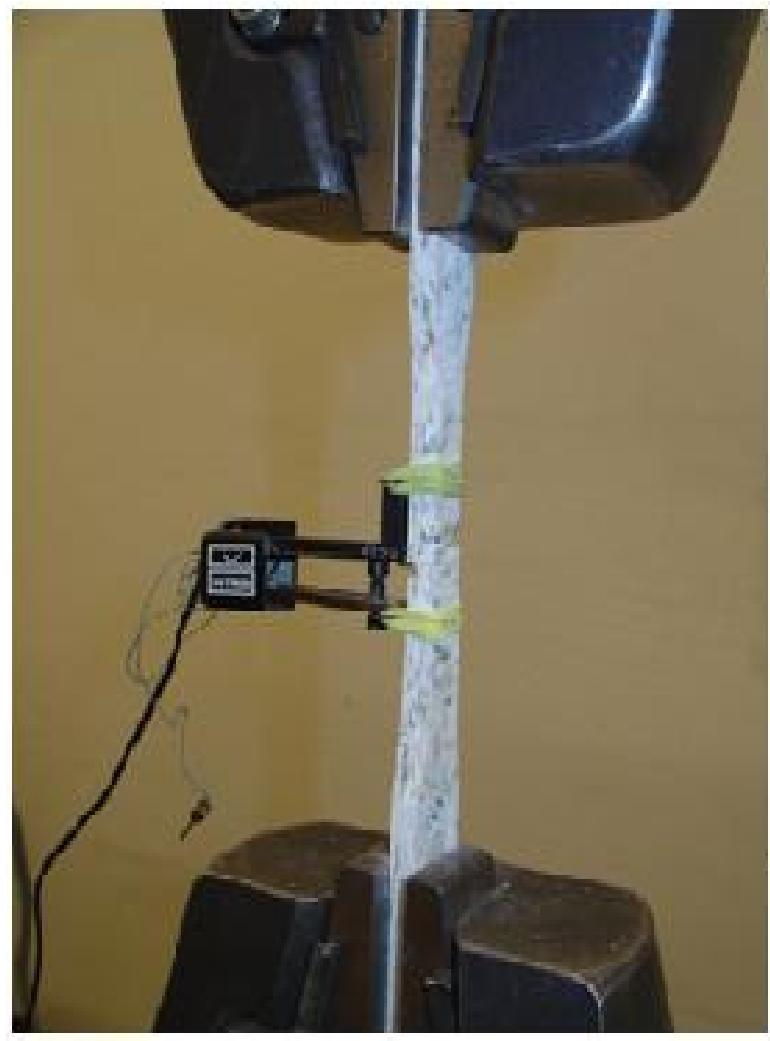

(c) Failure at center with moderate delamination (salt solution sample)

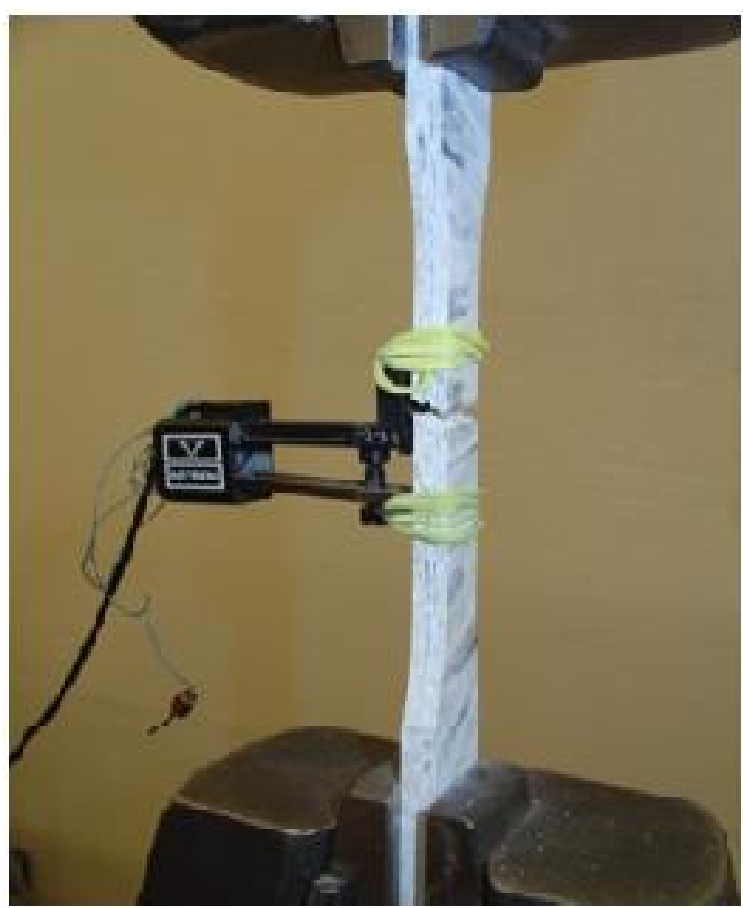

(b) Complete tearing of fabric (alkaline solution specimen

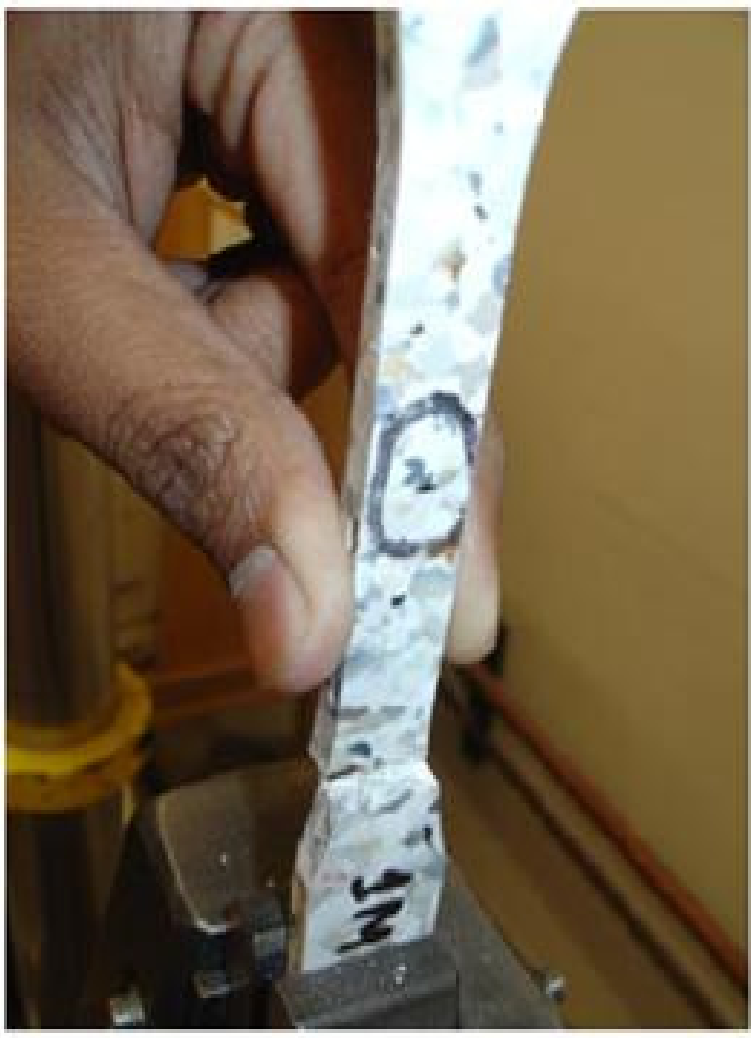

(d) Presence of large void in a non fabric specimen 


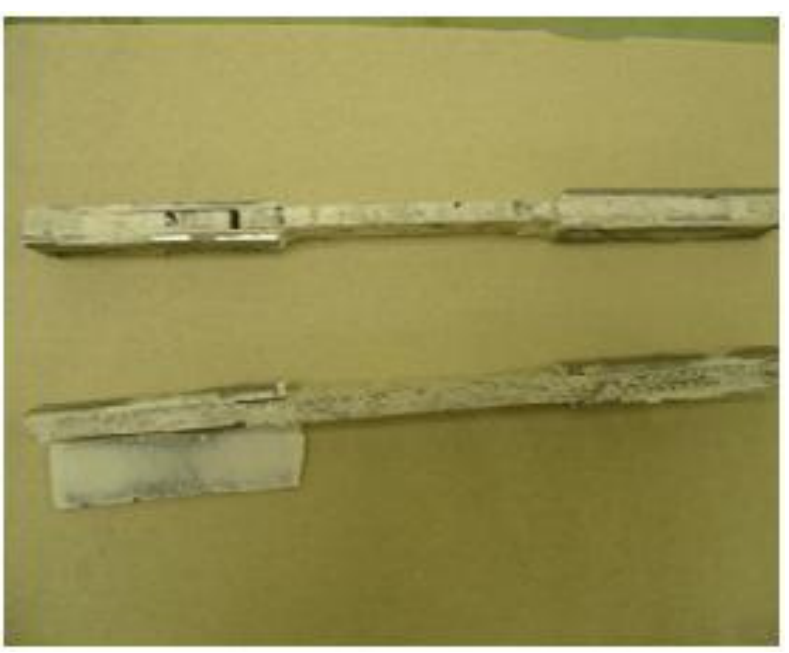

(e) Improper failure at grip

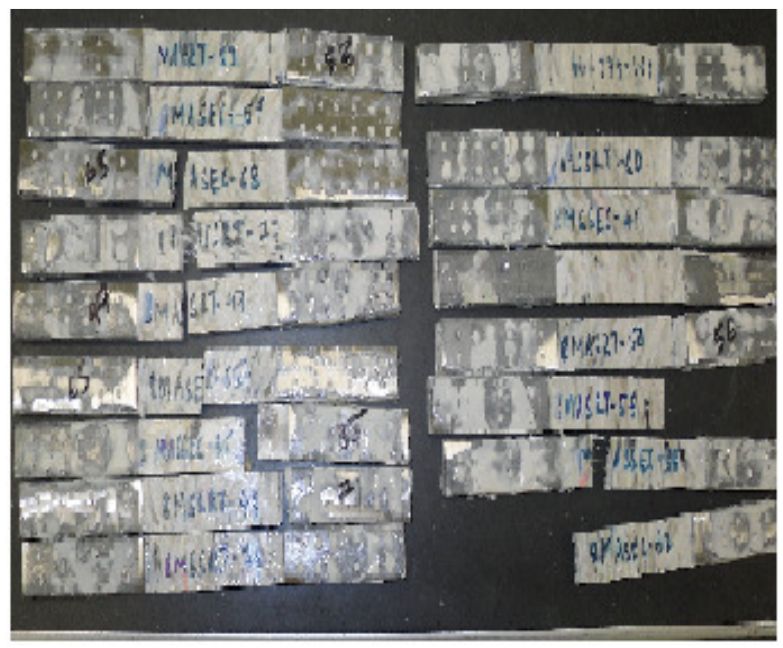

(f) Failure modes in tension test specimens with perforated tabs

Figure 7. 7 Failure modes in thermoplastic tension test coupon specimens

Failure Type: In this study, failures occurring in the gage length of the tension coupon (Figure 7.7 (a)) are used for calculations and comparison. Complete rupturing of fabric in tension specimens aged in alkaline solution under freeze-thaw variations might be due to damaging of fabric layers from leaching and/or etching process (Figure 7.7 (b)). In tension test specimens, rupture and delamination on either side of glass fabric layer in the gage length was noted, which might have been caused due to pressure exerted by freezing of diffused solution (Figure 7.7 (c)). Rupturing of coupon under tension near the grips was noted for few tension test samples, which might be due to the presence of voids and stress concentration near grip (Figure 7.7 (d)). Failure was noted inside the grip area for couple of test samples with tabs, which was due to improper distribution of adhesive leading to stress concentration (Figure 7.7 (e)). Conventional failure mode was noted for specimens with perforated tabs, where excess adhesive used for bending the tabs oozes out through the holes in the grip area. Uniform distribution of adhesive between the specimen and the tab and additional shear strength of the cured resin projected out of the holes improve grip bonding (Figure 7.7 (f)) and improved failure modes with the use of perforated tabs. 


\subsection{Bending Strength Variation under Aging}

Similar to tension test data, the average bending strengths of thermoplastic ABS specimens with $0,1,3$ and 5 layers of glass fabric were evaluated as per ASTM standards and are presented in the following sections:

\subsubsection{Alkaline aging under room temperature and freeze-thaw (Bending)}

Average bending strength of thermoplastic coupon specimens aged in alkaline solution at room temperature was evaluated through mechanical testing. The strength reductions of non-fabric aged bending specimens are reported in Table 7.8.

Table 7. 8 Bending strength reductions for non-fabric specimens under 12 months in salt and alkaline solution at freeze-thaw and room temperature

\begin{tabular}{|c|c|c|c|c|c|c|c|c|c|c|}
\hline \multicolumn{11}{|c|}{ Bending } \\
\hline \multirow{2}{*}{$\begin{array}{c}\text { Aging } \\
\text { Schemes }\end{array}$} & \multirow[b]{2}{*}{ Layers } & \multirow{2}{*}{$\begin{array}{c}\text { Base } \\
\text { test } \\
\text { (psi) }\end{array}$} & \multicolumn{2}{|c|}{$1 \mathrm{M}$} & \multicolumn{2}{|c|}{$4 \mathrm{M}$} & \multicolumn{2}{|c|}{$8 \mathrm{M}$} & \multicolumn{2}{|c|}{$12 \mathrm{M}$} \\
\hline & & & $\begin{array}{c}\text { Stress } \\
(\mathrm{psi})\end{array}$ & $\begin{array}{c}\% \\
\text { change } \\
\end{array}$ & $\begin{array}{c}\text { Stress } \\
(\mathrm{psi})\end{array}$ & $\begin{array}{c}\% \\
\text { change } \\
\end{array}$ & $\begin{array}{c}\text { Stress } \\
(\mathrm{psi})\end{array}$ & $\begin{array}{c}\% \\
\text { change } \\
\end{array}$ & $\begin{array}{c}\text { Stress } \\
(\mathrm{psi})\end{array}$ & $\begin{array}{c}\% \\
\text { change }\end{array}$ \\
\hline ASRT & \multirow{4}{*}{$\begin{array}{l}\text { No } \\
\text { fiber }\end{array}$} & \multirow{4}{*}{8516} & 8752 & 2.78 & 7950 & -6.65 & -- & -- & 8616 & 1.18 \\
\hline ASEC & & & 9295 & 9.15 & 7719 & -9.35 & -- & -- & 8662 & 1.71 \\
\hline SSRT & & & 7694 & -9.65 & 8644 & 1.51 & -- & -- & 8677 & 1.90 \\
\hline SSEC & & & 9162 & 7.58 & 8298 & -2.56 & -- & -- & 7382 & -13.31 \\
\hline
\end{tabular}

Note: AS: Alkaline solution, SS: Salt solution, RT: Room temperature, FT: Freeze-thaw

Average bending strengths of specimens with $0,1,3$ and 5 layers were evaluated after 1, 4, 8 and

12 months of aging in alkaline solution at room temperature and the corresponding maximum stress reductions were found to be $-7 \%,-7 \%,-30 \%$, and $-43 \%$, respectively, Table 7.9.

Table 7.9 Bending stress in alkaline solution at room temperature

\begin{tabular}{|c|c|c|c|c|c|c|}
\hline \multicolumn{7}{|c|}{ Alkaline solution room temperature } \\
\hline Months & \multirow{2}{*}{$\begin{array}{c}\text { Base test } \\
(\mathrm{psi})\end{array}$} & $1 \mathrm{M}$ & $4 \mathrm{M}$ & $8 \mathrm{M}$ & $12 \mathrm{M}$ & $\begin{array}{c}\text { Max stress } \\
\text { gain(+)/reduction(-)* }\end{array}$ \\
\cline { 3 - 7 } & $\begin{array}{c}\text { Stress } \\
(\mathrm{psi})\end{array}$ & $\begin{array}{c}\text { Stress } \\
(\mathrm{psi})\end{array}$ & $\begin{array}{c}\text { Stress } \\
(\mathrm{psi})\end{array}$ & Stress (psi) & $\%$ \\
\hline Nayers & 8516 & 8752 & $7950^{*}$ & -- & 8616 & $-7 \%$ \\
\hline 1-layer & 8587 & 9029 & $7999^{*}$ & -- & 8068 & $-7 \%$ \\
\hline 3-layers & 11045 & 10109 & 8434 & -- & $7714^{*}$ & $-30 \%$ \\
\hline 5-layers & 13044 & 11238 & 10971 & -- & $7442^{*}$ & $-43 \%$ \\
\hline
\end{tabular}


Similarly, the average bending strength of coupon specimens with $0,1,3$ and 5 layers of glass fabric were evaluated after 1, 4, 8 and 12 months of alkaline solution conditioning with freezethaw (environmental chamber) and the corresponding maximum stress reductions were found to be $-9 \%,-14 \%,-31 \%$, and $-52 \%$, respectively, Table 7.10 .

Table 7. 10 Bending stress under freeze-thaw conditions (environmental chamber)

\begin{tabular}{|c|c|c|c|c|c|c|}
\hline \multicolumn{7}{|c|}{ Alkaline solution freeze-thaw } \\
\hline Months & Base & $1 \mathrm{M}$ & $4 \mathrm{M}$ & $8 \mathrm{M}$ & $12 \mathrm{M}$ & $\begin{array}{c}\text { Max stress } \\
\text { gain }(+) / \text { reduction }(-)^{*}\end{array}$ \\
\hline Layers & (psi) & $\begin{array}{l}\text { Stress } \\
\text { (psi) }\end{array}$ & $\begin{array}{l}\text { Stress } \\
\text { (psi) }\end{array}$ & $\begin{array}{l}\text { Stress } \\
(\mathrm{psi})\end{array}$ & $\begin{array}{l}\text { Stress } \\
\text { (psi) }\end{array}$ & $\%$ \\
\hline No fiber & 8516 & 9295 & $7719 *$ & -- & 8662 & $-9 \%$ \\
\hline 1-layer & 8587 & 8612 & 8450 & -- & $7403 *$ & $-14 \%$ \\
\hline 3-layers & 11045 & 8061 & 7819 & -- & $7585^{*}$ & $-31 \%$ \\
\hline 5-layers & 13044 & 6824 & 7436 & -- & $6230^{*}$ & $-52 \%$ \\
\hline
\end{tabular}

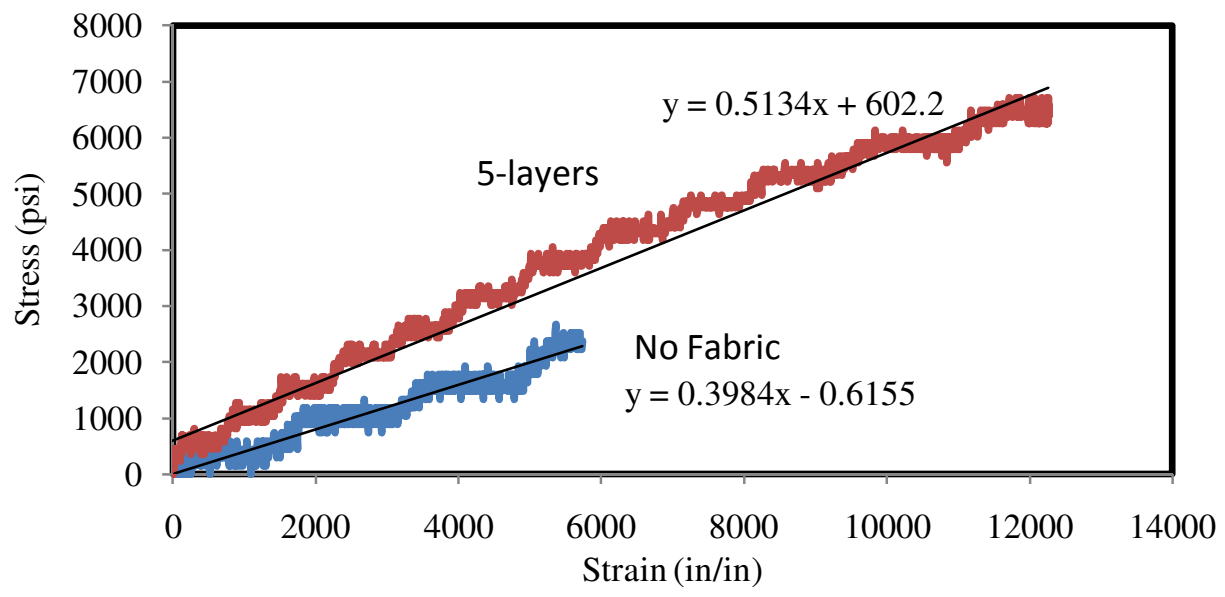

Figure 7. 8 Bending stress-strain in alkaline solution under freeze-thaw (environmental chamber) for one month

Bending modulus of one and eight months aged specimens in alkaline solution were evaluated from the initial slope of stress vs strain curve. Maximum change in bending modulus for specimens placed in alkaline solution with freeze thaw variations (in an environmental chamber) for one month were $69 \%$ and $-60 \%$ for without fibers and 5-layers of fabrics (12\% fiber volume fraction), respectively (Figures 7.8) (Table 7.11). 


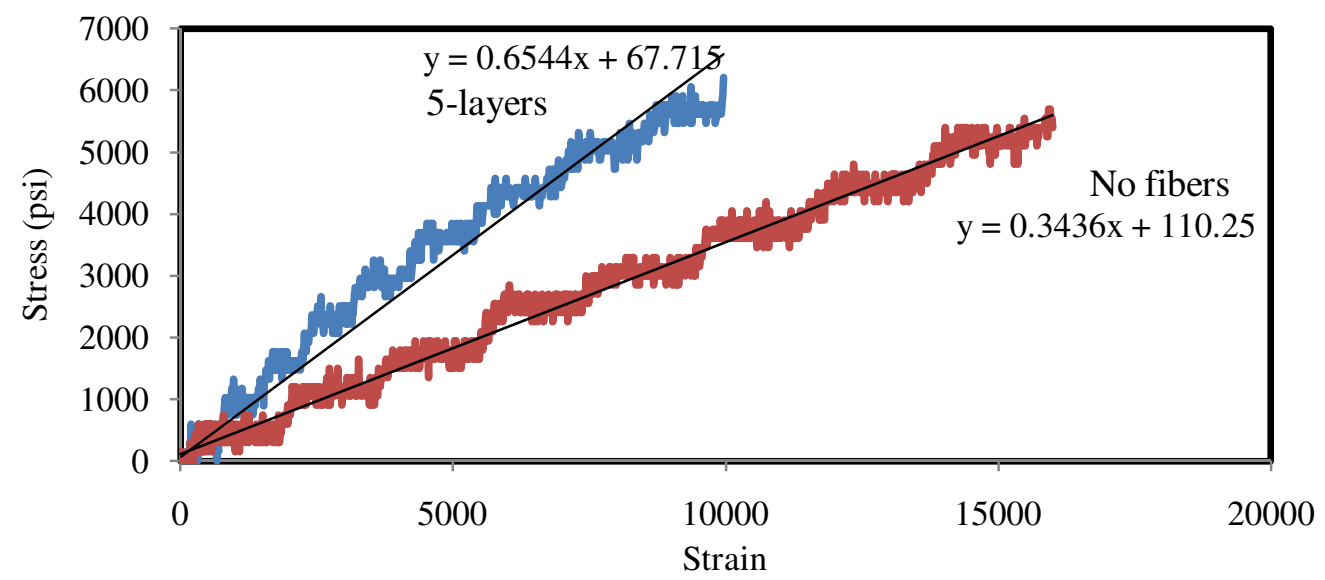

Figure 7.9 Bending stress-strain conditioned in alkaline solution under freeze-thaw (environmental chamber) for eight months

Maximum percentage change in bending modulus of coupons placed in alkaline solution under freeze thaw variations for up to eight months was $-65 \%$ for 5 -layers (12\% fiber volume fraction) (Figure 7.9 and Table 7.11).

Table 7. 11 Bending modulus in alkaline solution under freeze-thaw for one and eight months

\begin{tabular}{|c|c|c|c|c|c|}
\hline \multirow{2}{*}{$\begin{array}{c}\text { No of } \\
\text { layers }\end{array}$} & \multirow{2}{*}{$\begin{array}{c}\text { Modulus for } \\
\text { non aged }\end{array}$} & \multicolumn{4}{|c|}{ Alkaline solution freeze-thaw variation } \\
\cline { 3 - 6 } & $\begin{array}{c}\text { 1M aged } \\
\text { bending } \\
\text { modulus }\end{array}$ & $\begin{array}{c}\text { \% } \\
\text { change }\end{array}$ & $\begin{array}{c}\text { 8M aged } \\
\text { bending } \\
\text { modulus }\end{array}$ & $\begin{array}{c}\% \\
\text { change }\end{array}$ \\
\hline & $\mathrm{msi}$ & $\mathrm{msi}$ & $\%$ & $\mathrm{msi}$ & $\%$ \\
\hline No fibers & 0.304 & 0.513 & $69 \%$ & 0.654 & $115 \%$ \\
\hline 5-layers & 0.994 & 0.398 & $-60 \%$ & 0.343 & $-65 \%$ \\
\hline
\end{tabular}

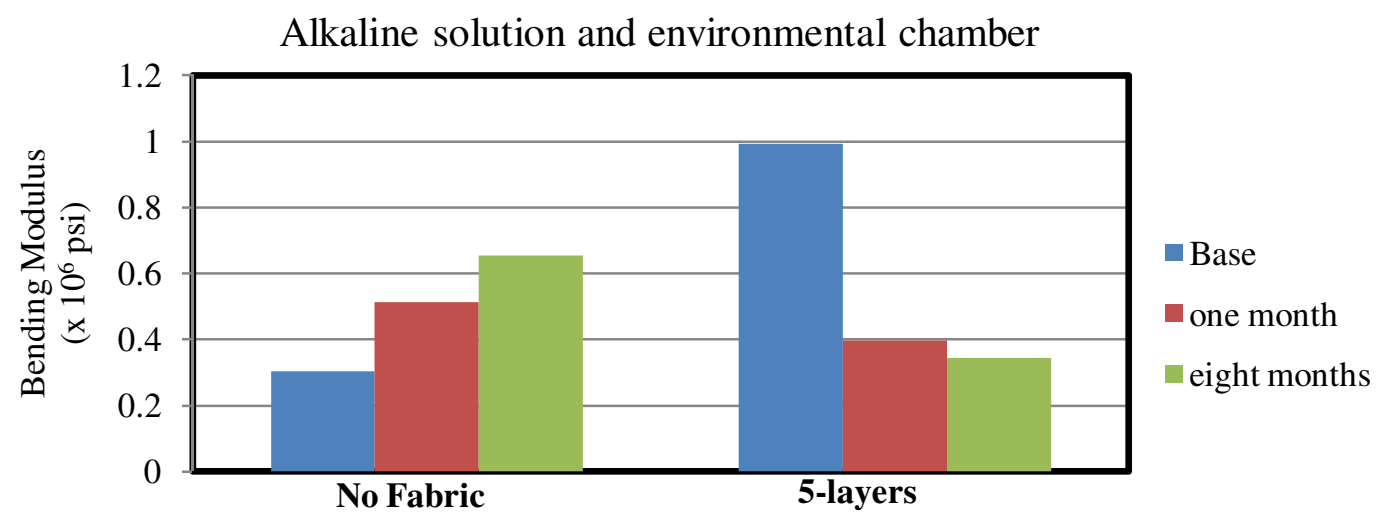

Figure 7. 10 Bending modulus in alkaline solution under freeze-thaw for one and eight months 
The bending modulus of coupons conditioned in alkaline solution with freeze-thaw (environmental chamber) increased after one and eight months of aging for non fabric specimens. However, the stress and modulus decreased for $12 \%$ fiber volume fraction specimens aged under same scenario (Figure 7.10).

\subsubsection{Salt aging under room temperature and freeze-thaw (Bending)}

In this research, average bending strength of thermoplastic coupons aged in salt solution at room temperature was evaluated through mechanical testing. Average bending strengths of coupons with $0,1,3$ and 5 layers were evaluated after 1, 4, 8 and 12 months of salt solution conditioning at room temperature and the corresponding maximum stress reductions were found to be $-10 \%$, $7 \%,-1 \%$, and $-18 \%$, respectively, Table 7.12 .

Table 7. 12 Bending stress in salt solution at room temperature

\begin{tabular}{|c|c|c|c|c|c|c|}
\hline \multicolumn{7}{|c|}{ Salt solution room temperature } \\
\hline Months & Base test & $1 \mathrm{M}$ & $4 \mathrm{M}$ & $8 \mathrm{M}$ & $12 \mathrm{M}$ & $\begin{array}{c}\text { Max stress } \\
\text { gain }(+) / \text { reduction(-)* }\end{array}$ \\
\hline Layers & (psi) & $\begin{array}{l}\text { Stress } \\
(\mathrm{psi})\end{array}$ & $\begin{array}{l}\text { Stress } \\
(\mathrm{psi})\end{array}$ & $\begin{array}{l}\text { Stress } \\
(\mathrm{psi})\end{array}$ & $\begin{array}{l}\text { Stress } \\
(\mathrm{psi})\end{array}$ & $\%$ \\
\hline No fiber & 8516 & $7694^{*}$ & 8644 & -- & 8677 & $-10 \%$ \\
\hline 1-layer & 8587 & $7969 *$ & 8465 & -- & 8110 & $-7 \%$ \\
\hline 3-layers & 11045 & 12355 & $10937 *$ & -- & 11193 & $-1 \%$ \\
\hline 5-layers & 13044 & 13023 & $10718^{*}$ & -- & 11786 & $-18 \%$ \\
\hline
\end{tabular}

Similar to aging of coupon specimens in salt solution at room temperature, the average bending strength of coupon specimens with $0,1,3$ and 5 layers of glass fabric are evaluated after 1, 4, 8 and 12 months salt solution aging in an environmental chamber and the corresponding maximum stress reductions were found to be $-13 \%,-4.2 \%,-5 \%$, and $-12 \%$, respectively, Table 7.13. 
Table 7. 13 Bending stress in salt solution with freeze-thaw (environmental chamber)

\begin{tabular}{|c|c|c|c|c|c|c|}
\hline \multicolumn{7}{|c|}{ Salt solution freeze-thaw } \\
\hline Months & $\begin{array}{c}\text { Base test } \\
(\mathrm{psi})\end{array}$ & $1 \mathrm{M}$ & $4 \mathrm{M}$ & $8 \mathrm{M}$ & $12 \mathrm{M}$ & $\begin{array}{c}\text { Max stress } \\
\text { gain(+)/reduction(-)* }\end{array}$ \\
\hline Layers & & $\begin{array}{c}\text { Stress } \\
(\mathrm{psi})\end{array}$ & $\begin{array}{c}\text { Stress } \\
(\mathrm{psi})\end{array}$ & $\begin{array}{c}\text { Stress } \\
(\mathrm{psi})\end{array}$ & $\begin{array}{c}\text { Stress } \\
(\mathrm{psi})\end{array}$ & $\%$ \\
\hline No fiber & 8516 & 9161 & 8298 & -- & $7382^{*}$ & $-13 \%$ \\
\hline 1-layer & 8587 & 9042 & 8932 & -- & $8224^{*}$ & $-4.2 \%$ \\
\hline 3-layers & 11045 & 12101 & 10608 & -- & $10493^{*}$ & $-5 \%$ \\
\hline 5-layers & 13044 & 12636 & 11980 & -- & $11501^{*}$ & $-12 \%$ \\
\hline
\end{tabular}

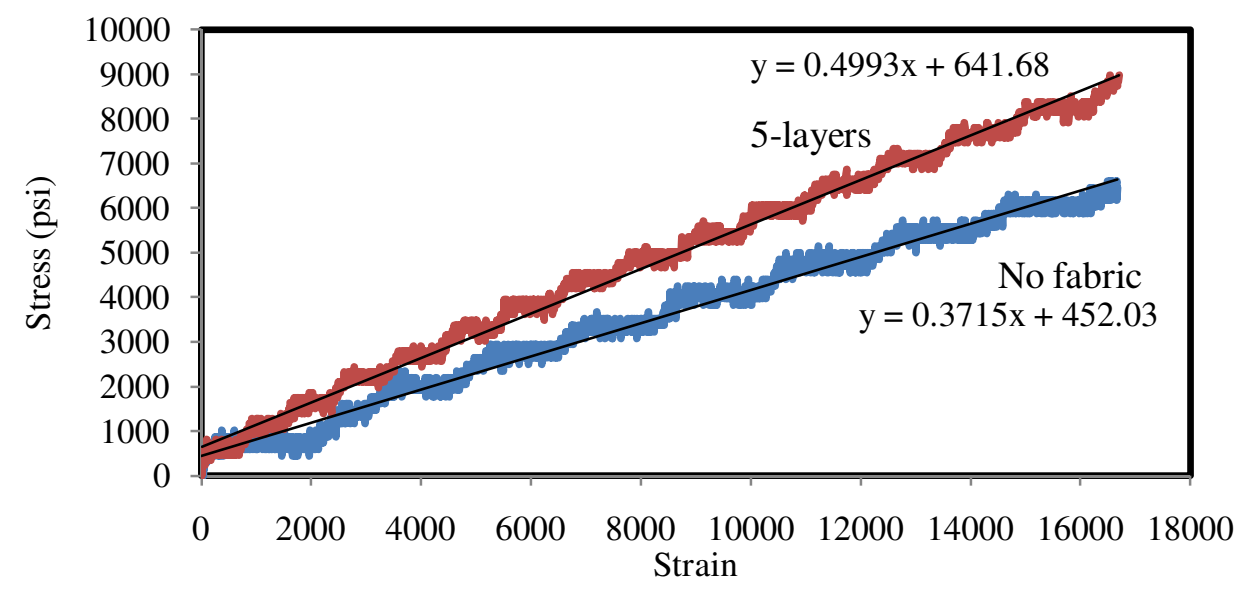

Figure 7. 11 Bending stress-strain in salt solution under freeze-thaw for one month

Maximum percentage change in bending modulus for specimens conditioned in salt solution with freeze thaw variation (in an environmental chamber) for up to one month was $64 \%$ and $63 \%$ for no fabric and 5-layers (12\% fiber volume fraction), respectively (Table 7.14). 


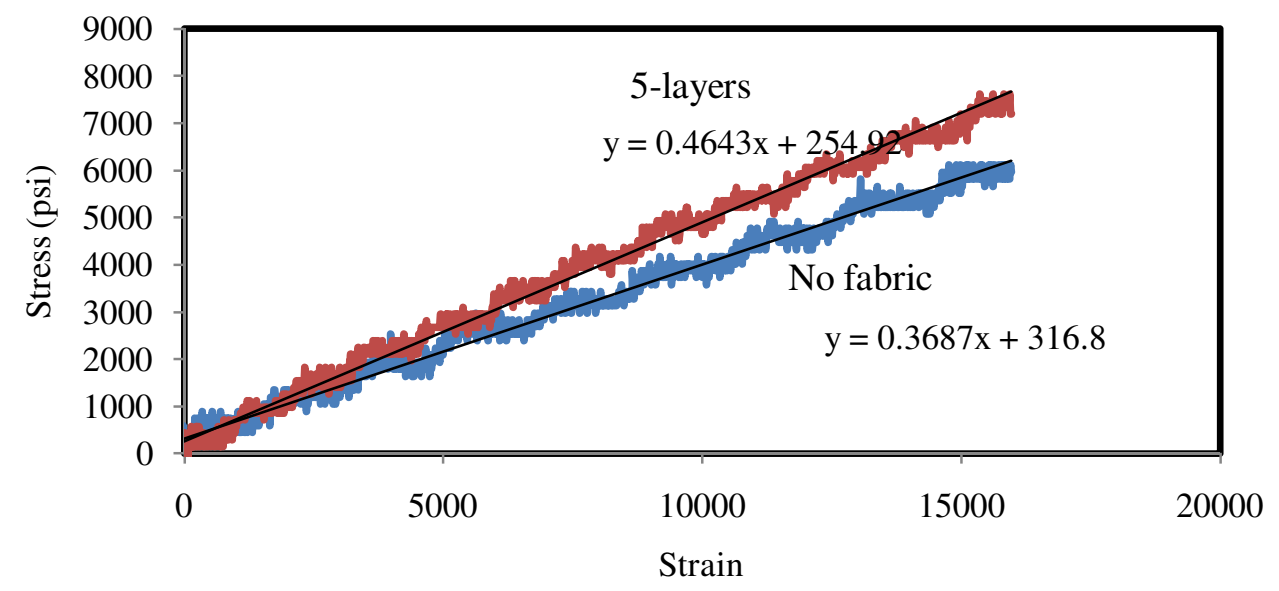

Figure 7.12 Bending stress-strain in salt solution underfreeze-thaw (environmental chamber) for eight months

Maximum percentage change in bending modulus for specimens conditioned in salt solution under freeze thaw variations for eight months was noted to be $53 \%$ and $-62 \%$ for non fabric and 5-layers specimens (12\% fiber volume fraction), respectively (Table 7.14).

Table 7. 14 Bending modulus in salt solution under freeze-thaw variations aged for one and eight months

\begin{tabular}{|c|c|c|c|c|c|}
\hline \multirow{2}{*}{$\begin{array}{c}\text { No of } \\
\text { layers }\end{array}$} & $\begin{array}{c}\text { Modulus } \\
\text { for } \\
\text { non aged }\end{array}$ & $\begin{array}{c}\text { SM aged } \\
\text { bending } \\
\text { modulus }\end{array}$ & \% change & $\begin{array}{c}\text { 8M aged } \\
\text { bending } \\
\text { modulus }\end{array}$ & $\begin{array}{c}\% \\
\text { change }\end{array}$ \\
\hline & $\mathrm{msi}$ & $\mathrm{msi}$ & $\%$ & $\mathrm{msi}$ & $\%$ \\
\hline No fibers & 0.304 & 0.499 & $64 \%$ & 0.464 & $53 \%$ \\
\hline 5-layers & 0.994 & 0.371 & $-63 \%$ & 0.368 & $-62 \%$ \\
\hline
\end{tabular}

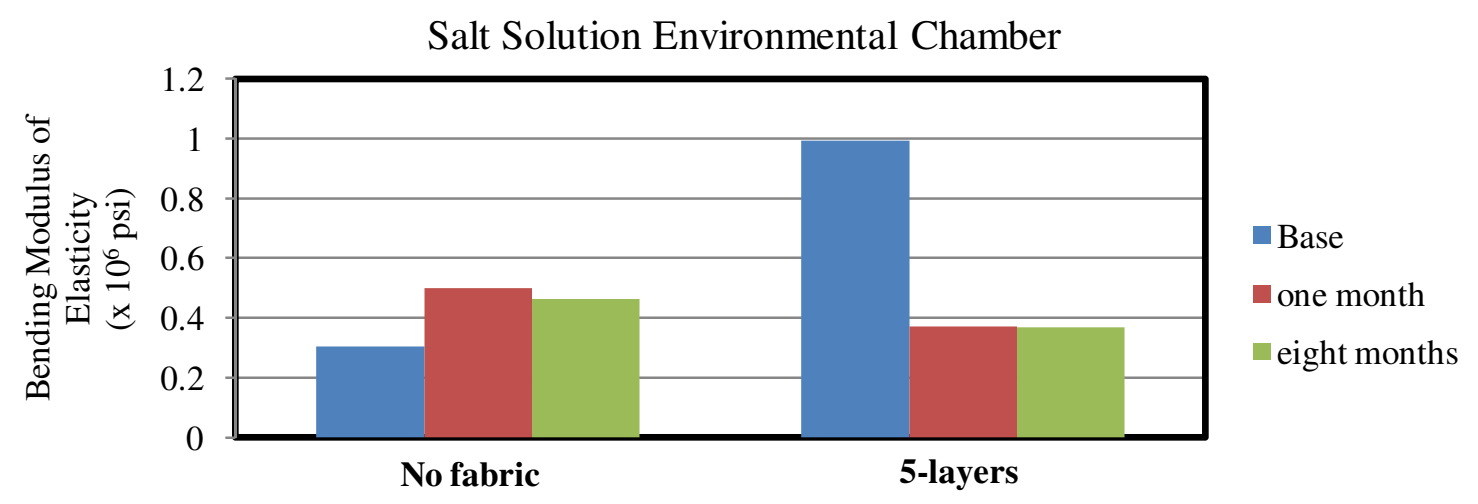

Figure 7. 13 Bending modulus in salt solution under freeze-thaw 
The bending modulus of non-fabric coupons increased under salt and alkaline solution aging with freeze-thaw variation after one and eight months, when compared to those of control specimens. However, the modulus decreased for specimens with 5 layers of fabric. The failure modes for 5 layered bending specimens in freeze-thaw variation indicated delamination/separation at fabric matrix interface (Figures 7.14 (c) and (d)). Modulus of bending test coupon specimens with fabric after salt solution and freeze-thaw aging was lower than that of the control samples.

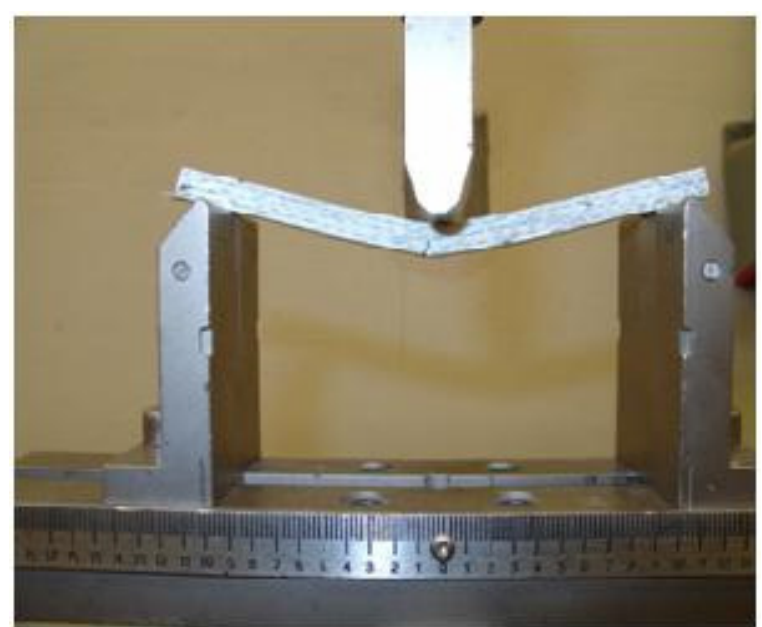

(a) Crack initiation in tension zone (Salt solution specimen)

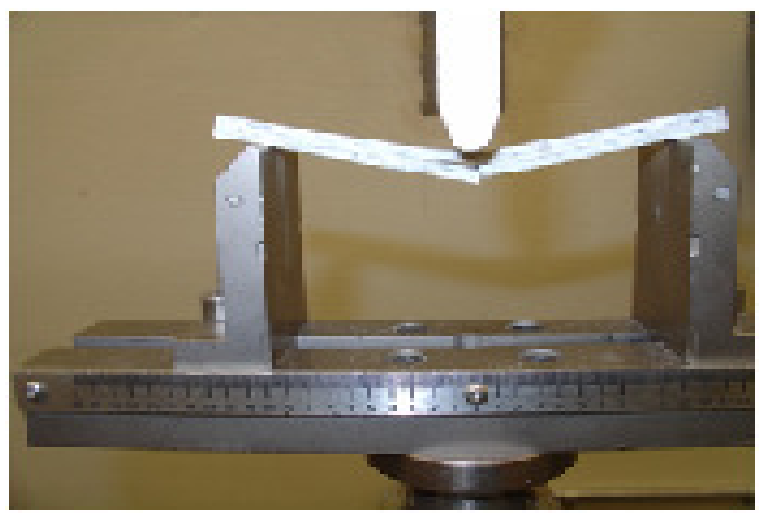

(c) Crack in tension zone and also delamination

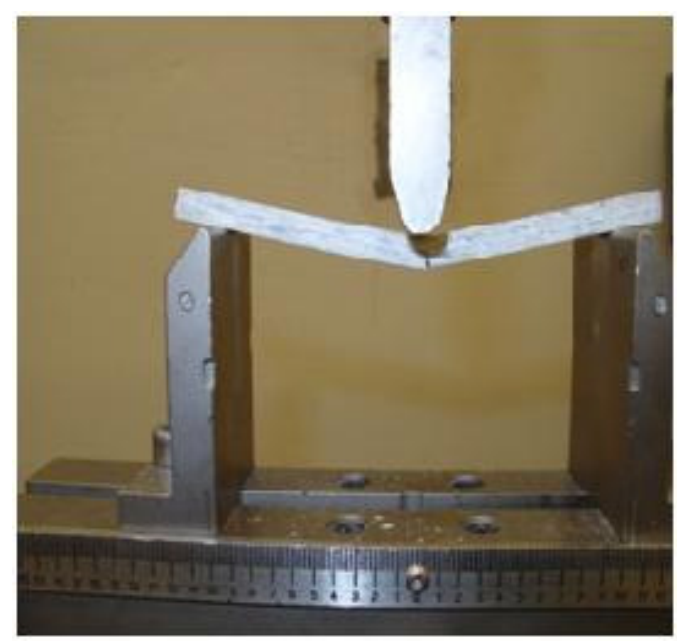

(b) Crack initiation in tension zone (Alkaline solution specimen)

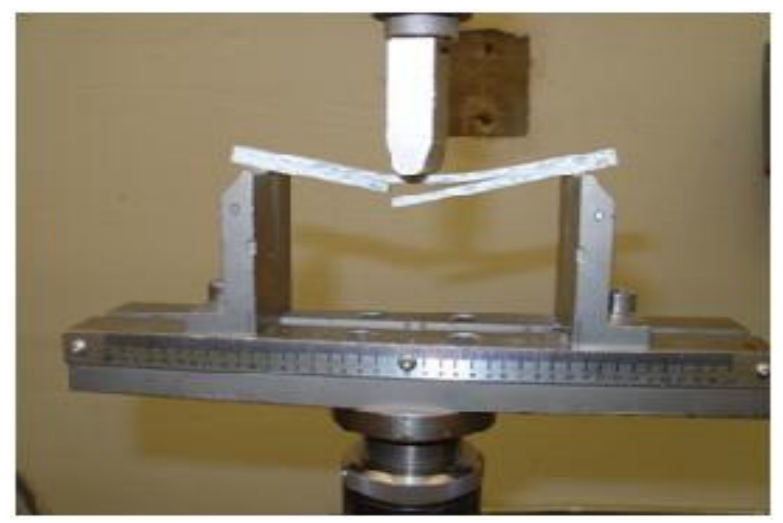

(d) Crack in tension zone and delamination Figure 7. 14 Failure modes conditioned in salt/alkaline solution and freeze-thaw (environmental chamber) 
Crack initiated from tension zone for coupons under bending with one and four months of aging in salt and alkaline solution and also under freeze-thaw conditions and room temperature (Figures 7.14 (a) and (b)). Formation of cracks in tension followed by delamination along fabricmatrix interface was observed for eight and twelve month aged bending specimens conditioned in salt and alkaline solution at room temperature and freeze-thaw as shown in Figures 7.14 (c) and (d), which is due to poor inter-laminar stress transfer.

\subsection{Compression Strength Variation under Aging}

The average compressive strengths of thermoplastic ABS coupon specimens with $0,2,6$ and 10 layers of glass fabric were evaluated as per ASTM and are presented in the following sections:

\subsubsection{Alkaline aging under room temperature and freeze-thaw (Compression)}

In this research, average compressive strength of thermoplastic coupons aged in alkaline solution at room temperature was evaluated through mechanical testing. The strength reductions of nonfabric aged Compressive specimens are reported in Table 7.15.

Table 7. 15 Compressive strength reductions for non-fabric specimens under 12 months in salt and alkaline solution at freeze-thaw and room temperature

\begin{tabular}{|c|c|c|c|c|c|c|c|c|c|c|}
\hline \multicolumn{11}{|c|}{ Compression } \\
\hline \multirow{2}{*}{$\begin{array}{c}\text { Aging } \\
\text { Scheme }\end{array}$} & \multirow[b]{2}{*}{ Layers } & \multirow[b]{2}{*}{$\begin{array}{c}\text { Base } \\
\text { test } \\
\text { (psi) }\end{array}$} & \multicolumn{2}{|c|}{$1 \mathrm{M}$} & \multicolumn{2}{|c|}{$4 M$} & \multicolumn{2}{|c|}{$8 \mathrm{M}$} & \multicolumn{2}{|c|}{$12 \mathrm{M}$} \\
\hline & & & $\begin{array}{c}\text { stress } \\
(\text { psi) }\end{array}$ & $\begin{array}{c}\% \\
\text { change }\end{array}$ & $\begin{array}{c}\text { stress } \\
\text { (psi) }\end{array}$ & $\begin{array}{c}\% \\
\text { change }\end{array}$ & $\begin{array}{c}\text { stress } \\
(\mathrm{psi})\end{array}$ & $\begin{array}{c}\% \\
\text { change }\end{array}$ & $\begin{array}{c}\text { stress } \\
(\text { psi) }\end{array}$ & $\begin{array}{c}\% \\
\text { change }\end{array}$ \\
\hline ASRT & \multirow{4}{*}{$\begin{array}{c}\text { No } \\
\text { fiber }\end{array}$} & \multirow{4}{*}{8278} & 8778 & 6.04 & 7824 & -5.49 & 8572 & 3.55 & 8031 & -2.98 \\
\hline ASFT & & & 8781 & 6.08 & 8245 & -0.39 & 7299 & -11.82 & 8250 & -0.34 \\
\hline SSRT & & & 8778 & 6.04 & 8121 & -1.89 & 8332 & 0.65 & 8115 & -1.96 \\
\hline SSFT & & & 8555 & 3.35 & 7976 & -3.65 & 7878 & -4.83 & 7836 & -5.33 \\
\hline
\end{tabular}

Note: AS: Alkaline solution, SS: Salt solution, RT: Room temperature, FT: Freeze-thaw

Average compressive strengths of coupons with $0,2,6$ and 10 layers of glass fabric were evaluated after 1, 4, 8 and 12 months of alkaline solution conditioning at room temperature and the corresponding maximum stress reductions were found to be $-5 \%,-12 \%,-10 \%$, and $-20 \%$, respectively, Table 7.16 . 
Table 7. 16 Compression test results of specimens conditioned in alkaline solution at room temperature

\begin{tabular}{|c|c|c|c|c|c|c|}
\hline \multicolumn{7}{|c|}{ Alkaline solution room temperature } \\
\hline Months & \multirow{2}{*}{$\begin{array}{c}\text { Base test } \\
(\mathrm{psi})\end{array}$} & $1 \mathrm{M}$ & $4 \mathrm{M}$ & $8 \mathrm{M}$ & $12 \mathrm{M}$ & $\begin{array}{c}\text { Max stress } \\
\text { gain(+)/reduction(-)* }\end{array}$ \\
\cline { 3 - 7 } & $\begin{array}{c}\text { Stress } \\
\text { Layers }\end{array}$ & $\begin{array}{c}\text { Stress } \\
(\mathrm{psi})\end{array}$ & $\begin{array}{c}\text { Stress } \\
(\mathrm{psi})\end{array}$ & $\begin{array}{c}\text { Stress } \\
(\mathrm{psi})\end{array}$ & $\%$ \\
\hline No fiber & 8278 & 8778 & $7824 *$ & 8572 & 8031 & $-5 \%$ \\
\hline 2-layer & 8172 & 7955 & 7426 & 7984 & $7202^{*}$ & $-12 \%$ \\
\hline 6-layers & 7404 & 7604 & 6970 & 7161 & $6708^{*}$ & $-10 \%$ \\
\hline 10-layers & 6969 & 6963 & 5662 & 6086 & $5552^{*}$ & $-20 \%$ \\
\hline
\end{tabular}

Similarly, the average compressive strength of coupon specimens with $0,2,6$ and 10 layers of glass fabric was evaluated after 1, 4, 8 and 12 months of conditioning in alkaline solution with freeze-thaw (environmental chamber) and the corresponding maximum stress reductions were found to be $-12 \%,-30 \%,-30 \%$, and $-46 \%$, respectively, are given in Table 7.17.

Table 7.17 Compression test results of thermoplastic specimens conditioned in alkaline solution with freezethaw (environmental chamber)

\begin{tabular}{|c|c|c|c|c|c|c|}
\hline \multicolumn{7}{|c|}{ Alkaline solution environmental chamber } \\
\hline Months & \multirow{2}{*}{$\begin{array}{l}\text { Base test } \\
\quad(\mathrm{psi})\end{array}$} & $1 \mathrm{M}$ & $4 \mathrm{M}$ & $8 \mathrm{M}$ & $12 \mathrm{M}$ & $\begin{array}{c}\text { Max stress } \\
\text { gain }(+) / \text { reduction(-)* }\end{array}$ \\
\hline Layers & & $\begin{array}{c}\text { Stress } \\
\text { (psi) }\end{array}$ & $\begin{array}{l}\text { Stress } \\
\text { (psi) }\end{array}$ & $\begin{array}{c}\text { Stress } \\
\text { (psi) }\end{array}$ & Stress (psi) & $\%$ \\
\hline No fiber & 8278 & 8781 & 8245 & $7299 *$ & 8250 & $-12 \%$ \\
\hline 2-layer & 8172 & 8337 & 6565 & 6153 & $5720^{*}$ & $-30 \%$ \\
\hline 6-layers & 7404 & 7503 & 5824 & 6305 & $5224 *$ & $-30 \%$ \\
\hline 10-layers & 6969 & 5454 & 4680 & 4607 & $3780 *$ & $-46 \%$ \\
\hline
\end{tabular}

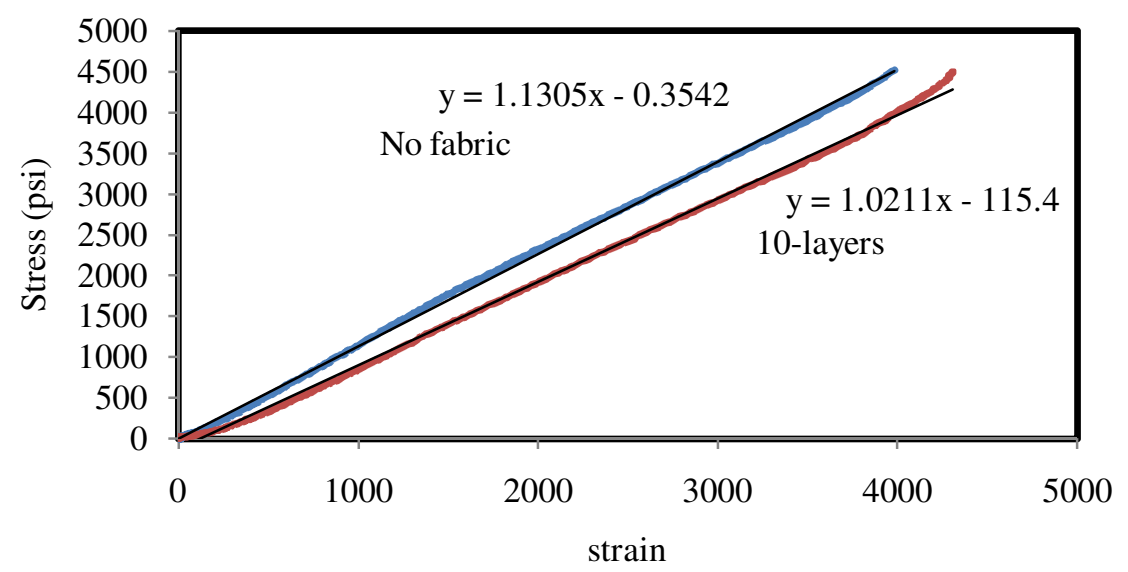

Figure 7. 15 Compressive stress-strain in alkaline solution under freeze-thaw for one month 
Maximum change in compressive modulus of coupon specimens conditioned in alkaline solution with freeze thaw variations (in an environmental chamber) for up to one month was 50\% for 5 layers of fabric (12\% fiber volume fraction) (Table 7.18).

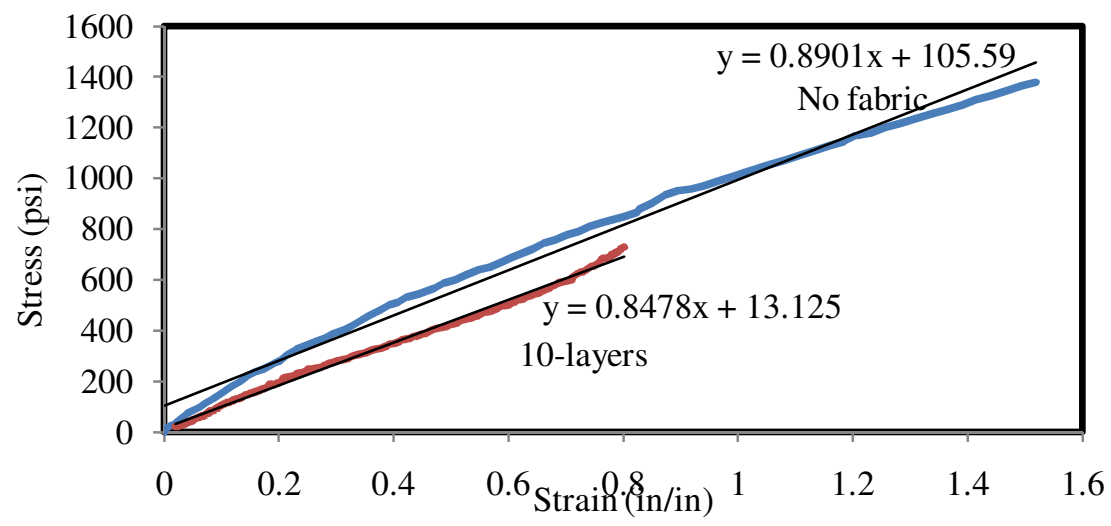

Figure 7. 16 Compressive stress-strain in alkaline solution under freeze-thaw (environmental chamber) for eight months

Change in compressive modulus of thermoplastic coupons in alkaline solution with freeze-thaw variations (in an environmental chamber) for up to eight months was $24 \%$ for 5-layers of fabric (12\% fiber volume fraction) (Figure 7.16).

Table 7. 18 Compression modulus variations of thermoplastic specimens conditioned for one and eight months

\begin{tabular}{|c|c|c|c|c|c|}
\hline \multirow{2}{*}{ No of layers } & \multirow{2}{*}{$\begin{array}{c}\text { Modulus for } \\
\text { non aged }\end{array}$} & $\begin{array}{c}\text { 1M aged comp } \\
\text { modulus }\end{array}$ & \% change & $\begin{array}{c}\text { 8M aged } \\
\text { comp } \\
\text { modulus }\end{array}$ & \% change \\
\cline { 3 - 6 } & $\mathrm{X} 10^{6} \mathrm{psi}$ & $\mathrm{X} 10^{6} \mathrm{psi}$ & & $\mathrm{X} 10^{6} \mathrm{psi}$ & \\
\hline No fibers & 0.312 & 1.13 & $262 \%$ & 0.89 & $185 \%$ \\
\hline 10-layers & 0.678 & 1.02 & $50 \%$ & 0.84 & $24 \%$ \\
\hline
\end{tabular}


Note: Due to inconsistency in test data, modulus values of the non-fabric compression test coupon specimens' have not been reported. Repetitions of those tests were not carried out because of the non-availability of recycled polymer from the same batch of recycled polymers (stream).

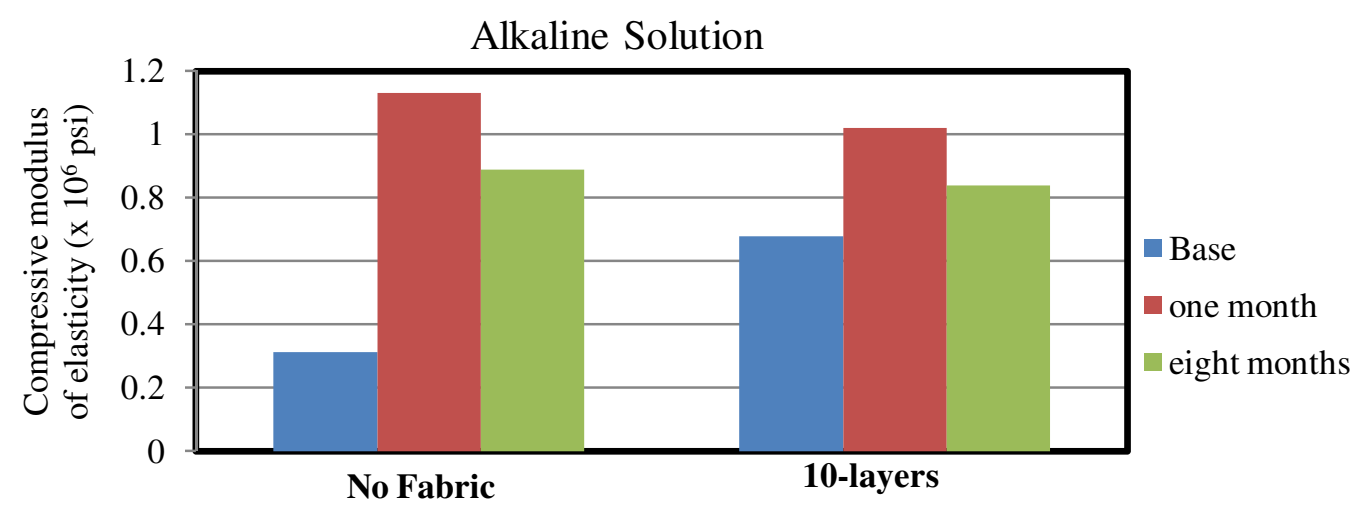

Figure 7. 17 Compression modulus in alkaline solution under freeze-thaw for one and eight months

The modulus of aged compression coupons increased for 10 layer specimens compared to corresponding non-aged control samples (Figure 7.17). The increase in modulus of compression test specimens might be due to increased bonding at fabric-matrix interface.

\subsubsection{Salt aging under room temperature and freeze-thaw (Compression)}

Average compressive strength of thermoplastic coupon specimens aged in salt solution at room temperature was evaluated through mechanical testing. Average strengths of specimens with 0 , 1, 3 and 5 layers were evaluated after 1, 4, 8 and 12 months of salt solution immersion at room temperature and the corresponding maximum stress reductions were found to be $-2 \%,-9 \%,-4 \%$, and $-16 \%$, respectively, as given in Table 7.19. 
Table 7. 19 Compression strength in salt solution at room temperature

\begin{tabular}{|c|c|c|c|c|c|c|}
\hline \multicolumn{9}{|c|}{ Salt solution room temp } \\
\hline Months & \multirow{2}{*}{$\begin{array}{c}\text { Base } \\
\text { test } \\
(\mathrm{psi})\end{array}$} & \begin{tabular}{c}
$1 \mathrm{M}$ \\
\cline { 4 - 7 }
\end{tabular} & $4 \mathrm{M}$ & $8 \mathrm{M}$ & $12 \mathrm{M}$ & $\begin{array}{c}\text { Max stress } \\
\text { gain(+)/reduction(-)* }\end{array}$ \\
\hline No fiber & 8278.4 & 8778 & $\begin{array}{c}\text { Stress } \\
(\mathrm{psi})\end{array}$ & $\begin{array}{c}\text { Stress } \\
(\mathrm{psi})\end{array}$ & $\begin{array}{c}\text { Stress } \\
(\mathrm{psi})\end{array}$ & $\%$ \\
\hline 2-layer & 8172.3 & 8540 & 7468 & 8332 & $8115^{*}$ & $-2 \%$ \\
\hline 6-layers & 7404.0 & 8039 & $7088^{*}$ & 7443 & 7229 & $-9 \%$ \\
\hline 10-layers & 6969.5 & 6012 & $5887^{*}$ & 6226 & 6034 & $-16 \%$ \\
\hline
\end{tabular}

Similarly, the average compressive strength of coupons with $0,1,3$ and 5 layers of glass fabric

were evaluated after $1,4,8$ and 12 months of aging in salt solution under freeze-thaw (environmental chamber) conditions and the corresponding maximum stress reductions were found to be $-5 \%,-8 \%,-2 \%$, and $-24 \%$, respectively, Table 7.20 .

Table 7. 20 Compression strength in salt solution with freeze-thaw conditioning

\begin{tabular}{|c|c|c|c|c|c|c|}
\hline \multicolumn{2}{|c|}{ Salt solution Freeze-thaw } \\
\hline Months & \multirow{2}{*}{$\begin{array}{c}\text { Base } \\
\text { test } \\
(\mathrm{psi})\end{array}$} & \begin{tabular}{c}
$1 \mathrm{M}$ \\
\cline { 4 - 7 }
\end{tabular} & $4 \mathrm{M}$ & $8 \mathrm{M}$ & $12 \mathrm{M}$ & $\begin{array}{c}\text { Max stress } \\
\text { gain(+)/reduction(-) }\end{array}$ \\
\hline Layers & $\begin{array}{c}\text { Stress } \\
(\mathrm{psi})\end{array}$ & $\begin{array}{c}\text { Stress } \\
(\mathrm{psi})\end{array}$ & $\begin{array}{c}\text { Stress } \\
(\mathrm{psi})\end{array}$ & $\%$ \\
\hline No fiber & 8278.4 & 8555 & 7976 & 7878 & $7836^{*}$ & $-5 \%$ \\
\hline 2-layer & 8172.3 & 8360 & $7508^{*}$ & 7986 & 7541 & $-8 \%$ \\
\hline 6-layers & 7404.0 & 7623 & 7379 & 7707 & $7290^{*}$ & $-2 \%$ \\
\hline 10-layers & 6969.5 & 6301 & 5822 & 5689 & $5821^{*}$ & $-24 \%$ \\
\hline
\end{tabular}

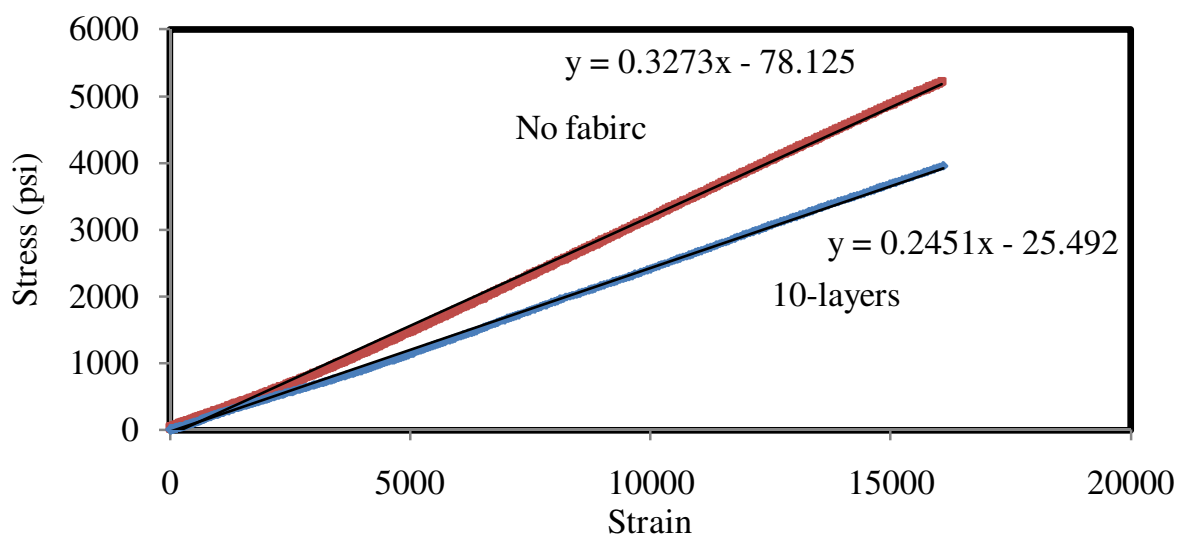

Figure 7. 18 Compression stress-strain in salt solution under freeze-thaw conditioning for one month 
Maximum percentage change in compressive modulus of coupon specimens in salt solution conditioning with freeze thaw variations (in an environmental chamber) for up to one month were 5\% and $-64 \%$ for without fibers and 5-layer specimens (Figure 7.19) (12\% fiber volume fraction), respectively (Table 7.21).

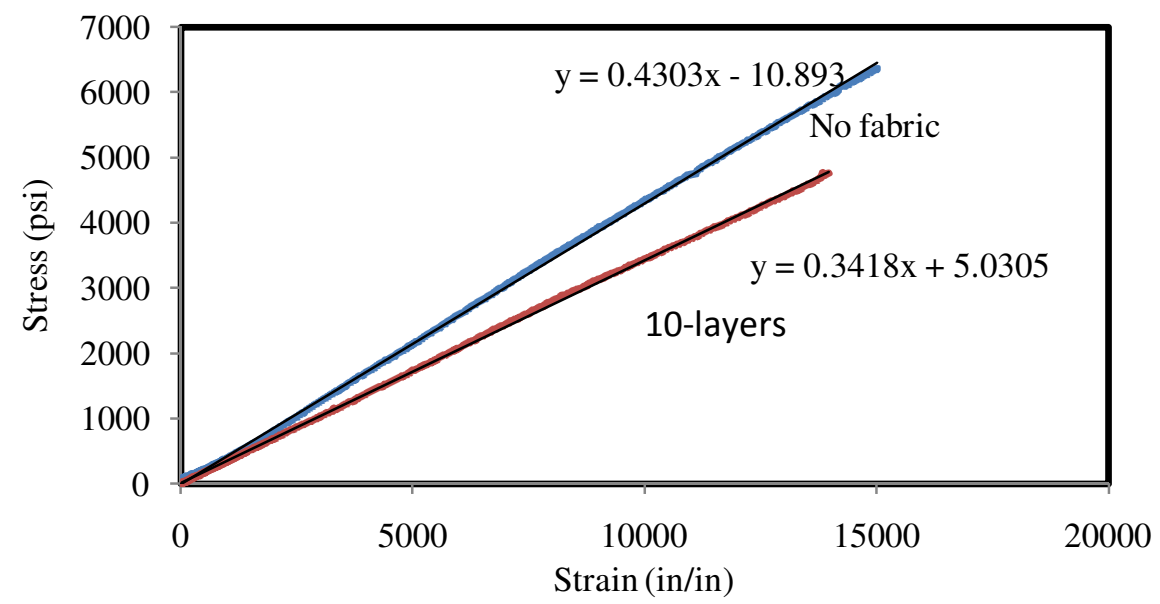

Figure 7. 19 Compression stress-strain in salt solution under freeze-thaw conditions for eight months Similarly, maximum change in compressive moduli of coupons conditioned in salt solution under freeze thaw (in an environmental chamber) for up to eight months were $38 \%$ and $-50 \%$ for samples without fibers and 5-layered specimens (Figure 7.19) (12\% fiber volume fraction), respectively, as given in Table 7.21.

Table 7.21 Modulus variations for one and eight months aged compression specimens

\begin{tabular}{|c|c|c|c|c|c|}
\hline \multirow[b]{2}{*}{$\begin{array}{l}\text { No of } \\
\text { layers }\end{array}$} & \multirow[b]{2}{*}{$\begin{array}{l}\text { Modulus for } \\
\text { non aged }\end{array}$} & \multicolumn{4}{|c|}{ Salt solution freeze-thaw variation } \\
\hline & & $\begin{array}{l}\text { 1M aged comp } \\
\text { modulus }\end{array}$ & $\begin{array}{c}\% \\
\text { change }\end{array}$ & $\begin{array}{c}\text { 8M aged comp } \\
\text { modulus }\end{array}$ & $\begin{array}{c}\% \\
\text { change }\end{array}$ \\
\hline & X $10^{6} \mathrm{psi}$ & $\mathrm{X} 10^{6} \mathrm{psi}$ & $\%$ & X $10^{6} \mathrm{psi}$ & $\%$ \\
\hline No fibers & 0.312 & 0.327 & $5 \%$ & 0.43 & $38 \%$ \\
\hline 10-layers & 0.678 & 0.245 & $-64 \%$ & 0.341 & $-50 \%$ \\
\hline
\end{tabular}




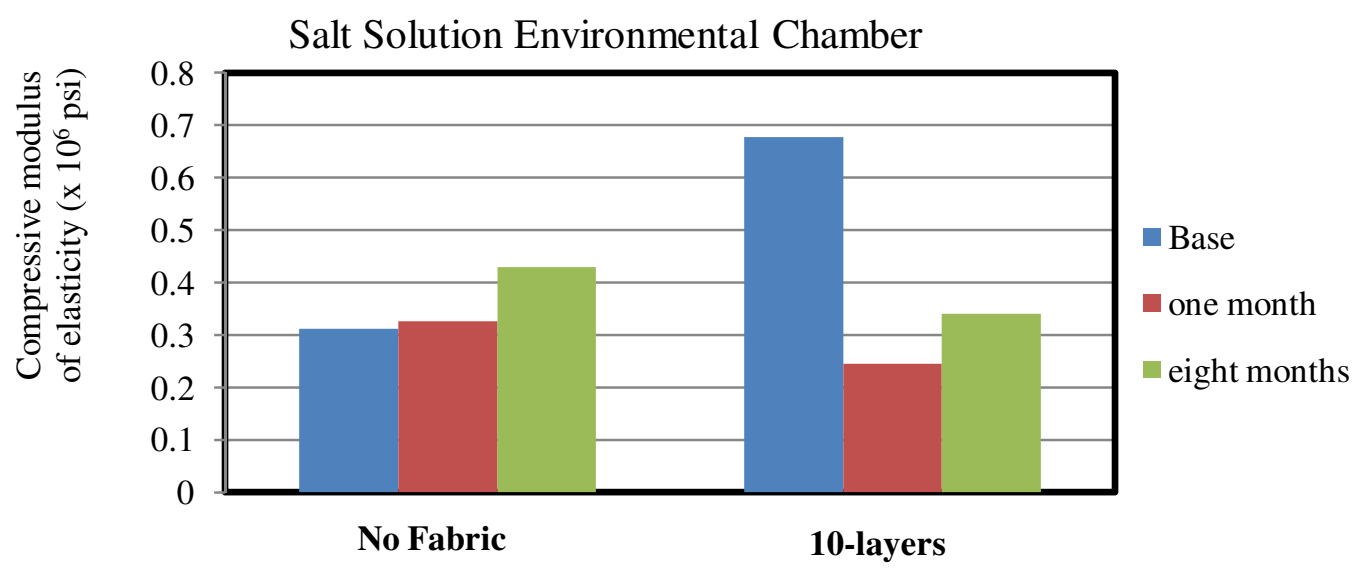

Figure 7. 20 Compression modulus in salt solution under freeze-thaw chamber after one and eight months

Compression modulus increased with increase in number of fabric layers for control specimens which might be due to better bonding at the fabric matrix interface and confinement of matrix between 2 fabric layers (Figure 7.20). However, the modulus increased initially for one month of conditioning and later reduced after eight months, which might be due to poor stress transfer and related to poor bonding at the fabric-matrix interface due to delaminations/separation at interface as show in Figure (7.20). Crushing, buckling and separation/delamination type of failure modes were noted for coupon specimens under compression as shown in Figures 7.21 (a), (b) and (c).

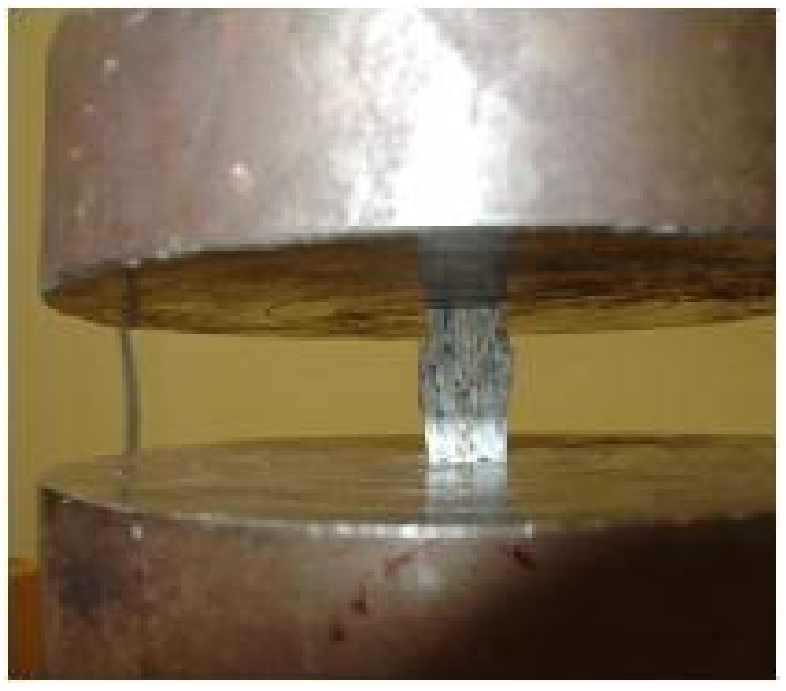

(a) Crushing of specimen

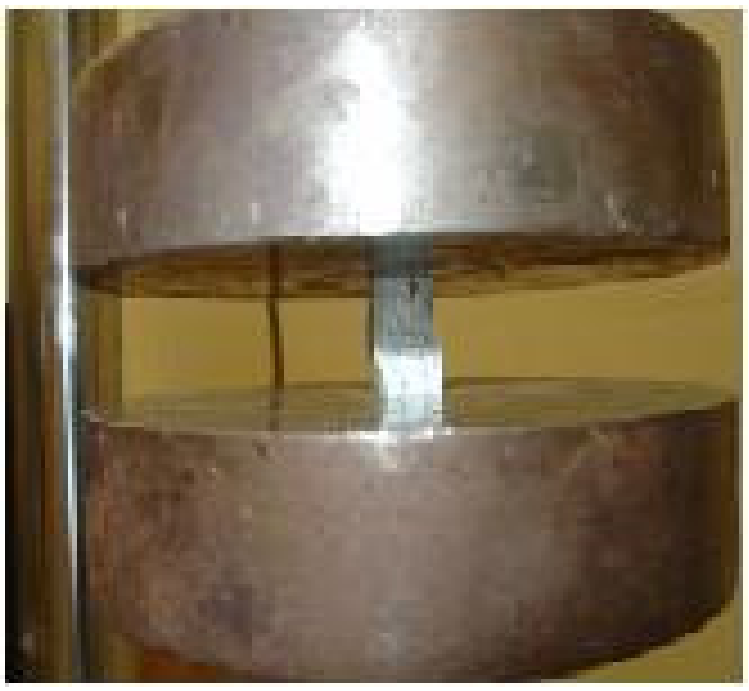

(b) Splitting/delamination of specimen 


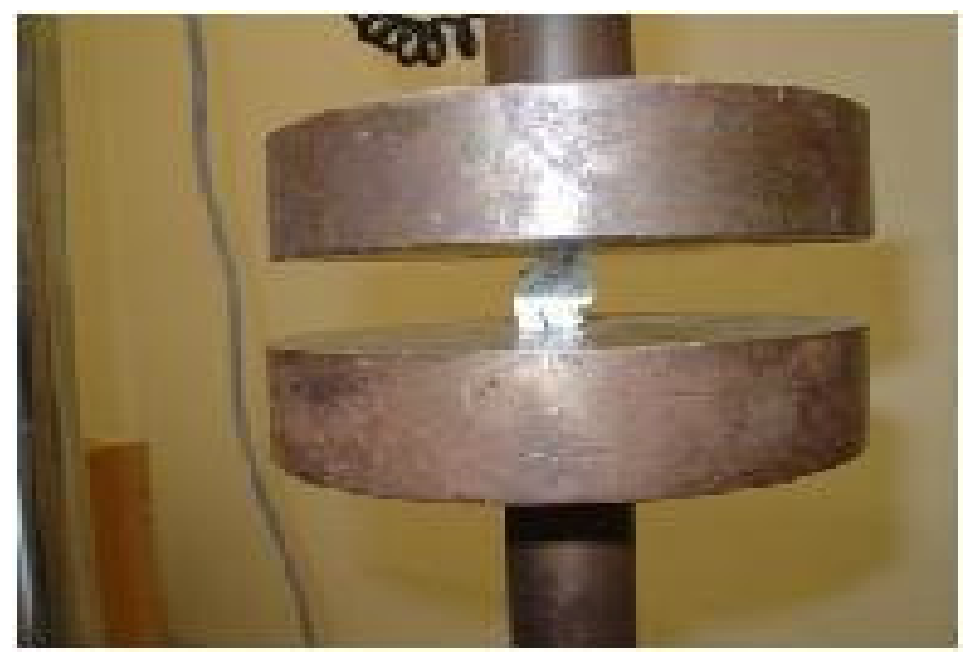

(c) Buckling of Specimen

Figure 7.21 Failure modes in thermoplastic compression test specimens

\subsection{Impact Strength Variation under Aging}

The average impact strengths of thermoplastic ABS coupon specimens with $0,1,3$ and 5 layers of glass fabric were evaluated as per ASTM D256 and are reported in the following sections:

\subsubsection{Alkaline aging under room temperature and freeze-thaw (Impact)}

In this research, average impact strength of thermoplastic coupon specimens conditioned in alkaline solution at room temperature was evaluated through mechanical testing using BLI testing equipment. The strength reductions of non-fabric aged impact test specimens are reported in Table 7.22.

Table 7. 22 Impact strength reductions for non-fabric specimens under 12 months in salt and alkaline solution at freeze-thaw and room temperature

\begin{tabular}{|c|c|c|c|c|c|c|c|c|c|c|}
\hline \multicolumn{11}{|c|}{ Impact } \\
\hline \multirow{2}{*}{$\begin{array}{c}\text { Aging } \\
\text { Scheme }\end{array}$} & \multirow{2}{*}{ Layers } & \multirow{2}{*}{$\begin{array}{c}\text { Base } \\
\text { test }\end{array}$} & \multicolumn{2}{|c|}{$1 \mathrm{M}$} & \multicolumn{2}{|c|}{$4 M$} & \multicolumn{2}{|c|}{$8 \mathrm{M}$} & \multicolumn{2}{|c|}{$12 \mathrm{M}$} \\
\hline & & & $\begin{array}{c}\text { strength } \\
\text { ft.lbs }\end{array}$ & $\begin{array}{c}\% \\
\text { change }\end{array}$ & $\begin{array}{c}\text { strength } \\
\text { ft.lbs }\end{array}$ & $\begin{array}{c}\% \\
\text { change }\end{array}$ & $\begin{array}{c}\text { strength } \\
\text { ft.lbs }\end{array}$ & $\begin{array}{c}\% \\
\text { change }\end{array}$ & $\begin{array}{c}\text { strength } \\
\text { ft.lbs }\end{array}$ & $\begin{array}{c}\% \\
\text { change }\end{array}$ \\
\hline ASRT & \multirow{4}{*}{$\begin{array}{l}\text { No } \\
\text { fiber }\end{array}$} & \multirow{4}{*}{0.36} & 0.35 & -3 & 0.46 & 28 & 0.38 & 6 & 0.42 & 17 \\
\hline ASFT & & & 0.3 & -17 & 0.37 & 3 & 0.38 & 6 & 0.38 & 6 \\
\hline SSRT & & & 0.35 & -3 & 0.44 & 22 & 0.44 & 22 & 0.44 & 22 \\
\hline SSFT & & & 0.39 & 8 & -0.35 & 3 & 0.41 & 14 & 0.48 & 33 \\
\hline
\end{tabular}

Note: AS: Alkaline solution, SS: Salt solution, RT: Room temperature, FT: Freeze-thaw 
Average impact strengths of specimens with 0,1,3 and 5 layers were evaluated after 1, 4, 8 and 12 months of aging in alkaline solution at room temperature and the corresponding maximum stress reductions were found to be $-3 \%,-66 \%,-73 \%$, and $-93 \%$, respectively, Table 7.23.

Table 7. 23 Impact energy in alkaline solution at room temperature

\begin{tabular}{|c|c|c|c|c|c|c|}
\hline \multicolumn{7}{|c|}{ Alkaline solution room temperature } \\
\hline Months & \multirow{2}{*}{$\begin{array}{c}\text { Base test } \\
\mathrm{ft} . l \mathrm{bs}\end{array}$} & $1 \mathrm{M}$ & $4 \mathrm{M}$ & $8 \mathrm{M}$ & $12 \mathrm{M}$ & $\begin{array}{c}\text { Max stress } \\
\text { gain(+)/reduction(-)* }\end{array}$ \\
\cline { 3 - 7 } Layers & $\begin{array}{c}\text { strength } \\
\mathrm{ft} . \mathrm{lbs}\end{array}$ & $\begin{array}{c}\text { strength } \\
\mathrm{ft} . \mathrm{lbs}\end{array}$ & $\begin{array}{c}\text { strength } \\
\mathrm{ft} . l \mathrm{bs}\end{array}$ & $\begin{array}{c}\text { strength } \\
\mathrm{ft} . \mathrm{lbs}\end{array}$ & $\%$ \\
\hline No fiber & 0.36 & 0.35 & 0.46 & 0.38 & 0.42 & $-3 \%$ \\
\hline 1-layer & 1.19 & 1.08 & 0.80 & $0.40^{*}$ & 0.41 & $-66 \%$ \\
\hline 3-layers & 2.21 & 1.68 & 1.76 & 0.60 & $0.60^{*}$ & $-73 \%$ \\
\hline 5-layers & 5.37 & 4.24 & 2.10 & 0.38 & $0.37^{*}$ & $-93 \%$ \\
\hline
\end{tabular}

Similarly, the average impact strength of coupon specimens with $0,1,3$ and 5 layers of glass fabric were evaluated through testing after 1, 4, 8 and 12 months of aging in alkaline solution with freeze-thaw (environmental chamber) and the corresponding maximum stress reductions were found to be $-17 \%,-72 \%,-83 \%$, and $-93 \%$, respectively, and these data are shown in Table 7.24.

Table 7. 24 Impact energy in alkaline solution under freeze-thaw

\begin{tabular}{|c|c|c|c|c|c|c|}
\hline \multicolumn{7}{|c|}{ Alkaline solution and freeze-thaw } \\
\hline Months & \multirow{2}{*}{$\begin{array}{c}\text { Base test } \\
\text { ft.lbs }\end{array}$} & \begin{tabular}{c}
$1 \mathrm{M}$ \\
\cline { 3 - 7 } Layers
\end{tabular} & $4 \mathrm{M}$ & $8 \mathrm{M}$ & $12 \mathrm{M}$ & $\begin{array}{c}\text { Max stress } \\
\text { gain(+)/reduction(-)* }\end{array}$ \\
\hline No fiber & 0.36 & 0.3 & $\begin{array}{c}\text { strength } \\
\mathrm{ft} . \mathrm{lbs}\end{array}$ & $\begin{array}{c}\text { strength } \\
\mathrm{ft} . \mathrm{lbs}\end{array}$ & $\begin{array}{c}\text { strength } \\
\mathrm{ft} . \mathrm{lbs}\end{array}$ & $\%$ \\
\hline 1-layer & 1.19 & 0.57 & 0.37 & 0.38 & 0.38 & $-17 \%$ \\
\hline 3-layers & 2.21 & 1.43 & 0.79 & $0.35^{*}$ & 0.37 & $-72 \%$ \\
\hline 5-layers & 5.37 & 1.56 & 0.89 & 0.37 & 0.42 & $-83 \%$ \\
\hline
\end{tabular}

\subsubsection{Salt aging under room temperature and freeze-thaw (Impact)}

Average impact strength of thermoplastic coupon specimens conditioned in salt solution at room temperature was evaluated through mechanical testing. Average strengths of impact specimens with $0,1,3$ and 5 layers were evaluated after 1, 4, 8 and 12 months of conditioning in salt 
solution at room temperature and the corresponding maximum stress reductions were found to be $-3 \%,-13 \%,+7 \%$, and $-45 \%$, respectively, Table 7.25 .

Table 7.25 Impact test results of thermoplastic specimens conditioned in salt solution at room temperature

\begin{tabular}{|c|c|c|c|c|c|c|}
\hline \multicolumn{7}{|c|}{ Salt solution room temperature } \\
\hline Months & \multirow{2}{*}{$\begin{array}{c}\text { Base test } \\
\text { ft.lbs }\end{array}$} & $1 \mathrm{M}$ & $4 \mathrm{M}$ & $8 \mathrm{M}$ & $12 \mathrm{M}$ & $\begin{array}{c}\text { Max stress } \\
\text { gain }(+) / \text { reduction }(-)^{*}\end{array}$ \\
\hline Layers & & $\begin{array}{l}\text { strength } \\
\text { ft.lbs }\end{array}$ & $\begin{array}{l}\text { strength } \\
\text { ft.lbs }\end{array}$ & $\begin{array}{l}\text { strength } \\
\text { ft.lbs }\end{array}$ & $\begin{array}{l}\text { strength } \\
\text { ft.lbs }\end{array}$ & $\%$ \\
\hline No fiber & 0.36 & 0.35 & 0.44 & 0.44 & 0.44 & $-3 \%$ \\
\hline 1-layer & 1.19 & 1.77 & 1.19 & $1.04 *$ & 1.16 & $-13 \%$ \\
\hline 3-layers & 2.21 & 2.48 & $2.36 *$ & 2.57 & 2.53 & $+7 \%$ \\
\hline 5-layers & 5.37 & 4.49 & 2.94 & 2.95 & $2.93 *$ & $-45 \%$ \\
\hline
\end{tabular}

Similarly, the average impact strength of tension coupon specimens with $0,1,3$ and 5 layers of glass fabric was evaluated after 1, 4, 8 and 12 months of aging in salt solution with freeze-thaw and the corresponding maximum stress reductions were found to be $-3 \%,-35 \%,-2 \%$, and $-57 \%$, respectively, Table 7.26.

Table 7. 26 Impact energy in salt solution under freeze-thaw variations (environmental chamber)

\begin{tabular}{|c|c|c|c|c|c|c|}
\hline \multicolumn{7}{|c|}{ Salt solution and environmental chamber } \\
\hline Layths & \multirow{2}{*}{$\begin{array}{c}\text { Base test } \\
\text { ft.lbs }\end{array}$} & \begin{tabular}{c}
$1 \mathrm{M}$ \\
\cline { 3 - 7 }
\end{tabular} & $4 \mathrm{M}$ & $8 \mathrm{M}$ & $12 \mathrm{M}$ & $\begin{array}{c}\text { Max stress } \\
\text { gain(+)/reduction(-)* }\end{array}$ \\
\hline No fiber & 0.36 & 0.39 & 0.35 & 0.41 & 0.48 & $\%$ \\
\hline 1-layer & 1.19 & 0.91 & 0.85 & $0.77^{*}$ & 1.03 & $-3 \%$ \\
\hline 3-layers & 2.21 & 2.47 & $2.16^{*}$ & 2.20 & 2.27 & $-35 \%$ \\
\hline 5-layers & 5.37 & 3.92 & 2.81 & $2.29^{*}$ & 2.55 & $-57 \%$ \\
\hline
\end{tabular}

Delamination at fabric-matrix interface before the mechanical testing was noted in some speicmens, which might be due to thermal freeze-thaw cycling effects of moisture entering along four cut-edges of the specimens conditioned in an environmental chamber (Figure 7.22 (a)). Hinge formation failure type was noted mostly for non aged specimens with $7 \%$ and $12 \%$ fiber volume fraction (Figure 7.22 (b)). Incomplete tear of fabric was noted for non-aged specimens 
and specimens conditioned in salt solution (Figure 7.22 (c)). Complete rupturing of fibers was noted for several specimens conditioned in alkaline solution Freeze-thaw and room temperature (Figure $7.22(\mathrm{c})$ ).

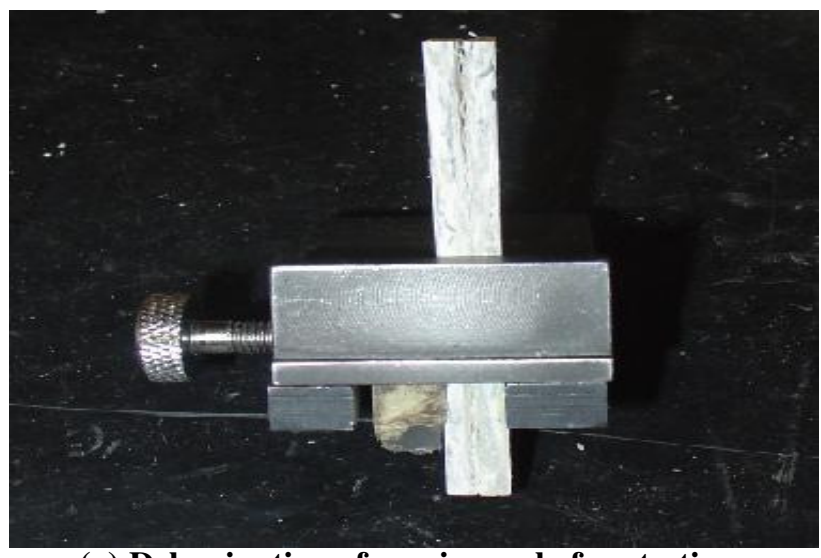

(a) Delamination of specimens before testing

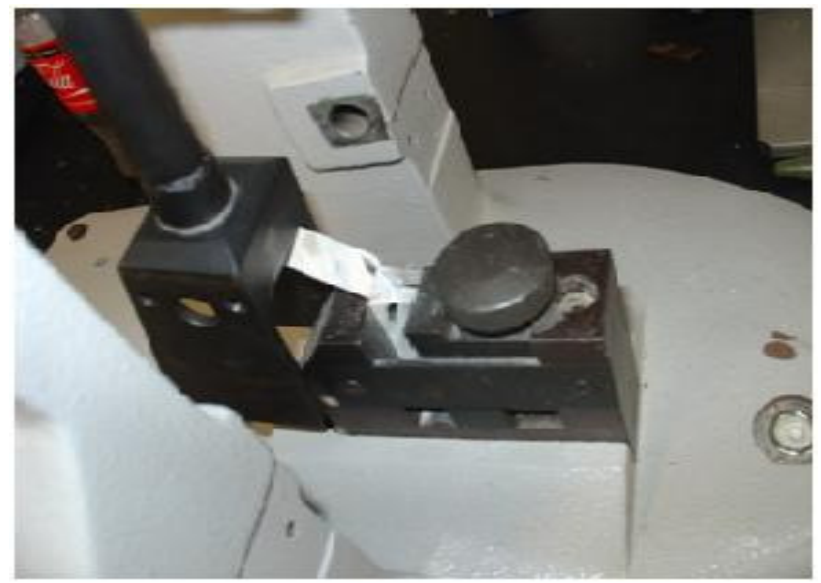

(c) Incomplete tear of fabric

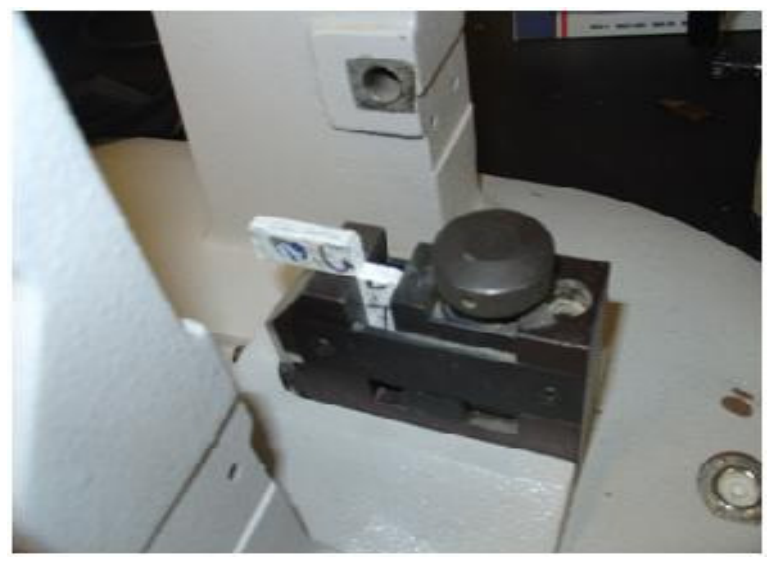

(b) Formation of hinge

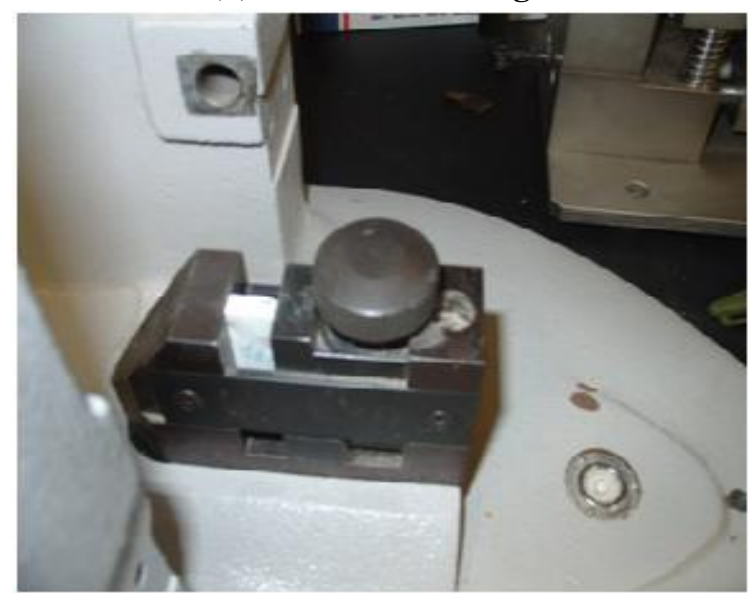

(d) Complete tearing of fabric

Figure 7.22 Failure modes in thermoplastic impact test specimens

\subsection{Effect of Aging}

Due to strength reduction in salt and alkaline aged specimens under room temperature and under freeze-thaw conditioning, the failed tension and bending specimens were visually inspected prior to SEM. Complete rupturing and absence of glass fabric in specimens subjected to alkaline solution was noted. It should be noted that use of small fiber volume fractions of glass (4\% to $12 \%$ bi-directional, with only half of those, i.e., $2 \%$ to $6 \%$ contributing to load carrying capacity) 
leads to quicker fiber disintegration under alkaline exposure, which results in the strength values of FRP composites being equal to those of the resin alone. Strength (stress) values of some of the alkaline conditioned GFRP specimens were found to be lower than those of the non-aged and unreinforced specimens. From test results, non-reinforced specimens subjected to conditioning showed strength reduction, e.g., (20\%) under tension (Table 7. 6). For reinforced and nonreinforced test specimens with identical dimensions, resin content in glass fabric reinforced specimens is lower than unreinforced specimens. Stress calculations for reinforced specimens are done with the same cross sectional area as that of the unreinforced even after fiber disintegration under aging, which makes the stress values to appear slightly lower than their unreinforced counterpart specimens. The specimens in this research were machined at sides and subjected to conditioning. Machined sides provide direct access along both edges of the $1 / 4$ " thick conditioned specimens for alkaline solution to reach the 0.5 to $1 \mathrm{inch}$ wide fabric layers. Hence, any field implemented GFRP specimens should have sufficient amount of glass reinforcement and exposure of any open locations that would provide direct access for moisture ingress. The rate and magnitude of strength reduction was lower in room temperature compared to freeze-thaw exposure.

\subsubsection{Effects of Alkaline Conditioning}

Almost all FRP tension test specimens subjected to alkaline conditioning at room temperature or freeze-thaw conditioning showed absence of glass fabrics near rupture/failure location (Figure 7.23). Considerable strength reduction resulting in glass reinforced specimens carrying stresses close to those of unreinforced specimens indicates the severity of glass fibers corrosion under direct alkaline solution exposure. Following observations are made from the test results: 


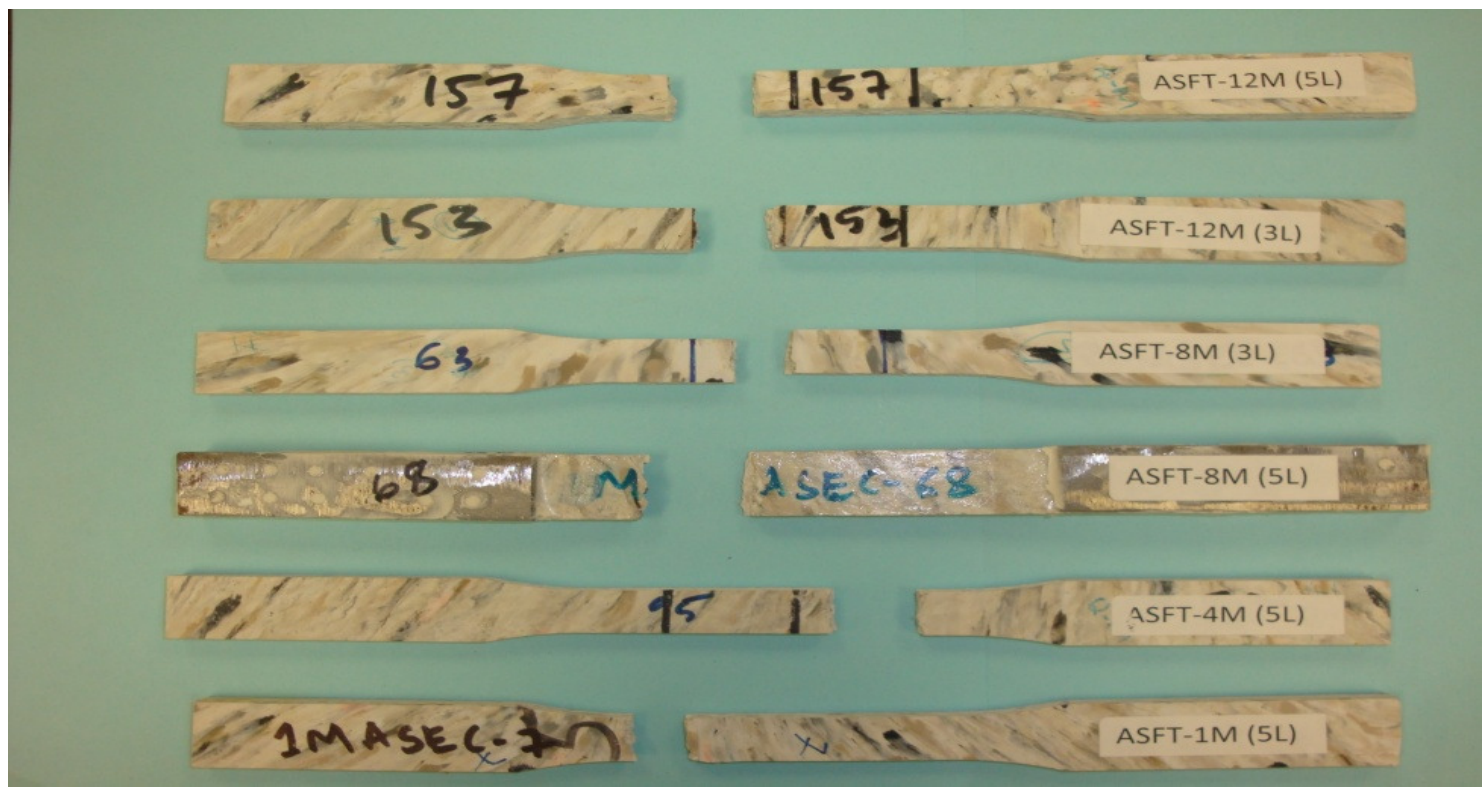

Figure 7. 23 Visual absence of fabric at rupture location (alkaline solution conditioning under freeze-thaw)

- Complete deterioration/degradation of glass fabric was noted in alkaline solution subjected to freeze-thaw conditioning, between one to eight months of aging (Figure 7.23). Ruptured locations showed no signs of fabric presence. Complete vanishing of fabric might be attributed to reaction between hydroxyl ions and fiber glass as described under leaching and etching effects (refer to chapter 8 section 8.3.2).

- Similar to alkaline and freeze-thaw conditioning, loss of glass fibers in low fiber volume fraction FRP specimens was also found for alkaline conditioned specimens at room temperature (Figure 7.24). However, complete fiber loss was observed in specimens after eight months of aging.

- It can also be recalled that the FRP specimens subjected to moisture absorption tests attained saturation under one month of salt, alkaline or water solution immersion at room temperature. Saturation related degradation of glass fibers is expected to be much severe and quicker under freeze-thaw conditions as compared to room temperature, which is discussed by several authors (Vijay and GangaRao, 1999). 


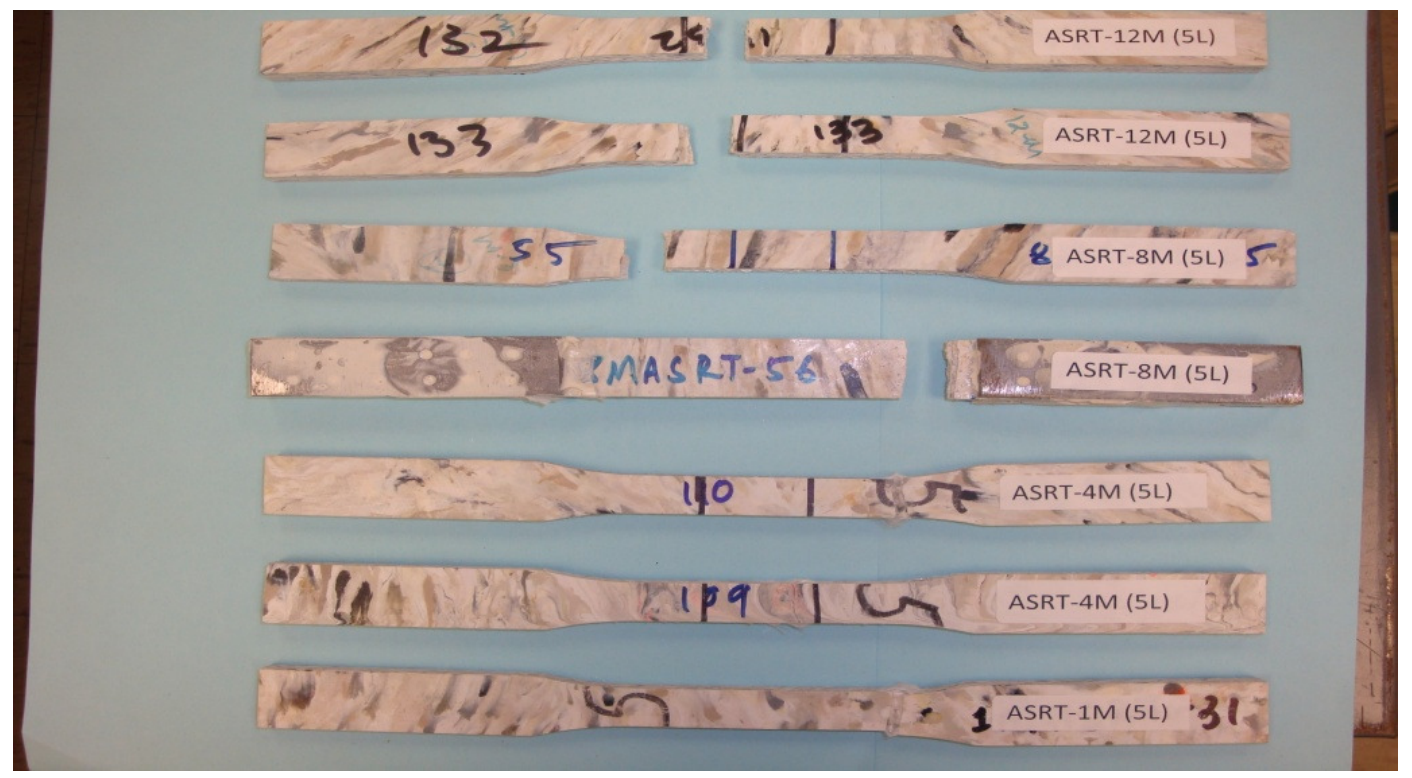

Figure 7.24 Rupturing of fabric was noted after eight months of aging in alkaline solution at room temperature

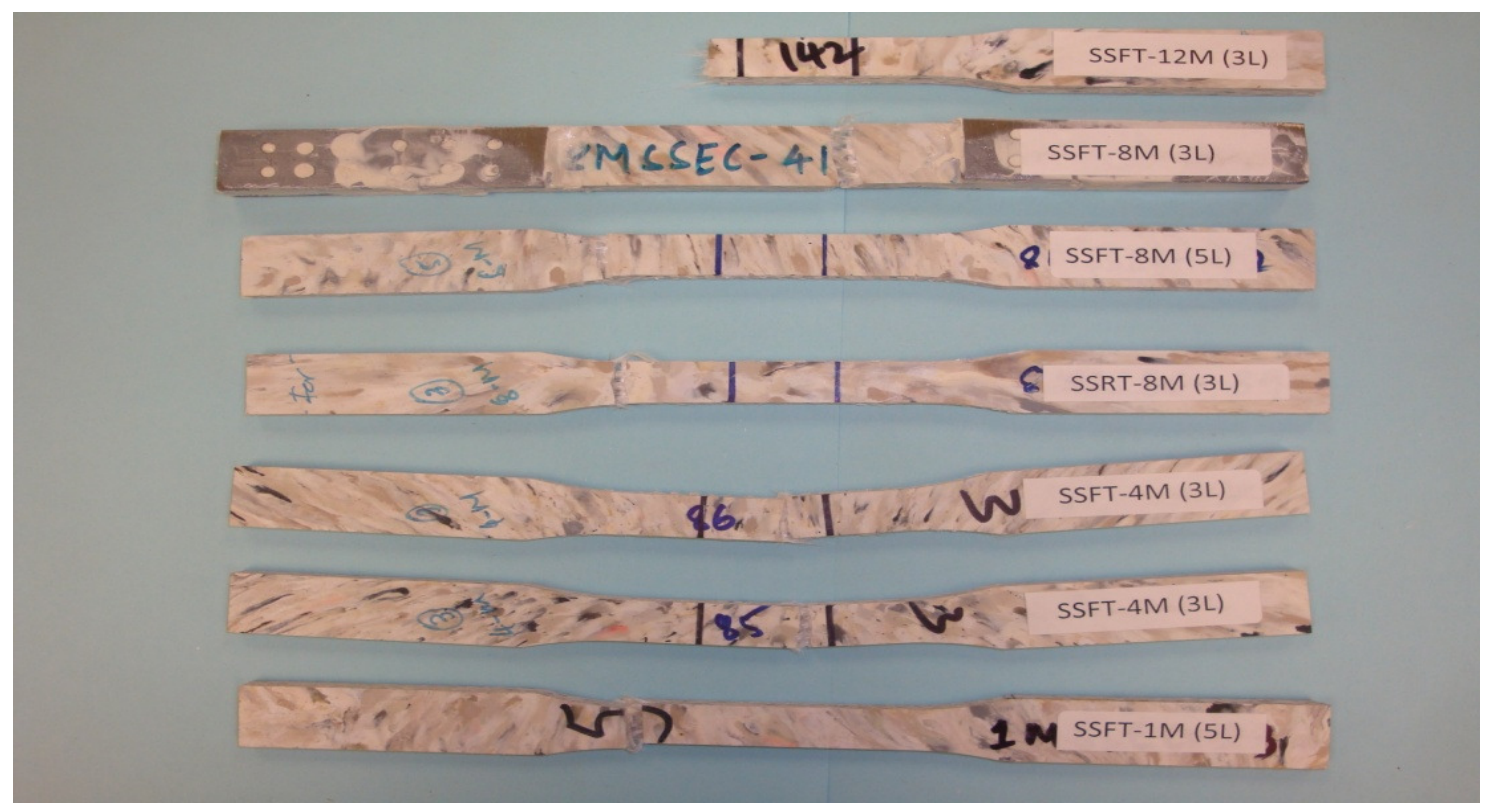

Figure 7. 25 Fabric were not ruptured in specimens subjected to salt solution under freeze-thaw

\subsubsection{Effect of Salt Conditioning}

Unlike alkaline conditioning, salt conditioned FRP tension test specimens showed clear physical presence of glass fabrics near rupture/failure locations (Figure 7. 25). Strength reduction (23\% to $41 \%$ ) resulting from glass fiber corrosion under direct salt solution exposure, though is less as 
severe than alkaline exposure and the degradation rate is much slower than the one caused by alkaline conditioning. Similar to alkaline conditioning, the rate and magnitude of strength reduction under salt solution conditioning was lower in room temperature compared to freezethaw exposure. Fabric presence was noticed in the broken samples after failure under room temperature and freeze-thaw conditioning of FRP specimens with salt solution (Figure $7.26 \& 7$. 27).

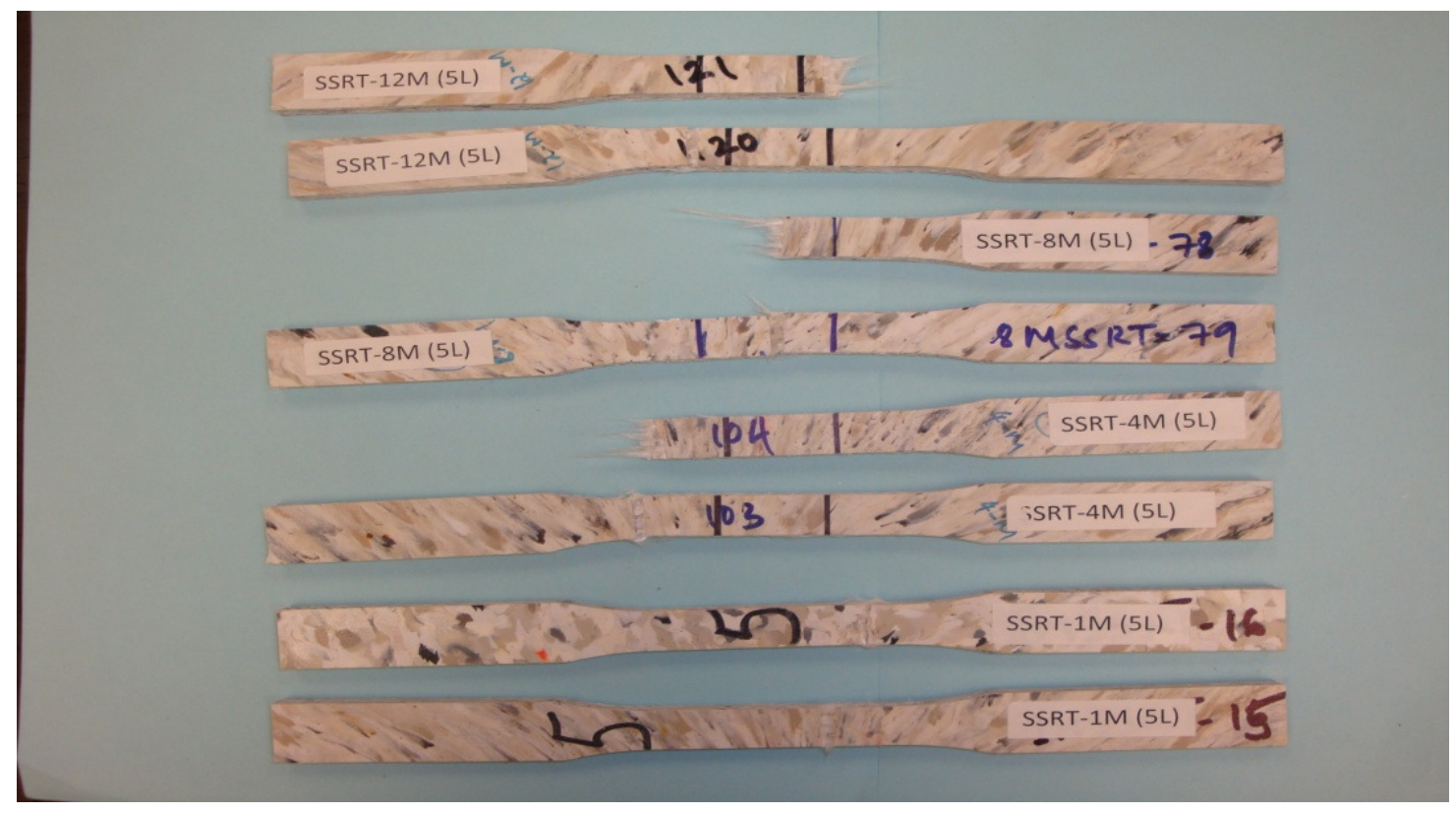

Figure 7. 26 Fabric were not ruptured in specimens subjected to salt solution at room temperature 


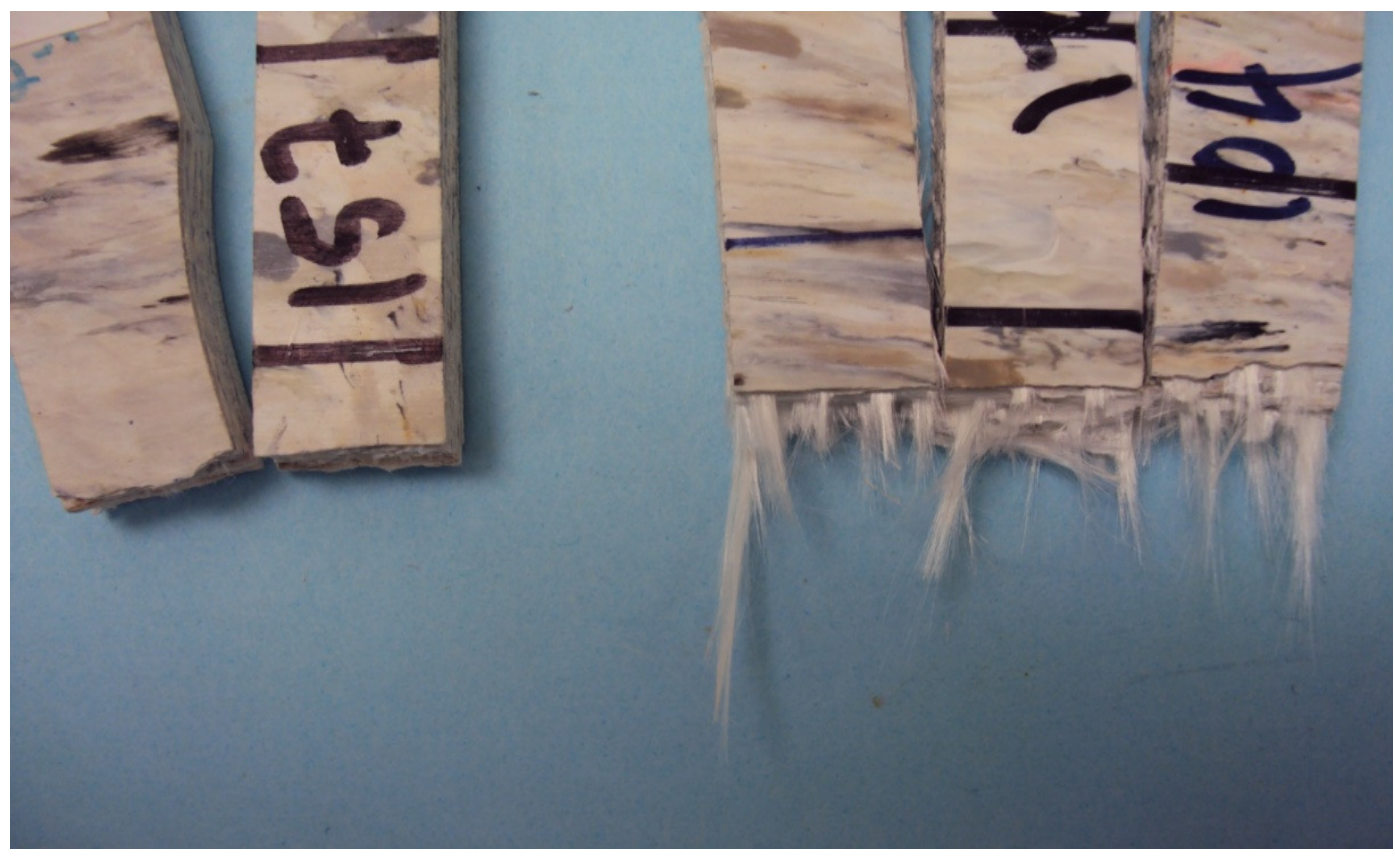

Figure 7.27 Absence of fabric (alkaline conditioning, left) and presence of fabric (salt conditioning, right)

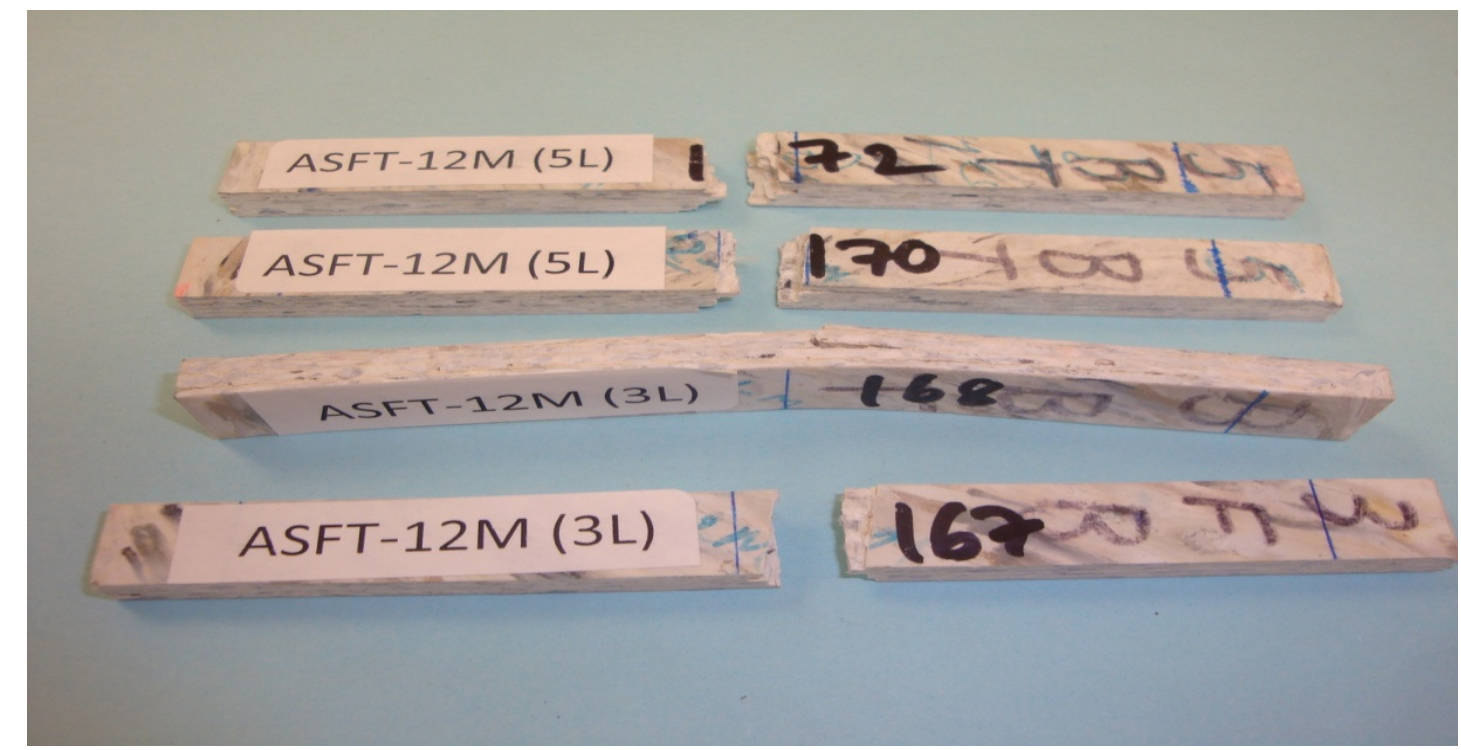

Figure 7.28 Complete rupturing of fabric and delamination at the fabric-matrix interface for specimens in alkaline solution under freeze-thaw

Similar to tension test specimens, complete rupturing and disappearing of fabric was noted in bending test specimens conditioned in alkaline solution under freeze-thaw after 12 months 
(Figure 7. 28). Glass fiber corrosion is attributed to process of "leaching" and "etching" effects described in section 8.3.2 of chapter 8 .

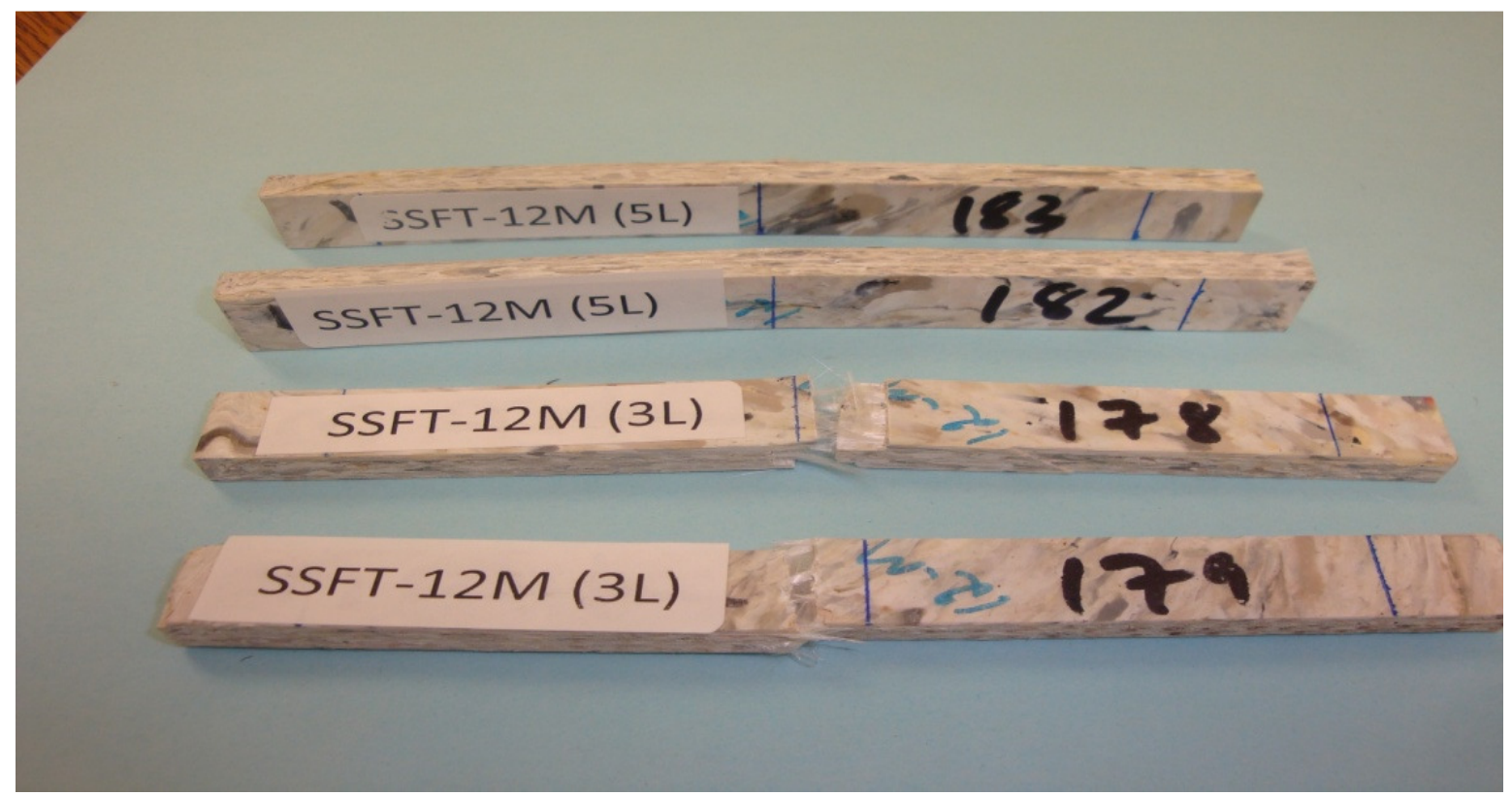

Figure 7.29 Crack formation in tension zone for specimens in salt solution under freeze-thaw

Initiation of crack from the tension zone of bending test specimens conditioned in salt and alkaline solution under room temperature and freeze-thaw aging after 12 months was noted (Figures 7.29, $7.30 \& 7.31$ ). However, the failed surfaces showed distinct presence of glass fibers in salt conditioned specimens (Figure 7. 29) and absence of glass fibers in alkaline conditioned specimens (Figure 7.28). 


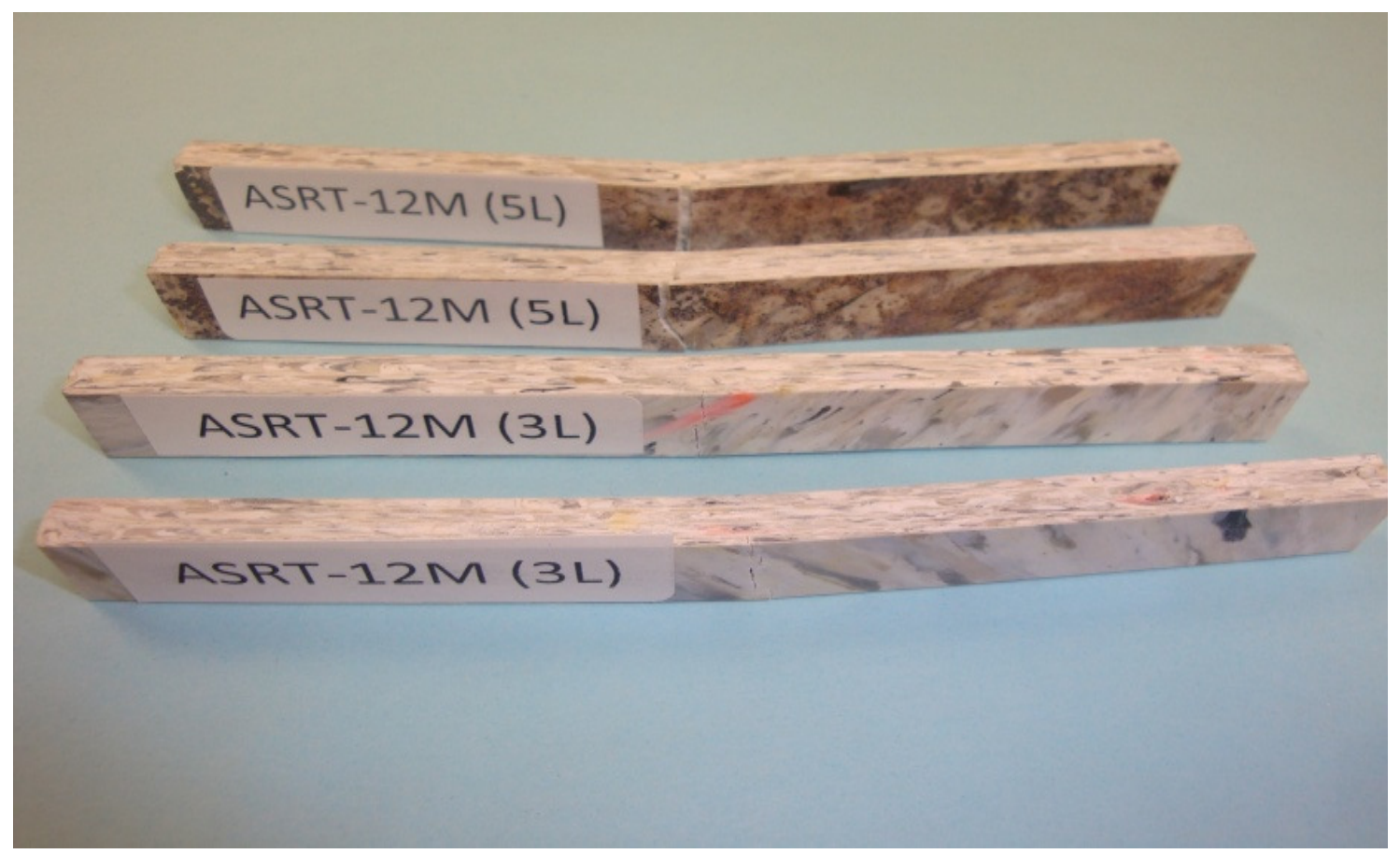

Figure 7.30 Crack formation in tension zone for specimens in alkaline solution at room temperature

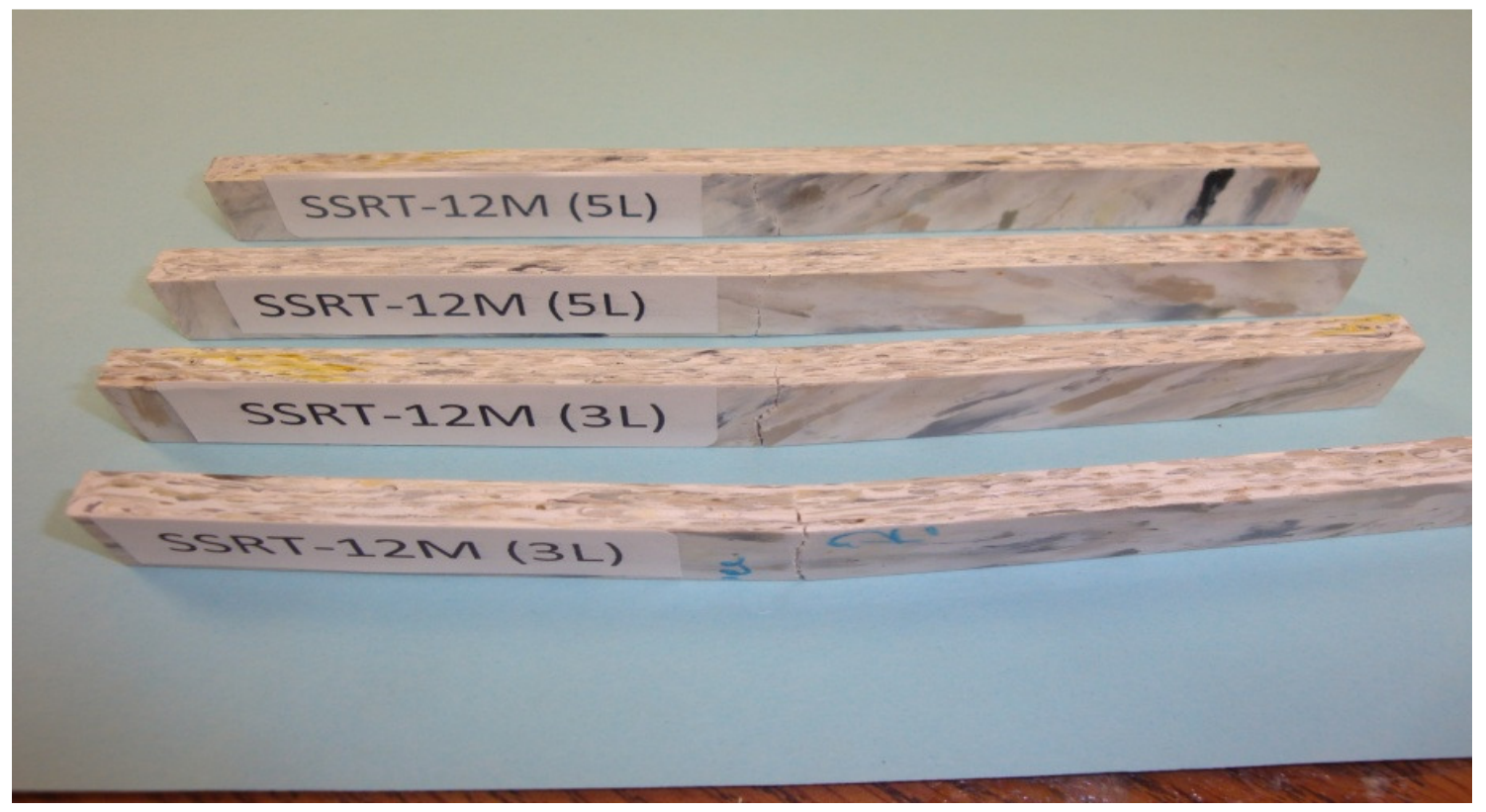

Figure 7.31 Cracks in the tension zone of bending test specimens 


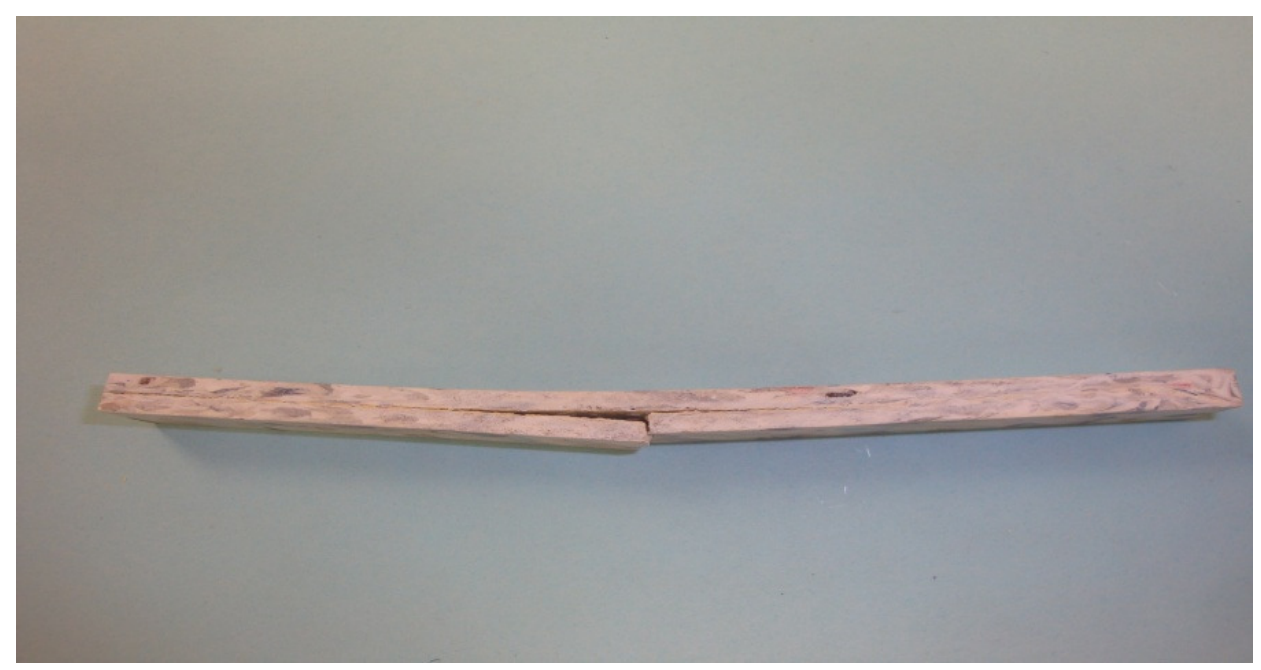

Figure 7.32 Crack formation and delamination for specimens in alkaline solution under freeze-thaw Formation of cracks in the tension zone was followed by delamination along the fabric-matrix interface including significant disintegration or absence of glass fibers in bending test specimens with one layer of glass fabric conditioned in alkaline solution with freeze-thaw variation (Figure 7.32).

\subsection{Recycled Polymer Composition Effects on Mechanical Properties}

Durability study on recycled ABS polymer was carried-out in this research. Due to higher strength variation in some specimens after salt and alkaline solution conditioning at room temperature and under freeze-thaw, the strength enhanced aged specimens' failure surfaces were visually inspected. The strength increase/decrease also depends on the impurities present in the recycled polymer pellets. Presence of different grades of polymer pellets at the failure location increased the impact strength of some specimens (Figure 7.33 (a)). Visual inspection of the impact strength specimens revealed the presence of voids at the failure plain (Figure 7.33 (b). Presence of different grades of polymers pellets, impurities and additives has to be carefully considered while evaluating recycled polymer stream and necessary test repetition should be carried out. 


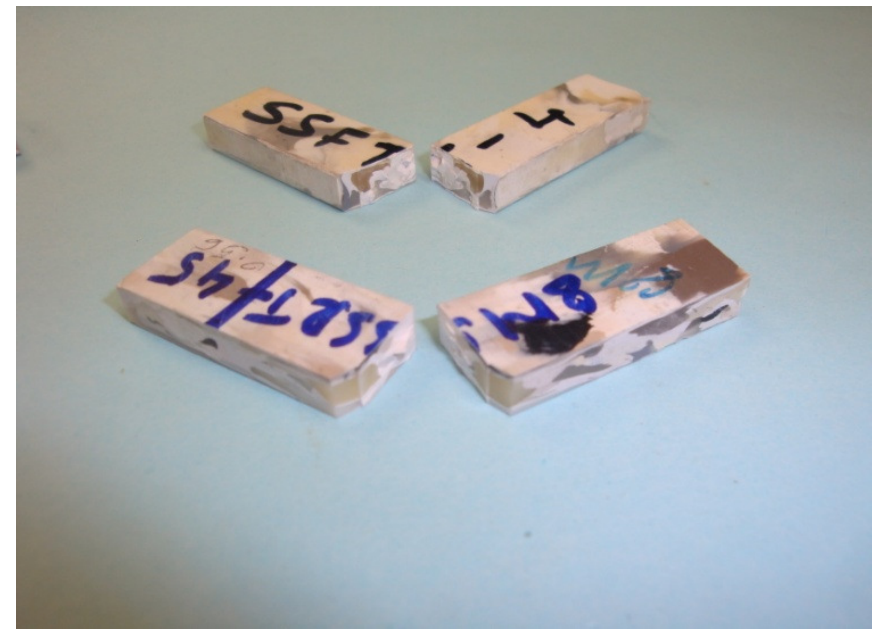

(a) Presence of different pellet grade at failure plain

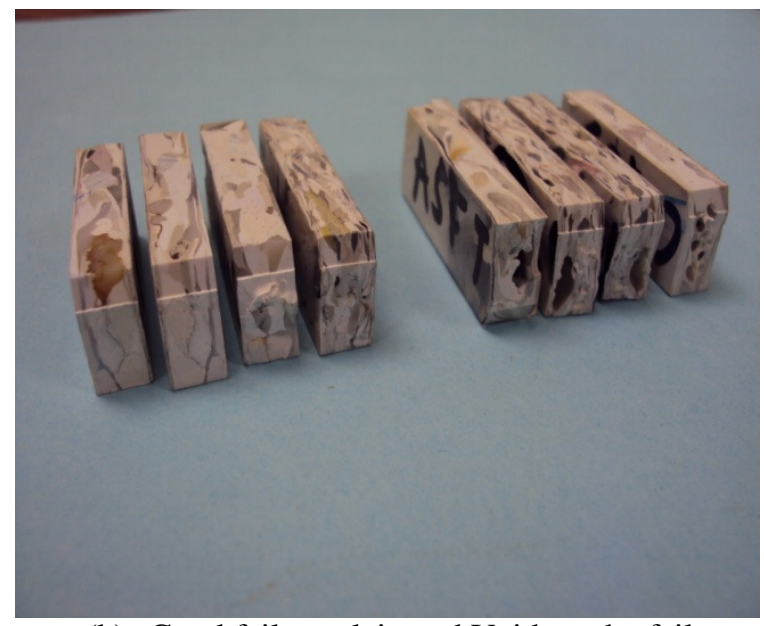

(b) Good failure plain and Voids at the failure location

Figure 7.33 Presence of different pellet grades and voids might alter the strength of polymer

After noticing the delaminations/separation, mechanical property reductions, and failure modes in the aged coupon specimens subjected to salt and alkaline aging, the specimens were considered for evaluation under scanning electron microscope, which is reported in chapter 8. 


\section{Scanning Electron Microscope (SEM) and Discussion of Durability Test Results}

\subsection{Introduction}

The strength and modulus of GFRPs mainly depend on stress transfer at fabric-matrix interface. In this research, some void formation/delamination prior to mechanical testing was noted for bending, impact and compression test coupon specimens manufactured through compression molding and aged in salt and alkaline solutions. In order to inspect the microscopic level bonding between fabric-matrix and condition of fibers, Scanning Electron Microscopy (SEM) was carried out in this research and reported.

Complete summary of the aging test results has been reported in Appendix C from Tables C. 1 through C.8. Bar graphs have been plotted in Figures C.1 through C.32 which shows the strength reductions due to aging at regular intervals.

Summary of maximum strength reduction values for various fiber volume fraction and aging scenarios are reported in Table 8.1. The maximum strength reductions for glass reinforced composite coupons (Tension, bending, compression and impact specimens as per ASTM) were highlighted under freeze-thaw conditions of alkaline solution in Table 8.1. However, the maximum strength reduction for non-reinforced polymer coupon specimens occurred in both salt and alkaline conditioning schemes.

\subsection{Scanning Electron Microscopy}

Scanning Electron Microscope (SEM) images of controlled and aged FRP specimens were examined in order to note the FRP surface texture, variation in fabric pattern, fabric, matrix, interface and the changes that occurred during the salt and alkaline aging at freeze-thaw scenario. 
Table 8. 1 Maximum percentage strength reduction of tension, bending comp and impact specimens

\begin{tabular}{|c|c|c|c|c|c|}
\hline \multicolumn{6}{|c|}{ Maximum property change in 12 months } \\
\hline $\begin{array}{l}\text { No of } \\
\text { layers } \\
\text { (FVF) }\end{array}$ & $\begin{array}{c}\text { Conditioning } \\
\text { scheme }\end{array}$ & Tension & Bending & Compression & Impact \\
\hline \multirow{4}{*}{ No fabric } & A-RT & $-13 \%$ & $-6.65 \%$ & $-5.49 \%$ & $-3 \%$ \\
\hline & A-FT & $-10 \%$ & $-9.35 \%$ & $-11.82 \%$ & $-17 \%$ \\
\hline & S-RT & $-19 \%$ & $-9.65 \%$ & $-1.96 \%$ & $-3 \%$ \\
\hline & S-E FT & $-20 \%$ & -13.31 & $-5.33 \%$ & $-3 \%$ \\
\hline \multirow{4}{*}{$\begin{array}{c}\text { 1-layer } \\
(4 \%)\end{array}$} & A-RT & $-24.36 \%$ & $-6.84 \%$ & $-11.87 \%$ & $-66.11 \%$ \\
\hline & A- FT & $-33.15 \%$ & $-13.78 \%$ & $-30 \%$ & $-70.87 \%$ \\
\hline & S-RT & $-7.03 \%$ & $-7.19 \%$ & $-9.25 \%$ & $-12.32 \%$ \\
\hline & S-FT & $-16.56 \%$ & $7.63 \%$ & $-8.12 \%$ & $-35.29 \%$ \\
\hline \multirow{4}{*}{$\begin{array}{c}\text { 3-layers } \\
(7 \%)\end{array}$} & A-RT & $-54.26 \%$ & $-30.15 \%$ & $-9.4 \%$ & $-72.71 \%$ \\
\hline & A- FT & $-61.46 \%$ & $-31.33 \%$ & $-29.44 \%$ & $-83.42 \%$ \\
\hline & S-RT & $-14.18 \%$ & $-1 \%$ & $-4.26 \%$ & $+6.89 \%$ \\
\hline & S-FT & -19.75 & $-4.99 \%$ & $-1.53 \%$ & $-2.31 \%$ \\
\hline \multirow{4}{*}{$\begin{array}{c}\text { 5-layers } \\
(12 \%)\end{array}$} & A-RT & $-65.76 \%$ & $42.94 \%$ & $-20.33 \%$ & $-93.17 \%$ \\
\hline & A-FT & $-75.07 \%$ & $-52.23 \%$ & $-45.75 \%$ & $-93.29 \%$ \\
\hline & S-RT & $-16.82 \%$ & $-17.83 \%$ & $-15.52 \%$ & $-45.33 \%$ \\
\hline & S-FT & $-41.02 \%$ & $-11.83 \%$ & $-18.36 \%$ & $-57.39 \%$ \\
\hline
\end{tabular}

Note: A- Alkaline solution, S- Salt solution, FT- Freeze-thaw, RT- Room temperature

\subsubsection{SEM on control specimens}

The coupon level control samples manufactured by compression molding process were examined at various locations under scanning electron microscope (SEM). SEM images of control samples (Figure 8.1) illustrated the incomplete wetting of fibers at the middle of fiber bundle (roving), which is mainly due to high viscosity of ABS resin during compression molding process. Incomplete wetting around fibers resulted in void formation and poor quality FRP. Incomplete wetting of fabric leads to poor stress transfer between fabric and matrix. In addition, the absorbed moisture is generally stored at voids in FRPs. Additional research has to be carried out 
to improve incomplete wetting limitation of thick thermoplastic composites ( $>1 / 4 \mathrm{inch})$. Attempts to ensure proper wetting of fabric has to be carried out to improve the mechanical and durability performance of thermoplastic FRPs. The thermoplastic coupon specimens were examined using SEM in both longitudinal and transverse direction.

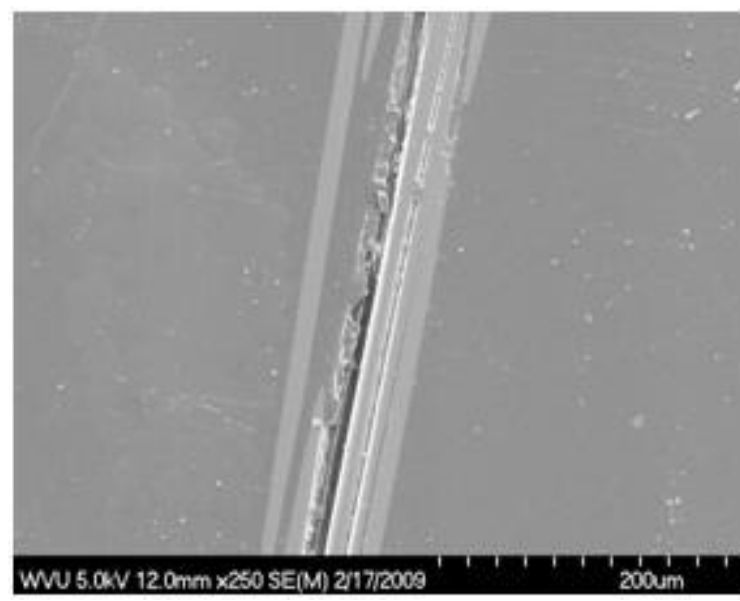

(a) Incomplete wetting of fabric longitudinal direction

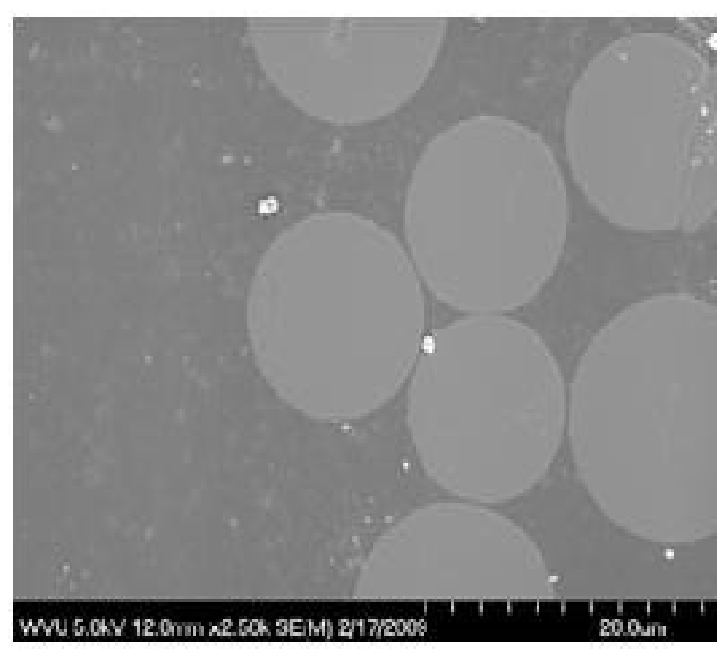

(c) Fibers at roving circumference

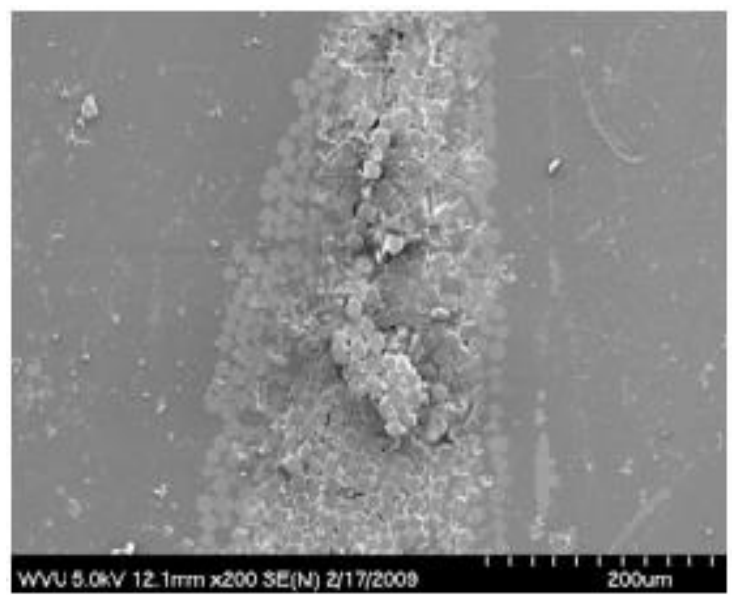

(b) Incomplete wetting of fibers in transverse direction

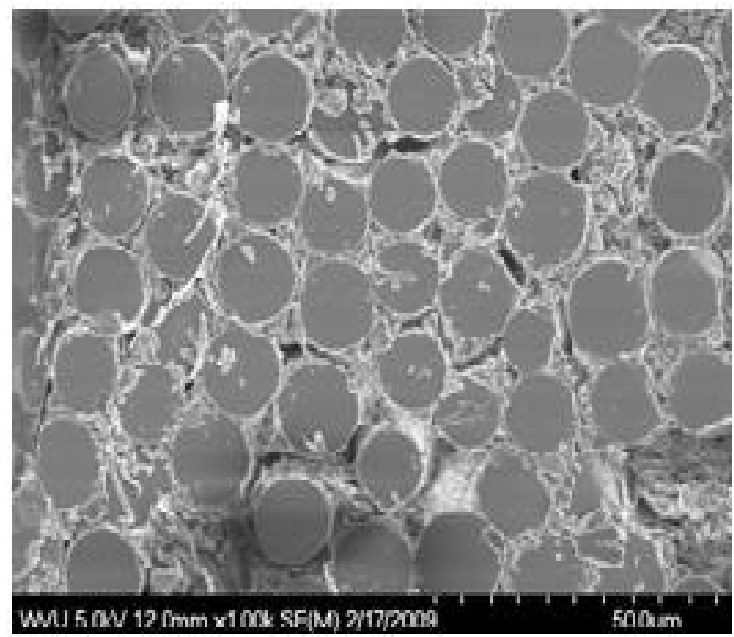

(d) Incomplete wetting of fabric in transverse direction

Figure 8. 1 SEM for reference sample 
The SEM of reference coupons is shown in Figure 8.1. Incomplete wetting of fabric at the center of fiber bundles (rovsings) can be noted from Figures 8.1 (a), (b) and (d). Figure 8.1 (c) shows proper wetting at fabric matrix interface which occurs under proper flow of resin around fibers.

\subsection{SEM on Aged Thermoplastic Specimens}

SEM on control specimens was carried out in order to observe and compare the changes that occurred in specimens conditioned in salt and alkaline solution with freeze-thaw (environmental chamber) due to aging.

- It was noted during mechanical testing that the tension modulus of specimens in alkaline and salt solution at freeze-thaw increased in relation to control specimens; however, the strength of aged composite specimens under tension decreased compared to control samples. Brittle behavior of tension specimens under aging in salt and alkaline solution has been observed due to increase in modulus.

- The moduli of non-fabric specimen were increased over control specimens under bending and compression. However, the modulus of glass fabric reinforced specimens reduced in relation to corresponding reference specimens.

- In order to understand this inconsistent modulus and strength variations under various mechanical tests, SEM analyses on reinforced and conditioned coupon specimens in salt and alkaline solution including freeze-thaw (environmental chamber) were carried out. The reinforced glass fabric at specimen's edge was exposed to aging solutions and varying temperatures. Due to inconsistent moisture absorption noted during moisture absorption testing, and contrast in diffusion co-efficient for various fiber volume fraction specimens, it was decided to examine the specimens through SEM in transverse and longitudinal directions. 


\subsubsection{SEM on specimens in alkaline solution (one month)}

In this research, delamination and/or splitting (poor bonding between resin and fiber before mechanical testing) of ASTM specified impact and compression test specimens was observed for those placed in alkaline solutions with irrespective of conditioning temperature, i.e., freeze-thaw and room temperature. Delamination is attributed to moisture wicking along the fiber-matrix interface that reduces fiber-matrix bond and structural changes in glass fibers initiated by moisture absorption as noted by other researchers (Karbhari et al., 2003).

Large air voids were noted under SEM within the matrix and at the middle of glass fabric cluster for specimens conditioned in alkaline solution for one month. For samples aged in alkaline solution for one month, delamination was noted to be initiated from the middle of fiber cluster and was more localized in with a roving zone (Figure 8.2 (a), (b) and (c)).

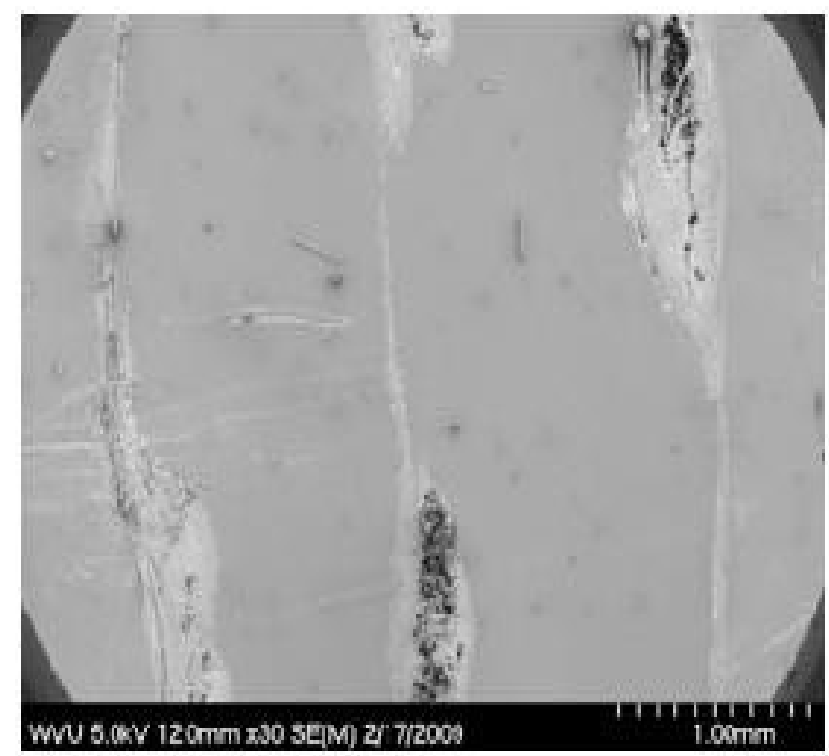

(a) Voids formation and delamination at roving center

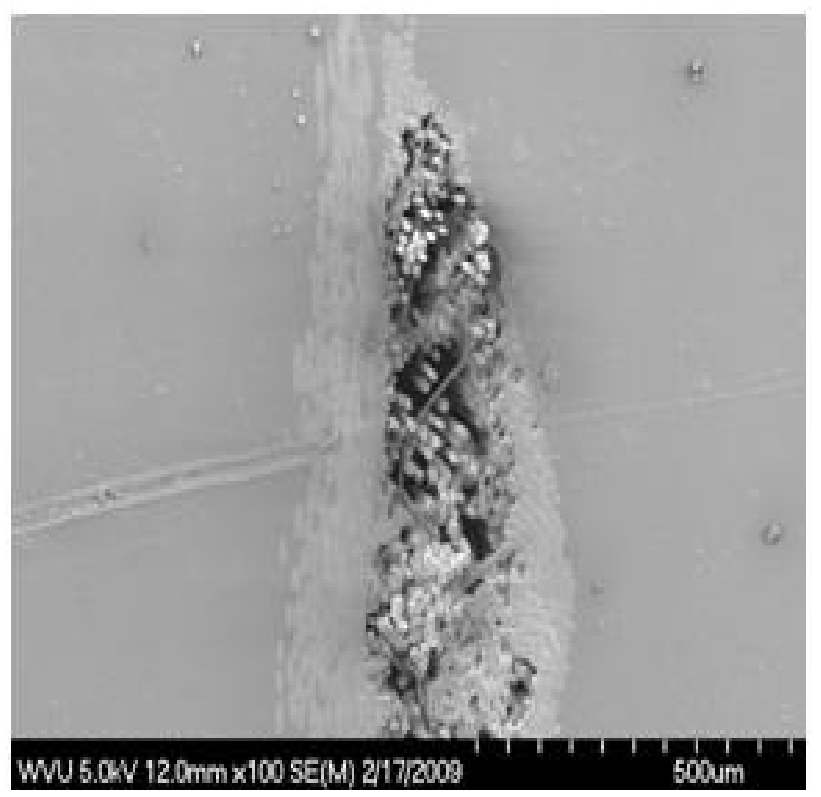

(b) Huge gap at fiber cluster center 


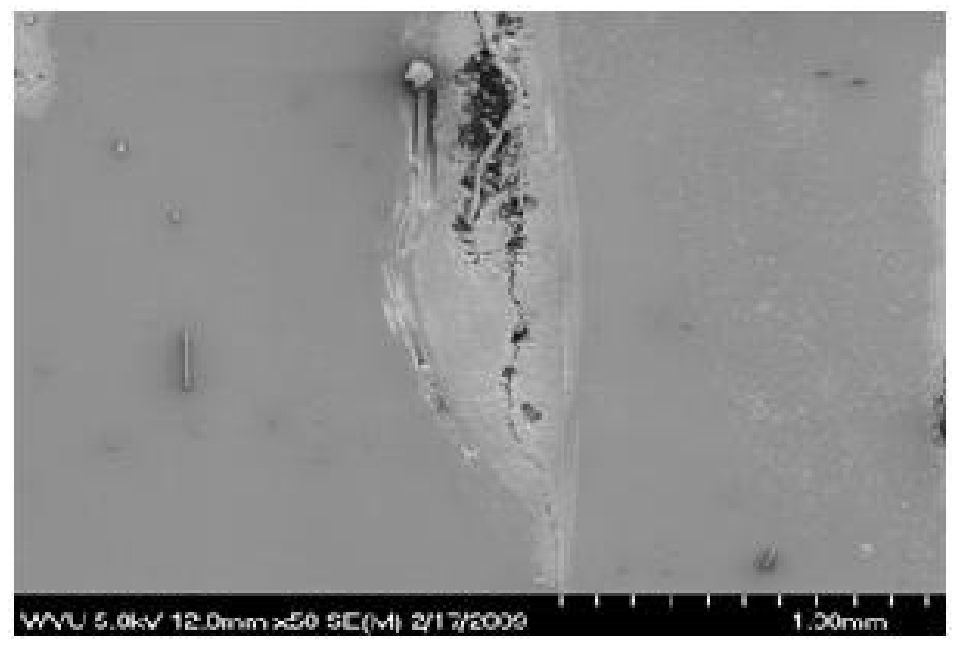

(c) Delamination progress

Figure 8. 2 SEM sample aged for 1 month alkaline solution environmental chamber (Axial Direction)

Freeze-thaw was noted to be more harmful due to the average freeze-thaw temperature being 88.8 F (31.6 C) (calculated by Vijay and GangaRao, 1999), which is higher than the average room temperature $71.6 \mathrm{~F}(22 \mathrm{C})$. Higher temperature can result in higher diffusion of ionic solution in FRPs (as discussed by several authors and freeze-thaw effects increase the cracking phenomenon). Due to moderate temperature difference and/or heat transfer within the FRP system, exposed fabric at the edges of test specimens, especially of fabric-matrix interface, and presence of voids help increase the rate of diffusion of aging into the specimens.

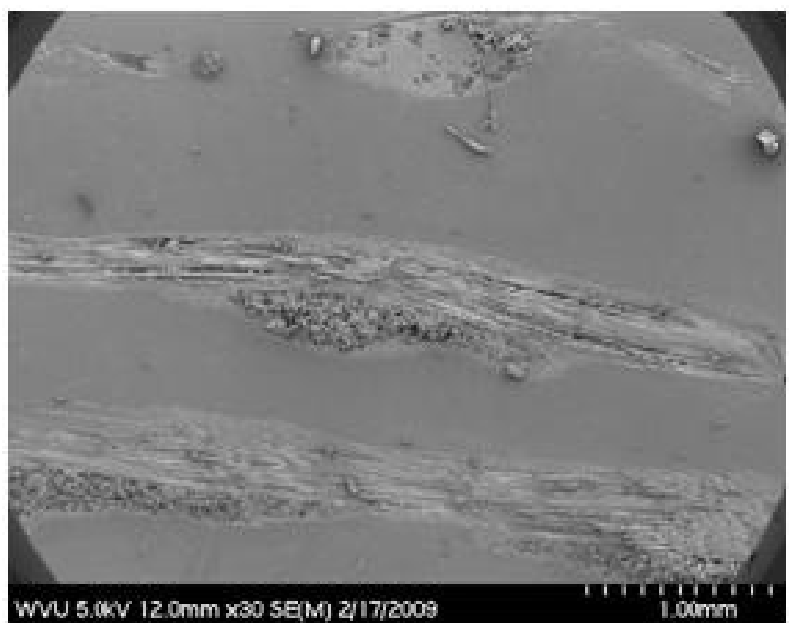

(a) Rupture of longitudinal fibers

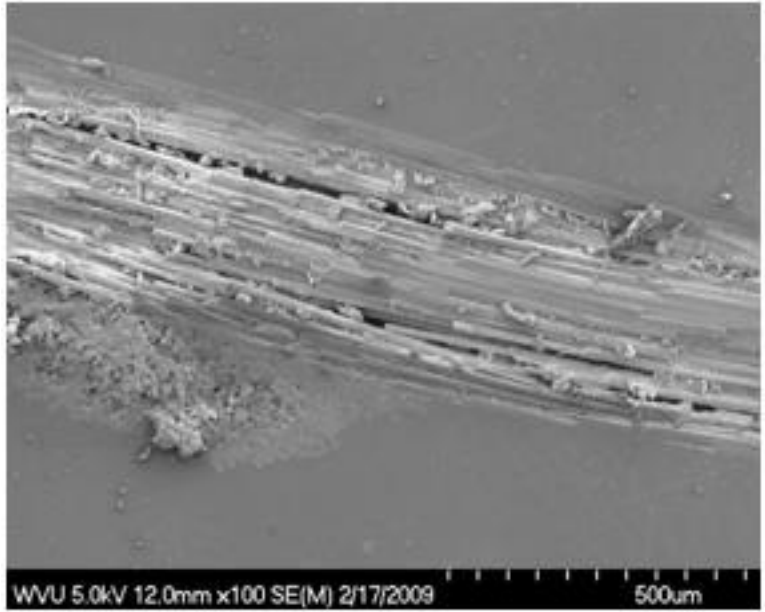

(b) Fabric rupture and air gaps 


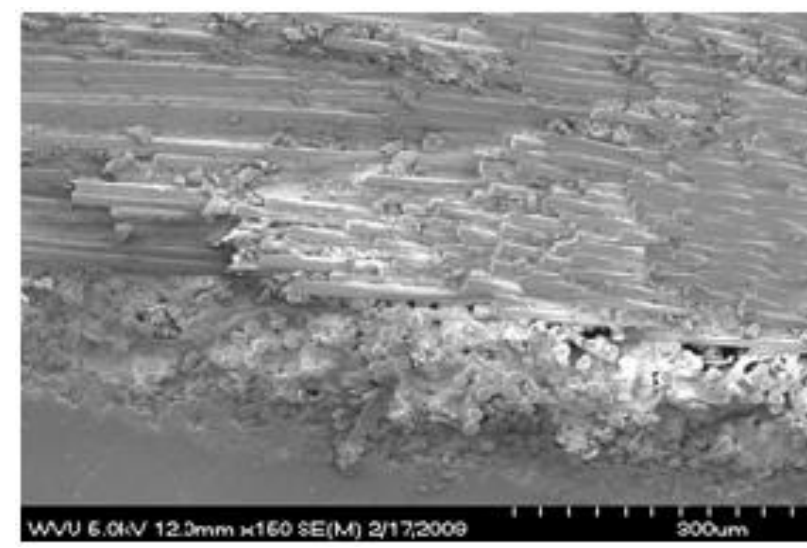

(c) Longitudinal fabric rupture

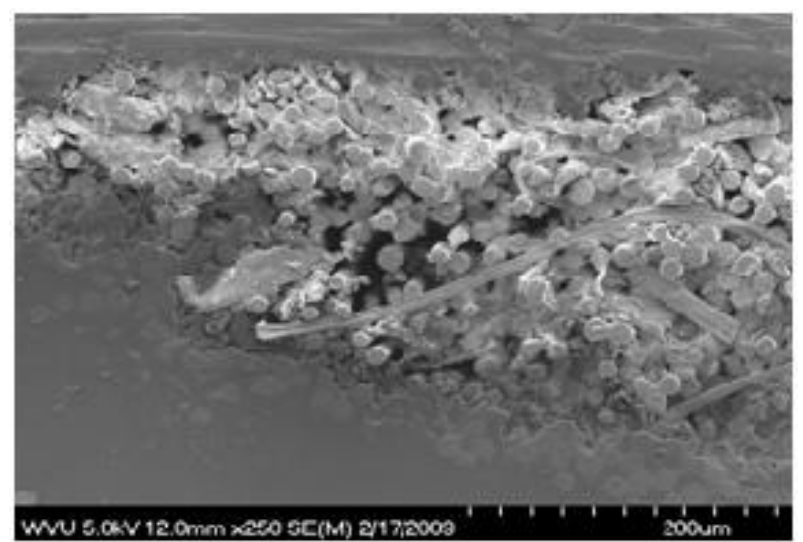

(d) Voids along transverse fabric

Figure 8. 3 SEM sample aged for 1 month alkaline solution environmental chamber (Transverse Direction)

Delamination was observed in longitudinal fabric of specimens subjected to alkaline solution in

freeze-thaw for one month (Figure 8.3 (a) and (b) and (d)). Both transverse and longitudinal fabrics were densely packed and rupturing of longitudinal fabric was observed (Figure 8.3 (c)).

\subsubsection{SEM on specimens in alkaline solution (four months)}

The brittle behavior of coupon specimens conditioned in alkaline solution was noted through modulus variation through tension test data. Fibers were observed to be tightly packed with moderate delamination crack. Deposition of reaction products between glass filaments was noted in coupon specimens conditioned in alkaline solution under freeze-thaw aging scenario for four months. Such deposition of reaction products was also noted on glass fibers of specimens conditioned in salt solution under freeze-thaw aging for 4 months. Deposition of reaction products is expected to be due to accumulation of hydration products between glass filaments (Zhang and Karbhari, 1999). 


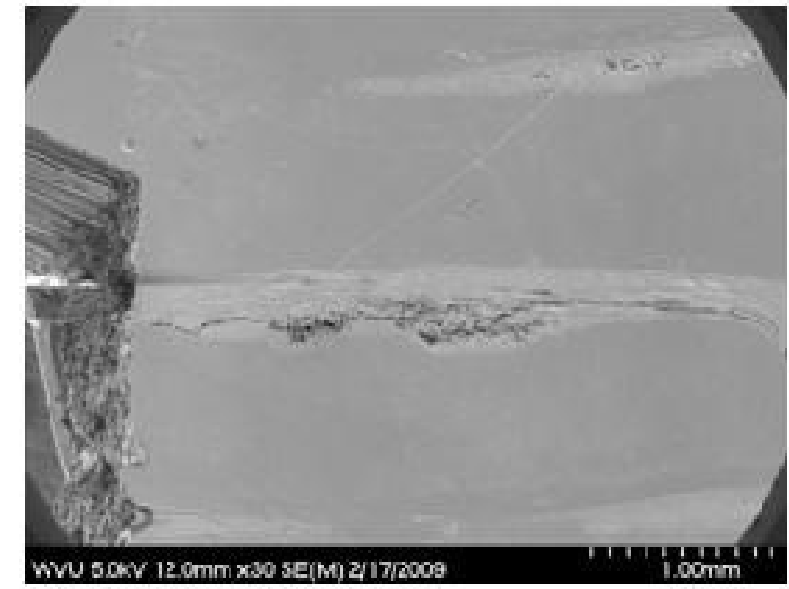

(a) Delamination crack along fabric

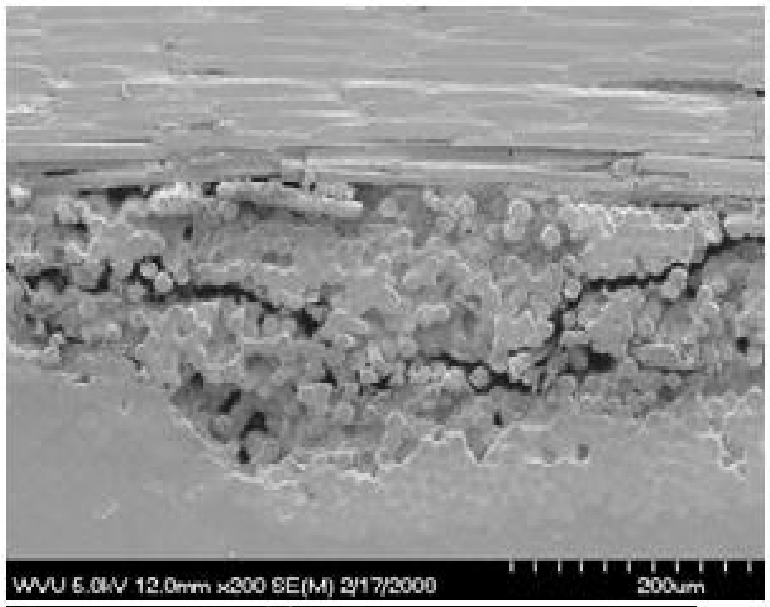

(b) Cracking parallel to transverse fibers

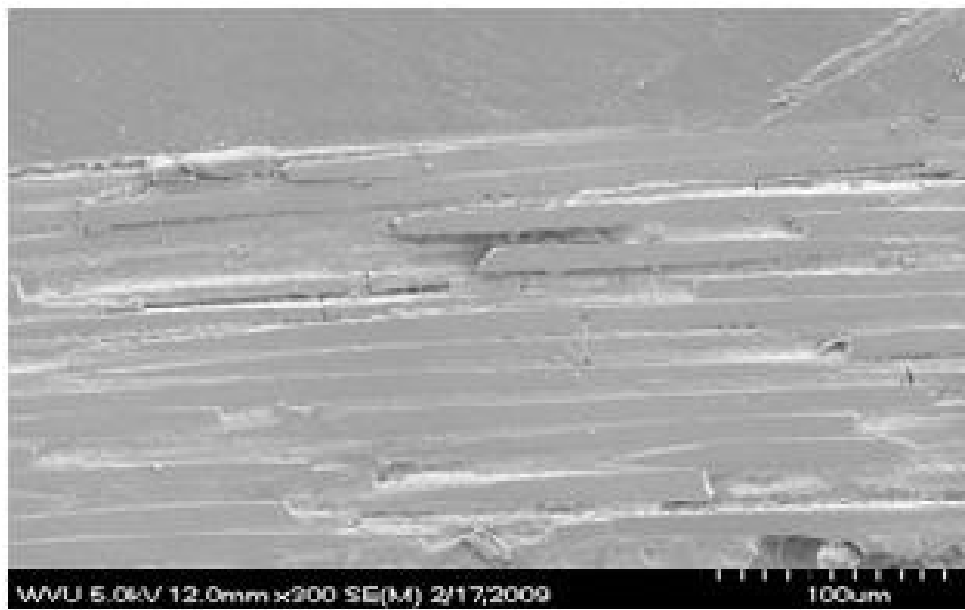

(c) Stacked and broken longitudinal fabric

Figure 8. 4 SEM Sample Aged for 4 Month Alkaline Solution Freeze-thaw (Axial Direction)

In this research, fibers were densely packed together and rupturing of specimens due to fiber hydroxylation was noted for coupons conditioned in alkaline solution under freeze-thaw conditioning of four months (Figures 8.4 (c) and 8.5 (c) and (d)). Zhang and Karbhari, (1999) have reported that hydroxylation itself can lead to fabric surface pitting and roughness, which make the fabric behave as flaws that result in reduction of mechanical properties and cause quicker material failure. Micrographic and EDAX analyses by Zhang and Karbhari, (1999) have 
discussed about formation of calcium hydroxide crystal under alkaline conditioning of GFRP which notches (scrapes) and abrades the fabric.

Zhang and Karbhari, (1999) reported that fiber embrittlement was caused by nucleation (formation of crystals from liquid) of calcium hydroxide on the fiber surface and cleavage cracks from crystal can progress in the direction parallel to (0001) pseudohexagonal cleavage of the crystal, but instead of discontinuing at fiber-crystal interface, they enter the fibers. Similarly, in this research, the rupturing of fibers (Figures 8.4 and 8.5) is also possible due to progression of cleavage cracks resulting from the formation and growth of calcium hydroxide crystals into fiber. Adams, (1981) has explained that the corrosion process can be described as an etching or leaching process or combination of both. Etching process is mainly due to alkalinity, where the silica network is damaged and it releases glass elements that deposit on the fiber surface. If there is no further deposition of reaction products on the remaining glass surface and no change in activity of the contacting solution, reaction continues at a constant rate. Under ideal situations, reaction rate is controlled by temperature as illustrated by Arrhenius equation and silica saturation may reduce the reaction to zero. The reaction products found on the surface of glass fibers noted through SEM on specimen conditioned in alkaline solution is expected to the Calcium hydroxide crystals and/or the deposition of silica elements due to etching and/or leaching process.

In this research, significant amount of rupturing of glass fabric for tension, bending, and impact test specimens (conforming to ASTM standards) placed in alkaline solution for four, eight and twelve months of aging were observed. In this research, among the $\mathrm{OH}^{-}$and $\mathrm{Cl}^{-}$ions present in alkaline and salt solution, respectively, the $\mathrm{OH}^{-}$ions were more harmful than $\mathrm{Cl}^{-}$ions for glass fibers. Tannous and Saadatmanesh, (1999) have reported that penetration of $\mathrm{Cl}^{-}$ions into 
polymer matrix caused micro cracking and fracturing of matrix, which increases the rate of diffusion and de-bonding. These mechanisms eventually lead to the strength loss. Similarly, authors Tannous and Saadatmanesh, (1999) have reported that the presence of hydroxide ions $\mathrm{OH}^{-}$from the alkaline solution are responsible for splitting of the basic components of glass (silica or $\mathrm{SiO}_{2}$ ) into $\mathrm{Si}-\mathrm{O}-\mathrm{Si}$ single bond forming the glass molecular structure, which eventually leads to corrosion of glass fabric and strength reduction.

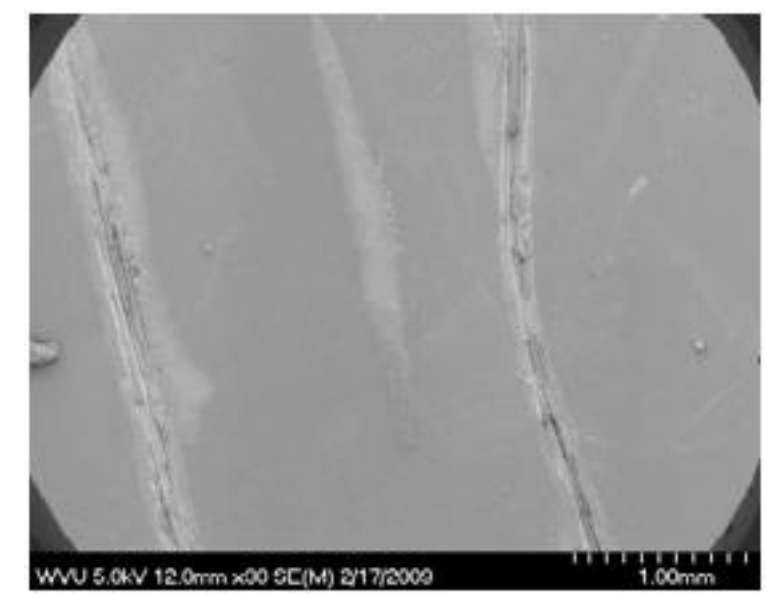

(a) Delamination and broken longitudinal fabric

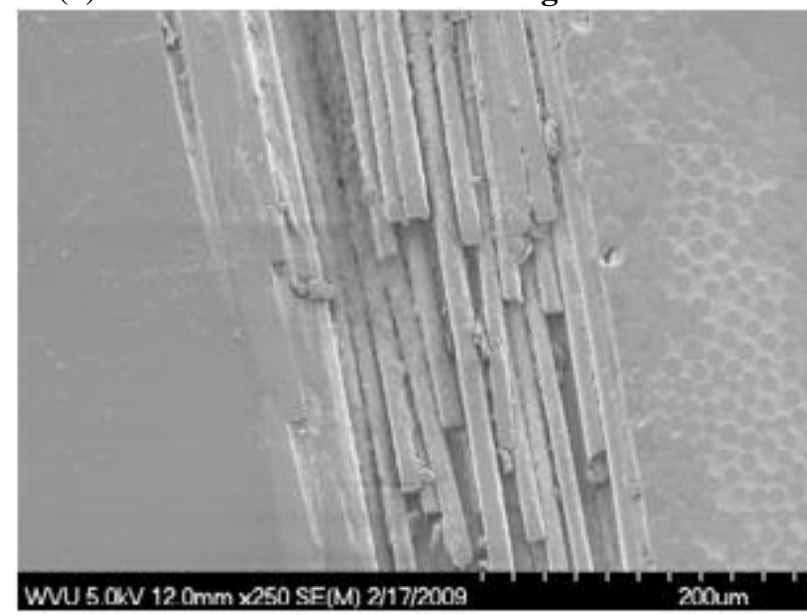

(c) Deposition of leached products on broken fabric

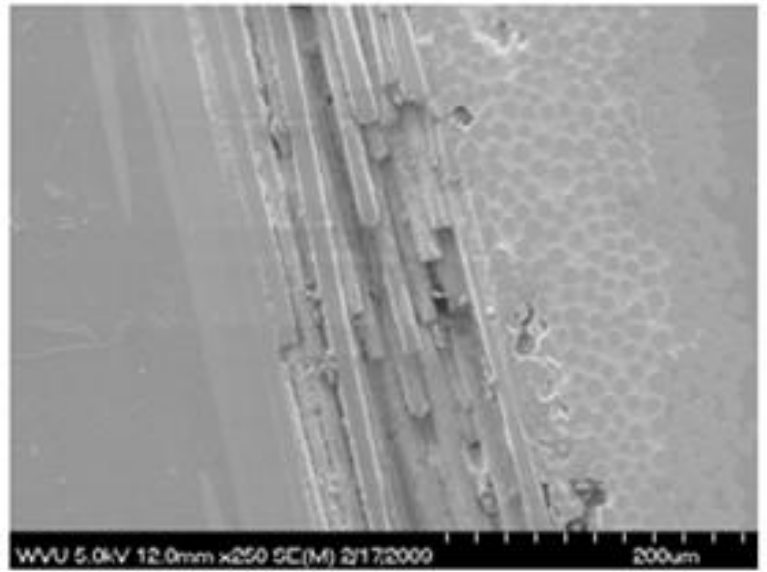

(b) Broken longitudinal direction fabric

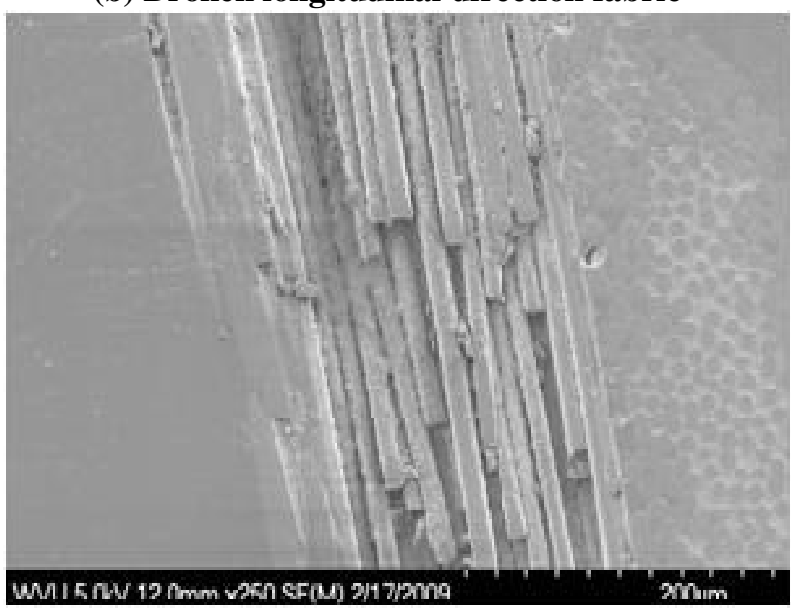

(d) Deposition of leached products on broken fabric Figure 8. 5 SEM sample aged for 4 month alkaline solution environmental chamber (Transverse Direction)

\subsubsection{SEM on specimens in salt solution (one month)}

In this research, rupturing of transverse direction fibers and crack along the fabric matrix interface for specimens placed in salt solution environmental chamber (Figure 8.6 (a), (b) and 
(c)) were noted. This cracking might also be due to the pressure exerted by freezing of solution stored within micro spaces of FRP fabric as noted by other researchers as well. The crack and/or delamination for specimens aged in salt solution were noted along fabric matrix interface of single or multiple fabric layers.

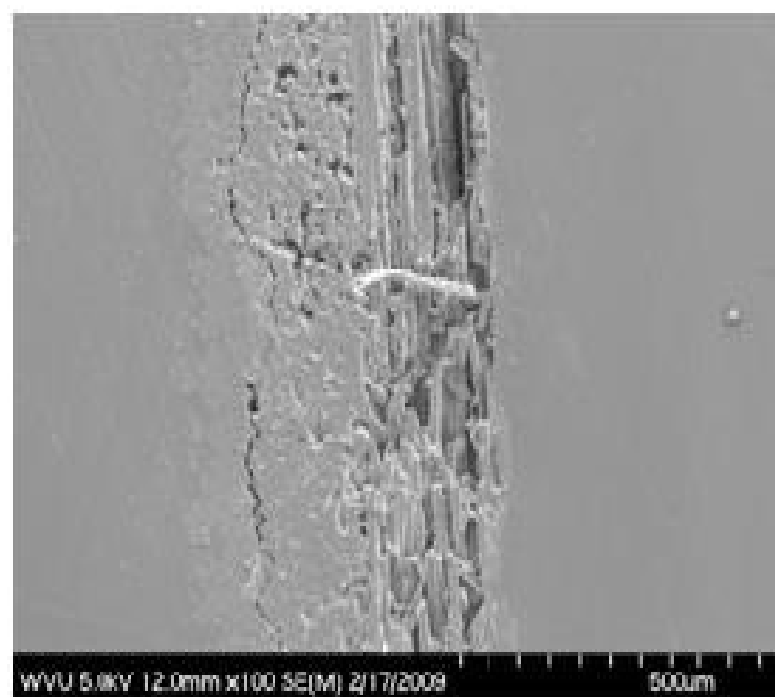

(a) Delamination at fabric matrix interface

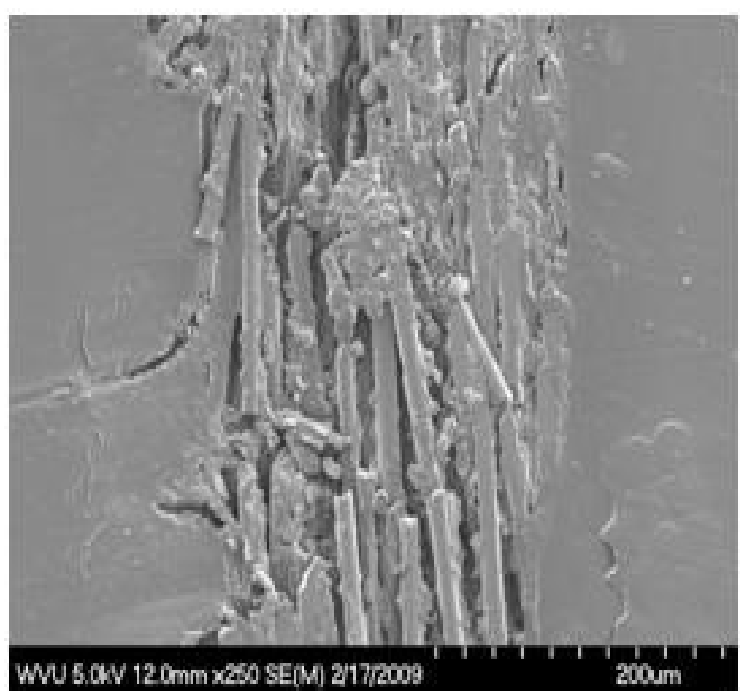

(b) Broken fabric in transverse direction

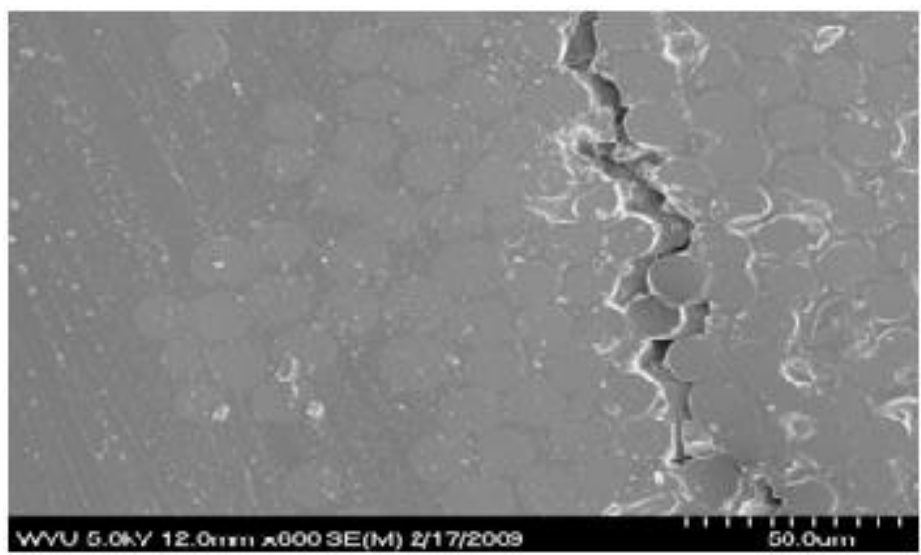

(c) Delamination at fabric matrix interface

Figure 8. 6 SEM sample aged for 1 month salt solution environmental chamber (Axial Direction)

As discussed earlier, matrix plays a vital role in holding the fabric in place and transferring and/or distributing the load in FRPs. Significant delamination at fabric matrix interface and some rupturing of longitudinal fabric was observed under SEM (Figure 8.7 (a) and (b)) for specimens conditioned in salt solution in Freeze-thaw, which resulted in reduction in strength and stiffness for bending and compression test specimens. 


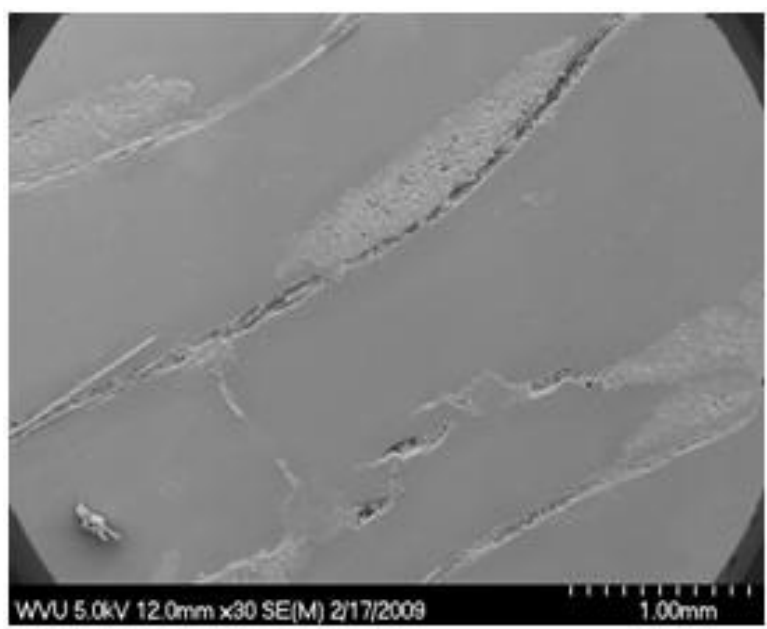

(a) Delamination at fabric matrix interface

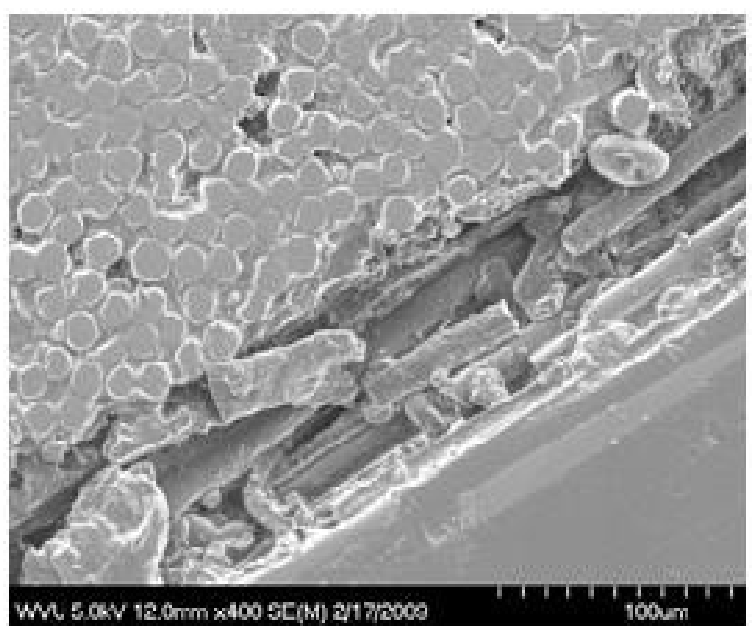

(b) Delamination at fabric matrix interface and broken longitudinal fabric

Figure 8. 7 SEM Sample Aged for one Month Salt Solution Freeze-thaw (Transverse Direction)

\subsubsection{SEM of specimens in salt solution (four months)}

Compared to specimens conditioned for one month in salt solution with freeze-thaw (environmental chamber), additional widening of delaminations was noted for four months aged specimens (Figure 8.8 (a) and (b)). Through the use of SEM, was noted that the moderate amount of longitudinal fabrics were found to be broken (Figure 8.8 (a) and (b)). Accumulation of leached products was noted on glass fabric surface (Figure 8.9 (b)).

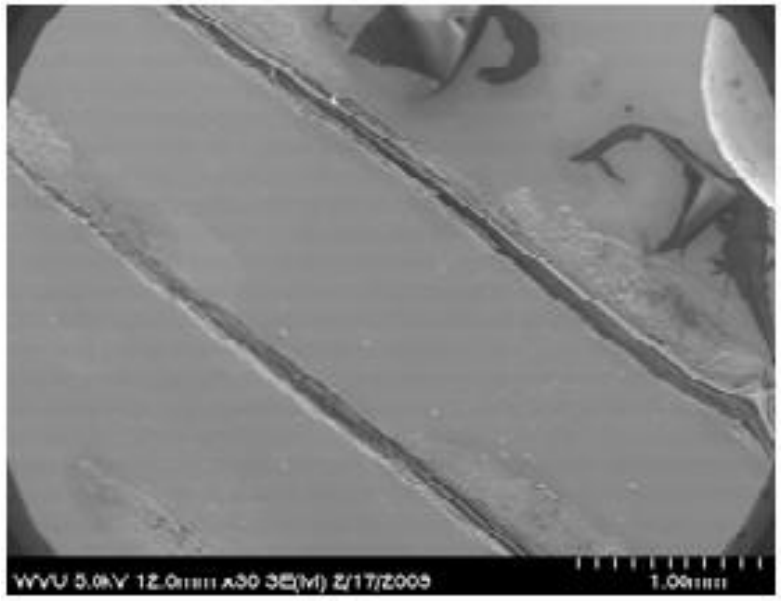

(a) Delamination in transverse direction

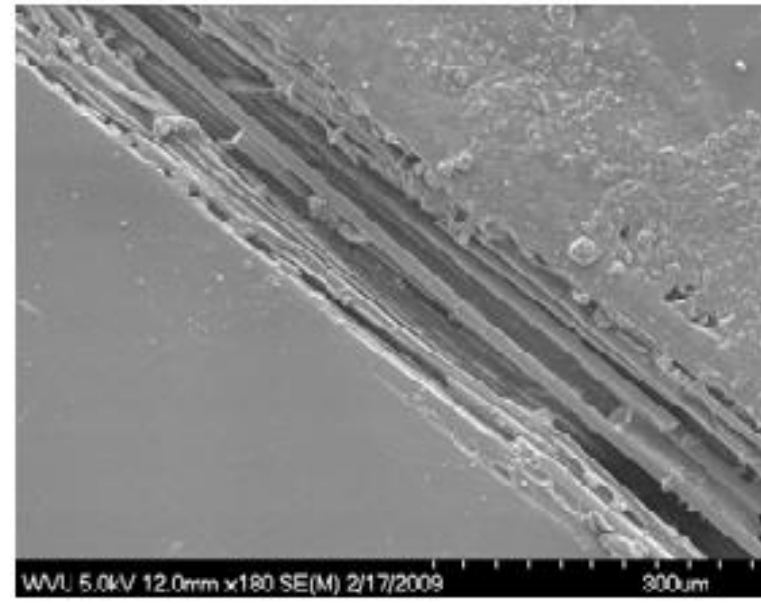

(b) Delamination and broken transverse fabric Figure 8. 8 SEM sample aged for 4 month salt solution environmental chamber (Axial Direction) 


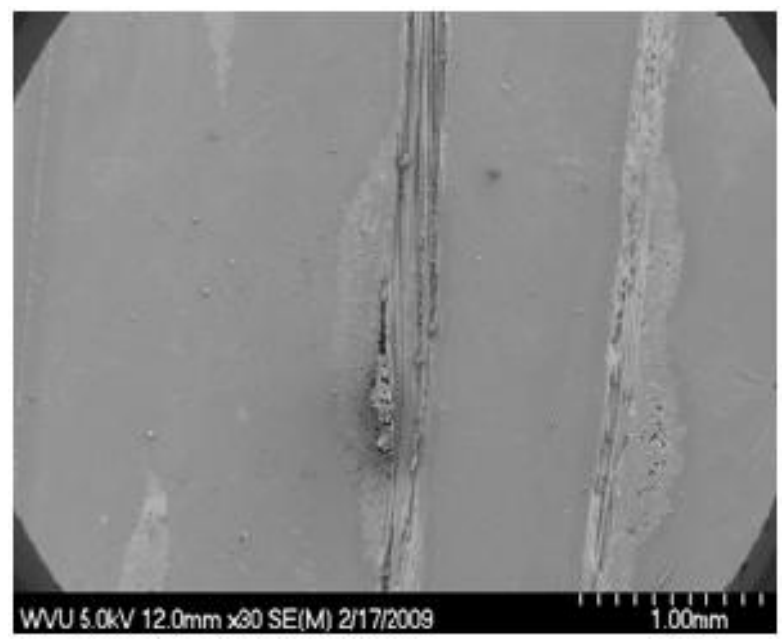

(a) Delamination at fabric matrix interface and accumulation of leached products

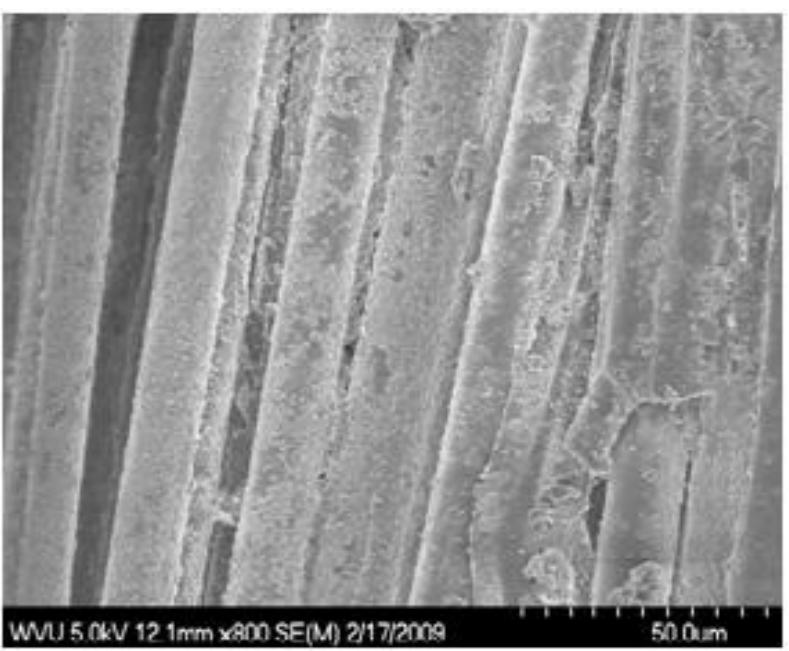

(b) Accumulation of leached products

Figure 8. 9 SEM sample aged for 4 month salt solution environment chamber (Transverse Direction)

\subsubsection{SEM of specimens in salt solution (eight months)}

Thermoplastic specimens aged in salt solution with freeze-thaw conditioning for eight months were inspected under SEM. Matrix cracking at the polymer surface edge and delaminations at the fiber matrix interface was noted (Figure 8.10 (b)) for salt solution under freeze-thaw conditioning of specimens for eight months. The absorbed solution concentration in FRP composites changes till they reach equilibrium. Non uniform moisture absorption through exposed fabric and voids at fabric-matrix interface was noted during moisture absorption test in this research. This might cause residual stresses which might cause the formation of microcracks particularly during transient situation, and might further reduce the strength of composites (Lee and Peppas, 1993). 


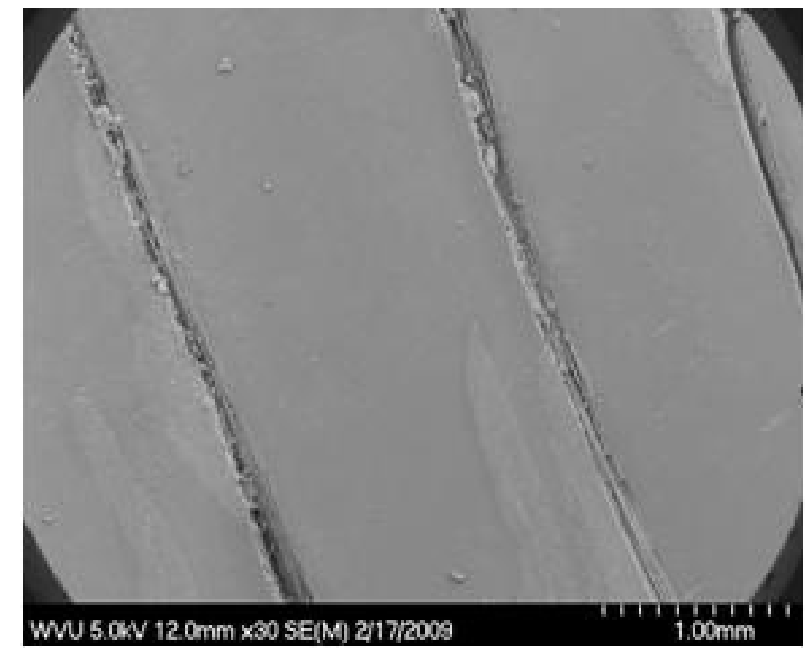

(a) Delamination at fabric matrix interface

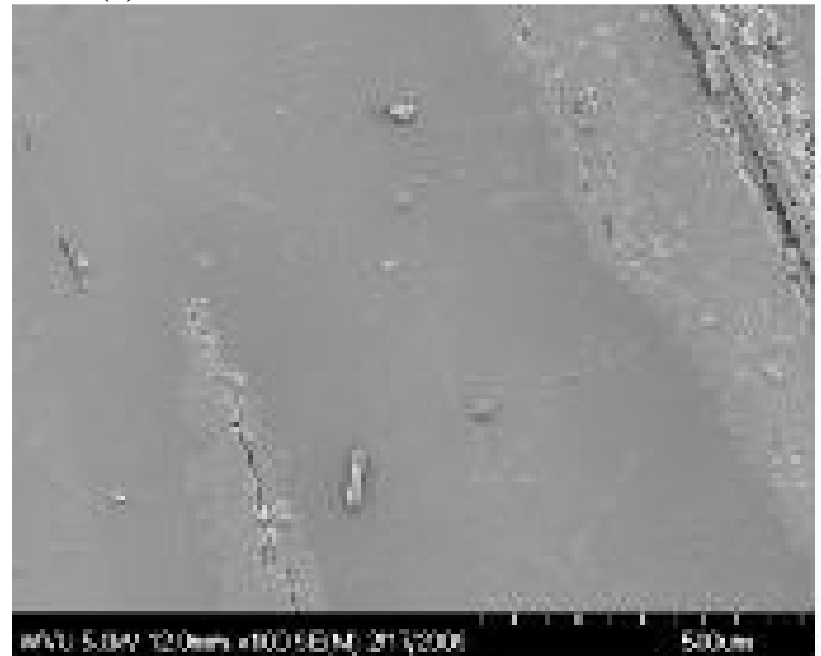

(c) Crack formation at fabric matrix interface

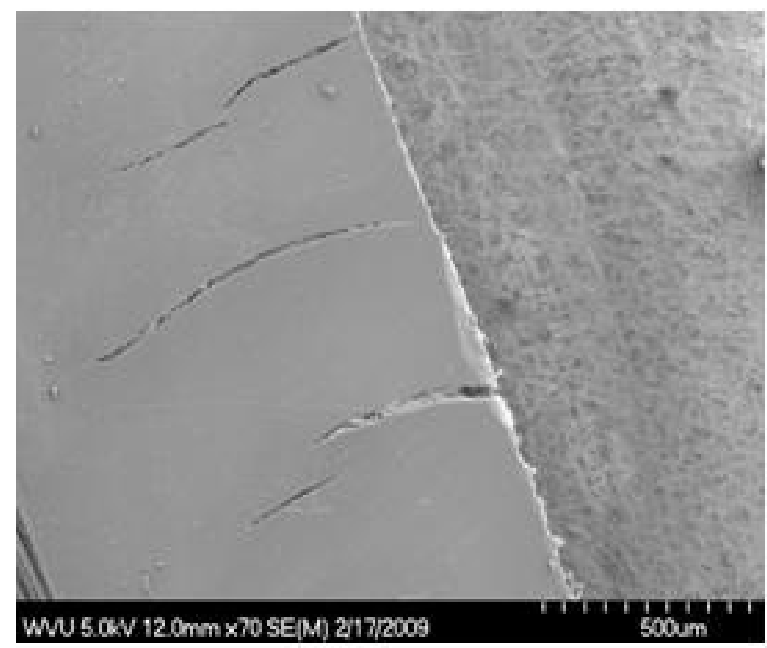

(b) Cracks on the matrix surface

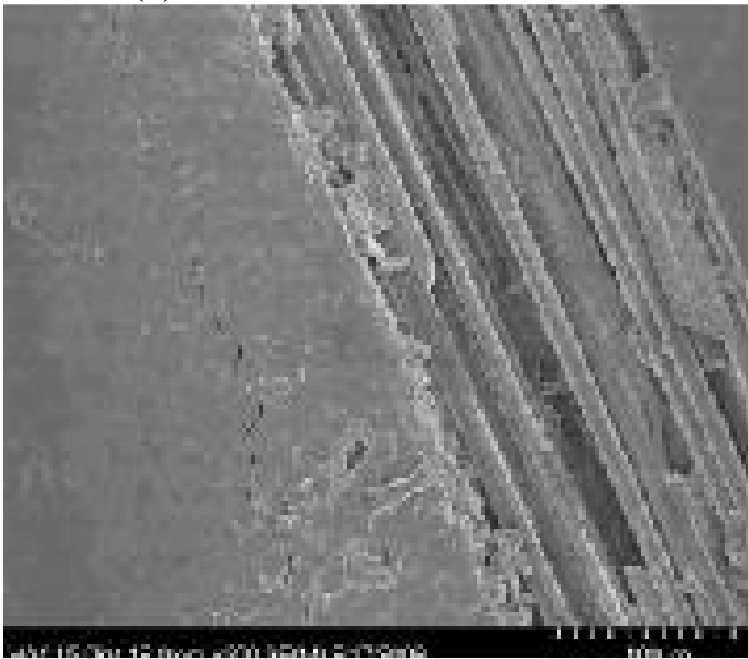

(d) Delamination, crack at fabric matrix interface and deposition of leached materials

Figure 8. 10 SEM sample aged for 8 month salt solution environmental chamber (Transverse Direction)

Matrix cracking of FRP (Figure 8.10 (b)) aged in salt solution and elevated under freeze-thaw variation was noted in this research, where freezing temperature exposure can lead to matrix hardening, matrix swelling/drying matrix cracking due to formation and expansion of salt deposits and fiber matrix bond deterioration (Karbhari et al., 2003). In this research, additional widening of delaminations at fabric matrix interface was also noted for specimen in salt solution at freeze-thaw for eight months (Figures 8.10 (a), (c) and (d)).

The development of alkaline resistant glass fibers in FRPs were introduced by several research group and industries for improved resistance to alkalinity. Proper selection of resins that are 
alkaline resistant in addition to glass fabric is also important, which can increase the durability properties of the GFRPs. Authors Shah et al., (1988) revealed that the amount of loss in glass elements were low in zirconsilicate (which are alkaline resistant) when compared with borosilicate (which are E glass fibers). Alkaline aging of borosilicate glass fabric occurred mainly by disruption of silicon bonds from hydroxyl ions.

Gupta et al. (1985) have evaluated that for higher temperature, the crosslink density governs the mechanical properties, and high crosslink density provides higher strength, modulus and elongation. At lower temperature, the low strain properties such as modulus and yield point are ruled by free volume and intermolecular packing. Authors also reported that the chemical structure, molecular architecture, free volume and crosslink density mainly govern the higher strain properties like tensile strength, elongation-to-break and toughness. For thermoplastics FRPs additional studies such as chemical structure and molecular architecture and atomic link density variation effects due to aging are suggested.

Authors Gotou et al. (2005) have reported the use of FT-IR and found the vanishing ester bonds in an FRP composite after 30\% NaOH exposure. Similarly for the FRP composites FT-IR and Xray element studies are suggested to observe the aging solution penetration into matrix for FRP thermoplastics.

\subsection{Durability Reduction Factor}

Reduction factors observed in this study under alkaline or salt solution exposure with room temperature or under freeze-thaw conditions indicate a reduction ranging between $66 \%$ to $75 \%$ for tension and $43 \%$ to $52 \%$ for bending over duration of 12 months. ACI 440 suggested a reduction factor of 0.7 to 0.8 (i.e., reduction of $30 \%$ and $20 \%$ ) for GFRP. Reductions noted in our case are higher than the suggested ACI values, which is mainly applicable to GFRPs with 
thermoset resins. Hence, additional considerations and research are necessary for specifying reductions to GFRPs with thermoplastic resins. 


\section{THERMOPLASTIC THERMOSET SANDWICH SPECIMENS}

\subsection{Background}

Thermoplastic (TP)-thermoset (TS) sandwich composites were manufactured with an objective to evaluate their composite behavior and application potential to some of the structural products previously developed at CFC-WVU laboratory. Manufacturing details of TP/TS sandwich specimens are provided in Appendix B of this report. Thermoplastic plates were manufactured using compression molding process. Sandwiching operation of TP with TS was carried out using hand pay-up method.

Need for TP and TS Sandwich Specimens: By developing TP/TS sandwich specimens, the mechanical properties can be optimized and structural applications can be increased by combining thermoset and thermoplastics to minimize the costs. Thermoset and thermoplastic combinations, potentially, is governed by thermo-mechanical properties (e.g., thermal coefficient and chemical compatibility). Previously, recycled ABS polymer was used to manufacture offset blocks offsetting highway guard rails from posts. Currently, rail road cross ties are manufactured using wood core and thermoplastic polymer shell with GFRP fabrics at CFC-WVU. This evaluation of thermoplastic-thermoset sandwich composites will help us understand the structural feasibility/cost benefits and developing offset block and RR ties by combining thermoplastic recycled FRP core or shell with thermoset shell material. This concept can increase the mechanical and durability performance, and applications. During manufacturing of FRP (thermoset) bridge deck using vacuum bagging technique (at CFC-WVU laboratory during 2008), initially, structural card board tubes were wrapped using dry glass fabric and held together before the resin infusion process. Absorption of vinyl ester resin by card board tubes, buckling of card board flanges and webs, and bent corners were noted in bridge decks manufactured using 
card board tubes. These problems can be reduced by utilizing ABS polymer core which has superior mechanical and durability properties and also acts as a structural member.

Details of TP/TS Sandwich Specimens: In order to evaluate the performance of thermoplasticthermoset composite combination, the sandwich plates were manufactured and coupon level specimens were machined to evaluate in tension and bending. Preliminary mold was machined to manufacture a TP/TS FRP sandwich plate in order to have equal amounts of thermoplastic and thermoset component, which in fact resulted in poor quality FRP with large air voids, uneven fabric and unsatisfactory edges and surface texture. The thermoplastic plates were manufactured using compression molding process. Later, thermoset/thermoplastic sandwich plates manufacturing method was modified to hand layup method. However, a 1/4" plate was manufactured using compression molding process initially and a vinyl-ester wet layer of glass fabric was over laid on thermoplastic plates using hand layup method. Required TP/TS plates were manufactured such that their interface between TS and TP were either smooth (no surface roughening-NSR) or roughened (surface roughening - SR). Thermoplastic surface was considered for roughening. The roughening of thermoplastic plate was achieved using a DeWALT Heavy-Duty 7"/ 9" large angle sander. In this research, altogether six combinations of thermoplastic and thermoset sandwich composite plates (Figure 9.1) were manufactured and evaluated in tension and bending:

i. Thermoplastic/thermoset/thermoplastic plate (TP/TS/TP) (roughened)

ii. Thermoplastic/thermoset/thermoplastic plate (TP/TS/TP) (un-roughened)

iii. Thermoset/thermoplastic/thermoset plate (TS/TP/TS) (roughened)

iv. Thermoset/thermoplastic/thermoset plate (TS/TP/TS) (un-roughened) 
v. Thermoset/thermoplastic plate (TP/TS) (roughened)

vi. Thermoset/thermoplastic plate (TP/TS) (un-roughened)
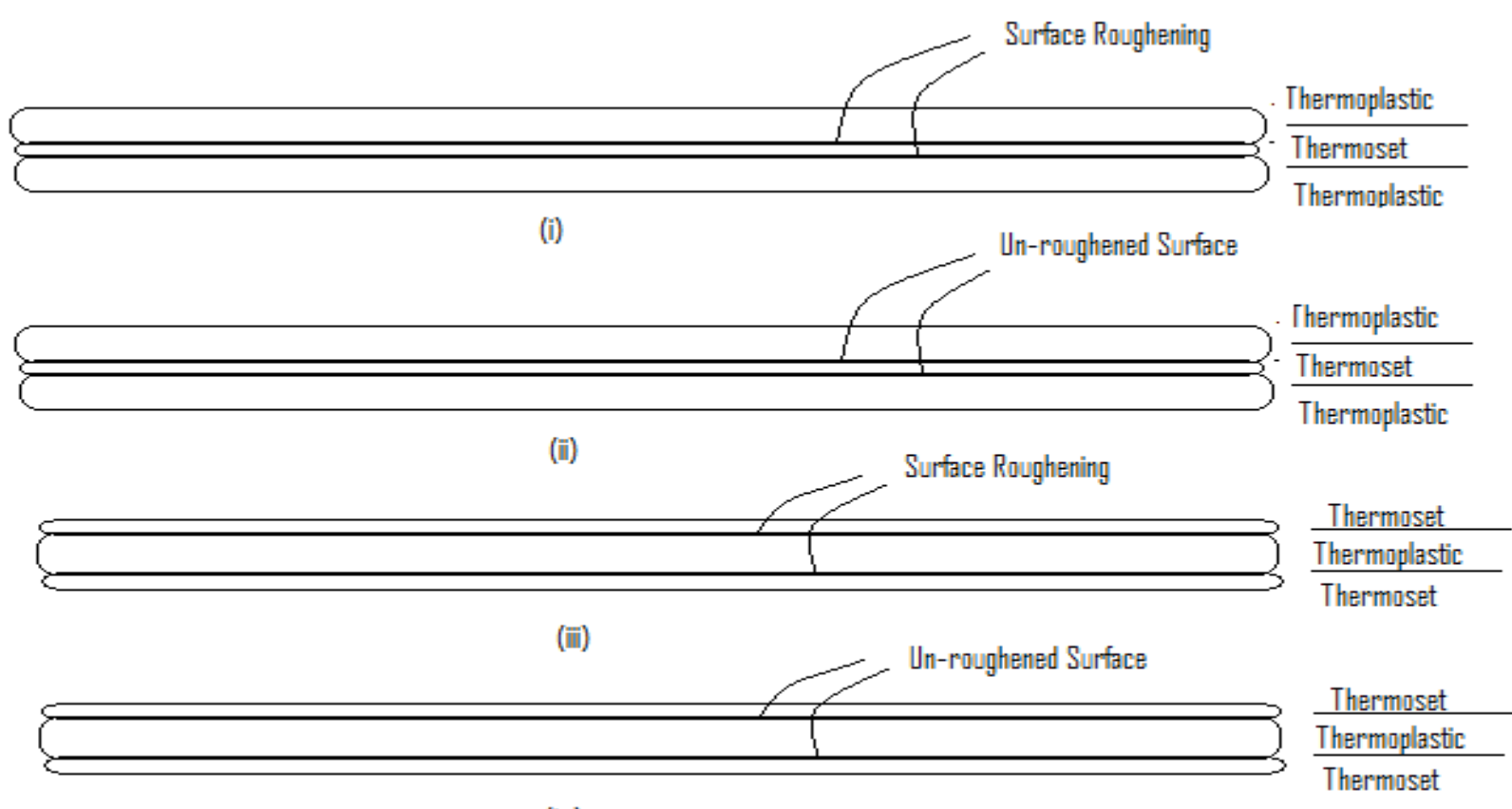

(iv)

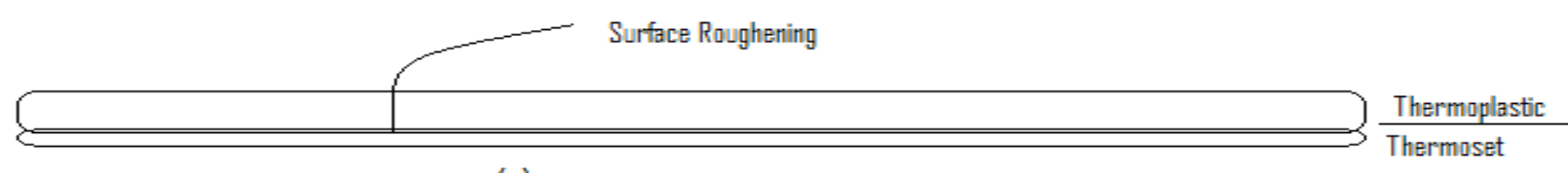

(v)

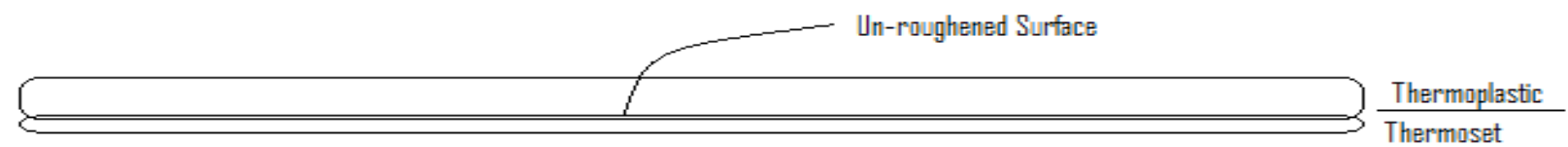

(vi)

Figure 9. 1 Six types of thermoplastic and thermoset composite plates

The manufacturing of six types of thermoplastic/thermoset sandwich composite plates was carried out using hand lay-up method and is reported in Appendix B of this report. 


\subsection{Tension Test Results}

Tension test results of thermoplastic (TP)/thermoset (TS) sandwich specimens with and without glass fabric reinforcement are reported in Table 9.1. The tensile strength and modulus (strain gage data) of specimens were evaluated through mechanical testing. The tension test samples were taken to failure.

Note: Average coupon dimensions of thermoset (with fabric) samples were 0.07" x 1 " and without fabric were 0.09 " x 1". Average dimensions of thermoplastics coupon specimens were 0.75 " $\mathrm{x} 0.25$ " at the gage length and overall length of samples was 10 ".

Table 9. 1 Vinyl ester and ABS tension test result

\begin{tabular}{|c|c|c|c|c|c|c|c|c|}
\hline $\begin{array}{c}\text { Tension } \\
\text { Test }\end{array}$ & $\begin{array}{c}\begin{array}{c}\text { No of } \\
\text { Layers } \\
\text { (fvf) }\end{array} \\
\end{array}$ & $\begin{array}{c}\text { Specimen } \\
\#\end{array}$ & $\begin{array}{l}\text { Avg. } \\
\text { Area }\end{array}$ & $\begin{array}{l}\text { Max. } \\
\text { Load }\end{array}$ & Strength & $\begin{array}{c}\text { Avg } \\
\text { strength }\end{array}$ & $\begin{array}{c}\% \\
\text { Diff }\end{array}$ & $\begin{array}{l}\text { Std } \\
\text { Dev }\end{array}$ \\
\hline & & & sq.in. & lbs. & psi. & psi. & & psi. \\
\hline \multirow{5}{*}{$\begin{array}{c}\text { Plain } \\
\text { Vinyl-ester } \\
\text { (TS) }\end{array}$} & \multirow{5}{*}{$\begin{array}{c}\mathbf{0} \\
(0 \%)\end{array}$} & 1 & 0.09 & 419 & 4651. & \multirow{5}{*}{4676} & & \multirow{5}{*}{141} \\
\hline & & 2 & 0.093 & 450 & 4828.0 & & & \\
\hline & & 3 & 0.087 & 324 & $3706.3^{*}$ & & & \\
\hline & & 4 & 0.084 & 301 & $3571.9^{*}$ & & & \\
\hline & & $5, \mathrm{~S}$ & 0.076 & 346 & 4548.9 & & & \\
\hline \multirow{5}{*}{$\begin{array}{l}\text { Vinyl-ester } \\
\text { (TS) }\end{array}$} & \multirow{5}{*}{$\begin{array}{c}2 \\
(21 \%)\end{array}$} & $22, S$ & 0.073 & 1317 & 18042.8 & \multirow{5}{*}{19864} & \multirow{5}{*}{$324.8 \%$} & \multirow{5}{*}{1584} \\
\hline & & 23 & 0.069 & 1313 & 19030.0 & & & \\
\hline & & 24 & 0.069 & 1538 & 22300.7 & & & \\
\hline & & 25 & 0.070 & 1385 & 19795.0 & & & \\
\hline & & 26 & 0.062 & 1250 & 20152.9 & & & \\
\hline \multirow{5}{*}{$\begin{array}{c}\text { Plain ABS } \\
\text { (TP) }\end{array}$} & \multirow{5}{*}{$\begin{array}{c}0 \\
(0 \%)\end{array}$} & 6 & 0.183 & 827 & 4497.1 & \multirow{5}{*}{4569} & & \multirow{5}{*}{321} \\
\hline & & 7 & 0.182 & 879.5 & 4806.3 & & & \\
\hline & & 8 & 0.181 & 883.6 & 4859.6 & & & \\
\hline & & 9 & 0.185 & 856.5 & 4627.8 & & & \\
\hline & & $10, \mathrm{~S}$ & 0.189 & 767.9 & 4055.9 & & & \\
\hline \multirow{4}{*}{$\begin{array}{l}\text { ABS } \\
\text { (TP) }\end{array}$} & \multirow{4}{*}{$\begin{array}{c}2 \\
(6 \%)\end{array}$} & 17 & 0.194 & 1290 & 6646.8 & \multirow{4}{*}{6709} & \multirow{4}{*}{$47 \%$} & \multirow{4}{*}{414} \\
\hline & & 18 & 0.193 & 1205 & 6242.9 & & & \\
\hline & & 19 & 0.192 & 1392.2 & 7251.0 & & & \\
\hline & & $20, S$ & 0.196 & 1313 & 6699.0 & & & \\
\hline
\end{tabular}

*values are not considered for averaging due to improper grip failure, fvf - fiber volume fraction 
Note: TP - thermoplastic, TS - thermoset, TP/TS/TP -thermoplastic/thermoset/thermoplastic, N/SR- No Surface Roughening SR- Surface Roughening.

The percentage strength increase for vinyl-ester specimens with 2 layers (21\% FVF) of glass fabric was $324.8 \%$ compared to non-fabric vinyl-ester specimens. The strength of ABS specimens with 2 fabric layers was $47 \%$ higher compared to non-fabric ABS specimens. The strength of Vinyl-ester with 2 layers of glass fabric was higher compared to ABS with fabric because of the higher fiber volume fraction for thermoset (vinyl-ester) specimens compared to thermoplastic (ABS) specimens and also presence of voids at fabric matrix interface in thermoplastic (ABS) specimens.

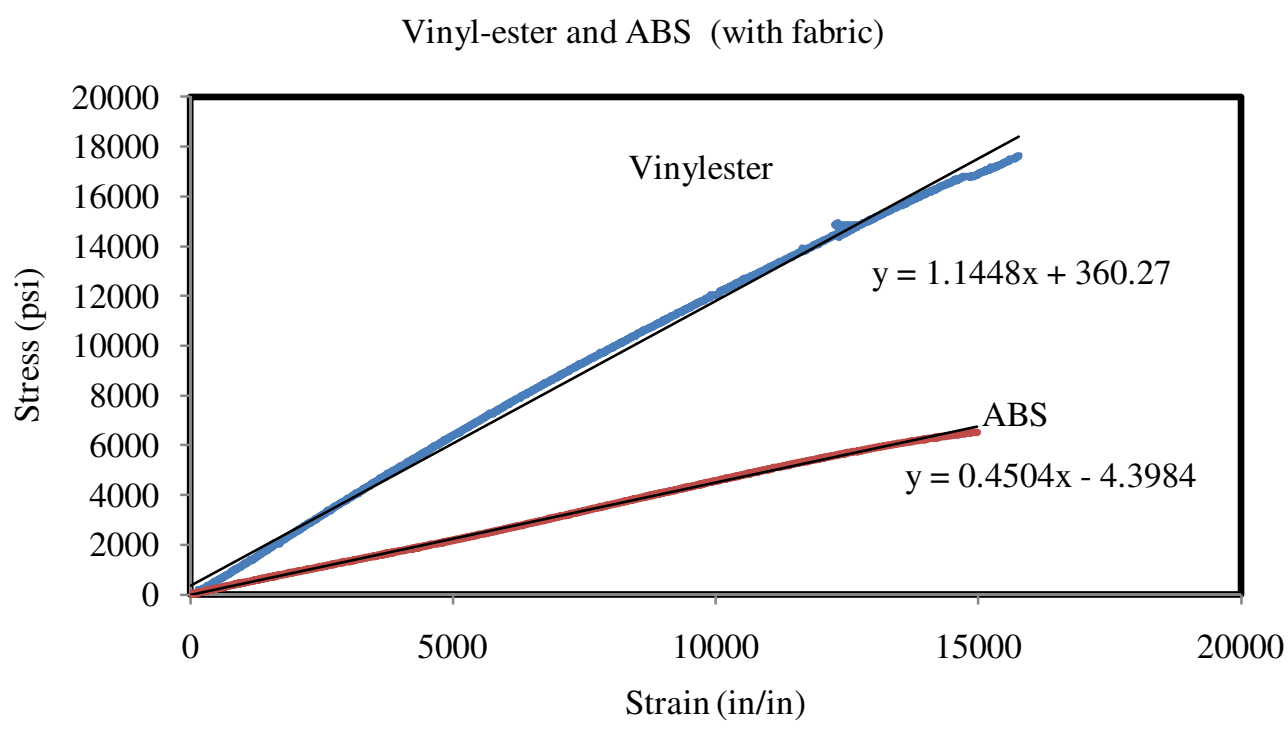

Figure 9. 2 Tensile stress-strain for vinyl ester and virgin ABS tension test specimen

The tensile modulus of vinyl-ester and ABS specimens with fabrics tested separated were evaluated to be $1.14 \times 10^{6} \mathrm{psi}$ and $0.45 \times 10^{6} \mathrm{psi}$, respectively (Figure 9.2). The tensile modulus for vinyl ester was $153.33 \%$ more than plain ABS specimen. Tensile strengths of vinyl-ester and ABS coupon specimens with two layers of fabrics were calculated to be 19864 psi and 6710 psi, respectively. 


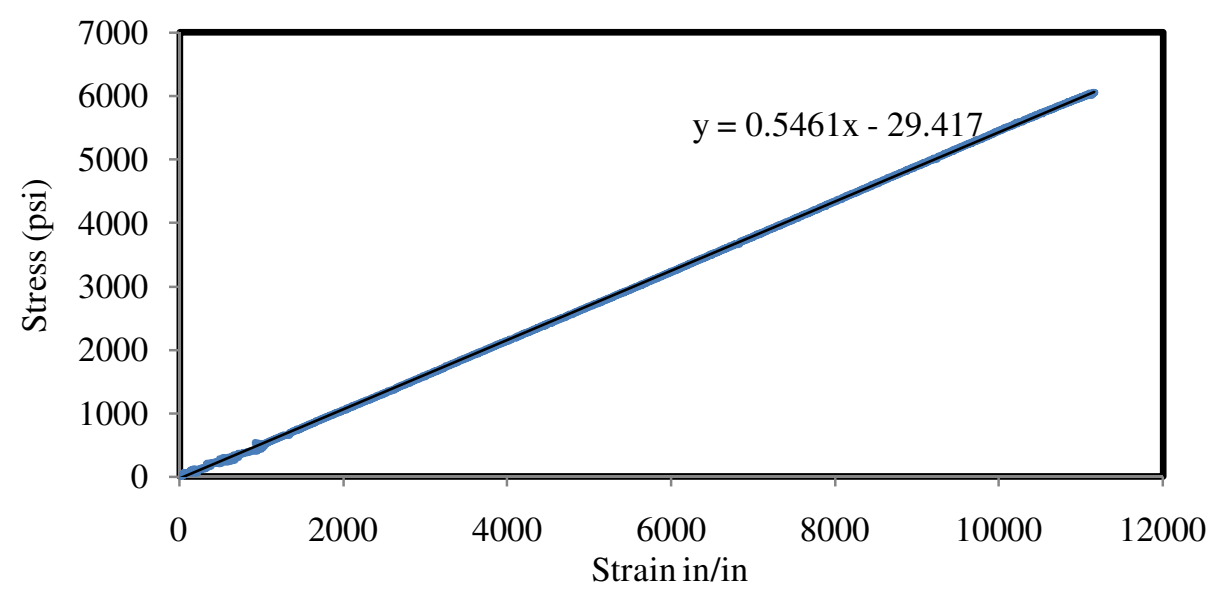

Figure 9. 3 Stress strain graph for TP/TS/TP roughened tension test specimen

TP/TS/TP No Roughening

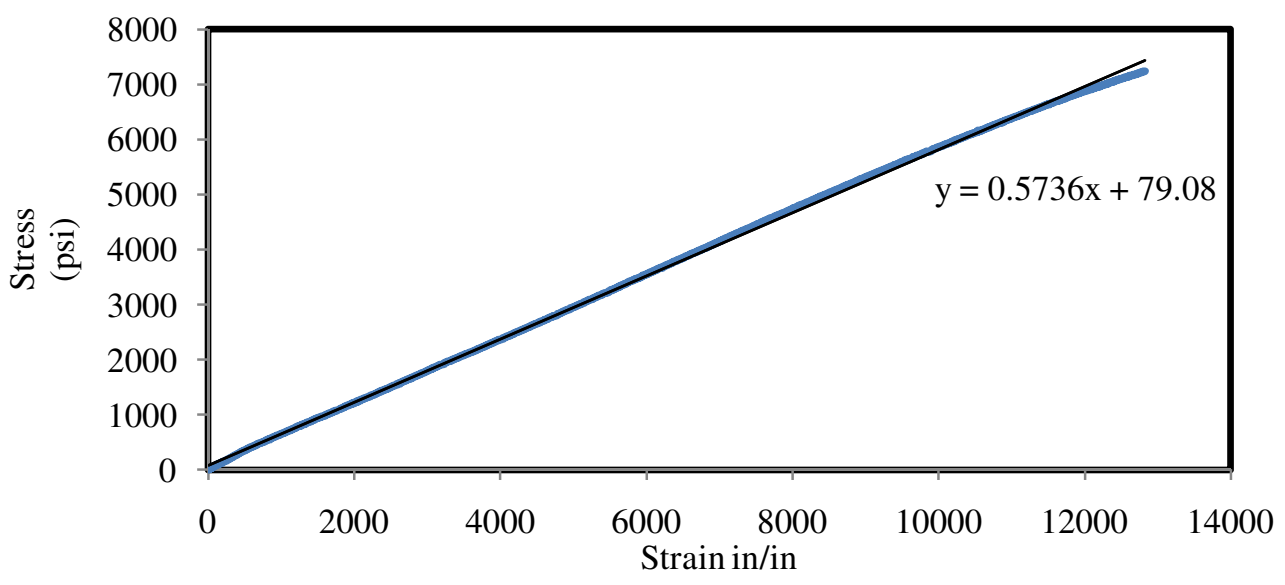

Figure 9. 4 Stress strain graph for TP/TS/TP roughened specimen

The modulus of elasticity of TP/TS/TP roughened and un-roughened specimens were evaluated to be $0.546 \times 10^{6} \mathrm{psi}$ and $0.573 \times 10^{6} \mathrm{psi}$, respectively (Figures 9.3 and 9.4 ). The average tensile strengths of un-roughened and roughened TP/TS/TP sandwich composite specimens were found to be 8470.6 psi and 8969.3 psi, respectively. The tensile strength of sandwich specimens with surface roughening was $6 \%$ higher than un-roughened specimens. Furthermore, the modulus of 
surface roughened TP/TS/TP specimen was $5 \%$ higher than un-roughened specimen. The failure of TP on the either side first and then yielding of TS at the center has been shown in Figures 9.5 (a), (b), (c) and (d).

Table 9. 2 Thermoplastic thermoset (TP/TS/TP) tension test result

\begin{tabular}{|c|c|c|c|c|c|c|c|c|}
\hline $\begin{array}{l}\text { Composite } \\
\text { sandwich }\end{array}$ & $\begin{array}{c}\text { Specimen } \\
\#\end{array}$ & $\begin{array}{l}\text { Avg. } \\
\text { area }\end{array}$ & Strength & $\begin{array}{l}\text { Avg. } \\
\text { strength }\end{array}$ & Mod. & $\begin{array}{l}\text { Std. } \\
\text { dev. }\end{array}$ & $\begin{array}{c}\% \\
\text { increase } \\
\text { in } \\
\text { strength } \\
\end{array}$ & $\begin{array}{c}\% \\
\text { increase } \\
\text { in } \\
\text { modulus }\end{array}$ \\
\hline & & sq.in. & (psi) & (psi) & msi. & psi. & & \\
\hline \multirow{5}{*}{$\begin{array}{c}\text { TP/TS/TP } \\
\text { N/SR }\end{array}$} & 1 & 0.444 & 8533.3 & \multirow{5}{*}{8470} & \multirow{5}{*}{0.573} & \multirow{5}{*}{425} & \multirow{5}{*}{--} & \multirow{5}{*}{--} \\
\hline & 2 & 0.462 & 7837.3 & & & & & \\
\hline & 3 & 0.457 & 8914.4 & & & & & \\
\hline & 4 & 0.428 & 8771.5 & & & & & \\
\hline & $5, \mathrm{~S}$ & 0.427 & 8296.4 & & & & & \\
\hline \multirow{5}{*}{$\begin{array}{c}\text { TP/TS/TP } \\
\text { SR }\end{array}$} & 6 & 0.416 & 9217.0 & \multirow{5}{*}{8969} & \multirow{5}{*}{0.546} & \multirow{5}{*}{433} & \multirow{5}{*}{$6 \%$} & \multirow{5}{*}{$5 \%$} \\
\hline & 7 & 0.408 & 9569.4 & & & & & \\
\hline & 8 & 0.422 & 8532.5 & & & & & \\
\hline & 9 & 0.431 & 8931.1 & & & & & \\
\hline & $10, S$ & 0.420 & 8596.3 & & & & & \\
\hline
\end{tabular}

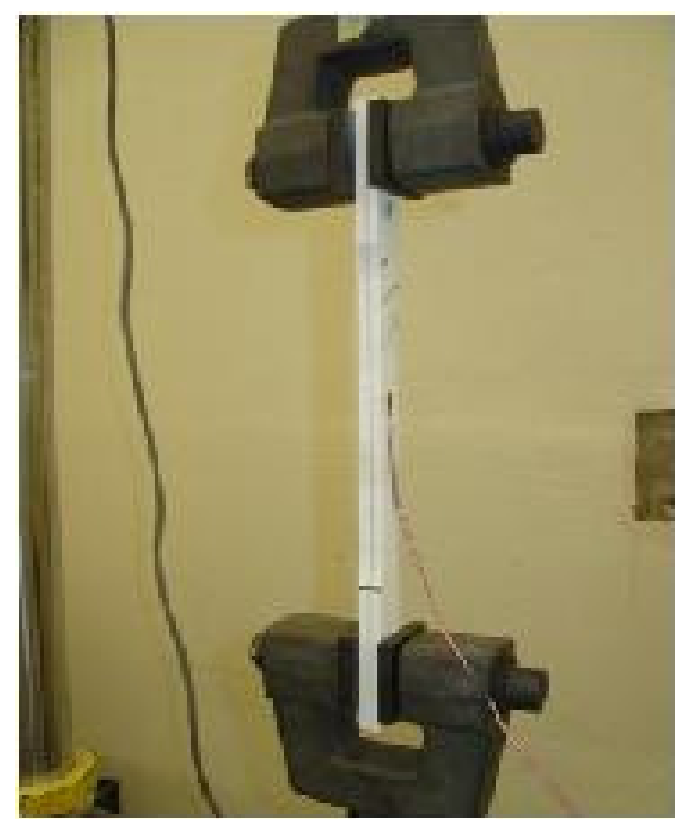

(a) TP/TS/TP tension test setup

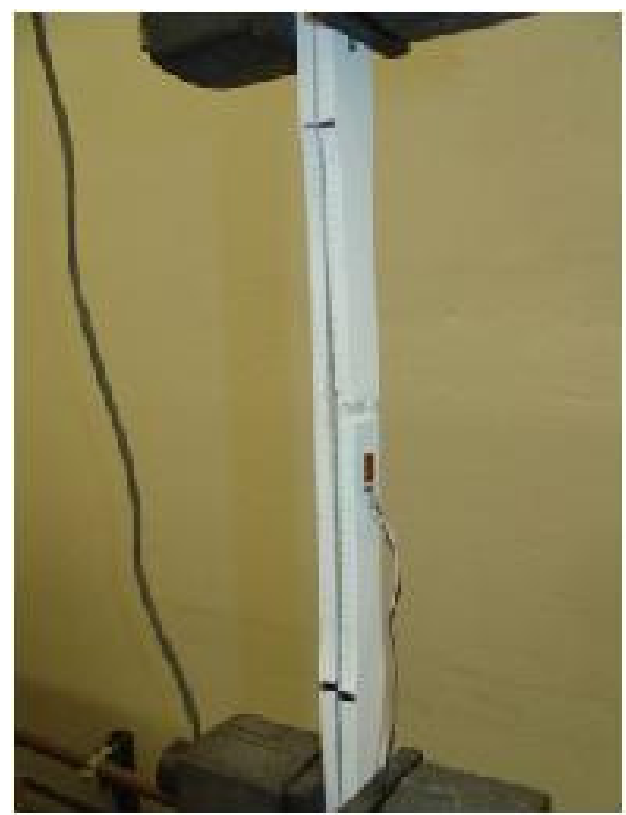

(b) TP/TS/TP initial rupture in outer TP 


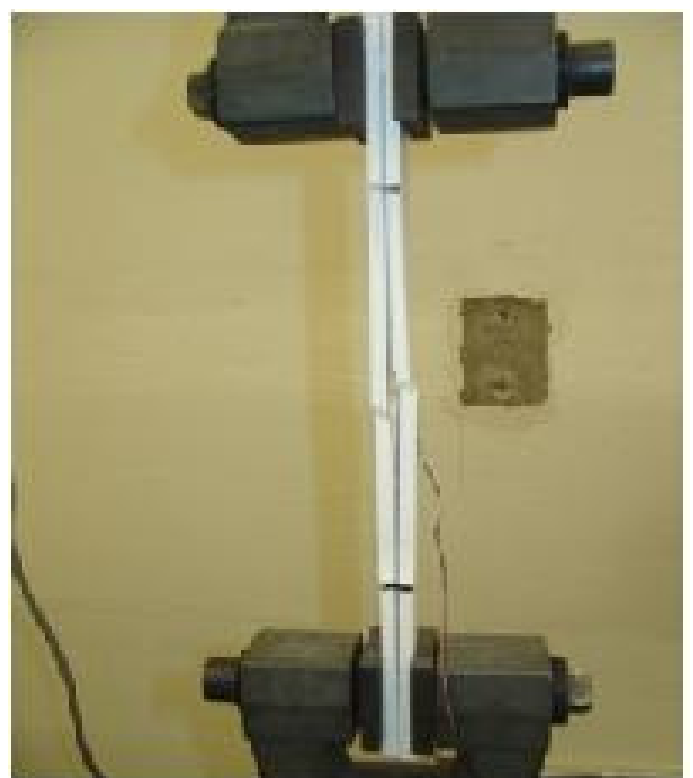

(c) TP/TS/TP rupture of TP on either side

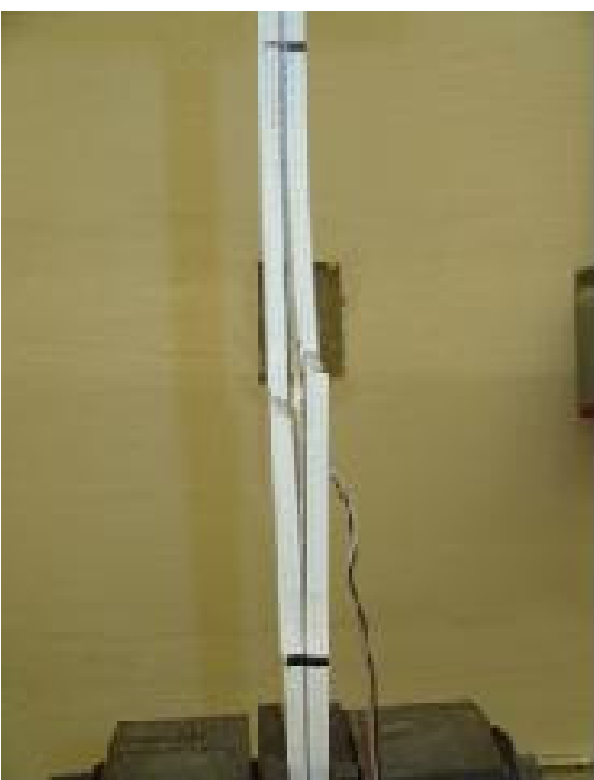

(d) TP/TS/TP rupturing of TS

Figure 9. 5 Thermoplastic/Thermoset/Thermoplastic tension test

Average tensile stress of TP/TS roughened and un-roughened specimens was evaluated to be 9174 psi and 9088 psi, respectively (Table 9.3).

Table 9. 3 Thermoplastic thermoset (TP/TS) tension test results

\begin{tabular}{|c|c|c|c|c|c|c|}
\hline $\begin{array}{c}\text { Specimen } \\
\text { type }\end{array}$ & $\begin{array}{c}\text { Specimen } \\
\#\end{array}$ & $\begin{array}{c}\text { Average } \\
\text { area }\end{array}$ & Stress & Average & $\begin{array}{c}\text { Std. } \\
\text { Dev. }\end{array}$ & $\begin{array}{c}\% \\
\text { increase } \\
\text { in } \\
\text { strength }\end{array}$ \\
\hline & & sq.in. & (psi) & (psi) & psi. & \\
\hline \multirow{2}{*}{$\begin{array}{c}\text { TP/TS } \\
\text { N/SR }\end{array}$} & 21 & 0.161 & 9088 & 9088 & & \\
\hline & 11 & 0.159 & 9031 & & & \\
\hline \multirow{2}{*}{$\begin{array}{c}\text { TP/TS } \\
\text { SR }\end{array}$} & 12 & 0.168 & $* 7658$ & \multirow{2}{*}{9174} & \multirow{2}{*}{169} & $5.88 \%$ \\
\cline { 2 - 4 } & 13 & 0.160 & 9362 & & & \\
\cline { 2 - 5 } & $14, \mathrm{~S}$ & 0.160 & 9128 & & & \\
\hline
\end{tabular}

*values are not considered for averaging due to improper grip failure

Strain gages were installed on either side of TP/TS (roughened) on tension test coupon specimen. The tensile modulus was evaluated to be almost identical on both components, i.e., $0.571 \times 10^{6} \mathrm{psi}$ for TS and $0.576 \times 10^{6} \mathrm{psi}$ for TP (Figure 9.6). 
TP/TS

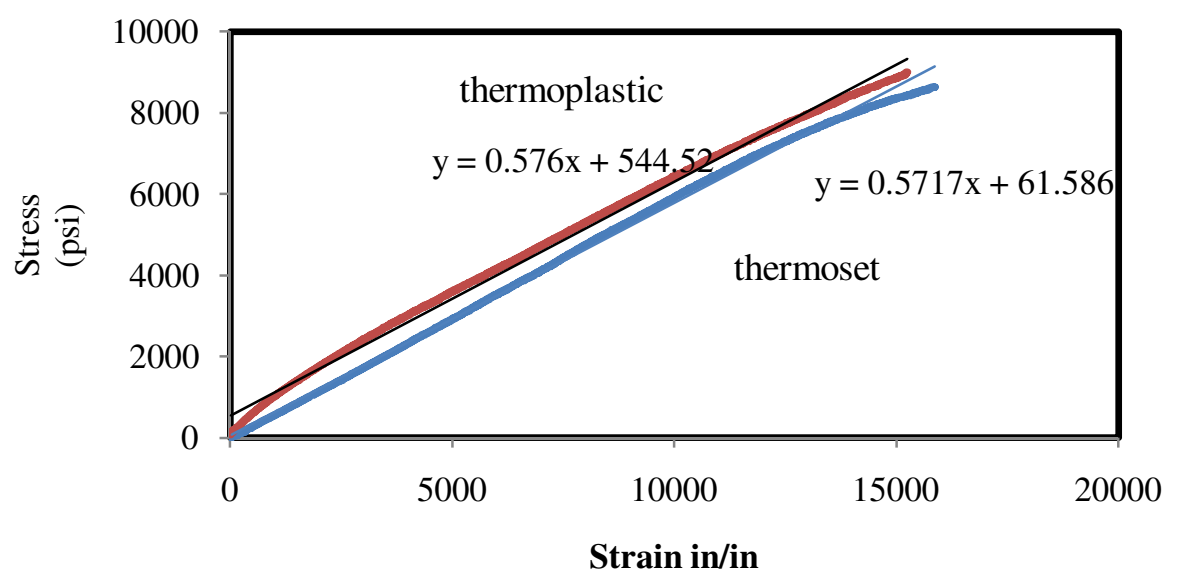

Figure 9. 6 Stress strain graph for TS/TP roughened tension test specimen

The maximum recorded strains for thermoset and thermoplastic specimens were 15869 and 15327 microstrains, respectively. Modulus, strain and strength of thermoplastic and thermoset were almost equal, which might be due to roughening at the interface which implies proper stress transfer at the TS/TP interface under tension.

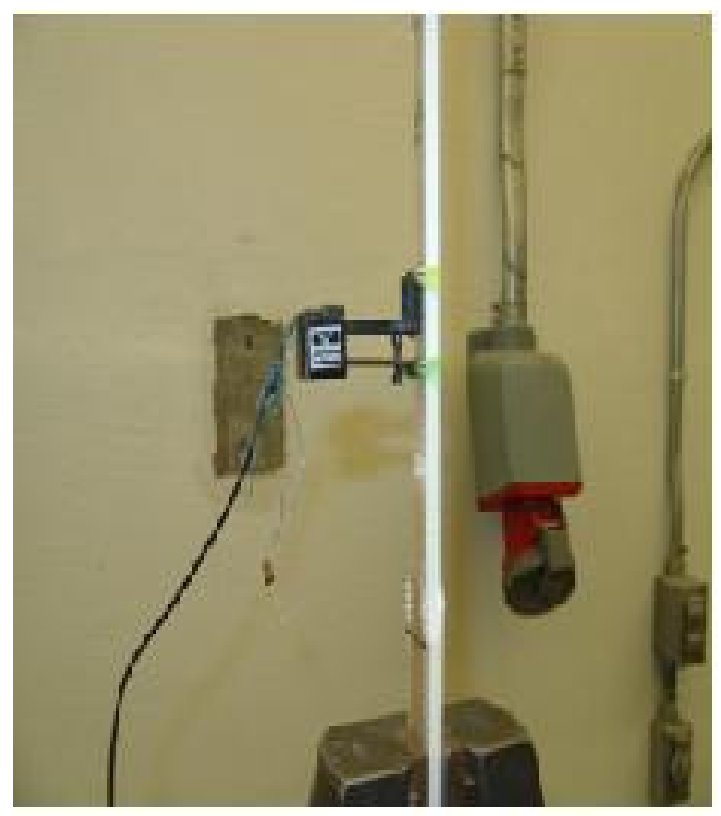

(a) Rupturing of thermoset before thermoplastic

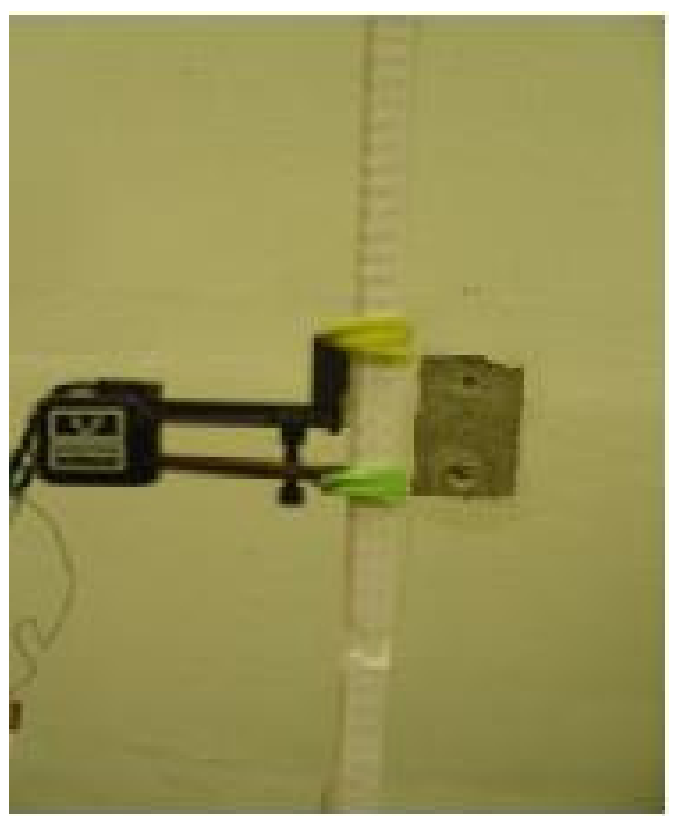

(b) Followed by rupturing of thermoplastic

Figure 9. 7 TP/TS Tension Test

The strength of roughened and un-roughened TP/TS coupon specimens was not compared because only one specimen survived the machine's vibration without delamination/separation 
during cutting from un-roughened TP/TS group. Delamination was noted for all the specimens during testing before failure, which may be attributed to difference in strain between TS and TP. In the case of TP/TS roughened specimen, thermoset (VE) failed first followed by thermoplastic (ABS), the reason being non-uniform thickness of TS and TP, and the c.g. of load would be slightly on the TP side, because TP is thicker than TS (Figure 9.7). TS would be experiencing direct tensile stresses in addition to bending moment, which makes the TS to fail first even though it has higher failure stress than TP.

Table 9. 4 Thermoplastic thermoset (TS/TP/TS) tension test results

\begin{tabular}{|c|c|c|c|c|c|c|}
\hline $\begin{array}{c}\text { Specimen } \\
\text { type }\end{array}$ & Specimen & $\begin{array}{c}\text { Avg. } \\
\text { Area }\end{array}$ & $\begin{array}{c}\text { Max } \\
\text { load }\end{array}$ & Stress & Avg. & $\begin{array}{c}\text { Std } \\
\text { Dev }\end{array}$ \\
\hline \multirow{4}{*}{$\begin{array}{c}\text { TS/TP/TS } \\
\text { SR }\end{array}$} & Sq.in. & lbs. & psi. & psi. & psi. \\
\cline { 2 - 5 } & 15 & 0.191 & 2200 & 11467 & & \\
\cline { 2 - 5 } & 16, S & 0.192 & 2174 & 11274 & \multirow{2}{*}{11371} & 136 \\
\cline { 2 - 5 } & sample1 & 0.22 & 1958.5 & $* 8902$ & & \\
\hline
\end{tabular}

*not considered for averaging due to improper grip failure

The tension modulus of elasticity for TS/TP/TS roughened sandwich specimens from Figure 9.12 was evaluated to be $0.72 \times 10^{6}$ psi from strain data. The strength of TS/TP/TS specimen was noted to be highest in the group, which was $11.37 \mathrm{ksi}$ from Table 9.4. Similar type of specimens without surface roughening delaminated during machining operation due to poor bond at TS/TP interface. In case of TS/TP/TS during testing, rupture of specimen started with yielding of TS on either side first and then followed by yielding of TP in the middle (Figure 9.9 (a) and (b)). 
TS/TP/TS roughened

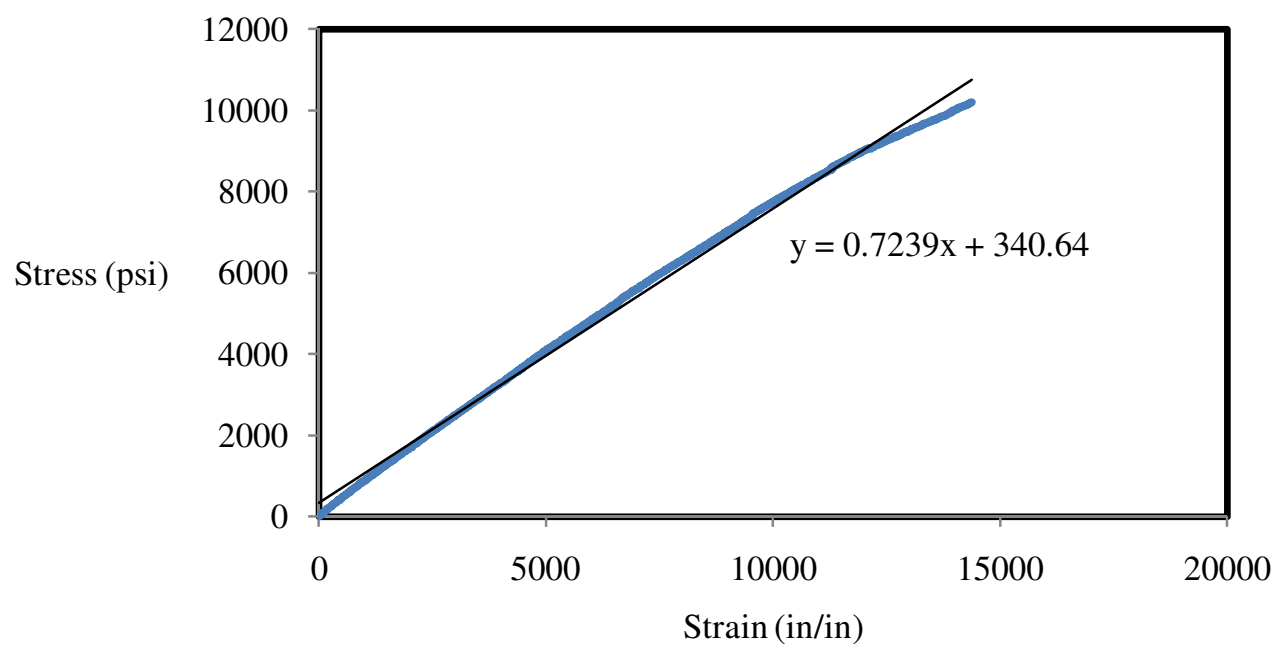

Figure 9. 8 Stress strain graph for TS/TP/TS roughened tension test specimen

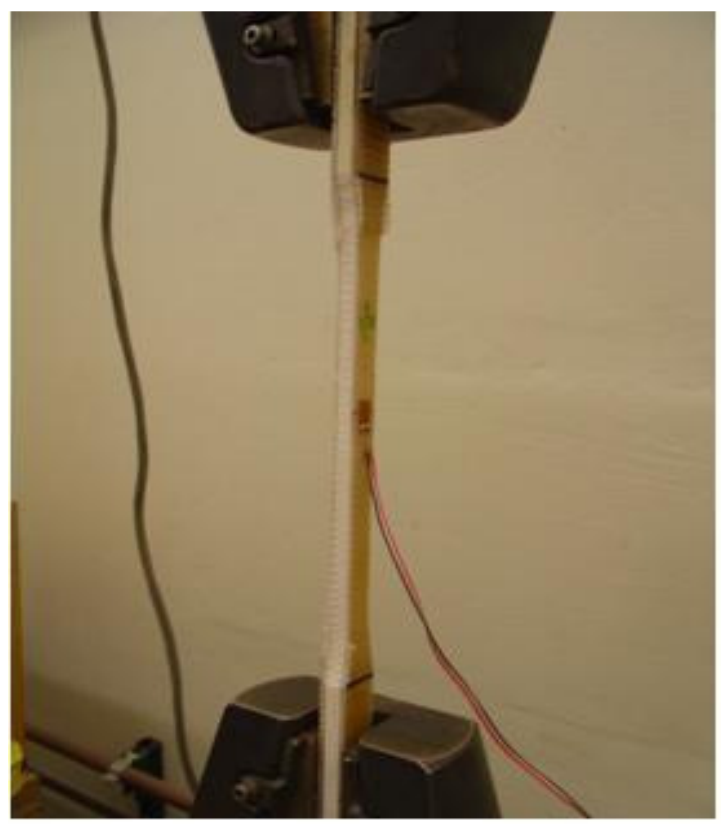

(a) TS/TP/TS tension test setup

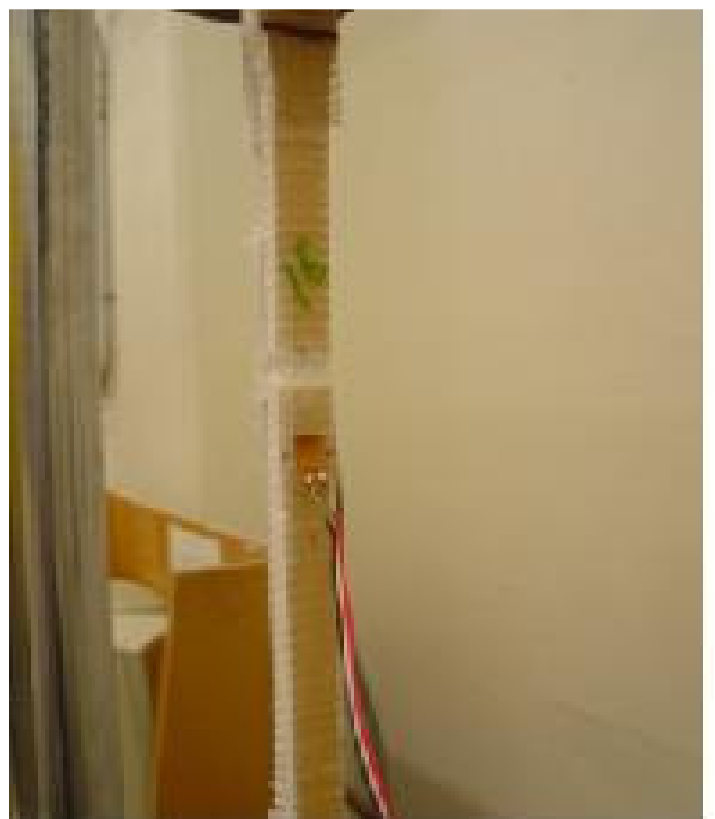

(b) TS/TP/TS rupture of specimen elongation Figure 9. 9 TS/TP/TS tension test 


\subsection{Bending Test Results}

The coupon specimens from TP/TS/TP plate were tested in bending as per ASTM D 790 03. The bending strengths of TP/TS/TP (Table 9.5) sandwich specimens were calculated to be 4164 psi and 6067 psi for un-roughened and roughened specimens, respectively.

Table 9. 5 Thermoplastic thermoset bending test results

\begin{tabular}{|c|c|c|c|c|c|c|}
\hline $\begin{array}{c}\text { Specimen } \\
\text { Type }\end{array}$ & Specimen & Avg. area & Stress & Avg. & $\begin{array}{c}\text { Std } \\
\text { Dev. }\end{array}$ & $\begin{array}{c}\text { \% } \\
\text { increase }\end{array}$ \\
\hline & $\#$ & sq. in. & psi. & psi. & psi. & \\
\hline \multirow{2}{*}{$\begin{array}{c}\text { TP/TS/TP } \\
\text { N/SR }\end{array}$} & 27 & 0.592 & 4115 & & & \\
\cline { 2 - 4 } & 28 & 0.600 & 3916 & \multirow{2}{*}{4164} & 275 & \\
\cline { 2 - 4 } & 29 & 0.584 & 4460 & & & \\
\hline \multirow{2}{*}{$\begin{array}{c}\text { TP/TS/TP } \\
\text { SR }\end{array}$} & 30 & 0.568 & 6833 & & & \\
\cline { 2 - 4 } & 31 & 0.561 & 5780 & \multirow{2}{*}{6067} & 670 & $45.70 \%$ \\
\cline { 2 - 4 } & 32 & 0.573 & 5588 & & & \\
\hline
\end{tabular}

Roughening of ABS plates to grip vinyl-ester was efficient for TP/TS/TP specimens, which improved the bending stresses by $45.7 \%$ when compared with TP/TS/TP un-roughened specimens. Surface roughening in bending test ensured the better stress transfer between TS and TP. Delamination was observed in every TP/TS, TP/TS/TP and TS/TP/TS coupon sandwich composites specimens tested in bending (Figures 9.10 (a), (b), (c) and (d)). Bending strength of TP/TS composite specimens tested with thermoplastic on bottom side was calculated to be 8064 psi. Bending strength increased by $12.7 \%$ when the TP/TS specimens were tested with vinyl-ester on the tension side with strength of 9092.3 psi (Table 9.6). 
Table 9. 6 Thermoplastic thermoset (TP/TS) bending test results

\begin{tabular}{|c|c|c|c|c|c|c|}
\hline Specimen & Specimen & Avg. area & $\begin{array}{l}\text { Max } \\
\text { load }\end{array}$ & Stress & Avg. & $\begin{array}{c}\% \\
\text { increase }\end{array}$ \\
\hline Type & \# & b x d & (lbs) & (psi) & (psi) & \\
\hline \multirow{3}{*}{$\begin{array}{c}\text { TS/TP (SR) } \\
\text { ABS } \\
\text { bottom } \\
\end{array}$} & 37 & 0.233 & 62 & 7531 & \multirow{3}{*}{8064} & \\
\hline & 38 & 0.239 & 69 & 7969 & & \\
\hline & 39 & 0.233 & 69 & 8692 & & \\
\hline \multirow{4}{*}{$\begin{array}{l}\text { TS/TP (SR) } \\
\text { VE bottom }\end{array}$} & 40 & 0.230 & 71 & 8980 & \multirow{4}{*}{9092} & \multirow{4}{*}{$12.70 \%$} \\
\hline & 41 & 0.224 & 62.69 & 8303 & & \\
\hline & 42 & 0.225 & 74.6 & 9763 & & \\
\hline & 43 & 0.232 & 74 & 9322 & & \\
\hline \multirow{4}{*}{$\begin{array}{c}\text { TS/TP/TS } \\
\text { SR }\end{array}$} & 44 & 0.277 & 116.75 & 10558 & \multirow{4}{*}{10354} & \multirow{4}{*}{$\begin{array}{c}13.88 \% \\
\text { (compared } \\
\text { to VE } \\
\text { bottom) }\end{array}$} \\
\hline & 45 & 0.280 & 108.89 & 9557 & & \\
\hline & 46 & 0.275 & 143.34 & 12722 & & \\
\hline & 47 & 0.280 & $\begin{array}{l}96.98 \\
\end{array}$ & 8580 & & \\
\hline
\end{tabular}

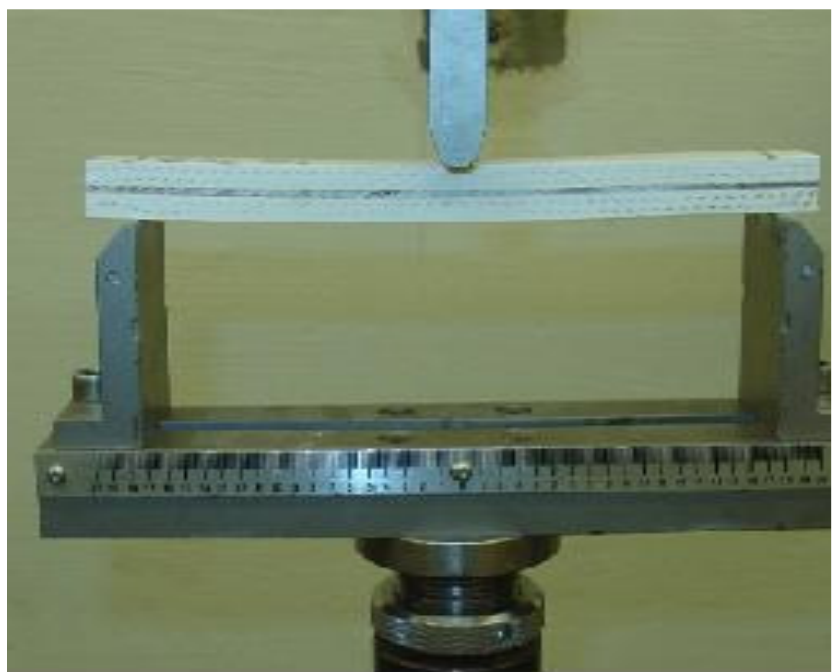

(a) Bending test setup

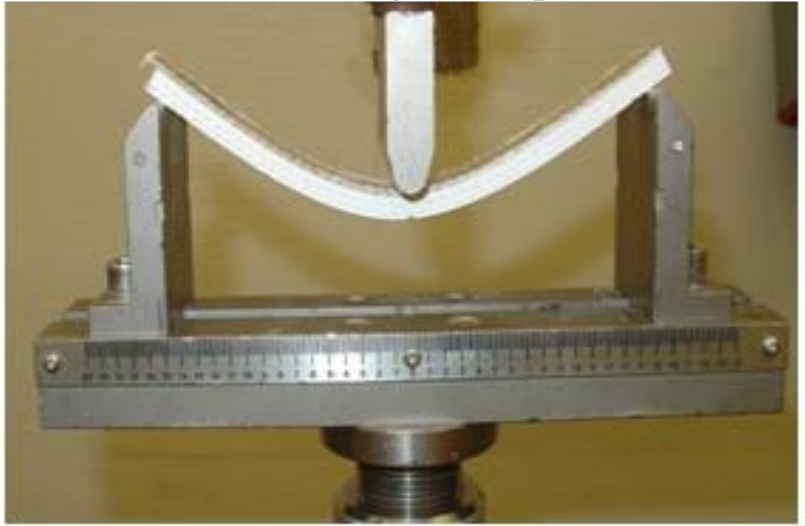

(c) Delamination of TP/TS with ABS in compression

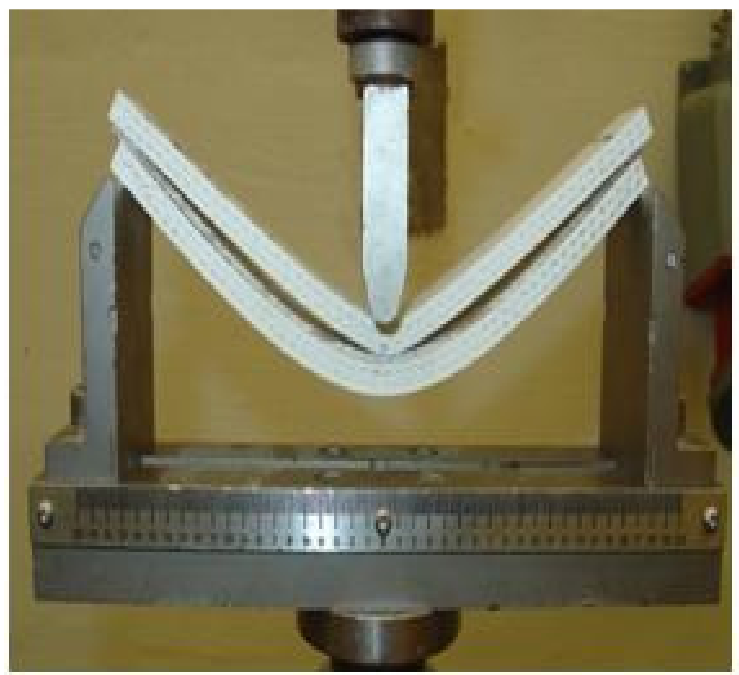

(b) Delamination of TP/TS/TP bending specimen

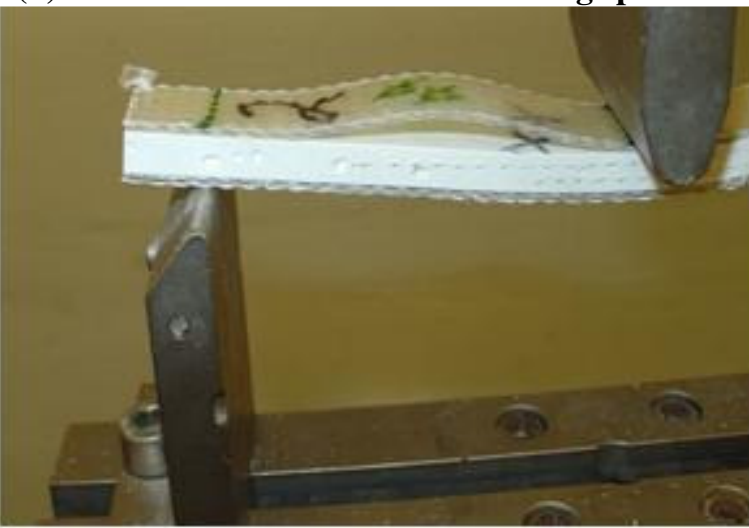

(d) Delamination of TS/TP/TS specimen

Figure 9. 10 Delamination of thermoplastic and thermoset sandwich composite 
Bending strength of TS/TP/TS composite specimens having vinyl-ester on either side of roughened ABS plate increased by $13.8 \%$ compared to those of coupon specimen with vinylester in tension zone. This might be due to better bending resistance offered by reinforced vinylester in tension and compression zone of TS/TP/TS beam.

\subsection{Bond Test}

In this research, six different combinations of thermoplastic (TP) and thermoset (TS) sandwich composite specimens were manufactured with and without TP surface roughening at the TS/TP interface. Delamination at TS/TP interface was noted for every coupon specimen tested in tension and bending. Amongst roughened and un-roughened thermoplastic surface, un-roughened performance was poor. To evaluate the bond strength between thermoplastic and thermoset due to roughening of surface, bond tests were carried out. The manufacturing procedure of bond test specimens has been reported in Appendix B of this report.

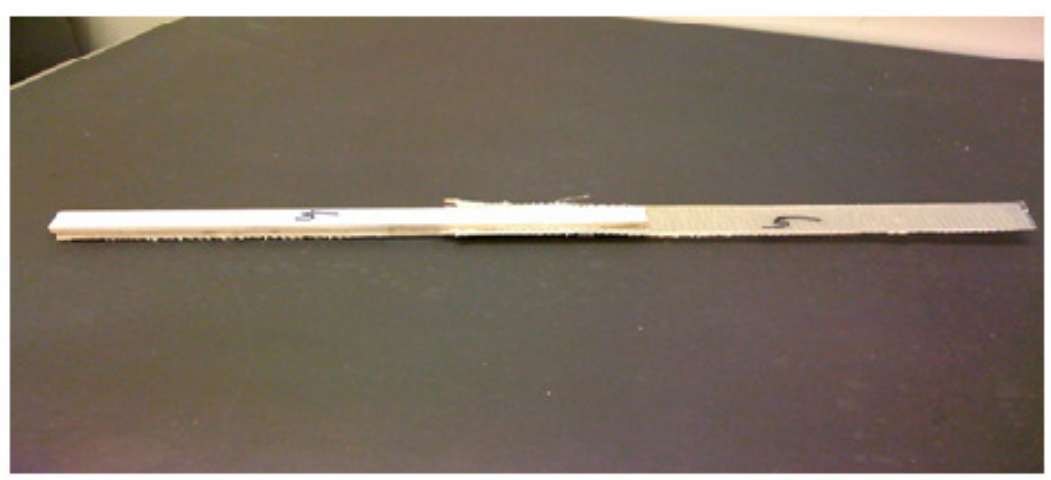

Figure 9. 11 Bond test specimen

The manufactured bond test plate was machined to coupon specimens (Figure 9.12). Bond tests were carried out using Instron 8501 with the same test configuration used for standard tension test specified by ASTM D 638 - 03 for standard tension test FRP specimens. The setup of the bond test and delamination of bonded area has been shown in Figures 13 and 14. 


\subsubsection{Bond test results}

The bond strength was evaluated to be 290 psi (Table 9.7), which is low compared to usual mechanical properties of thermoplastic and thermoset composites. A better stress transfer medium is suggested to further more enhance the strength performances and applications. The bonded and roughened thermoplastic surface to thermoset after the bond test revealed that small amount of bond strength was also coming from stitches in the glass fabric.

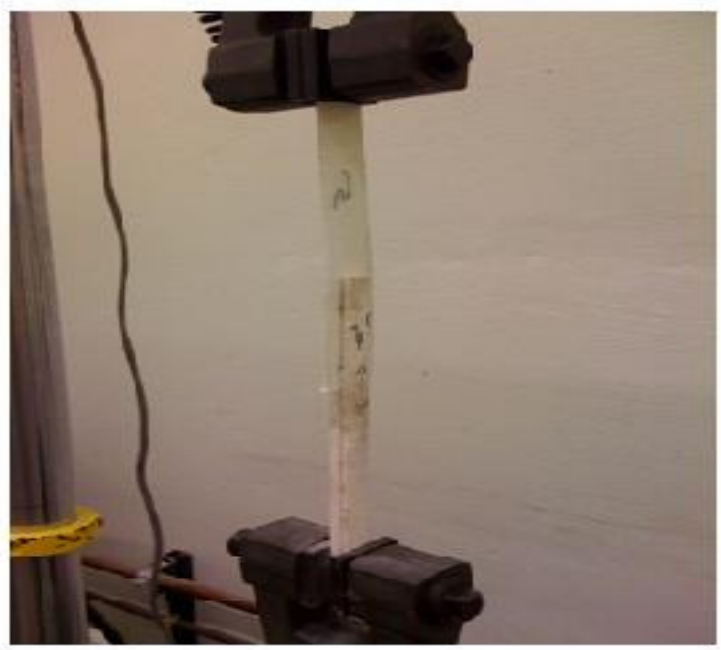

Figure 9. 12 Bond test specimen

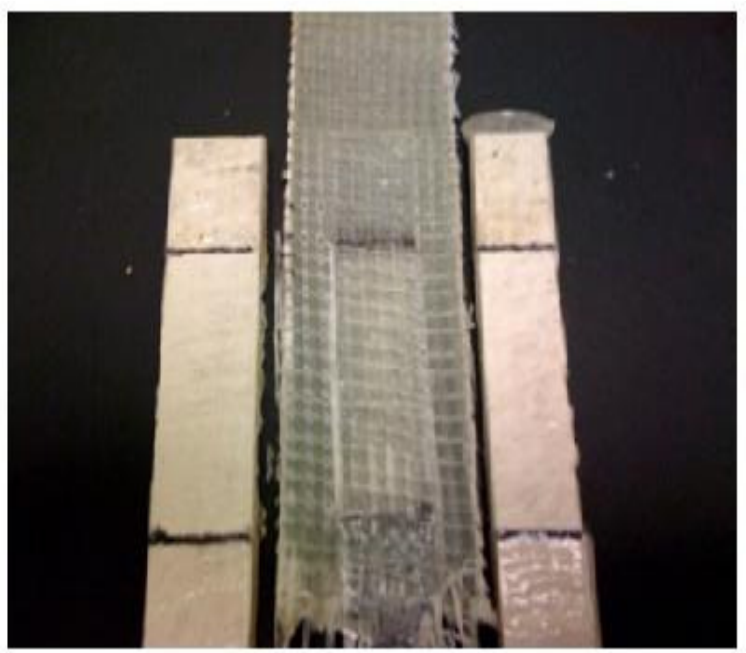

Figure 9. 13 Specimen after bond test

Table 9. 7 Bond test summary

\begin{tabular}{|c|c|c|c|c|}
\hline Sample \# & Area & Load & Strength & Avg Strength \\
\hline & sq.in. & lbs. & psi. & psi. \\
\hline $\mathbf{1}$ & 2.94 & 875 & 297.6 & \\
\hline $\mathbf{2}$ & 2.91 & 846 & 290.7 & \multirow{2}{*}{290} \\
\hline $\mathbf{3}$ & 2.96 & 868 & 293.2 & \\
\hline $\mathbf{4}$ & 2.98 & 830 & 278.5 & \\
\hline $\mathbf{5}$ & 2.9 & 840 & 289.6 & \\
\hline
\end{tabular}

\subsection{Summary}

Test results show that vinyl ester composite with 2 layers of glass fabric is about 3 times stronger and 2.5 times stiffer than similarly reinforced ABS (Note: refer to effects of fiber volume fraction (fvf) in Table 9.1. Hence, in a sandwich specimen it is advantageous to use 
thermoset composite as a shell and thermoplastic as a core to maximize bending strength of products as composite RR ties.

\section{CONCLUSIONS}

\subsection{Introduction}

This chapter comprises the conclusions from durability tests on coupon specimens. The coupon specimens manufactured from compression molding process were conditioned in both alkaline and salt solutions at room temperature and under freeze-thaw variations before testing in tension, bending, compression and impact (conforming to ASTM standards). In addition to data generated for durability evaluations, conclusions from moisture absorption test and SEM observations are reported in sections 10.2 and 10.3, respectively.

For alkaline conditioning at room temperature, maximum reduction in percentage strengths over 12 months conditioning for tension, bending, compression and impact were $-65.76 \%$, $42.94 \%,-20.33 \%$ and $-93.17 \%$, respectively, at $12 \%$ FVF. Similarly, for alkaline conditioning at freeze-thaw, the maximum reduction/gain in percentage strengths over 12 months conditioning for tension, bending, compression and impact were $-75.07 \%,-52.23 \%$, $-45.75 \%$ and $-93.29 \%$, respectively, for $12 \% \mathrm{FVF}$.

For specimens in salt solution conditioning at room temperature the maximum reduction in percentage strengths over 12 months conditioning for tension, bending, compression and impact were $-35.1 \%,-9.65 \%,-15.52 \%$ and $-45.33 \% \%$, respectively. Similarly, for salt conditioning at freeze-thaw, the maximum reduction in percentage strengths over 12 months conditioning for tension, bending, compression and impact were $-41.02 \%,-13.31 \%,-18.36 \%$, and $-57.39 \%$, respectively, for $12 \% \mathrm{FVF}$. 


\subsubsection{Tension test conclusions}

- To ensure proper failure modes in rectangular tension test specimens, perforated metal tabs were developed, which worked well and ensured proper failure of specimens away from the grip location.

- Average tensile strength of coupons without glass fabric was found to be 4112 psi and those with 1, 3 and 5 layers of glass fabric were found to be 5010, 8563 and 10484 psi, respectively. The corresponding strength increase was $22 \%, 108 \%$ and $155 \%$ for 1,3 and 5 layers, respectively, $(4 \%, 7 \%, 12 \%$ of fiber volume fraction) when compared to non-fabric specimen. Per layer stress increase was $22 \%, 36 \%$ and $31 \%$ for 1,3 and 5 layers of glass fabric, respectively. Based on our test data, per layer strength increase was found to be lower after exceeding threshold number of layers (i.e., fiber volume fraction).

- Average tensile modulus of specimens without fabric was $0.31 \times 10^{6} \mathrm{psi}$, and with 1,3 and 5 layers the values were noted to be $0.463 \times 10^{6} \mathrm{psi}, 0.675 \times 10^{6} \mathrm{psi}$, and $0.774 \times 10^{6} \mathrm{psi}$, respectively. Per layer tensile modulus increase was 49\%, 39\% and 30\% for 1, 3 and 5 layered specimens, respectively. These experimental values were found to correlate well with the theoretical values based on Rule of Mixtures (ROM) as shown in Appendix E.

- Among different conditioning schemes, maximum tensile strength reduction for non-fabric specimen was noted to be $20 \%$ in salt solution under freeze-thaw for up to 12 months. Maximum tensile strength reductions were $33.15 \%, 61.46 \%$, and $75.07 \%$, for specimens with 1, 3 and 5 layers of fabric, respectively, in alkaline solution with freeze-thaw (environmental chamber) for 12 months when compared to corresponding non-aged specimens.

- Maximum gains in tensile modulus for specimens conditioned in alkaline solution with freeze thaw variations (in an environmental chamber) up to eight months were $16 \%$ and $28 \%$ 
for non fabric and 5-layer fabric (12\% fiber volume fraction), respectively. Materials brittleness and corresponding rigidity as a result of aging along with secondary curing enhanced modulus values in FRP composites.

- Similarly, maximum gain in tensile modulus for specimens conditioned in salt solution with freeze thaw variation (in an environmental chamber) for up to eight months were $15 \%$ and $37 \%$ for no fibers and 5-layers of fabric (12\% fiber volume fraction), respectively.

\subsubsection{Bending test results}

- Average bending strength of non-fabric recycled FRP specimens was 8516 psi. Bending strength of specimens with 1, 3 and 5 layers of bi-directional glass fabrics increased to 8587 psi, 11045 psi and 13044 psi, respectively. Percentage increase in bending strength for 1, 3 and 5 fabric layer specimens $(4 \%, 7 \%$ and $12 \%$ fiber volume fraction, respectively) when compared to specimens without fabric was $1 \%, 30 \%$ and $53 \%$, respectively. Therefore, per layer bending strength increase was $1 \%, 10 \%$ and $11 \%$ for 1,3 and 5 layers of fabric, respectively.

- Bending modulus for non-fabric specimens was 0.304 x $10^{6}$ psi and the modulus of specimens with 1,3 and 5 layers were noted to be $0.447 \times 10^{6}$ psi, $0.447 \times 10^{6}$ psi and $0.994 \times$ $10^{6}$ psi, respectively. Percentage increase in bending modulus was $47 \%$ for 1 and 3 layer specimens, and $227 \%$ for 5-layer specimens. Per layer increase in modulus was $47 \%$, $16 \%$ and $45 \%$ for 1,3 and 5 layer specimens, respectively.

- Among different conditioning schemes of salt and alkaline solution at room temperature and freeze-thaw variations, maximum bending strength reduction for non fabric specimens was $13.31 \%$ in salt solution under freeze-thaw conditioning. Whereas, the maximum bending strength reductions for specimens with fabric was noted only in alkaline solution with freeze- 
thaw (environmental chamber) aging scheme. The bending strength reductions when compared to corresponding non aged specimens were $13.78 \%, 31.33 \%$ and $52.33 \%$ for 1,3 , and 5 layer specimens, respectively.

- Maximum loss in bending modulus for specimens placed in alkaline and salt solution with freeze thaw variation for eight months were $-65 \%$ and $-62 \%$, respectively, for 5-layers specimen (12\% fiber volume fraction), respectively.

\subsubsection{Compression test conclusions}

- Average compressive strength of specimens with no fabric was 8278 psi and the strength decreased with the increase in number of fabric layers. Average strength of 2-layer compression test specimens was 8172 psi which was 1\% (approx) lower than the specimen without fabric. Similarly, $11 \%$ and $16 \%$ strength reductions were noted for 6 and 10 layer compression specimens with the average strength values of 7404 psi and 6969 psi, respectively. This strength reduction in compression specimens with the addition of fabric resulted in shearing de-bonding, buckling and splitting types of failure modes when the load was applied axially (parallel) to fabrics.

- Compression modulus of specimens without fabric was $0.312 \times 10^{6}$ psi. The modulus with 2 layers of bi-directional glass fabric increased by $34 \%$ with an average modulus of $0.419 \times 10^{6}$ psi. Similarly, the compressive modulus for 6 and 10 layer specimens were $0.598 \times 10^{6}$ psi and $0.678 \times 10^{6}$ psi, respectively, and the corresponding percentage increase was $91 \%$ and $117 \%$, respectively compared to those of non-fabric specimens. Therefore, per layer compressive modulus increase was $17 \%, 15 \%$ and $12 \%$ for 2,6 , and 10 layer of glass fabric, respectively. 
- Compression modulus was inconsistent for specimens conditioned in salt and alkaline solution. Initial increase in compressive modulus was noted for one month conditioning in alkaline solution with freeze-thaw variation and then reduced after eight months, however, the modulus after eight months conditioning remained higher than control specimens.

- Among different conditioning schemes (salt and alkaline solution at room temperature and freeze-thaw variations), the maximum compressive strength reduction was noted for specimens aged in alkaline solution with freeze-thaw (environmental chamber) when compared to corresponding non-aged specimens. These strength reductions for specimens with $0,1,3$, and 5 layers of fabrics were $11.82 \%, 24.7 \%, 30 \%$ and $45.75 \%$, respectively.

- Significant de-bonding (splitting) at fabric-matrix interface was observed for some of the compression test specimens with 6 and 10 layers of glass fibers aged in alkaline solution. This is due to the effects from freeze-thaw, similar to those of thermoset composites observed by other researchers (Ray, 2005) and due to formation and expansion of salt deposits. Also, moisture ingress leads to induced swelling and drying (Karbhari et al., 2003).

- There was $24 \%$ gain in compressive modulus of specimens with 10 layer specimens in alkaline solution at freeze thaw variations after eight months. The brittle behavior of samples may be attributed to growth of hydration products between glass filaments (Zhang and Karbhari, 1999) which might have increased the compression modulus. Change in compressive modulus for specimens aged in salt solution with freeze thaw variation after eight months were $38 \%$ (gain) for non fabric and 50\% (loss) for 10 layered fabric specimens (12\% fiber volume fraction). 


\subsubsection{Impact test conclusions}

- Average impact strength of specimens without fabric was noted to be 0.36ft.lbs. The strength increased to $1.19 \mathrm{ft} .1 \mathrm{bs}, 2.21 \mathrm{ft} . \mathrm{lbs}$, and $5.36 \mathrm{ft} .1 \mathrm{bs}$ with fabric addition of $4 \%, 7 \%$ and $12 \%$ fiber volume fraction, respectively. The percentage impact strengths increased by $230 \%, 516 \%$ and $1388 \%$ corresponding to the addition of 1, 3 and 5 layers, respectively.

- Among various aging schemes of salt and alkaline solution at room temperature and environmental chamber, the maximum impact strength reduction of non fabric specimens was $17 \%$ in alkaline solution aging under freeze-thaw. The maximum impact strength reductions (when compared to control specimens) after 12 months of aging in alkaline solution environmental chamber were $70.87 \%, 83.42 \%$ and $93.29 \%$ for 1,3 and 5 layers, respectively.

- Complete tearing of fabric (type $\mathrm{C}$ failure) was noted for specimens placed in alkaline solution. Hinge formation was observed for specimens with 3 and 5 layers of fibers aged in salt solution.

\subsection{Conclusions for Moisture Absorption Test}

\subsubsection{Introduction}

The long term durability of a material can be evaluated by subjecting the material to aggressive environment for short period of time. In this research, the recycled FRP specimens were subjected to salt and alkaline solution aging at room temperature and freeze-thaw temperature in an environmental chamber. In order to understand the moisture diffusion in FRPs, coupon specimens with 0,1,3 and 5 layers of fabric were immersed in water, salt and alkaline solution at room temperature. Moisture absorption was noted at regular intervals and moisture diffusion coefficient was evaluated using Fickian diffusion equation. The moisture diffusion coefficient 
gives us an idea about the rate of moisture ingress in FRPs. Diffusion coefficients were compared with previous work at WVU by Shah et al., (2002). Following conclusions are drawn from moisture absorption study:

- Diffusion of moisture occurred through exposed fabric layers at the specimen edges that were cut during manufacturing and through voids at the interfaces. Based on the non-uniform moisture absorption trend, presence of voids in thermoplastic composites can be concluded. Due to presence of voids and exposed fabric at the specimen edges the diffusion coefficients in this research were 7-8 times higher compared with Shah et al., (2002). Also, presence of nano-particles in thermoset FRP specimens of Shah et al., (2002) led to lower diffusion coefficient.

- The moisture absorption was non uniform for $0,1,3$ and 5 layer specimens, because of presence of voids at fabric-matrix interface and discontinuities, which might have formed during manufacturing process.

- The rate of saturation was faster in specimens with salt and alkaline solution for 1 and 3 layer specimens compared to non fabric and 5 layers specimen.

\subsection{Conclusions for SEM}

\subsubsection{Introduction}

In order to examine fiber and resin, and interfacial degradations due to aging at the microscopic level, Scanning Electron Microscopy (SEM) was carried out in this research. SEM was performed on non-aged, one, four and eight-month specimens aged in salt and alkaline solution under freeze thaw conditioning. The conclusions are as follows 
- SEM images of control specimens at several locations showed partial wetting of fabric with resin at some location. This was mainly due to high viscosity of ABS resin used in compression molding process as compared to thermoset resins.

- Longitudinal and transverse direction fabrics were ruptured for specimens conditioned under salt solution with freeze thaw variations for one month. Delamination/splitting of fabricmatrix interface were also noted for specimens aged in salt solution under freeze thaw scenario.

- Transverse and longitudinal fabric was ruptured in specimens subjected to alkaline solution with freeze thaw variation for one month. Moderate amount of delamination/separation was also noted in those specimens. Delamination/cracking at the roving center (localized delamination) and crack propagation through the fabric was also noted.

- Additional widening of delaminations was noted in specimens after 4 months of aging under salt solution with freeze-thaw (environmental chamber), when compared to corresponding one month specimens. Depositions of opaque (expected to be the crystals of calcium hydroxide) material seen on fibers were typically a result of hydroxylation.

- Moderately enlarged crack widths at the fabric matrix interface was noted in specimens after four months of alkaline solution aging with freeze-thaw (environmental chamber), when compared to corresponding one month specimens.

- Matrix cracking was noted for specimens aged in salt solution for eight months, might be due to freeze thaw variations, lower polymer phase, and presence of $\mathrm{Cl}^{-}$ion in salt solution as discussed by several authors. (Note: No SEM was carried out on 8 months specimens conditioned in alkaline solution at freeze-thaw). 


\subsection{General Conclusions for Durability}

- Grinding of pellets was advantageous in improving the quality of FRP plate by reducing the amount of voids.

- Perforated tabs with uniformly staggered hole pattern were introduced in this research to test rectangular FRP specimens in tension. Use of these tabs eliminated grip failure and provided consistent results with proper failure modes in gage length for the tension test specimens.

- Alkaline solution under freeze-thaw aging scenario was noted to be most detrimental among both at room temperature and under freeze-thaw aging.

- Complete deterioration/degradation of glass fabric was noted in alkaline solution subjected to freeze-thaw conditioning. Ruptured locations showed no signs of fabric presence. Complete vanishing of fabric might be attributed to reaction between hydroxyl ions and fiber glass as described under leaching and etching effects (refer to chapter 8 section 8.3.2).

- Strength reduction resulting from glass fiber corrosion under direct salt solution exposure, is less severe than in case of alkaline solution exposure, and the degradation rate is much slower than the one caused by alkaline conditioning.

\subsection{Conclusions for Thermoplastic and Thermoset Sandwich Composites}

\subsubsection{Introduction}

Thermoplastic (TP) and thermoset (TS) composite sandwich plates were manufactured using hand layup method and evaluated for their potential civil engineering applications. Six types of sandwich plates (TS/TP, TP/TS/TP and TS/TP/TS- roughened and un-roughened) were manufactured and tested in tension and bending. Following conclusions may be drawn: 


\subsubsection{Sandwich composite in tension}

- Tensile strength of neat vinyl-ester was noted to be 4676 psi and increased to 19864 psi (324.8\%) with the addition of 2 layers $(21 \%$ FVF) of glass fabric. Similarly, the tensile strength of plain ABS was noted to be 4569 psi and increased to 6710 psi (47\%) with two layers of glass fabric reinforcement (fiber volume fraction was 6\%).

- The tensile modulus of reinforced vinyl-ester and ABS specimens was noted to be $153 \%$ higher and was calculated to be $1.14 \times 10^{6} \mathrm{psi}$ and $0.45 \times 10^{6} \mathrm{psi}$, respectively.

- The tensile strength of un-roughened and roughened TP/TS/TP specimens was noted to be 8470 psi and 8969 psi, respectively. Tensile modulus of roughened and un-roughed (TP/TS/TP) specimen was evaluated to be $0.546 \times 10^{6} \mathrm{psi}$ and $0.573 \times 10^{6}$ psi, respectively, with a percentage difference of $5 \%$ and $6 \%$ in modulus and strength, respectively.

- The tensile strength of TS/TP roughened specimen was 9174 psi. The modulus of TS/TP roughened specimen was noted to be $0.576 \times 10^{6} \mathrm{psi}$ and $0.571 \times 10^{6} \mathrm{psi}$ on TP and TS side, respectively.

- The strength and modulus of TS/TP/TS roughened specimen was 11371 psi and $0.723 \times 10^{6}$ psi, respectively, which was maximum in the entire group of sandwich specimens (TS/TP, TS/TP/TS, TP/TS/TP-roughened and un-roughened).

\subsubsection{Sandwich composite in bending}

- The bending strength of roughened and un-roughened TP/TS/TP specimens was noted to be 4164 psi and 6067 psi, respectively, which was $45.7 \%$ higher in roughened specimens compared to un-roughened specimens. 
- Bending strength of roughened TP/TS composite specimens tested with thermoplastic (ABS) and thermoset (VE) on tension side of beam was calculated to be 8064 psi and 9092.3 psi, respectively. The strength was higher by $12.7 \%$ with TS in tension zone of beam.

- Bending strength of specimens with vinyl-ester on either side of roughened ABS plate was evaluated to be 10354 psi, which in turn increased the strength by $13.88 \%$, when compared to vinyl ester facing bottom side of the specimen.

\subsubsection{General conclusions for TS and TP sandwich composites}

- During manufacturing of TS/TP sandwich composite plate, it was found that a wet TS layer over cured TS resulted in poor bonding. Bonding of TS layer over other TS has to be carried out before both are cured.

- TS/TP/TS surface roughened specimens demonstrated better mechanical properties in the entire six combination of TS/TP specimen.

- Bond strength of roughened thermoplastic and thermoset resin sandwich was evaluated to be 290 psi.

\subsection{Summary}

Among salt and alkaline conditioning schemes at room temperature and freeze thaw variations, maximum reduction in tensile and bending strengths with up to 5 layers of glass fabrics were found to be $75 \%$ and $52 \%$, respectively, whereas reduction in those of compression and impact strengths were $46 \%$ and $93 \%$, respectively. These reductions are expected when glass reinforcements are subjected to high $\mathrm{pH}$ alkaline environment in freeze-thaw variations. With a one day of conditioning in environmental chamber in accelerated aging studies that relate to an actual service life of 34 days of natural weathering in Morganton, WV, or 36 days of U.K weathering (Vijay and GangaRao, 1999). These durability studies provide a basis for 
understanding degradation patterns of FRP composites with recycled resins and highlight the importance of proper resin saturation.

Research results of this study indicate the significant strength gains and potential of recycled polymer composites with the use of continuous glass fabrics (e.g., bi-directional fabrics). These fabrics can be successfully utilized in making recycled polymer composite structural components for highway, housing, and automobile applications. These products can be scaled to suit other prototype applications. One such application involving the manufacture and development of fullscale recycled railroad composite tie is being further explored at CFC-WVU. This study indicates the importance of ensuring proper resin coating of continuous glass fabrics in structural composites, because they are susceptible to aging related degradations (locally or globally), particularly under alkaline solution exposures. 


\subsection{Recommendations for Future Work}

I. Evaluation of degradation of fabrics only in salt and alkaline solution to check how well is the matrix in protecting the fibers and comparing results with other resins.

II. Selection of appropriate thickness of matrix for the protection of fibers (suggested by karbhari et al., (2003).

III. Coating of FRPs with paint for better protection from environmental attack.

IV. Conducting FT-IR and X-ray on aged specimens to evaluate the corrosion and check the diffusion of $\mathrm{OH}$ and $\mathrm{Cl}$ ions in Matrix. 


\section{REFERENCES}

1. P. V. Vijay., G. Hota., Narendra T., (2006). "Reinforced concrete design with GFRP composites", CRC Press Taylor and Francis Group, Boca Raton London, New York.

2. W.V.Ttitow, B. J. Lanham, "Reinforced thermoplastics", John Wiley and Sons, New YorkToronto.

3. Bargo, J. E. (2000). "Mechanical property characterization of recycled thermoplastics," Thesis Report, Constructed Facilities Center, West Virginia University, West Virginia.

4. Basto, J.R. (2002). "Mechanical Characterization of Aged Recycled Polymers and Applications," Thesis Report, Constructed Facilities Center, West Virginia University, West Virginia.

5. Aditham, R.P. (2004). "Manufacturing and Evaluation of Structural Products with Recycled Polymers," Thesis Report, Constructed Facilities Center, West Virginia University, West Virginia.

6. S. Amarnath. V., (2006). Manufacturing, testing and evaluation of structural products with recycled polymers, Thesis Report, Constructed Facilities Center, West Virginia University, West Virginia.

7. Vijay, P.V., GangaRao, H.V.S., Bargo, J.E., (2000), "Mechanical Characterization of Recycled Thermoplastic Polymers for Infrastructure Applications," 3rd International Conference on Advanced Composite Materials in Bridges and Structures, August 2000.

8. A. AL Far., F. Rostasy., H. BudelMann., T AL Hadid., "Durability of reinforced concrete members strengthened with CFRP plates and subjected to moisture and salts", FRPRCS-8, University of Patras, Greece, July 2007

9. B. C. Ray., Surendra Kumar M., Neeti. S., "Acidic degradation of FRP composites", "National conference on developments in Composites" National Institute of Technology Rourkela, India. April (2007)

10. B. C. Ray, "Effects of changing environment and loading speed on mechanical behavior of FRP composites", Journal of Reinforced plastics and Composites, 2006, vol. 25,12, pp. 1227-1240.

11. V. T. Wallder, "Aging problems of Plastics" Bell Laboratories. 
12. Abdulrahman M. A., "Durability of glass fiber reinforced plastic bars", Project 5/417, The Research Center College of Engineering King Saud University, Riyadh, Saudi Arabia.

13. Omar Khelifi., Antonio Nanni., (2004) "Effects of Different Coating on the Durability of Thermoplastic E-Glass FRP Bars"., Proceedings of the First International Conference on Innovative Materials and Technologies for Constuction and Restoration, Vol I, pp 210, June.

14. Hartman, D.R., Greenwood, M.E., Miller, D.M., (1996) "High strength glass fibers", Technical paper-Owens Corning.

15. B. C. Ray., "Freeze-thaw Response of glass-polyester composite at different loading rate", Journal of Reinforced Plastics and Composites, vol. 24, issue 16, pp. 1771-1776, 2005.

16. Gyorgy L. Balazs., "Detailing, technological aspects and durability". Retrofitting of concrete structures by externally bonded FRPs: with Emphasis on Seismic Applications. By Federation internationale du Béton(FIB), International Federation for Structural Concrete, Published by FIB - Féd. Int. du Béton, 2006, pp 29- 38.

17. Kajorncheappungam. S, R. R. Gupta., H.V.S. GangaRao., "Part IV - The effect of Aging Environment on the Degradation of Glass Reinforced Epoxy"., Submitted to Department of Transportation, Division of Highways., CFC 03-102 (WVDOH \#T-669-CIDDMOC) 2003.

18. F. Micelli., A. Nanni., A. Tegola., "Effects of conditioning environment on GFRP bars", $22^{\text {nd }}$ Sampe Europe International Conference, CNIT, Paris, March 2001.

19. Hwai-Chung Wu., Gongkang Fu., Ronald F. Gibson., An Yan., Kraig Warenmuende., Vijay Anumandla., "Durability of FRP Composites Bridge Deck Materials under Freeze-Thaw and Low Temperature Conditions", Journal of Bridge Engineering @ ASCE July/Aug 2006, pp 443-451.

20. Gupta, V.B., L.T. Drzal, C.Y.-C. Lee and M.J. Rich, The temperature-dependence of some mechanical properties of a cured epoxy resin system, Polymer Engineering and Science, 25, 812-823 (1985).

21. Chin, J. W., Aouadi, K., Nguyen, T., “ Effect of Environment Exposure on Fiber-Reinforced Plastics (FRP) Materials used in Construction", Journal of composites Technology and Research, JCTRER, Vol 19, No. 4, October 1997, pp 205-213.

22. S. P. Shah., D. Ludirdja., J.I. Daniel., B. Mobasher., "Toughness-Durability of Glass Fiber Reinforced Concrete Systems", ACI Material Journal, Sept/Oct 1988, pp 352-360. 
23. F E. Tannous., H. Saadatmanesh., "Durability of AR Glass Fiber Reinforced Plastic Bars", Journal of Composites for Construction, Feb 1999, pp 12-19.

24. M. Tavakkolizadeh; and H. Saadatmanesh., "Environmental Effects on Tensile Properties of FRP Laminates made using Wet Lay-up Method", Proceeding of The Advanced Polymer Composites for Structural Applications in Construction (ACIC 2004), University of Surrey, England, pp 617-632.

25. De'Neve, B; and M.E.R. Shanahan., "Water absorption by an epoxy resin and its effect on the mechanical properties and infra-red spectra", Polymer, 34, 5099-5105 (1993).

26. Lee, C.L; and N.A. Peppas., "Water transport in epoxy resins", Prog. Polym. Sci., 18, 947-961 (1993).

27. Zhang S; Karbhari C, M., "Effects of Alkaline Environment on Durability of E-glass Fibers Composites for use in Civil Infrastructure". Proceedings of the American Society for Composites Fourteenth Technical Conference, Sept, 1999, pp 12-20.

28. Lawrence C Bank; Moshe Puterman; and Amnon Ktaz., "The Effects of Material Degradation on Bond Properties of Fiber Reinforced Plastics Reinforcing Bars in Concrete", ACI Material Journal, V-95, \#3, 1998.

29. Adams, P. B. (1984), "Glass Corrosion, A record of the past? A predator of the future?" Journal of non-crystalline solids, Vol.67, pp. 193-205.

30. V. M. Karbhari; J. W. Chin; Hunston; B. Benmokrane; T. Juska; R. Morgan; J. J. Lesko; U. Sorathia; and D. Reynaud., "Durability Gap Analysis for Fiber-Reinforced Polymer Composite in Civil Infrastructure", Journal of Composites for Construction () ASCE/Aug, 2003.

31. Mesfer M. Al-Zahrani; Salah U. Dulaijan; Alfarabi Sharif; and Mohammad Maslehuddin., "Durability Performance of Glass Fiber Reinforced Plastic Reinforced in Harsh Envoronments", The $6^{\text {th }}$ Saudi Engineering Conference, KFUPM, Dhahran, Dec-2002.

32. Donna A. Johnson; David A. Johnson; James L. Urich; Roger M. Rowell; Rodney Jacobson; Daniel F. Caufield., "Weathering characteristics of fiber-polymer composites", The Fifth International Conference on Woodfiber-plastic Composites., May 1999.

33. Vijay, P.V; and H.V.S. GangaRao, "Accelerated and Natural Weathering of Glass FRP Bars", American Concrete Institute, Special Publication (SP)-188, November 1999, pp. 605-614. 
34. Apoorva P. Shah; Rakesh K. Hupta; Hota V. S. GangaRao; and Cloise E Powell., "Moisture Diffusion Through Vinyl Ester Nanocomposites Made with Montmorillonite Clay”, Polymer Engineering and Science, Sept 2002 Vol.42, \#9.

35. V M. Karbhari; Joannie W. Chin; David Reynaud., "Critical Gaps in Durability Data for DRP Composites in Civil Infrastructure", Society for the Advancement in Materials and Process Engineering (SAMPE), $45^{\text {th }}$ International SAMPE Symposium and Exhibition. Vol. 45. Proceedings. May 2000.

36. Nishizaki; T, Kishima; and I. Sasaki., "Detritions of Mechanical Propertiesof Pultruded FRP through Exposure Tests", Durability and Field Applicatiosn of Fiber Reinforced Polymer Composites for Construction., CDCC-2007.

37. B.C. Ray., "Temperature Effect during Humid Ageing on Interfaces of Glass and Carbon Fibers Reinforced Epoxy Composites" Journal of colloid and Interface Science, Vol.298, Issue1, 2006, pp. 111-117.

38. Gotou T.; Noda M.; Tomiyama T.; Sembokuya H.; Kubouchi M.; Tsuda K., "In situ health monitoring of corrosion resistant polymers exposed to alkaline solutions using $\mathrm{pH}$ indicators", Sensors and Actuators B, 2006, 119, pp 27-32.

39. Chateauminois A.; Chabert B.; Soulier J. P.; Vincent L., "Effects of hygrothermal aging on the durability of glass/epoxy composites. Physico-chemical analysis and damage mapping in static fatigue".

40. Nanni A.; Bakis C. E.; Mathew J. A., "Acceleration of FRP bond degradation", $C D C C$ International Conference; Durability of fiber reinforced polymer composites for construction; Proceedings of the first international Sherbrooke, Que’bec, 1998, pp 45-56.

41. Stevanovic D.; Lowe A.; Kalyanasundaram S.; Jar P. -Y B. ; Otieno-Alego V., "Chemical and mechanical properties of vinyl-ester/ABS blends", Polymer, 2002, 43, pp 4503-4514.

42. Green M. F. ; Bisby L. A. ; Beaudoin Y.; Labossièr P., "Effect of freeze-thaw cycles on the bond durability between fibre reinforced polymer plate reinforcement and concrete", Can. J. Civ. Eng., 2000, 27, pp 949-959. 
43. Alsayed S. H. ; Alhozaimy A. M. ; Al-Salloum Y. A. ; Almusallam T. H., "Long term performance of the new generation of GFRP rebars under severe environments", The $6^{\text {th }}$ Saudi Engineering Conference, KFUPM, Dhahran, 2002, 3, pp 277.

44. http://www.ejnet.org/plastics/polystyrene/styrene.html

45. http://www.lenntech.com/hazardous-substances/acrylonitrile.htm

46. http://www.bpf.co.uk/bpfindustry/plasticsmaterials_Acrylonitrile_Butadiene_Styrene $\underline{\mathrm{ABS} . \mathrm{cfm}}$

47. http://www.humiditycontrol.com/

48. http://neon.mems.cmu.edu/cramb/27-100/lab/S00_lab2/lab2.html

49. www.bryair.com/pdf/pde paper.pdf

50. http://practicalaction.org/home 


\section{APPENDIX A:}

\section{A.1 Earlier Research at CFC-WVU}

Work on the evaluation of thermoplastics composites for civil engineering applications was started in the year 1999 at the Constructed Facilities Center (CFC) research laboratories, WVU.

Table A. 1 Samples tested, resin type, and type of fibers (Bargo, 2000)

\begin{tabular}{|c|c|c|c|c|c|c|c|c|c|c|}
\hline \multirow{3}{*}{ Test } & \multicolumn{4}{|c|}{ No of Test Samples } & \multicolumn{4}{|c|}{ Type of fabric } & \multicolumn{2}{|c|}{$\begin{array}{c}\text { Type of } \\
\text { chopped fabric }\end{array}$} \\
\hline & \multicolumn{2}{|c|}{ With Fabrics } & \multicolumn{2}{|c|}{$\begin{array}{l}\text { Without } \\
\text { Fabric }\end{array}$} & \multicolumn{2}{|c|}{$\begin{array}{l}\text { With } \\
\text { Fabrics }\end{array}$} & \multicolumn{2}{|c|}{$\begin{array}{l}\text { Without } \\
\text { Fabric }\end{array}$} & & \\
\hline & ABS & PC & ABS & PC & ABS & PC & ABS & PC & ABS & PC \\
\hline Tension & 16 & 16 & 15 & 15 & \multirow{6}{*}{\multicolumn{4}{|c|}{$\begin{array}{c}100 \% \text { Virgin } \\
100 \% \text { Recycled } \\
80 \% \text { Virgin } 20 \% \text { Recycled }\end{array}$}} & \multirow{6}{*}{$\begin{array}{c}4 \mathrm{~mm} \\
14 \mu\end{array}$} & \multirow{6}{*}{$\begin{array}{c}3.18 \mathrm{~mm} \\
13 \mu\end{array}$} \\
\hline Bending & 16 & 15 & 17 & 15 & & & & & & \\
\hline Compression & 20 & 19 & 15 & 16 & & & & & & \\
\hline Impact & 15 & 15 & 15 & 18 & & & & & & \\
\hline Hardness & 48 & 48 & 48 & 48 & & & & & & \\
\hline Creep & 7 & 6 & 8 & 6 & & & & & & \\
\hline
\end{tabular}

Bargo (2000) worked on the evaluation of mechanical properties of virgin/recycled, ABS and PC polymers with (25\% by weight) and without glass fibers. In addition, specimens using $20 \% / 80 \%$ blend of recycled and virgin $\mathrm{ABS}$ and $\mathrm{PC}$ with $25 \%$ fibers by weight and without fibers were manufactured. Six types of tests, i.e., namely, tension, compression, bending, impact, hardness and creep of ABS and PC plastics were carried out (shown in Table A.1).

Basto, (2002) carried out the evaluation of mechanical properties of polymers such as tension, with chopped and continuous fibers (Table A.2 and A.3) specimens were subject to limited chemical aging for up to 18 months. In addition, manufacturing and testing ( 3 and 4 point bending) of structural components like offset block modules with rubber tire core for highway guard rail system, channel section, trapezoidal section, box section, and flat plate made of recycled ABS and PC was carried out (Table A.4). 
Table A. 2 Types of coupon specimens from conditioned recycled thermoplastics (Basto, 2002)

\begin{tabular}{|c|c|c|c|c|c|c|c|c|c|c|c|c|c|c|c|c|}
\hline \multicolumn{17}{|c|}{ Number of Tested Samples and Aging Times } \\
\hline \multirow{3}{*}{ Test } & \multicolumn{4}{|c|}{2 months } & \multicolumn{4}{|c|}{4 months } & \multicolumn{4}{|c|}{10 months } & \multicolumn{4}{|c|}{18 months } \\
\hline & \multicolumn{2}{|c|}{$\begin{array}{c}\text { With } \\
\text { Fabrics }\end{array}$} & \multicolumn{2}{|c|}{$\begin{array}{c}\text { Without } \\
\text { Fabric }\end{array}$} & \multicolumn{2}{|c|}{$\begin{array}{c}\text { With } \\
\text { Fabrics }\end{array}$} & \multicolumn{2}{|c|}{$\begin{array}{c}\text { Without } \\
\text { Fabric }\end{array}$} & \multicolumn{2}{|c|}{$\begin{array}{c}\text { With } \\
\text { Fabrics }\end{array}$} & \multicolumn{2}{|c|}{$\begin{array}{c}\text { Without } \\
\text { Fabric }\end{array}$} & \multicolumn{2}{|c|}{$\begin{array}{c}\text { With } \\
\text { Fabrics }\end{array}$} & \multicolumn{2}{|c|}{$\begin{array}{c}\text { Without } \\
\text { Fabric }\end{array}$} \\
\hline & ABS & PC & ABS & PC & ABS & PC & $\begin{array}{c}\mathbf{A B} \\
\mathbf{S}\end{array}$ & PC & ABS & PC & ABS & PC & $\begin{array}{c}\mathbf{A B} \\
\mathbf{S}\end{array}$ & PC & ABS & PC \\
\hline Tension & 3 & 3 & 3 & 3 & 3 & 3 & 3 & 3 & 6 & 6 & 5 & 5 & 5 & 6 & 5 & 6 \\
\hline Bending & 3 & 3 & 2 & 3 & 3 & 3 & 3 & 3 & 6 & 6 & 6 & 6 & 6 & 6 & 6 & 6 \\
\hline Comp. & 4 & 6 & 6 & 6 & 5 & 5 & 4 & 3 & - & - & - & - & 6 & 6 & 6 & 6 \\
\hline Impact & 3 & 3 & - & - & 3 & 3 & 3 & 3 & 6 & 3 & 7 & 3 & 6 & 6 & 11 & 6 \\
\hline Hardness & 3 & 3 & 3 & 3 & 3 & 3 & 3 & 3 & 6 & 6 & 6 & 6 & 6 & 6 & 6 & 6 \\
\hline Total & 16 & 18 & 14 & 15 & 17 & 17 & 16 & 15 & 24 & 21 & 24 & 20 & 29 & 30 & 34 & 30 \\
\hline $\begin{array}{c}\text { Grand } \\
\text { Total }\end{array}$ & & & & & & & & & & & & & & & & \\
\hline
\end{tabular}

Table A. 3 Guardrail post, rail and offset block specimens tested times (Basto, 2002)

\begin{tabular}{|c|c|c|c|c|c|c|c|c|c|}
\hline \multirow{2}{*}{ Test } & $\begin{array}{c}\text { Channel } \\
\text { section }\end{array}$ & $\begin{array}{c}\text { Trapezoidal } \\
\text { section }\end{array}$ & \multicolumn{2}{|c|}{ Box section } & $\begin{array}{c}\text { ABS } \\
\text { sheets }\end{array}$ & $\begin{array}{c}\text { ABS } \\
\text { belt- } \\
\text { type }\end{array}$ & $\begin{array}{c}\text { Rubber- } \\
\text { wood } \\
\text { block }\end{array}$ & $\begin{array}{c}\text { Wood from } \\
\text { rubber-wood } \\
\text { block }\end{array}$ & $\begin{array}{c}\text { ABS- } \\
\text { rubber }\end{array}$ \\
\cline { 2 - 11 } & Polypropylene & Polypropylene & $\begin{array}{c}\text { Recycled } \\
\text { ABS }\end{array}$ & $\begin{array}{c}\text { Virgin } \\
\text { Vinylester }\end{array}$ & ABS & ABS & $\begin{array}{c}\text { Rubber- } \\
\text { wood }\end{array}$ & Wood & \\
\hline Bending & 1 & 1 & 3 & 2 & 4 & - & - & - & - \\
\hline Tension & - & 5 (strips) & 1 & - & 2 & 6 & - & - & - \\
\hline Comp. & - & - & - & - & 2 & & 1 & $3(\mathrm{~Pa})^{*}+2(\mathrm{Pe}) *$ & - \\
\hline Impact & - & - & - & - & - & - & - & 6 & - \\
\hline $\begin{array}{c}\text { Bond } \\
\text { strength }\end{array}$ & - & - & - & - & - & - & - & - & 6 \\
\hline Total & 1 & 6 & 4 & 2 & 8 & 6 & 1 & 5 & 6 \\
\hline \multicolumn{7}{|c|}{} \\
\hline
\end{tabular}

*Pa= Parallel to grain, $\mathbf{P e}=$ Perpendicular to grain

Table A. 4 Types of bending specimens for guardrail systems (Basto, 2002)

\begin{tabular}{|c|c|c|c|c|}
\hline Section & Recycled resin & $\begin{array}{c}\text { Fiber volume } \\
\text { fraction } \\
(\boldsymbol{\%})\end{array}$ & Length & Test type \\
\hline Channel & Polypropylene & 43 & 16.5 & 3-point bending \\
\hline Trapezoidal & Polypropylene & 41 & 16.5 & 3-point bending \\
\hline Box & ABS & 25 & 20 & 3-point bending \\
\hline Box & Virgin Vinylester* & 41 & 20 & 3-point bending \\
\hline Fabric wrapped box & ABS & 22 & 20 & $\begin{array}{c}\text { 3-point bending } \\
\text { 4-pointbending }\end{array}$ \\
\hline $\begin{array}{c}\text { Flat specimens cut from } \\
\text { sheets }\end{array}$ & ABS & 25 & 4 (small coupons) & 3-point bending \\
\hline
\end{tabular}


*not a recycled resin, 14" was used for channel and trapezoidal sections and 16" span was used for box section Later, work on the development of the offset block with discarded tire/wood core and glass fabric shell was continued by Adhitam, (2004). Compression molding process parameters such as pressure and temperature were also investigated. Coupon specimens using recycled ABS with and without continuous fibers were manufactured and evaluated and were compared with vinylester specimens. Use of continuous fibers with virgin ABS polymer coupon specimens increased impact strength as compared to chopped fiber specimens. Heat propagation in offset blocks was studied using infrared thermography. An FEM model of offset block was developed and analyzed under thermal loading. In addition to offset block, angled plates and dowel bars were manufactured and evaluated under 3-point bending loads (Aditham, 2004).

Table A. 5 Structural components manufactured with different fiber volume fractions (Amarnath, 2006)

\begin{tabular}{|c|c|c|c|c|c|}
\hline \multicolumn{2}{|c|}{$\begin{array}{l}\text { Product Type With and Without Glass } \\
\text { Fabric }\end{array}$} & $\begin{array}{l}\text { Number of } \\
\text { Specimens }\end{array}$ & $\begin{array}{l}\text { Fiber Volume } \\
\text { Fraction }(\%)\end{array}$ & $\begin{array}{l}\text { Total Number } \\
\text { of Specimens }\end{array}$ & $\begin{array}{l}\text { Bending Tests } \\
\text { Performed }\end{array}$ \\
\hline \multirow{4}{*}{ REINFORCED GRID } & No Layer & 5 & No Fabric & \multirow{4}{*}{17} & \multirow{4}{*}{$\begin{array}{l}3 \text { Point Bending with } \\
\text { Patch Loading }\end{array}$} \\
\hline & 1 Layer & 5 & $4 \%$ & & \\
\hline & 3 Layers & 5 & $7 \%$ & & \\
\hline & 5 Layers & 2 & $12 \%$ & & \\
\hline \multirow{4}{*}{ SIGNBOARD } & No Layer & 3 & No Fabric & \multirow{4}{*}{12} & \multirow{4}{*}{$\begin{array}{l}3 \text { Point Bending with } \\
\text { Line Loading }\end{array}$} \\
\hline & 1 Layer & 3 & $4 \%$ & & \\
\hline & 3 Layers & 3 & $7 \%$ & & \\
\hline & 5 Layers & 3 & $12 \%$ & & \\
\hline \multirow{4}{*}{ SIGNPOST } & No Layer & 5 & No Fabric & \multirow{4}{*}{20} & \multirow{4}{*}{$\begin{array}{l}\text { (i) } 3 \text { Point Bending } 8 \\
\text { (ii) } 4 \text { Point Bending }\end{array}$} \\
\hline & 1 Layer & 5 & $4 \%$ & & \\
\hline & 3 Layers & 5 & $7 \%$ & & \\
\hline & 5 Layers & 5 & $12 \%$ & & \\
\hline \multirow{4}{*}{$\begin{array}{l}\text { RECTANGULAR } \\
\text { STIFFENED PANEL }\end{array}$} & No Layer & 2 & No Fabric & \multirow{4}{*}{8} & \multirow{4}{*}{$\begin{array}{l}3 \text { Point Bending with } \\
\text { (i) Line Load \& } \\
\text { (ii) Patch Load }\end{array}$} \\
\hline & 1 Layer & 2 & $4 \%$ & & \\
\hline & 3 Layers & 2 & $7 \%$ & & \\
\hline & 5 Layers & 2 & $12 \%$ & & \\
\hline \multirow{4}{*}{$\begin{array}{c}\text { HEXAGONAL } \\
\text { STIFFENED PANEL }\end{array}$} & No Layer & 5 & No Fabric & \multirow{4}{*}{20} & \multirow{4}{*}{$\begin{array}{l}3 \text { Point Bending with } \\
\text { (i) Line Load \& } \\
\text { (ii) Patch Load }\end{array}$} \\
\hline & 1 Layer & 5 & $4 \%$ & & \\
\hline & 3 Layers & 5 & $7 \%$ & & \\
\hline & 5 Layers & 5 & $12 \%$ & & \\
\hline WINDOW PANEL & No Layer & 3 & No Fabric & 3 & - \\
\hline
\end{tabular}


Amarnath (2006) evaluated the mechanical properties of recycled ABS coupon specimens with and without fibers. In addition to coupon specimens, reduced scale rectangular grid, hexagonal stiffened panel, rectangular panel, sign post, and sign board were manufactured through compression molding process and evaluated under bending loads (Tables A.5 and A.6).

Finite Element modeling and analysis were carried out using Ansys software to evaluate stress and strains due to processing temperature and applied load for various structural components. Stiffeners were used to test the structural components with open cell geometry. The manufactured structural components were tested using line, patch, and 3/4-point bending loads (Tables A.5 and A.6).

Table A. 6 Bending tests on structural components (Amarnath, 2006)

\begin{tabular}{|c|c|c|c|c|}
\hline \multicolumn{2}{|c|}{ Component Type Without and With Fabric } & $\begin{array}{c}\text { No. of } \\
\text { Components } \\
\text { Tested } \\
\end{array}$ & $\begin{array}{c}\text { Testing within } 75 \% \text { of } \\
\text { Peak Load }\end{array}$ & Testing to Failure \\
\hline \multirow{3}{*}{ Rectangular Grid } & \multirow{2}{*}{ Without Stiffeners } & 3 & - & Patch Load \\
\hline & & 2 & Patch Load & - \\
\hline & With Stiffeners & 2 & Patch Load & Patch Load \\
\hline \multirow{3}{*}{$\begin{array}{c}\text { Hexagonal Stiffened } \\
\text { Panel }\end{array}$} & \multirow[b]{2}{*}{ Without Stiffeners } & 3 & - & Line Load \\
\hline & & 2 & $\begin{array}{l}\text { (i) Line Load \& } \\
\text { (ii) Patch Load }\end{array}$ & Line Load \\
\hline & With Stiffeners & 2 & $\begin{array}{l}\text { (i) Line Load \& } \\
\text { (ii) Patch Load }\end{array}$ & Patch Load \\
\hline \multirow{2}{*}{$\begin{array}{c}\text { Rectangular Ribbed } \\
\text { Panel }\end{array}$} & Without Stiffeners & \multirow{2}{*}{2} & $\begin{array}{l}\text { (i) Line Load \& } \\
\text { (ii) Patch Load }\end{array}$ & - \\
\hline & With Stiffeners & & $\begin{array}{l}\text { (i) Line Load \& } \\
\text { (ii) Patch Load }\end{array}$ & Patch Load \\
\hline \multirow[b]{2}{*}{ Signpost } & Without Stiffeners & 3 & 3 Point Bending & \multirow[b]{2}{*}{4 Point Bending } \\
\hline & With Stiffeners & 2 & $\begin{array}{l}\text { (i) } 3 \text { Point Bending \& } \\
\text { (ii) } 4 \text { Point Bending }\end{array}$ & \\
\hline Signboard & Without Stiffeners & 3 & - & Line Load \\
\hline
\end{tabular}

Past research work at CFC-WVU shows that manufacturing and evaluation of coupon specimens, components, and structural products with recycled FRPs with and without glass reinforcement (Tables A.1 through A.6). Based on the positive results regarding the use of 
recycled composites for structural applications, this research focuses on their long term mechanical properties through aging studies. 


\section{Appendix B}

\section{B.1 Moisture Diffusion Co-efficient}

Shah et al. (2002) carried out moisture diffusion test in distilled water on neat resin vinylester specimens at room temperature $(25 \square \mathrm{C}$ ). Authors weighed samples (after drying with lint-free tissue) at regular intervals for 10 days and weight readings were monitored every 15 minutes on the first day. Fickian theory was used to calculate the diffusion co-efficient, for one-dimensional and unsteady diffusion as reported by Shah et al. (2002).

$$
\frac{\partial c}{\partial t}=D \frac{\partial^{2} c}{\partial x^{2}}
$$

Solving equation (6.1) with constant boundary conditions of time and concentration, it reduces to equation (B.2). During the primary stage of diffusion, the solution for Fick's law is reduced to

$$
\frac{M_{t}}{M_{\infty}}=\left[1-\sum_{0}^{\infty} \frac{8}{-D(2 \mathrm{n}+1)^{2} \pi^{2}} \exp \left[\frac{-D(2 n+1)^{2} \pi^{2} t}{4 l^{2}}\right]\right]
$$

$D$ - Diffusion co-efficient, $c$ - concentration, $t$ - time, $x$ - is the position in the Diffusion direction, $M_{\infty}$ - equilibrium increase in specimen mass, $M_{t}$ - moisture uptake.

$\frac{M_{t}}{M_{\infty}}=4\left(\frac{D t}{\pi(2 l)^{2}}\right)^{1 / 2}$

Finally, Shah et al. (2002) reported that the diffusion co-efficient can be evaluated by the initial slope of $M_{t} / M_{\infty}$ versus $\mathrm{t}^{1 / 2} / 2 l$ using short time uptake. 


\section{Appendix C}

\section{Summary of Coupon Strength Variations under Salt and Alkaline Aging at Room Temperature and Freeze-thaw}

\section{C.1 Summary for tension strength under aging}

Summary of the strength gain and/or loss of thermoplastic tension specimens after $1 \mathrm{M}, 4 \mathrm{M}, 8 \mathrm{M}$

and $12 \mathrm{M}$ of aging in alkaline and salt solution at room temperature and freeze-thaw are assembled (Tables C.1 and C.2).

Table C. 1 Strength variations for non-fabric tension test specimens subjected to aging for 1, 4, 8 and 12 months

\begin{tabular}{|c|c|c|c|c|c|c|c|c|c|c|}
\hline \multicolumn{11}{|c|}{ Tension } \\
\hline \multirow{2}{*}{$\begin{array}{c}\text { Aging } \\
\text { Scheme }\end{array}$} & \multirow[b]{2}{*}{ Layers } & \multirow{2}{*}{$\begin{array}{c}\text { Base } \\
\text { test } \\
\text { (psi) }\end{array}$} & \multicolumn{2}{|c|}{$1 \mathrm{M}$} & \multicolumn{2}{|c|}{$4 \mathrm{M}$} & \multicolumn{2}{|c|}{$8 \mathrm{M}$} & \multicolumn{2}{|c|}{$12 \mathrm{M}$} \\
\hline & & & $\begin{array}{l}\text { Stress } \\
\text { (psi) }\end{array}$ & $\begin{array}{c}\% \\
\text { change }\end{array}$ & $\begin{array}{c}\text { Stress } \\
\text { (psi) }\end{array}$ & $\begin{array}{c}\% \\
\text { change }\end{array}$ & $\begin{array}{c}\text { stress } \\
\text { (psi) }\end{array}$ & $\begin{array}{c}\% \\
\text { change }\end{array}$ & $\begin{array}{l}\text { Stress } \\
\text { (psi) }\end{array}$ & $\begin{array}{c}\% \\
\text { change }\end{array}$ \\
\hline ASRT & \multirow{4}{*}{ No fiber } & \multirow{4}{*}{4112} & 3660 & -11 & -- & -- & 3570 & -13 & 3633 & -12 \\
\hline ASFT & & & 3863 & -6 & -- & -- & 3855 & -6 & 3692 & -10 \\
\hline SSRT & & & 4325 & 5 & -- & -- & -- & -- & 3331 & -19 \\
\hline SSFT & & & 3778 & -8 & - & - & 3309 & -20 & 4140 & 1 \\
\hline
\end{tabular}

Note: AS: Alkaline solution, SS: Salt solution, RT: room temperature, FT: Freeze-thaw

Table C. 2 Strength variations for tension test specimens subjected to aging for 1, 4, 8 and 12 months

\begin{tabular}{|c|c|c|c|c|c|c|c|c|c|}
\hline Tension & \multicolumn{9}{|c|}{ Alkaline solution room temperature } \\
\hline \multirow[b]{2}{*}{ Layers } & \multirow[b]{2}{*}{$\begin{array}{c}\text { Base } \\
\text { test } \\
\text { (psi) }\end{array}$} & \multicolumn{2}{|c|}{$1 \mathrm{M}$} & \multicolumn{2}{|c|}{$4 \mathrm{M}$} & \multicolumn{2}{|c|}{$8 \mathrm{M}$} & \multicolumn{2}{|c|}{$12 \mathrm{M}$} \\
\hline & & $\begin{array}{c}\text { Stress } \\
(\mathrm{psi})\end{array}$ & $\begin{array}{c}\% \\
\text { change }\end{array}$ & $\begin{array}{c}\text { Stress } \\
\text { (psi) }\end{array}$ & $\begin{array}{c}\% \\
\text { chang } \\
\mathrm{e}\end{array}$ & $\begin{array}{l}\text { stress } \\
\text { (psi) }\end{array}$ & $\begin{array}{c}\% \\
\text { change }\end{array}$ & $\begin{array}{c}\text { Stress } \\
(\mathrm{psi})\end{array}$ & $\begin{array}{c}\% \\
\text { change }\end{array}$ \\
\hline No fiber & 4112 & 3660 & -11 & -- & -- & 3570 & -13 & 3633 & -12 \\
\hline 1-layer & 5010 & 5141 & 2.61 & 4622 & -7.75 & 3790 & -24.36 & 3892 & -22.32 \\
\hline 3-layers & 8563 & 6999 & -18.26 & 6381 & -25.48 & 4310 & -49.67 & 3916 & -54.26 \\
\hline 5-layers & 10484 & 7624 & -27.28 & 8382 & -20.05 & 4106 & -60.83 & 3589 & -65.76 \\
\hline \multicolumn{10}{|c|}{ Alkaline solution freeze-thaw variation } \\
\hline \multirow[b]{2}{*}{ Layers } & \multirow[b]{2}{*}{$\begin{array}{c}\text { Base } \\
\text { test } \\
\text { (psi) }\end{array}$} & \multicolumn{2}{|c|}{$1 \mathrm{M}$} & \multicolumn{2}{|c|}{$4 \mathrm{M}$} & \multicolumn{2}{|c|}{$8 \mathrm{M}$} & \multicolumn{2}{|c|}{$12 \mathrm{M}$} \\
\hline & & $\begin{array}{c}\text { Stress } \\
\text { (psi) }\end{array}$ & $\begin{array}{c}\% \\
\text { change }\end{array}$ & $\begin{array}{c}\text { Stress } \\
\text { (psi) }\end{array}$ & $\begin{array}{c}\% \\
\text { chang } \\
\mathrm{e}\end{array}$ & $\begin{array}{c}\text { Stress } \\
\text { (psi) }\end{array}$ & $\begin{array}{c}\% \\
\text { change }\end{array}$ & $\begin{array}{c}\text { Stress } \\
(\mathrm{psi})\end{array}$ & $\begin{array}{c}\% \\
\text { change }\end{array}$ \\
\hline No fiber & 4112 & 3863 & -6 & -- & -- & 3855 & -6 & 3692 & -10 \\
\hline 1-layer & 5010 & 3790 & -24.35 & 3683 & -26.47 & 4126 & -17.64 & 3349 & -33.15 \\
\hline 3-layers & 8563 & 4267.32 & -50.17 & 3685 & -56.96 & 4114 & -51.95 & 3300 & -61.46 \\
\hline
\end{tabular}




\begin{tabular}{|c|c|c|c|c|c|c|c|c|c|}
\hline 5-layers & 10484 & 4199 & -68.31 & 3645 & -65.23 & 3642 & -65.26 & 2613 & -75.07 \\
\hline \multicolumn{10}{|c|}{ Salt solution room temperature } \\
\hline \multirow[b]{2}{*}{ Layers } & \multirow[b]{2}{*}{$\begin{array}{c}\text { Base } \\
\text { test } \\
\text { (psi) }\end{array}$} & \multicolumn{2}{|c|}{$1 \mathrm{M}$} & \multicolumn{2}{|c|}{$4 \mathrm{M}$} & \multicolumn{2}{|c|}{$8 \mathrm{M}$} & \multicolumn{2}{|c|}{$12 \mathrm{M}$} \\
\hline & & $\begin{array}{c}\text { Stress } \\
\text { (psi) }\end{array}$ & $\begin{array}{c}\% \\
\text { change }\end{array}$ & $\begin{array}{c}\text { Stress } \\
(\mathrm{psi})\end{array}$ & $\begin{array}{c}\% \\
\text { chang } \\
\mathrm{e}\end{array}$ & $\begin{array}{c}\text { Stress } \\
(\mathrm{psi})\end{array}$ & $\begin{array}{c}\% \\
\text { change }\end{array}$ & $\begin{array}{l}\text { Stress } \\
\text { (psi) }\end{array}$ & $\%$ change \\
\hline No fiber & 4112 & 4325 & 5 & -- & -- & -- & -- & 3331 & -19 \\
\hline 1-layer & 5010 & 5351 & 6.80 & 4657 & -7.03 & 5486 & 9.51 & 4970 & -0.79 \\
\hline 3-layers & 8563 & 8004 & -6.52 & 7731 & -9.71 & 8290 & -3.1 & 7349 & -14.18 \\
\hline 5-layers & 10484 & 8720 & -16.82 & 10097 & -3.69 & 11078 & 5.67 & 8954 & -14.59 \\
\hline \multicolumn{10}{|c|}{ Salt solution freeze-thaw variation } \\
\hline \multirow[b]{2}{*}{ Layers } & \multirow[b]{2}{*}{$\begin{array}{c}\text { Base } \\
\text { test } \\
\text { (psi) }\end{array}$} & \multicolumn{2}{|c|}{$1 \mathrm{M}$} & \multicolumn{2}{|c|}{$4 \mathrm{M}$} & \multicolumn{2}{|c|}{$8 \mathrm{M}$} & \multicolumn{2}{|c|}{$12 \mathrm{M}$} \\
\hline & & $\begin{array}{c}\text { Stress } \\
\text { (psi) }\end{array}$ & $\begin{array}{c}\% \\
\text { change }\end{array}$ & $\begin{array}{c}\text { Stress } \\
(\mathrm{psi})\end{array}$ & $\begin{array}{c}\% \\
\text { chang } \\
\mathrm{e}\end{array}$ & $\begin{array}{l}\text { Stress } \\
\text { (psi) }\end{array}$ & $\begin{array}{c}\% \\
\text { chan } \\
\text { ge }\end{array}$ & $\begin{array}{c}\text { Stress } \\
\text { (psi) }\end{array}$ & $\begin{array}{c}\% \\
\text { change }\end{array}$ \\
\hline No fiber & 4112 & 3778 & -8 & -- & -- & 3309 & -20 & 4140 & 1 \\
\hline 1-layer & 5010 & 4180 & -16.56 & 4500 & -10.17 & 5203 & 3.87 & 4514 & -9.89 \\
\hline 3-layers & 8563 & 6871 & -19.75 & 7170 & -16.27 & 7633 & -10.8 & 6914 & -19.26 \\
\hline 5-layers & 10484 & 6183 & -41.02 & 10207 & -2.64 & 9878 & -5.78 & 8079 & -22.93 \\
\hline
\end{tabular}

Note: Fiber/fabric location within the specimen during compression molding and the degree of protection against direct alkaline exposure influences the results seen in Table C.1 \& C.2

Change in overall tensile strength values of specimens made of recycled ABS polymers with 0 , 1, 3 and 5 layers of glass fabric due to $1,4,8$ and 12 months (1M, 4M, 8M, and $12 \mathrm{M})$ of aging as compared to those without aging are presented (Table C.1 and C.2)

Aging scheme: strength change under alkaline solution room temperature

Strength change with 0-layer: $-11 \%$, NA, $-13 \%,-12 \%$

$$
\begin{aligned}
& \text { 1-layer: } 2.61 \%,-7.75 \%,-24.36 \%, 22.32 \% \\
& \text { 3-layers: }-18.26 \%,-25.48 \%,-49.67 \%,-54.26 \% \\
& \text { 5-layers: }-27.28 \%,-20 \%,-60.86 \%,-65.76 \%
\end{aligned}
$$

Aging scheme: strength change under alkaline solution under freeze-thaw

Strength change with 0-layer: $-6 \%$, NA, $-6 \%,-10 \%$

$$
\text { 1-layer: }-24.35 \%,-26.47 \%,-17.64 \%,-33.15 \%
$$


3-layers: $-50.17 \%,-56.96 \%,-51.95 \%,-61.46 \%$

5-layers: $-68.31 \%,-65.23 \%,-65.26 \%,-75.07 \%$

Aging scheme: strength change under salt solution room temperature

Strength change with 0-layer: 5\%, NA, NA, -19\%

1-layer: $6.80 \%,-7.03 \%, 9.51 \%,-1 \%$

3-layers: $-6.52 \%,-9.71 \%,-3.1 \%,-14.18 \%$

5-layers: $-16.82 \%,-3.69 \%, 5.67 \%,-14.59 \%$

Aging scheme: strength change under salt solution under freeze-thaw

Strength change with 0-layer: $-8 \%$, NA, $-20 \%, 1 \%$

1-layer: $-16.56 \%,-10.17 \%, 3.87 \%,-9.89 \%$

3-layers: $-19.75 \%,-16.27 \%,-10.85 \%,-19.26 \%$

5-layers: $-41.02 \%,-2.64 \%,-5.78 \%,-22.93 \%$

\section{C.1.1 Bar graph for tension strength variation for aged specimens}

Stress variation in tension test specimens due to aging are represented in the form of bar graphs as per various aging scenario.

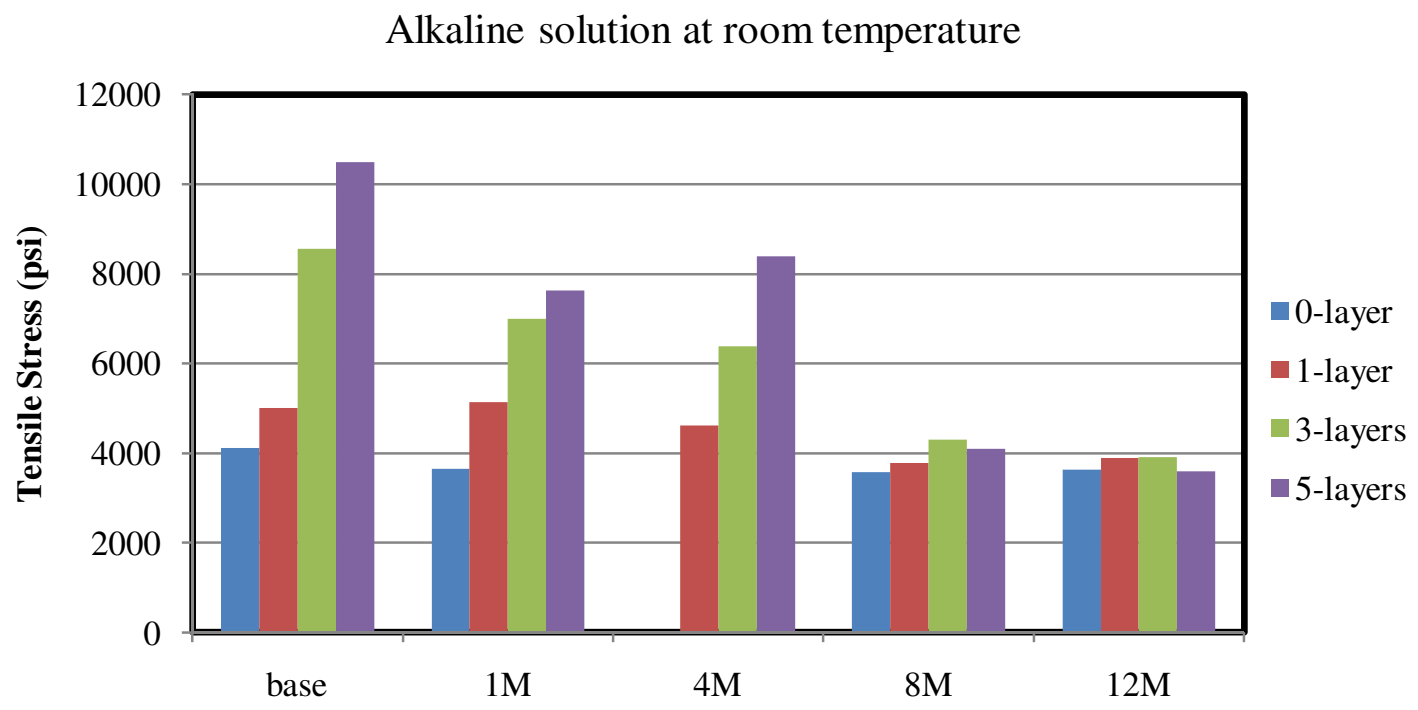

Figure C. 1 Strength reductions in alkaline solution at room temperature 
The variation in tensile strength of specimens with $0,1,3$ and 5 layers of glass fabric aged in alkaline solution at room temperature after 12 months were $-12 \%,-22.32 \%,-54.26 \%$ and 65.76\%, respectively (Figures C.1 and C.2). Strength reduction was higher in 5 layer thermoplastic tension specimens, might be due to exposed fabric-matrix interface at the specimen edge.

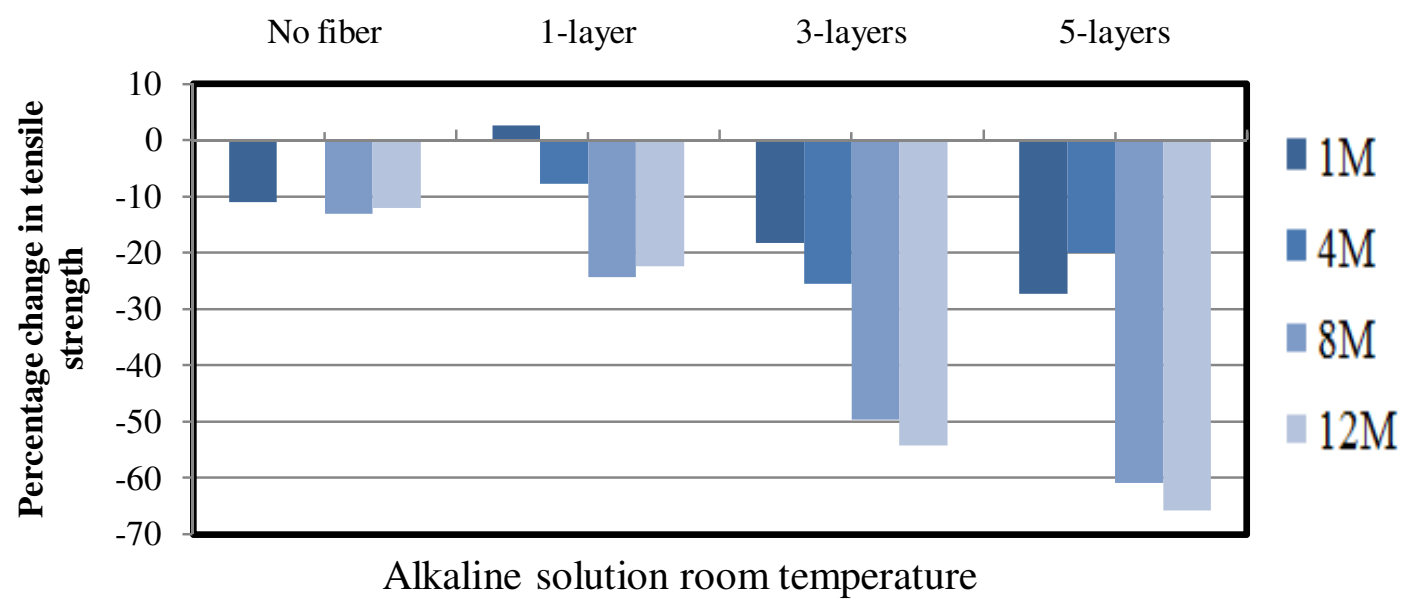

Figure C. 2 Percentage strength reductions in alkaline solution at room temperature

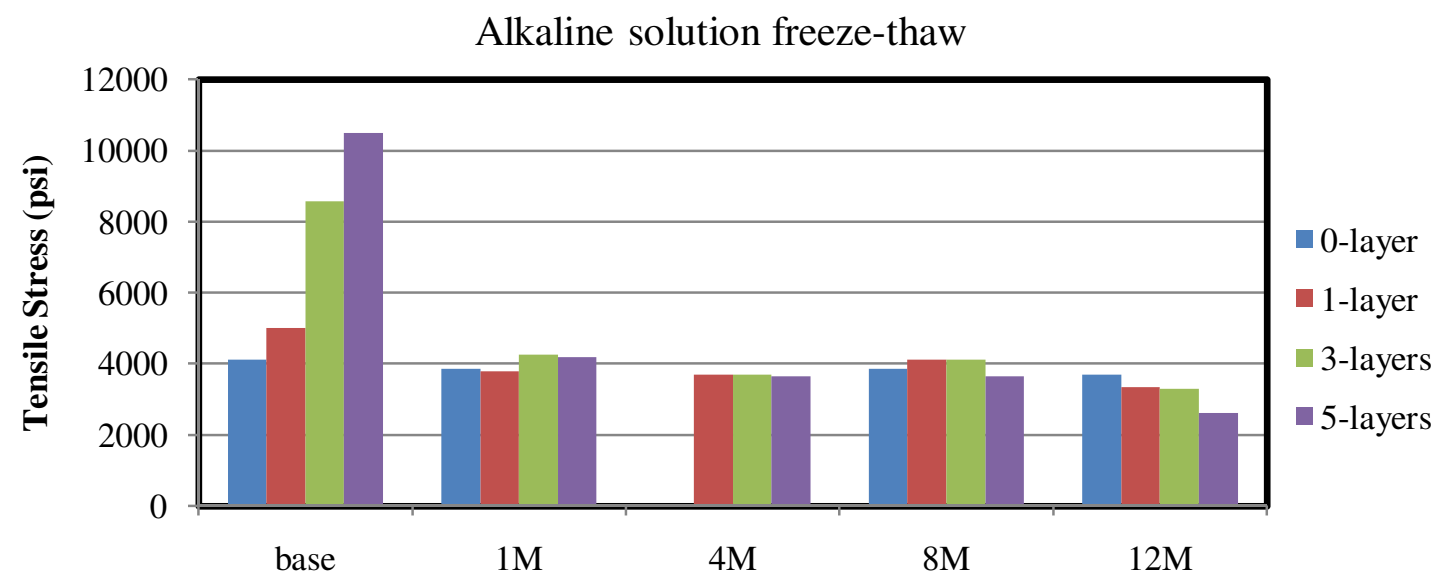

Figure C. 3 Strength reductions in alkaline solution under freeze-thaw

The variation in tensile strength of specimens with $0,1,3$ and 5 layers of glass fabric aged in alkaline solution with freeze-thaw (environmental chamber) after 12 months were -10\%, - 
$33.15 \%,-61.46 \%$, and $-75.07 \%$, respectively (Figures C.3 and C.4). The tensile stress in specimens with 5 layers fabric was lower compared with those without fabrics, which might be due to larger amount of fabric exposed at the tension specimen edges. Strength reduction was higher in 5 layer thermoplastic tension specimens might be due to exposed fabric-matrix interface at the specimen edge.

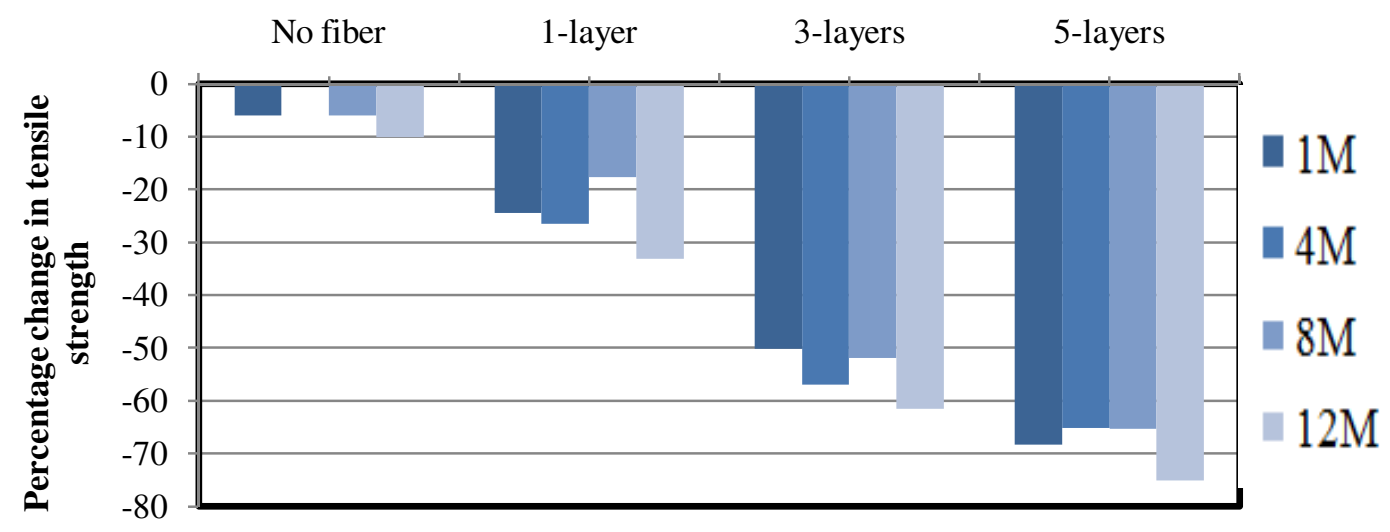

Alkaline solution environmental chamber

Figure C. 4 Percentage strength reductions in alkaline solution under freeze-thaw

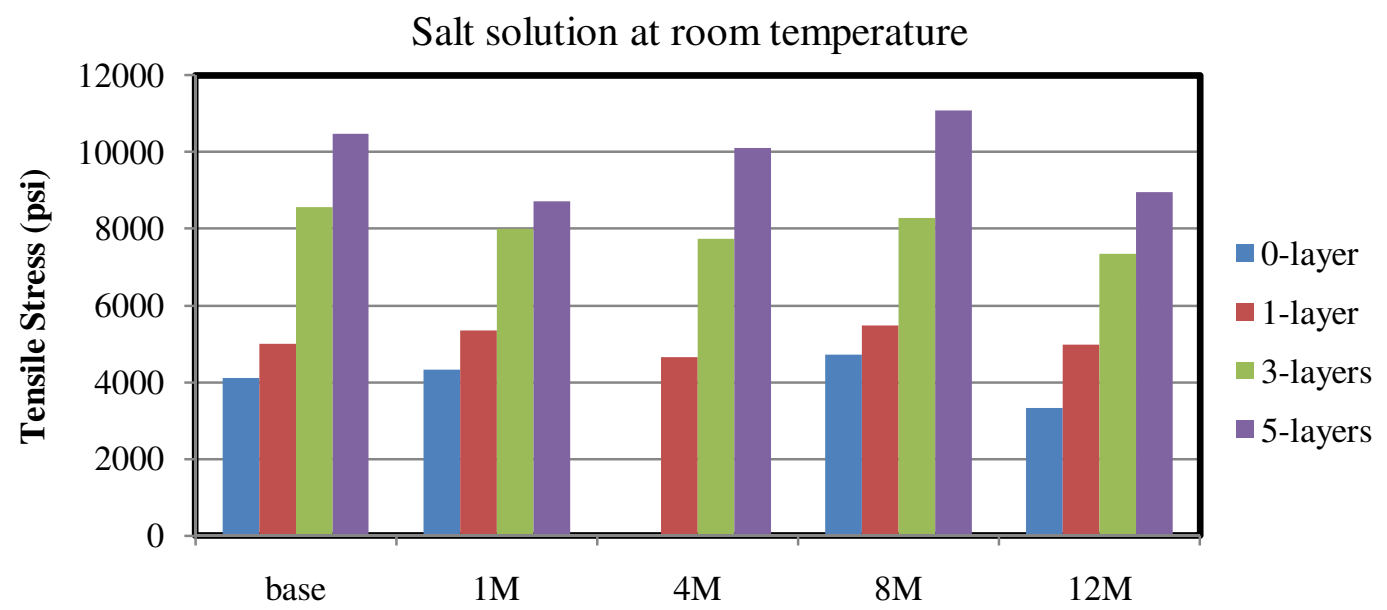

Figure C. 5 Strength reductions in salt solution at room temperature 
The variation in tensile strength of specimens with $0,1,3$ and 5 layers of glass fabric aged in salt solution at room temperature after 12 months were $-19 \%,-1 \%,-14 \%$ and $-15 \%$, respectively (Figures C.5 and C.6).

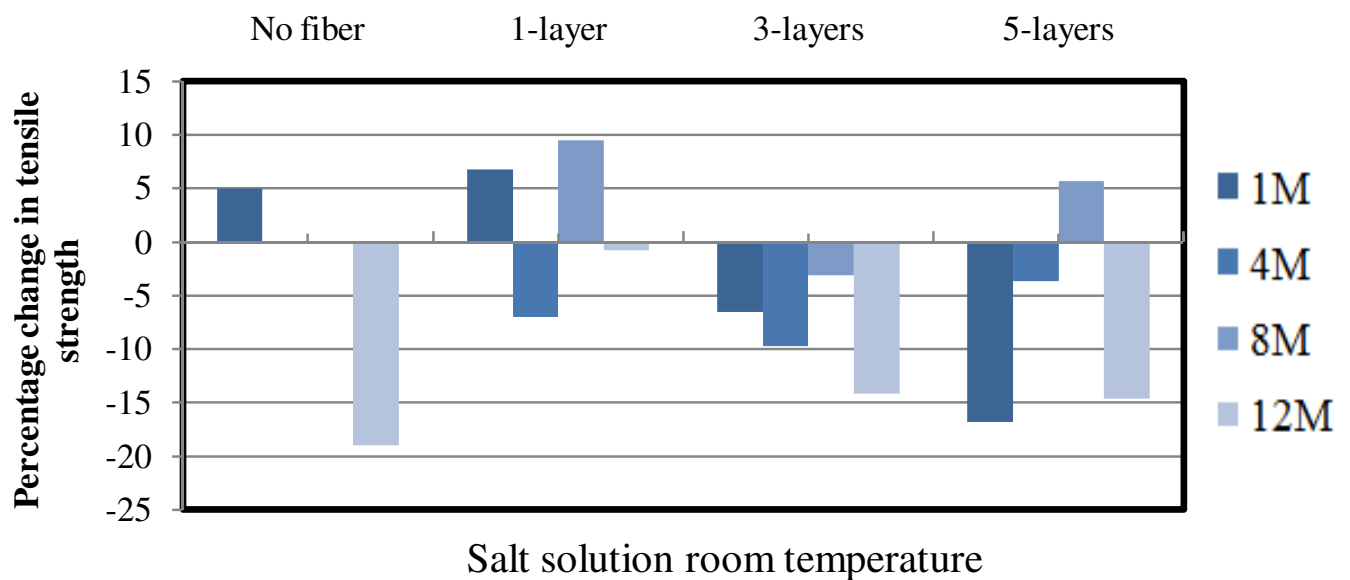

Figure C. 6 Percentage strength reductions in salt solution at room temperature

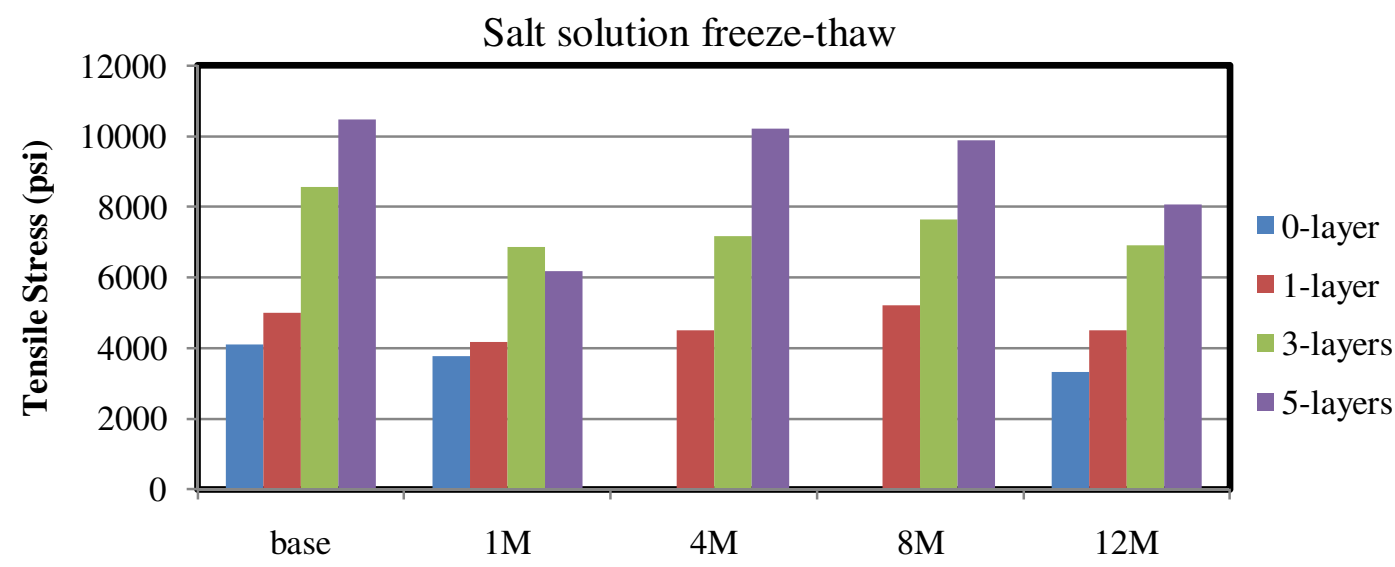

Figure C. 7 Strength reductions in salt solution under freeze-thaw 


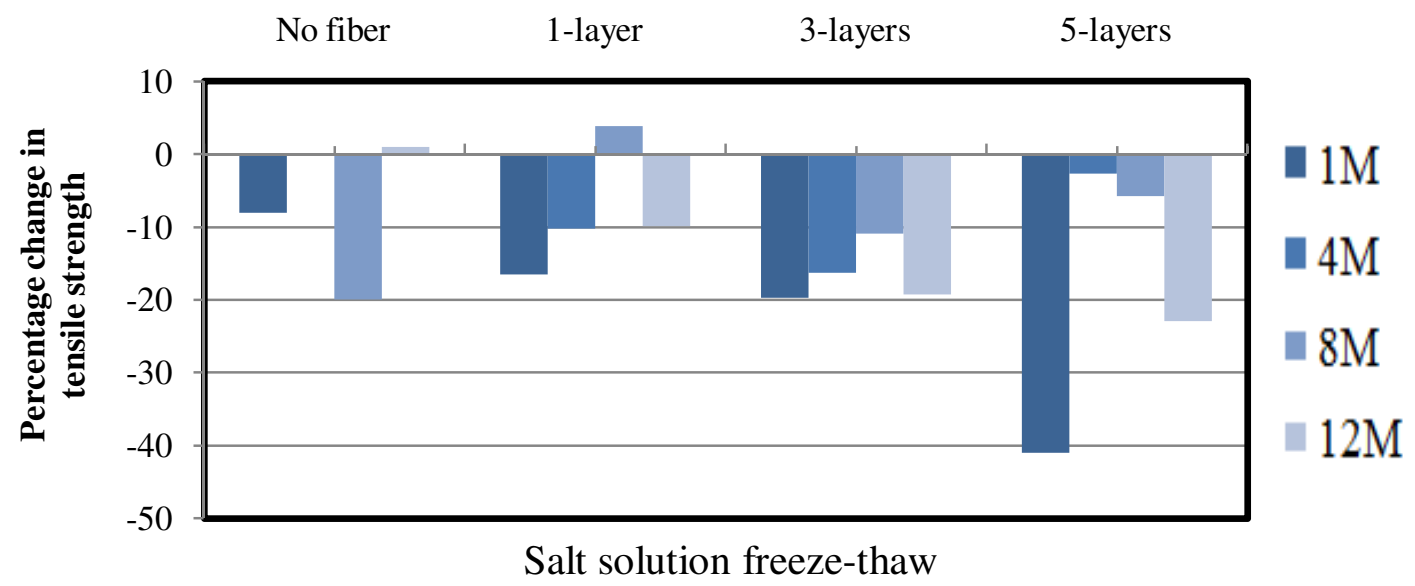

Figure C. 8 Percentage strength reductions in salt solution under freeze-thaw

The variation in tensile strength of specimens with $0,1,3$ and 5 layers of glass fabric aged in salt solution with freeze-thaw (environmental chamber) after 12 months were 1\%, $-9.89 \%,-19.26 \%$, and $-22.93 \%$, respectively (Figure C.7 and C.8).

\section{C.2 Summary for bending strength under aging}

Summary of the strength gain and/or loss of thermoplastic bending specimens after $1 \mathrm{M}, 4 \mathrm{M}, 8 \mathrm{M}$ and $12 \mathrm{M}$ of aging in alkaline and salt solution at room temperature and freeze-thaw are assembled (Table C.3 and C.4).

Table C. 3 Strength variations for non-fabric bending test specimens subjected to aging for 1, 4, 8 and 12 months

\begin{tabular}{|c|c|c|c|c|c|c|c|c|c|c|}
\hline \multicolumn{11}{|c|}{ Bending } \\
\hline \multirow{2}{*}{$\begin{array}{c}\text { Aging } \\
\text { Scheme }\end{array}$} & \multirow[b]{2}{*}{ Layers } & \multirow{2}{*}{$\begin{array}{c}\text { Base } \\
\text { test } \\
\text { (psi) }\end{array}$} & \multicolumn{2}{|c|}{$1 \mathrm{M}$} & \multicolumn{2}{|c|}{$4 \mathrm{M}$} & \multicolumn{2}{|c|}{$8 \mathrm{M}$} & \multicolumn{2}{|c|}{$12 \mathrm{M}$} \\
\hline & & & $\begin{array}{c}\text { Stress } \\
(\mathrm{psi})\end{array}$ & $\begin{array}{c}\% \\
\text { change }\end{array}$ & $\begin{array}{c}\text { Stress } \\
(\mathrm{psi})\end{array}$ & $\begin{array}{c}\% \\
\text { change }\end{array}$ & $\begin{array}{c}\text { Stress } \\
(\mathrm{psi})\end{array}$ & $\begin{array}{c}\% \\
\text { change }\end{array}$ & $\begin{array}{l}\text { Stress } \\
\text { (psi) }\end{array}$ & $\begin{array}{c}\% \\
\text { change }\end{array}$ \\
\hline ASRT & \multirow{4}{*}{$\begin{array}{l}\text { No } \\
\text { fiber }\end{array}$} & \multirow{4}{*}{8516} & 8752 & 2.78 & 7950 & -6.65 & -- & -- & 8616 & 1.18 \\
\hline ASFT & & & 9295 & 9.15 & 7719 & -9.35 & -- & -- & 8662 & 1.71 \\
\hline SSRT & & & 7694 & -9.65 & 8644 & 1.51 & -- & - & 8677 & 1.90 \\
\hline SSFT & & & 9162 & 7.58 & 8298 & -2.56 & -- & -- & 7382 & -13.31 \\
\hline
\end{tabular}

Note: AS: Alkaline solution, SS: Salt solution, RT: room temperature, FT: Freeze-thaw 
Table C. 4 Strength variations for thermoplastic bending test specimens subjected to aging for 1, 4, 8 and 12 months

\begin{tabular}{|c|c|c|c|c|c|c|c|c|c|}
\hline Bending & \multicolumn{9}{|c|}{ Alkaline solution room temperature } \\
\hline \multirow[b]{2}{*}{ Layers } & \multirow{2}{*}{$\begin{array}{c}\text { Base } \\
\text { test } \\
\text { (psi) }\end{array}$} & \multicolumn{2}{|c|}{$1 \mathrm{M}$} & \multicolumn{2}{|c|}{$4 \mathrm{M}$} & \multicolumn{2}{|c|}{$8 \mathrm{M}$} & \multicolumn{2}{|c|}{$12 \mathrm{M}$} \\
\hline & & $\begin{array}{l}\text { Stress } \\
(\mathrm{psi})\end{array}$ & $\begin{array}{c}\% \\
\text { change }\end{array}$ & $\begin{array}{l}\text { Stress } \\
\text { (psi) }\end{array}$ & $\begin{array}{c}\% \\
\text { change }\end{array}$ & $\begin{array}{l}\text { Stress } \\
\text { (psi) }\end{array}$ & $\begin{array}{c}\% \\
\text { change }\end{array}$ & $\begin{array}{l}\text { Stress } \\
\text { (psi) }\end{array}$ & $\begin{array}{c}\% \\
\text { change }\end{array}$ \\
\hline No fiber & 8516 & 873 & 2.78 & 7950 & -6.65 & -- & -- & 8616 & 1.18 \\
\hline 1-layer & 8587 & 9030 & 5.16 & 7999 & -6.84 & -- & -- & 8068 & -6.04 \\
\hline 3-layers & 11045 & 10109 & -8.47 & 8434 & -23.63 & -- & -- & 7714 & -30.15 \\
\hline 5-layers & 13044 & 11239 & -13.84 & 10972 & -15.89 & -- & -- & 7442 & -42.94 \\
\hline \multicolumn{10}{|c|}{ Alkaline solution Freeze-thaw } \\
\hline \multirow[b]{2}{*}{ Layers } & \multirow{2}{*}{$\begin{array}{c}\text { Base } \\
\text { test } \\
\text { (psi) }\end{array}$} & \multicolumn{2}{|c|}{$1 \mathrm{M}$} & \multicolumn{2}{|c|}{$4 \mathrm{M}$} & \multicolumn{2}{|c|}{$8 \mathrm{M}$} & \multicolumn{2}{|c|}{$12 \mathrm{M}$} \\
\hline & & $\begin{array}{c}\text { Stress } \\
(\mathrm{psi})\end{array}$ & $\begin{array}{c}\% \\
\text { change }\end{array}$ & $\begin{array}{l}\text { Stress } \\
(\mathrm{psi})\end{array}$ & $\begin{array}{c}\% \\
\text { change }\end{array}$ & $\begin{array}{l}\text { Stress } \\
(\mathrm{psi})\end{array}$ & $\begin{array}{c}\% \\
\text { change }\end{array}$ & $\begin{array}{c}\text { Stress } \\
\text { (psi) }\end{array}$ & $\begin{array}{c}\% \\
\text { change }\end{array}$ \\
\hline No fiber & 8516 & 9295 & 9.15 & 7719 & -9.35 & -- & -- & 8662 & 1.71 \\
\hline 1-layer & 8587 & 8612 & 0.29 & 8450 & -1.59 & -- & -- & 7403 & -13.78 \\
\hline 3-layers & 11045 & 8061 & -27.02 & 7819 & -29.20 & -- & -- & 7585 & -31.33 \\
\hline 5-layers & 13044 & 6824 & -47.68 & 7436 & -42.99 & -- & -- & 6230 & -52.23 \\
\hline \multicolumn{10}{|c|}{ Salt solution room temperature } \\
\hline \multirow[b]{2}{*}{ Layers } & \multirow{2}{*}{$\begin{array}{c}\text { Base } \\
\text { test } \\
\text { (psi) } \\
\end{array}$} & \multicolumn{2}{|c|}{$1 \mathrm{M}$} & \multicolumn{2}{|c|}{$4 \mathrm{M}$} & \multicolumn{2}{|c|}{$8 \mathrm{M}$} & \multicolumn{2}{|c|}{$12 \mathrm{M}$} \\
\hline & & $\begin{array}{l}\text { Stress } \\
(\mathrm{psi})\end{array}$ & $\begin{array}{c}\% \\
\text { change }\end{array}$ & $\begin{array}{l}\text { Stress } \\
\text { (psi) }\end{array}$ & $\begin{array}{c}\% \\
\text { change }\end{array}$ & $\begin{array}{l}\text { Stress } \\
(\mathrm{psi})\end{array}$ & $\begin{array}{c}\% \\
\text { change }\end{array}$ & $\begin{array}{l}\text { Stress } \\
\text { (psi) }\end{array}$ & $\begin{array}{c}\% \\
\text { change }\end{array}$ \\
\hline No fiber & 8516 & 7694 & -9.65 & 8644 & 1.51 & -- & -- & 8677 & 1.90 \\
\hline 1-layer & 8587 & 7969 & -7.19 & 8465 & -1.42 & -- & -- & 8110 & -5.54 \\
\hline 3-layers & 11045 & 12355 & 11.87 & 10937 & -1 & -- & -- & 11193 & 1.34 \\
\hline 5-layers & 13044 & 13024 & -0.15 & 10718 & -17.83 & -- & -- & 11786 & -9.64 \\
\hline \multicolumn{10}{|c|}{ Salt solution Freeze-thaw } \\
\hline \multirow[b]{2}{*}{ Layers } & \multirow{2}{*}{$\begin{array}{c}\text { Base } \\
\text { test } \\
\text { (psi) }\end{array}$} & \multicolumn{2}{|c|}{$1 \mathrm{M}$} & \multicolumn{2}{|c|}{$4 \mathrm{M}$} & \multicolumn{2}{|c|}{$8 \mathrm{M}$} & \multicolumn{2}{|c|}{$12 \mathrm{M}$} \\
\hline & & $\begin{array}{l}\text { Stress } \\
(\mathrm{psi})\end{array}$ & $\begin{array}{c}\% \\
\text { change }\end{array}$ & $\begin{array}{l}\text { Stress } \\
\text { (psi) }\end{array}$ & $\begin{array}{c}\% \\
\text { change }\end{array}$ & $\begin{array}{l}\text { Stress } \\
\text { (psi) }\end{array}$ & $\begin{array}{c}\% \\
\text { change }\end{array}$ & $\begin{array}{c}\text { Stress } \\
\text { (psi) }\end{array}$ & $\begin{array}{c}\% \\
\text { change }\end{array}$ \\
\hline No fiber & 8516 & 9161 & 7.58 & 8298 & -2.56 & -- & -- & 7382 & -13.31 \\
\hline 1-layer & 8587 & 9042 & 5.31 & 8932 & 4 & -- & -- & 8224 & -4.22 \\
\hline 3-layers & 11045 & 12101 & 9.57 & 10608 & -4 & -- & -- & 10493 & -4.99 \\
\hline 5-layers & 13044 & 12636 & -3.12 & 12354 & -5.3 & -- & -- & 11501 & -11.83 \\
\hline
\end{tabular}

Note: Results not included because of lack of specimens from the same batch for required repetition

Change in overall strength values of specimens made of recycled ABS polymers with $0,1,3$ and

5 layers of glass fabric due to $1,4,8$ and 12 months of aging as compared to those without aging are presented (Table C.3 and C.4). 
Aging scheme: strength change under alkaline solution room temperature

Strength change with 0-layer: $2.78 \%,-6.65 \%$, NA, $1.18 \%$

$$
\begin{aligned}
& \text { 1-layer: 5.16\%, -6.84\%, NA \%, }-6.04 \% \\
& \text { 3-layers: }-8.47 \%,-23.63 \%, \text { NA } \%,-30.15 \% \\
& \text { 5-layers: }-13.84 \%,-15.89 \%, \text { NA } \%,-42.94 \%
\end{aligned}
$$

Aging scheme: strength change under alkaline solution freeze-thaw

Strength change with 0-layer: $9.15 \%,-9.35 \%$, NA, $1.71 \%$

$$
\begin{aligned}
& \text { 1-layer: } 0.29 \%,-1.59 \%, \text { NA } \%,-13.78 \% \\
& \text { 3-layers: }-27.02 \%,-29.2 \% \text {, NA } \%,-31.33 \% \\
& \text { 5-layers: }-47.68 \%,-42.99 \% \text {, NA } \%,-52.23 \%
\end{aligned}
$$

Aging scheme: strength change under salt solution room temperature

Strength change with 0-layer: $-9.65 \%, 1.51 \%$, NA, $1.9 \%$

$$
\begin{aligned}
& \text { 1-layer: }-7.19 \%,-1.42 \% \text {, NA } \%,-5.54 \% \\
& \text { 3-layers: } 11.87 \%,-1 \% \text {, NA } \%, 1.34 \% \\
& \text { 5-layers: }-0.15 \%,-18 \% \text {, NA } \%,-9.64 \%
\end{aligned}
$$

Aging scheme: strength change under salt solution freeze-thaw

Strength change with 0-layer: $7.57 \%,-2.56 \%$, NA, $-13.31 \%$

$$
\begin{aligned}
& \text { 1-layer: } 5.31 \%, 4 \%, \text { NA } \%,-4.22 \% \\
& \text { 3-layers: } 9.57 \%,-4 \%, \text { NA } \%,-4.99 \% \\
& \text { 5-layers: }-3.12 \%,-8.15 \%, \text { NA, }-11.83 \%
\end{aligned}
$$

\section{C.2.1 Bar graph for bending strength variation for aged specimens}

Stress variation in bending test specimens under 12 months of aging are represented in the form of bar graph-chart in following sections 


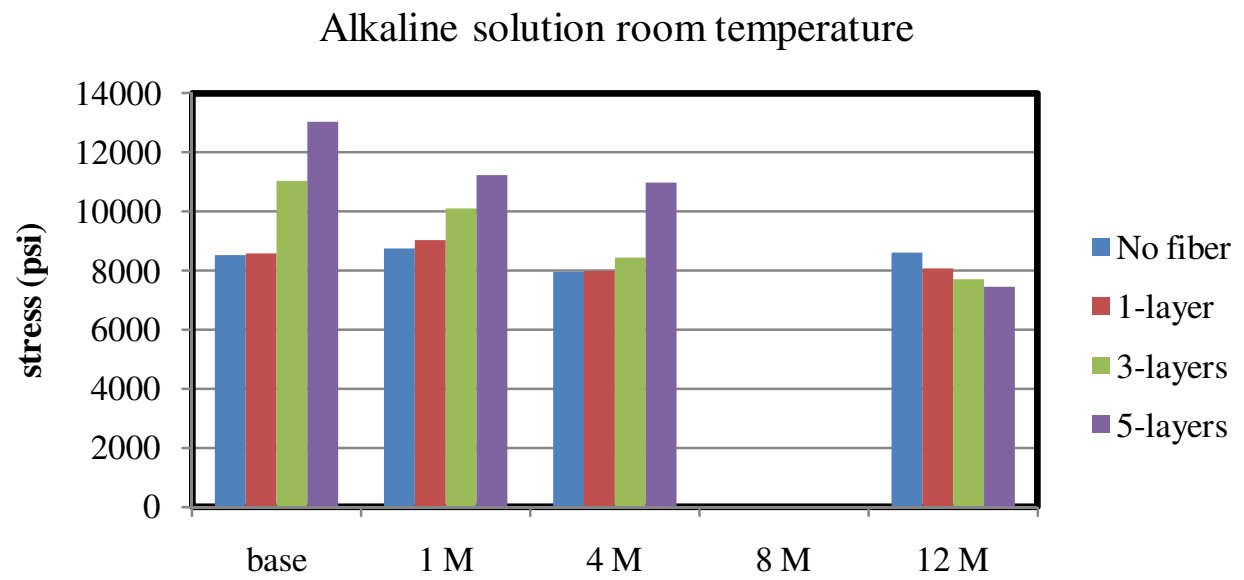

Figure C. 9 Strength reductions in alkaline solution at room temperature

The variation in bending strength of specimens with $0,1,3$ and 5 layers of glass fabric aged in alkaline solution at room temperature after 12 months were $1.18 \%,-6.04 \%,-30.15 \%$ and 42.94\%, respectively (Figures C.9 and C.10).

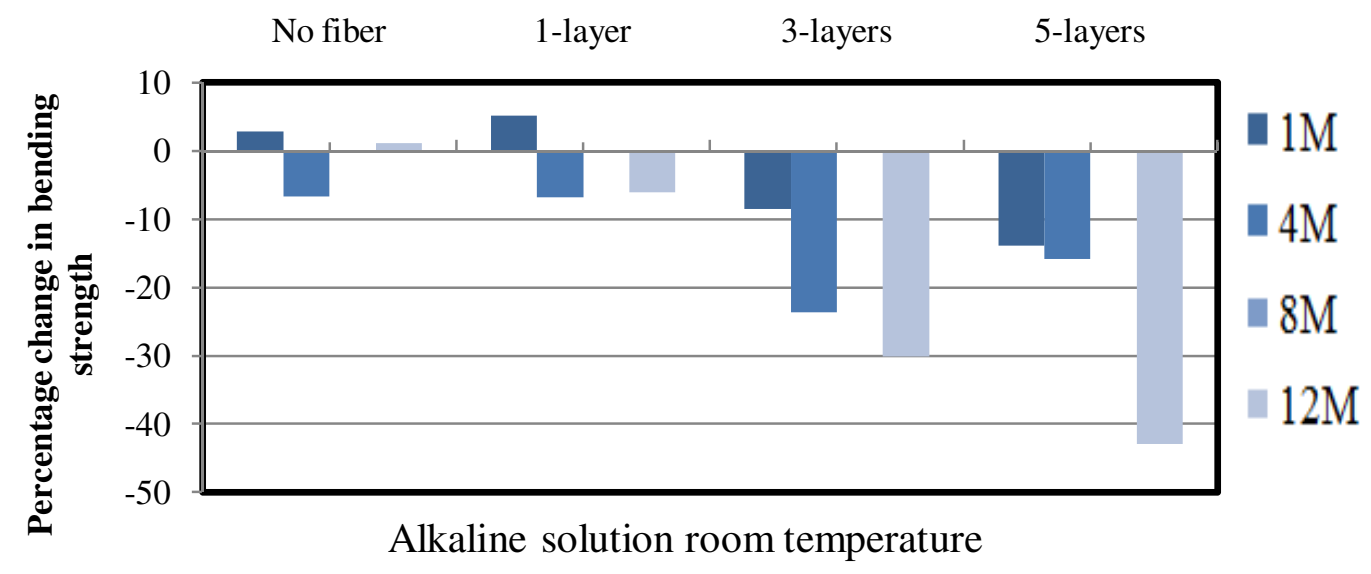

Figure C. 10 Percentage strength reductions in alkaline solution at room temperature 


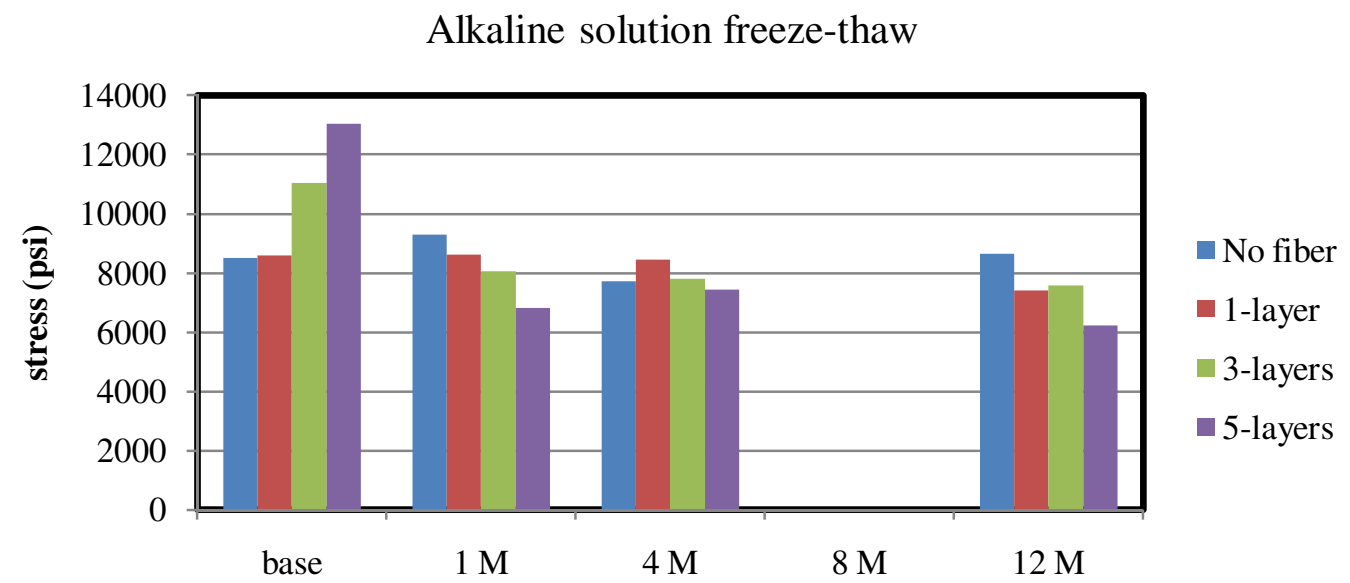

Figure C. 11 Strength reductions in alkaline solution under freeze-thaw

The variation in bending strength of specimens with $0,1,3$ and 5 layers of glass fabric aged in alkaline solution with freeze-thaw (environmental chamber) after 12 months were $1.71 \%$, 13.78\%, $-31.33 \%$ and $-52.23 \%$, respectively (Figures C.11 and C.12). Higher strength reduction in 5 layer thermoplastic bending specimens might be due to exposed fabric-matrix interface at the specimen edge.

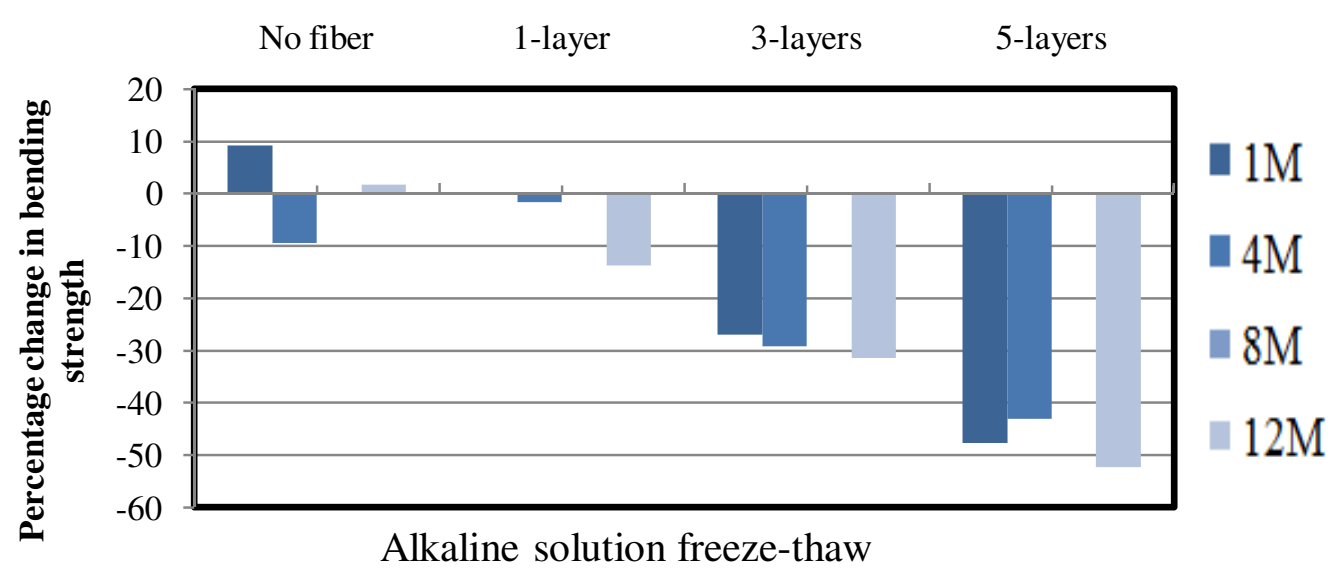

Figure C. 12 Percentage strength reductions in alkaline solution under freeze-thaw 
Salt solution room temperature

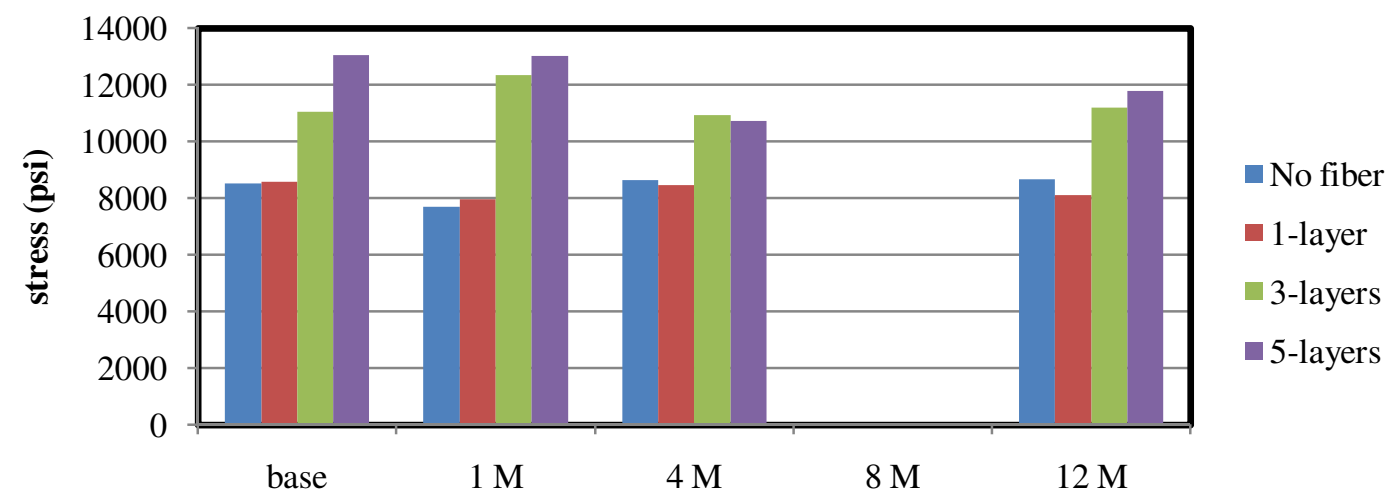

Figure C. 13 Strength reductions in salt solution at room temperature

The variation in bending strength of specimens with $0,1,3$ and 5 layers of glass fabric aged in salt solution at room temperature after 12 months were $2 \%,-6 \%, 1.34 \%$ and $-9.64 \%$, respectively (Figures C.13 and C.14).

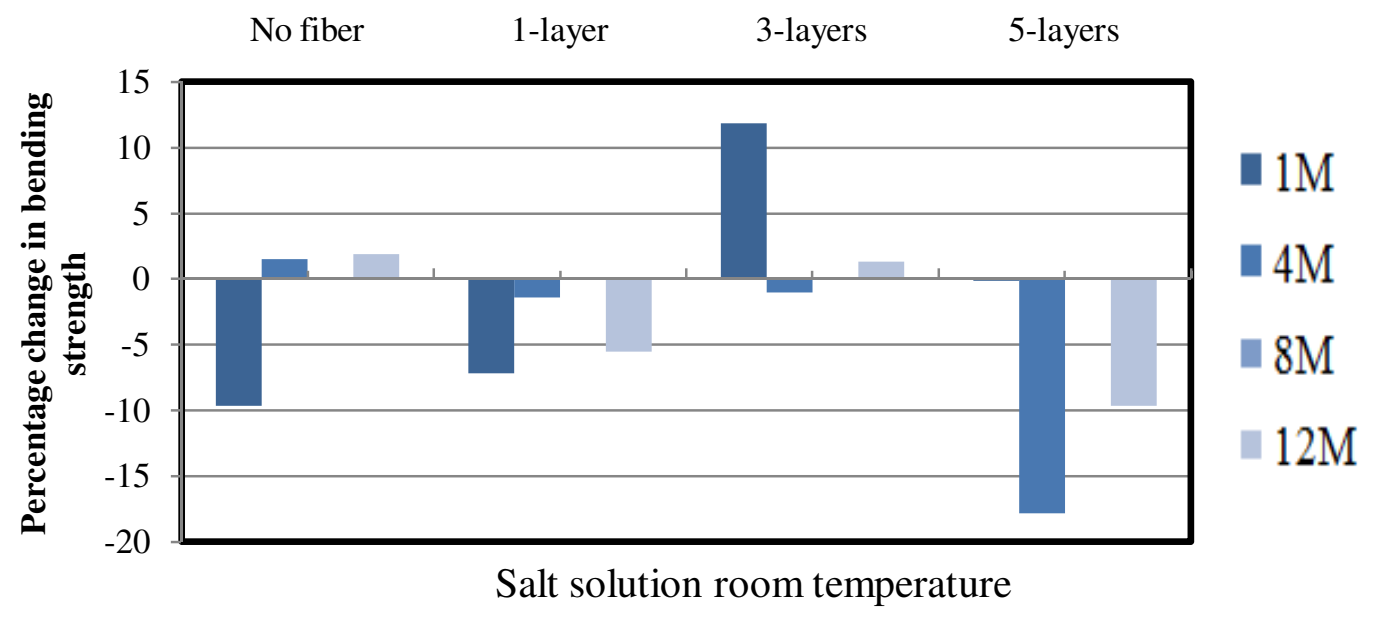

Figure C. 14 Percentage strength reductions in salt solution at room temperature 
Salt solution freeze-thaw

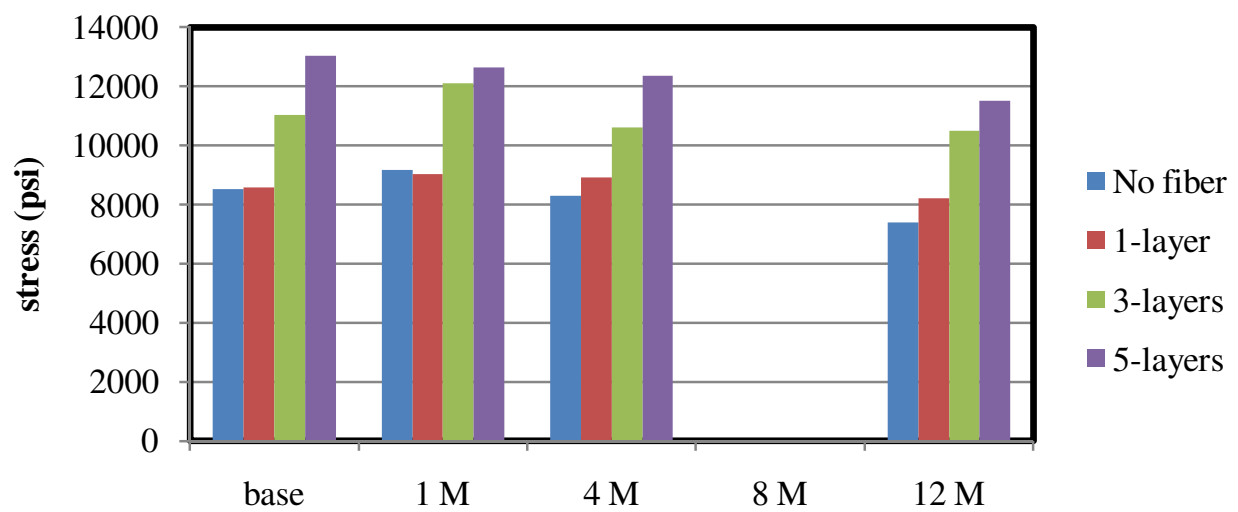

Figure C. 15 Strength reductions in salt solution under freeze-thaw

The variation in bending strength of specimens with $0,1,3$ and 5 layers of glass fabric aged in salt solution with freeze-thaw (environmental chamber) after 12 months were $-13.31 \%,-4.22 \%$, $4.99 \%$ and $-11.83 \%$, respectively (Figures C.15 and C.16).

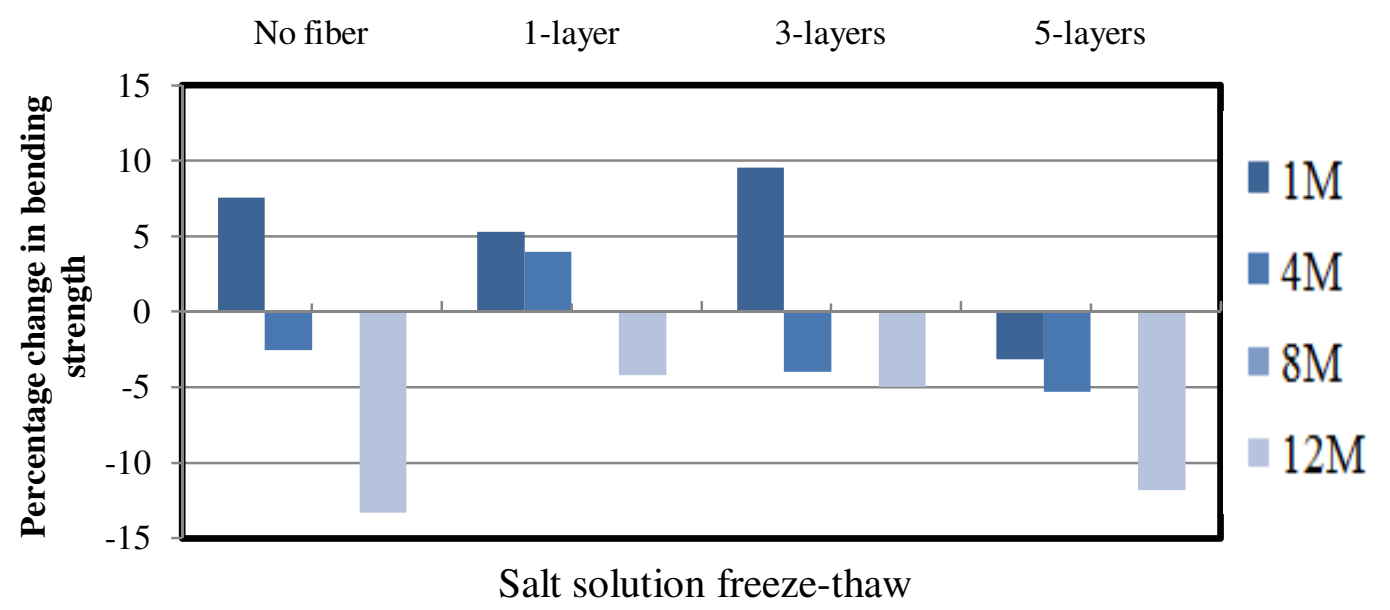

Figure C. 16 Percentage strength reductions in salt solution under freeze-thaw

\section{C.3 Summary for bending strength under aging}

Summary of the strength gain and/or loss of thermoplastic compression specimens after 1M, 4M, $8 \mathrm{M}$ and $12 \mathrm{M}$ of aging in alkaline and salt solution at room temperature and freeze-thaw are assembled (Table C.5 and C.6). 
Table C. 5 Strength variations for non-fabric compression test specimens after 1, 4, 8 and 12 months of aging

\begin{tabular}{|c|c|c|c|c|c|c|c|c|c|c|}
\hline \multicolumn{11}{|c|}{ Compression } \\
\hline \multirow{2}{*}{$\begin{array}{l}\text { Aging } \\
\text { Scheme }\end{array}$} & \multirow[b]{2}{*}{ Layers } & \multirow[b]{2}{*}{$\begin{array}{c}\text { Base } \\
\text { test } \\
\text { (psi) }\end{array}$} & \multicolumn{2}{|c|}{$1 \mathrm{M}$} & \multicolumn{2}{|c|}{$4 \mathrm{M}$} & \multicolumn{2}{|c|}{$8 \mathrm{M}$} & \multicolumn{2}{|c|}{$12 \mathrm{M}$} \\
\hline & & & $\begin{array}{l}\text { stress } \\
\text { (psi) }\end{array}$ & $\begin{array}{c}\% \\
\text { change }\end{array}$ & $\begin{array}{c}\text { stress } \\
\text { (psi) }\end{array}$ & $\begin{array}{c}\% \\
\text { change }\end{array}$ & $\begin{array}{l}\text { stress } \\
\text { (psi) }\end{array}$ & $\begin{array}{c}\% \\
\text { change }\end{array}$ & $\begin{array}{c}\text { stress } \\
(\mathrm{psi})\end{array}$ & $\begin{array}{c}\% \\
\text { change }\end{array}$ \\
\hline ASRT & \multirow{4}{*}{$\begin{array}{l}\text { No } \\
\text { fiber }\end{array}$} & \multirow{4}{*}{8278} & 8778 & 6.04 & 7824 & -5.49 & 8572 & 3.55 & 8031 & -2.98 \\
\hline ASFT & & & 8781 & 6.08 & 8245 & -0.39 & 7299 & -11.82 & 8250 & -0.34 \\
\hline SSRT & & & 8778 & 6.04 & 8121 & -1.89 & 8332 & 0.65 & 8115 & -1.96 \\
\hline SSFT & & & 8555 & 3.35 & 7976 & -3.65 & 7878 & -4.83 & 7836 & -5.33 \\
\hline
\end{tabular}

Note: AS: Alkaline solution, SS: Salt solution, RT: room temperature, FT: Freeze-thaw

Table C. 6 Strength variations for compression test specimens subjected to aging for $1,4,8$ and 12 months

\begin{tabular}{|c|c|c|c|c|c|c|c|c|c|}
\hline Comp & \multicolumn{9}{|c|}{ Alkaline solution room temperature } \\
\hline \multirow[b]{2}{*}{ Layers } & \multirow[b]{2}{*}{$\begin{array}{c}\text { Base } \\
\text { test } \\
\text { (psi) } \\
\end{array}$} & \multicolumn{2}{|c|}{$1 \mathrm{M}$} & \multicolumn{2}{|c|}{$4 \mathrm{M}$} & \multicolumn{2}{|c|}{$8 \mathrm{M}$} & \multicolumn{2}{|c|}{$12 \mathrm{M}$} \\
\hline & & $\begin{array}{c}\text { stress } \\
\text { (psi) }\end{array}$ & $\begin{array}{c}\% \\
\text { change }\end{array}$ & $\begin{array}{l}\text { stress } \\
\text { (psi) }\end{array}$ & $\begin{array}{c}\% \\
\text { change }\end{array}$ & $\begin{array}{c}\text { stress } \\
(\mathrm{psi})\end{array}$ & $\begin{array}{c}\% \\
\text { change }\end{array}$ & $\begin{array}{l}\text { stress } \\
(\mathrm{psi})\end{array}$ & $\begin{array}{c}\% \\
\text { change }\end{array}$ \\
\hline No fiber & 8278 & 8778 & 6.04 & 7824 & -5.49 & 8572 & 3.55 & 8031 & -2.98 \\
\hline 2-layer & 8172 & 7955 & -2.66 & 7426 & -9.13 & 7984 & -2.30 & 7202 & -11.87 \\
\hline 6-layers & 7404 & 7604 & 2.71 & 6970 & -5.86 & 7161 & -3.28 & 6708 & -9.40 \\
\hline 10-layers & 6969 & 6963 & -0.09 & 5662 & -18.75 & 6086 & -12.67 & 5552 & -20.33 \\
\hline \multicolumn{10}{|c|}{ Alkaline solution freeze-thaw } \\
\hline \multirow[b]{2}{*}{ Layers } & \multirow[b]{2}{*}{$\begin{array}{c}\text { Base } \\
\text { test } \\
\text { (psi) }\end{array}$} & \multicolumn{2}{|c|}{$1 \mathrm{M}$} & \multicolumn{2}{|c|}{$4 \mathrm{M}$} & \multicolumn{2}{|c|}{$8 \mathrm{M}$} & \multicolumn{2}{|c|}{$12 \mathrm{M}$} \\
\hline & & $\begin{array}{c}\text { Stress } \\
\text { (psi) }\end{array}$ & $\begin{array}{c}\% \\
\text { change }\end{array}$ & $\begin{array}{l}\text { Stress } \\
\text { (psi) }\end{array}$ & $\begin{array}{c}\% \\
\text { change }\end{array}$ & $\begin{array}{c}\text { Stress } \\
\text { (psi) }\end{array}$ & $\begin{array}{c}\% \\
\text { change }\end{array}$ & $\begin{array}{c}\text { Stress } \\
\text { (psi) }\end{array}$ & $\begin{array}{c}\% \\
\text { change }\end{array}$ \\
\hline No fiber & 8278 & 8781 & 6.08 & 8245 & -0.39 & 7299 & -11.82 & 8250 & -0.34 \\
\hline 2-layer & 8172 & 8337 & 2.02 & 6565 & -19.66 & 6153 & -24.70 & 5720 & -30.00 \\
\hline 6-layers & 7404 & 7503 & 1.34 & 5824 & -21.33 & 6305 & -14.84 & 5224 & -29.44 \\
\hline 10-layers & 6969 & 5454 & -21.74 & 4680 & -32.85 & 4607 & -33.89 & 3780 & -45.75 \\
\hline \multicolumn{10}{|c|}{ Salt solution room temperature } \\
\hline \multirow[b]{2}{*}{ Layers } & \multirow[b]{2}{*}{$\begin{array}{c}\text { Base } \\
\text { test } \\
\text { (psi) } \\
\end{array}$} & \multicolumn{2}{|c|}{$1 \mathrm{M}$} & \multicolumn{2}{|c|}{$4 \mathrm{M}$} & \multicolumn{2}{|c|}{$8 \mathrm{M}$} & \multicolumn{2}{|c|}{$12 \mathrm{M}$} \\
\hline & & $\begin{array}{c}\text { Stress } \\
\text { (psi) }\end{array}$ & $\begin{array}{c}\% \\
\text { change }\end{array}$ & $\begin{array}{l}\text { Stress } \\
(\mathrm{psi})\end{array}$ & $\begin{array}{c}\% \\
\text { change }\end{array}$ & $\begin{array}{c}\text { Stress } \\
\text { (psi) }\end{array}$ & $\begin{array}{c}\% \\
\text { change }\end{array}$ & $\begin{array}{c}\text { Stress } \\
(\mathrm{psi})\end{array}$ & $\begin{array}{c}\% \\
\text { change }\end{array}$ \\
\hline No fiber & 8278 & 8778 & 6.04 & 8121 & -1.89 & 8332 & 0.65 & 8115 & -1.96 \\
\hline 2-layer & 8172 & 8540 & 4.50 & 7468 & -8.61 & 8553 & 4.66 & 7416 & -9.25 \\
\hline 6-layers & 7404 & 8039 & 8.58 & 7088 & -4.26 & 7443 & 0.54 & 7229 & -2.35 \\
\hline 10-layers & 6969 & 6012 & -13.73 & 5887 & -15.52 & 6226 & -10.66 & 6034 & -13.41 \\
\hline
\end{tabular}




\begin{tabular}{|c|c|c|c|c|c|c|c|c|c|}
\hline \multicolumn{10}{|c|}{ Salt solution freeze-thaw } \\
\hline \multirow{2}{*}{ Layers } & \multirow{2}{*}{$\begin{array}{c}\text { Base } \\
\text { test } \\
(\mathrm{psi})\end{array}$} & $\begin{array}{c}\text { Stress } \\
(\mathrm{psi})\end{array}$ & $\begin{array}{c}\% \\
\text { change }\end{array}$ & $\begin{array}{c}\text { Stress } \\
(\mathrm{psi})\end{array}$ & $\begin{array}{c}\% \\
\text { change }\end{array}$ & $\begin{array}{c}\text { Stress } \\
(\mathrm{psi})\end{array}$ & $\begin{array}{c}\% \\
\text { change }\end{array}$ & $\begin{array}{c}\text { Stress } \\
(\mathrm{psi})\end{array}$ & $\begin{array}{c}\% \\
\text { change }\end{array}$ \\
\hline No fiber & 8278 & 8555 & 3.35 & 7976 & -3.65 & 7878 & -4.83 & 7836 & -5.33 \\
\hline 2-layer & 8172 & 8360 & 2.30 & 7508 & -8.12 & 7986 & -2.28 & 7541 & -7.72 \\
\hline 6-layers & 7404 & 7623 & 2.96 & 7379 & -0.33 & 7707 & 4.09 & 7290 & -1.53 \\
\hline 10-layers & 6969 & 6301 & -9.59 & 5822 & -16.46 & 5689 & -18.36 & 5821 & -16.47 \\
\hline
\end{tabular}

Change in overall strength values of specimens made of recycled ABS polymers with $0,1,3$ and 5 layers of glass fabric due to 1, 4, 8 and 12 months of aging as compared to those without aging are presented (Table C.5 and C.6)

Aging scheme: strength change under alkaline solution room temperature

Strength change with 0-layer: $6.04 \%,-5.49 \%, 3.55 \%,-2.98 \%$

$$
\begin{aligned}
& \text { 2-layers: }-2.66 \%,-9.13 \%,-2.3 \%,-11.87 \% \\
& \text { 6-layers: } 2.71 \%,-5.86 \%,-3.28 \%,-9.4 \% \\
& \text { 10-layers: }-0.1 \%,-18.75 \%,-12.67 \%,-20.33 \%
\end{aligned}
$$

Aging scheme: strength change under alkaline solution under freeze-thaw

Strength change with 0-layer: $6.08 \%,-0.4 \%,-11.82 \%,-0.34 \%$

$$
\begin{aligned}
& \text { 2-layers: } 2 \%,-19.66 \%,-24.7 \%,-30 \% \\
& \text { 6-layers: } 1.34 \%,-21.33 \%,-14.84 \%,-29.44 \% \\
& \text { 10-layers: }-21.74 \%,-32.85 \%,-33.89 \%,-45.75 \%
\end{aligned}
$$

Aging scheme: strength change under salt solution room temperature

Strength change with 0-layer: $6.04 \%,-1.89 \%, 0.65 \%,-1.96 \%$

$$
\begin{aligned}
& \text { 2-layers: } 4.5 \%,-8.61 \%, 4.66 \%,-9.25 \% \\
& \text { 6-layers: } 8.58 \%,-4.26 \%, 0.54 \%,-2.35 \% \\
& \text { 10-layers: }-13.73 \%,-15.52 \%,-10.66 \%,-13.41 \%
\end{aligned}
$$

Aging scheme: strength change under salt solution under freeze-thaw 
Strength change with 0-layer: $3.35 \%,-3.65 \%,-4.83 \%,-5.33 \%$

$$
\begin{aligned}
& \text { 2-layers: } 2.3 \%,-8.12 \%,-2.28 \%,-7.72 \% \\
& \text { 6-layers: } 2.96 \%,-0.33 \%, 4.09 \%,-1.53 \% \\
& \text { 10-layers: }-9.59 \%,-16.46 \%,-18.36 \%,-16.47 \%
\end{aligned}
$$

\section{C.3.1 Bar graph for compressive strength variation for aged specimens}

Stress variation in compression test specimens due to aging under 12 months are represented in the form of bar graph-chart in following sections

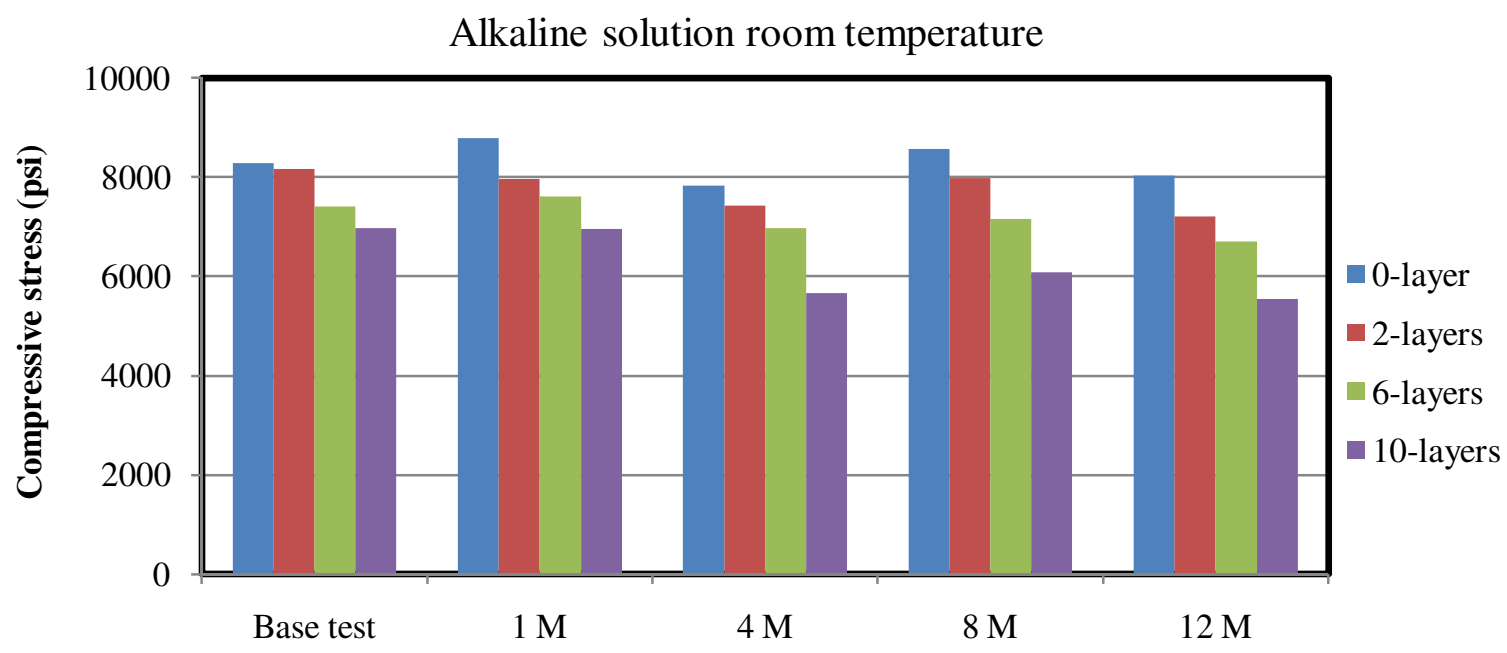

Figure C. 17 Strength reductions in alkaline solution at room temperature

The variation in compressive strength of specimens with $0,1,3$ and 5 layers of glass fabric aged in alkaline solution at room temperature after 12 months were $-2.98 \%,-11.87 \%,-9.4 \%$ and 20.33\%, respectively (Figures C.17 and C.18). 


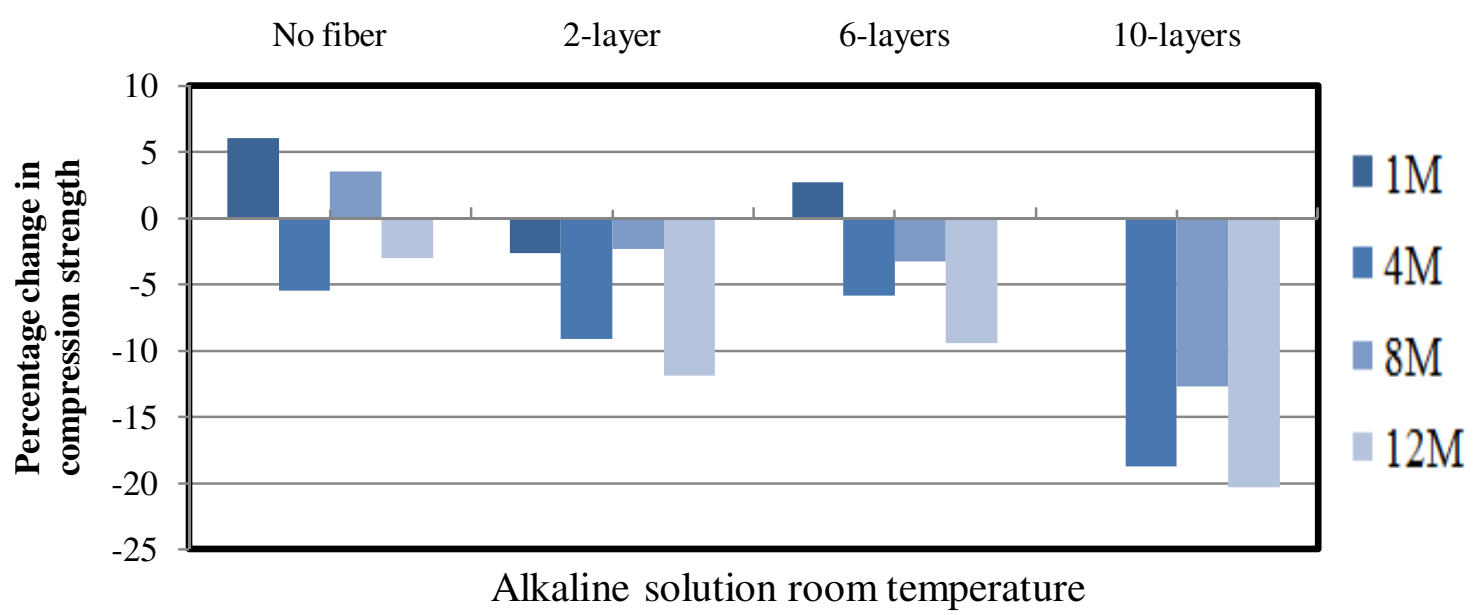

Figure C. 18 Percentage strength reductions in alkaline solution at room temperature

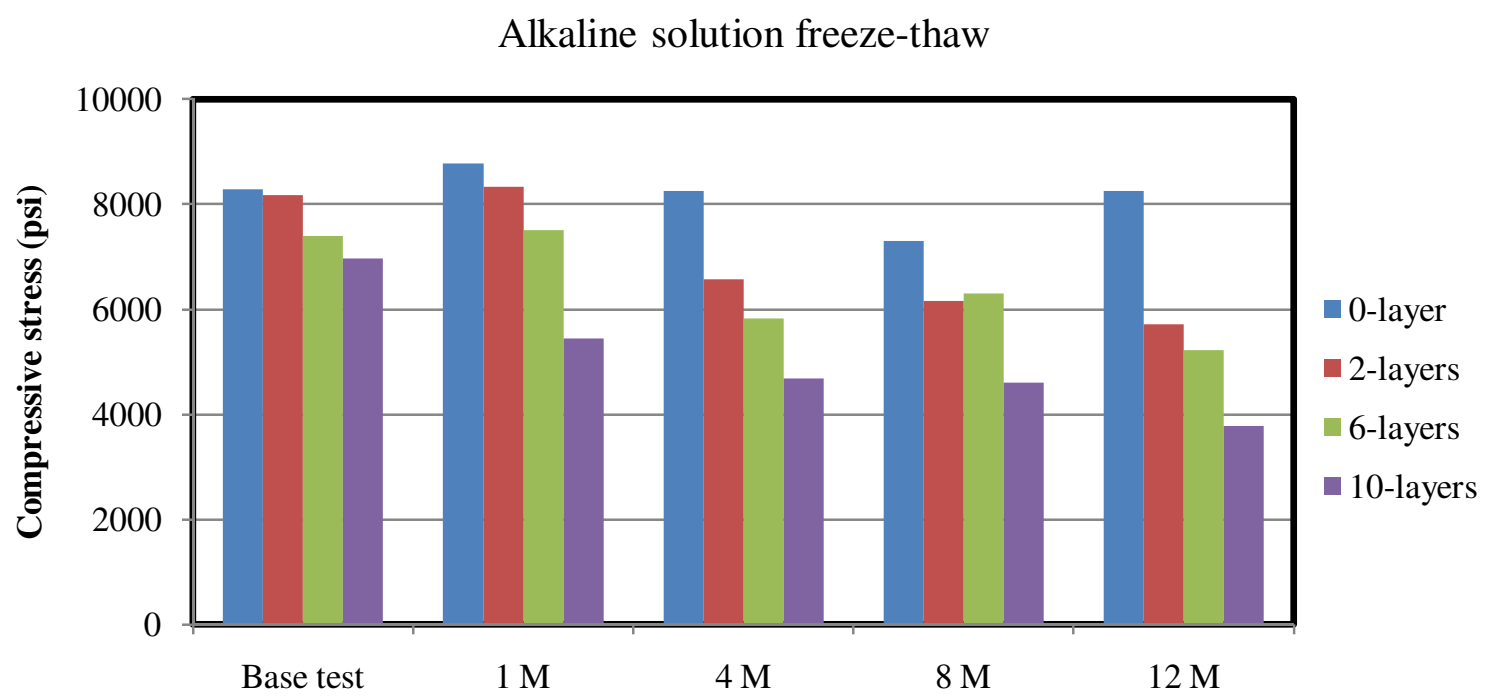

Figure C. 19 Strength reduction in alkaline solution under freeze-thaw

The variation in compressive strength of specimens with $0,1,3$ and 5 layers of glass fabric aged in alkaline solution under freeze-thaw (environmental chamber) after 12 months were -1\%, $30 \%,-29.4 \%$ and $-45.75 \%$, respectively (Figures C.19 and C.20). 


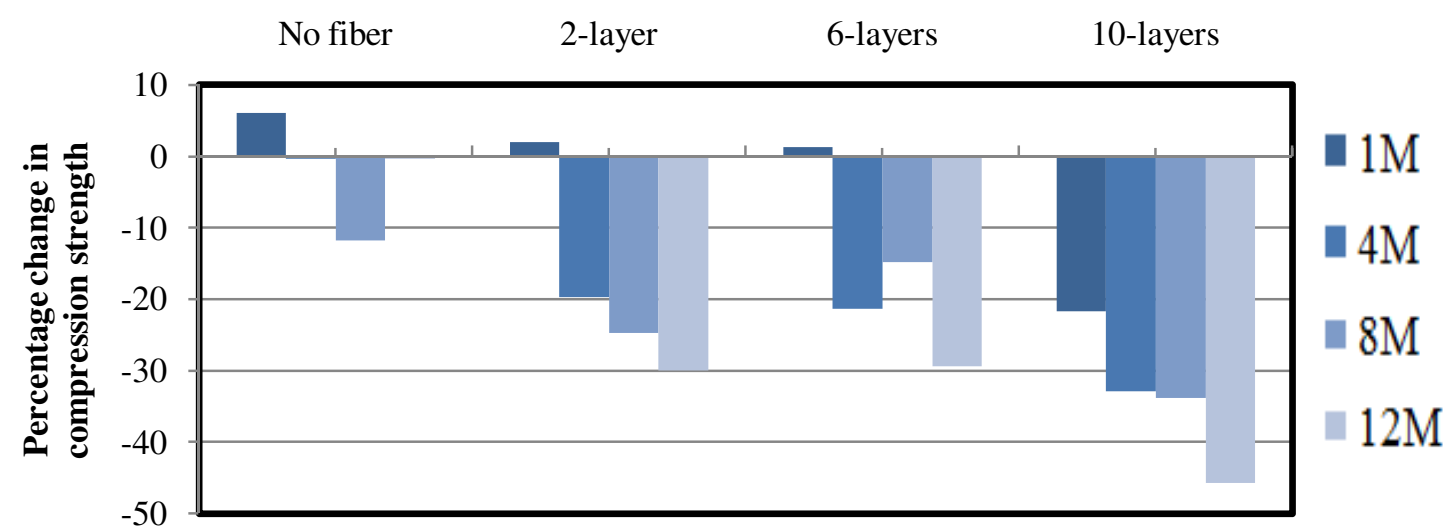

Alkaline solution freeze-thaw

Figure C. 20 Percentage strength reductions in alkaline solution under freeze-thaw

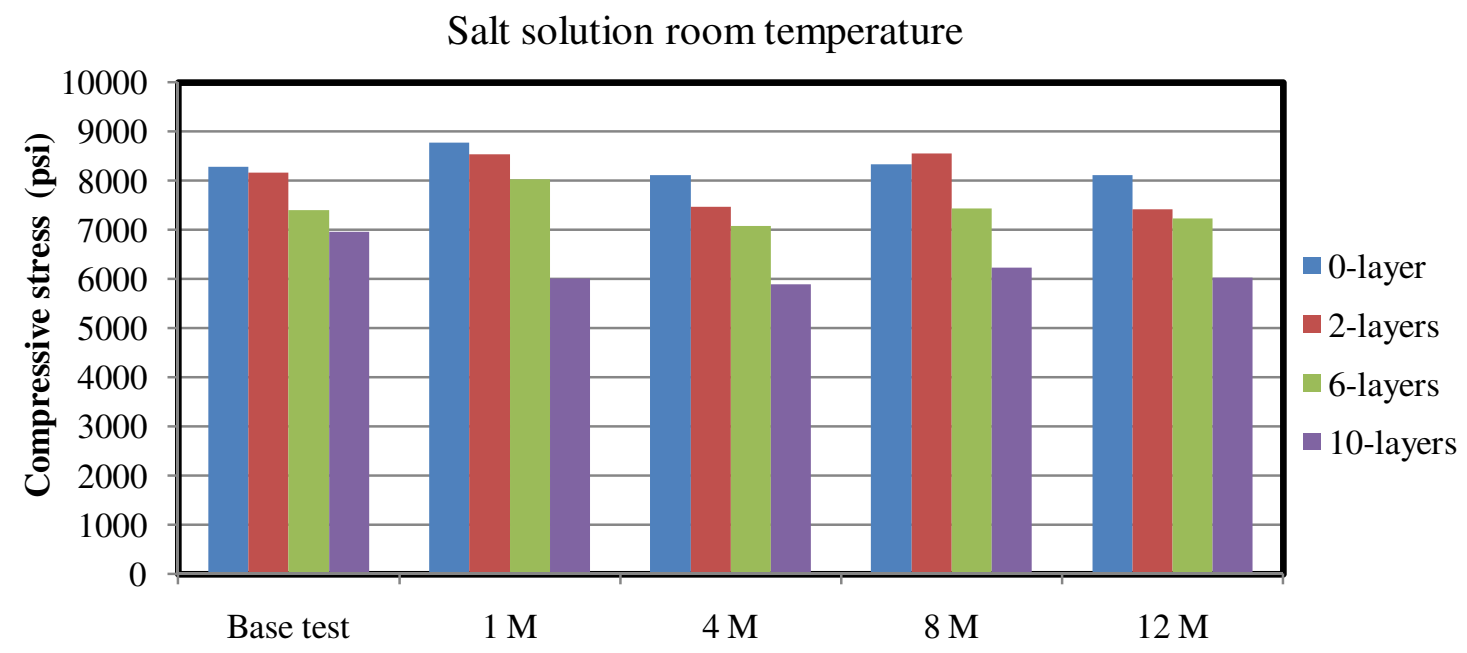

Figure C. 21 Strength reductions in salt solution at room temperature

The variation in compressive strength of specimens with $0,1,3$ and 5 layers of glass fabric aged in salt solution at room temperature after 12 months were $-2 \%,-9.25 \%,-2.35 \%$ and $-13.41 \%$, respectively (Figures C.21 and C.22). 


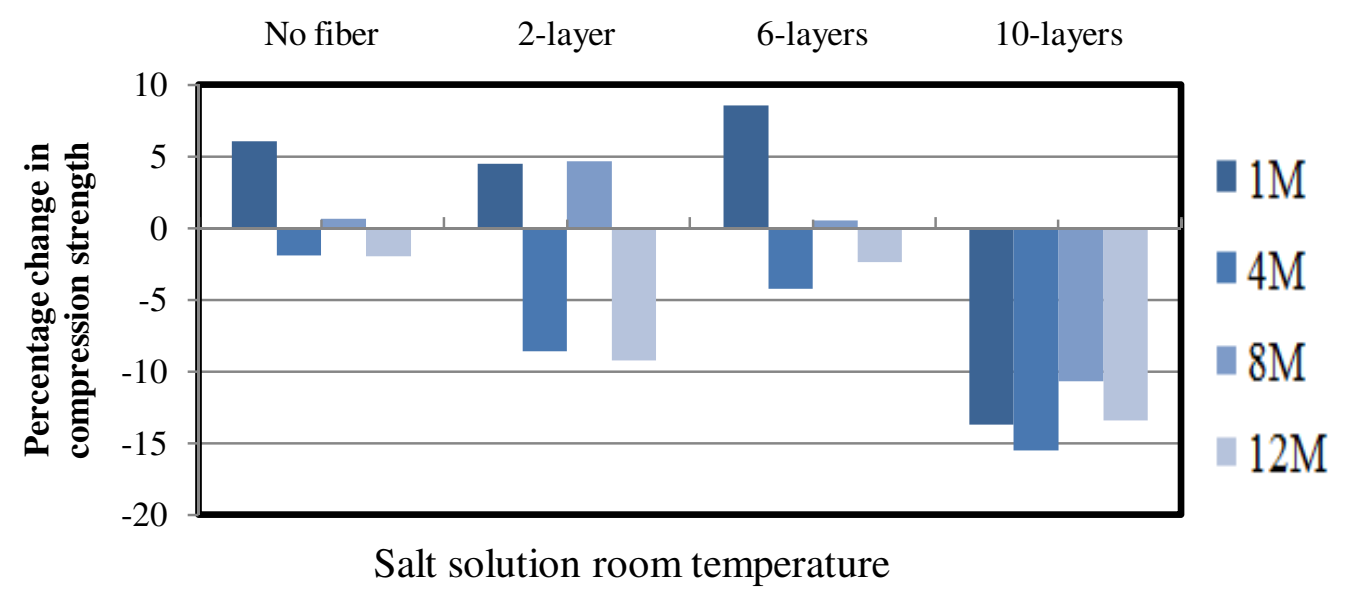

Figure C. 22 Percentage Strength reductions in salt solution at room temperature

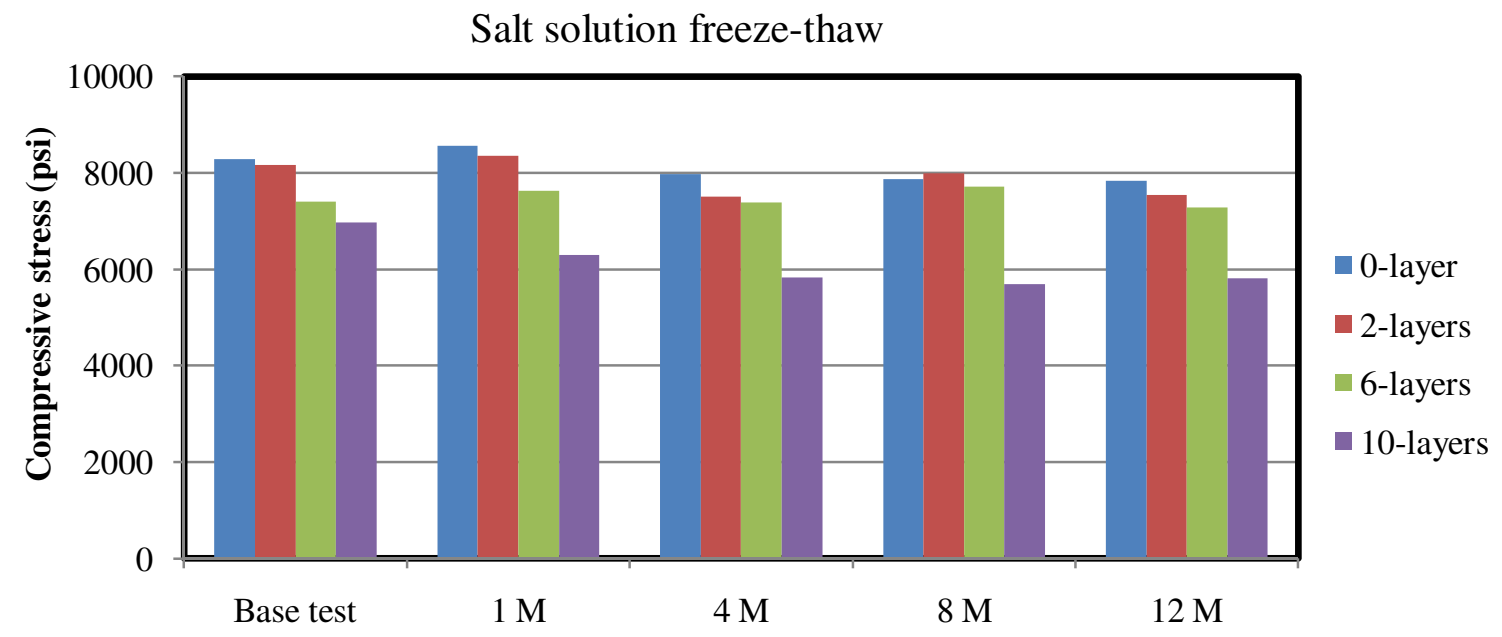

Figure C. 23 Strength reductions in salt solution under freeze-thaw

The variation in compressive strength of specimens with $0,1,3$ and 5 layers of glass fabric aged in salt solution with freeze-thaw (environmental chamber) under 12 months were -5.33\%, $7.72 \%,-2 \%$ and $-16.4 \%$, respectively (Figures C.23 and C.24). 


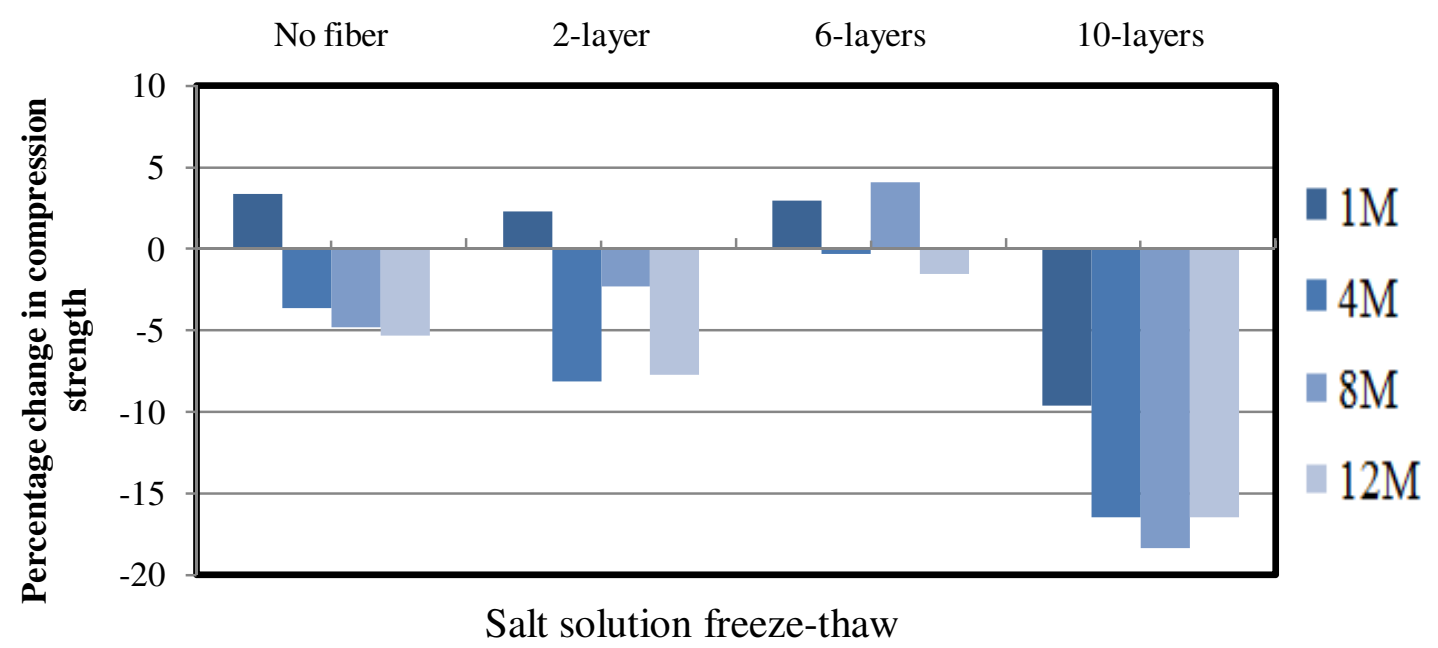

Figure C. 24 Percentage strength reductions in salt solution under freeze-thaw

\section{C.4 Summary for bending strength under aging}

Summary of the strength gain and/or loss of thermoplastic impact specimens after $1 \mathrm{M}, 4 \mathrm{M}, 8 \mathrm{M}$ and $12 \mathrm{M}$ of aging in alkaline and salt solution at room temperature and freeze-thaw are assembled (Table C.7 and C.8)

Table C. 7 Strength variations for non-fabric impact test specimens subjected to aging for 1, 4, 8 and 12 months

\begin{tabular}{|c|c|c|c|c|c|c|c|c|c|c|}
\hline \multicolumn{11}{|c|}{ Impact } \\
\hline \multirow{2}{*}{$\begin{array}{l}\text { Aging } \\
\text { Scheme }\end{array}$} & \multirow{2}{*}{ Layers } & \multirow{2}{*}{$\begin{array}{l}\text { Base } \\
\text { test }\end{array}$} & \multicolumn{2}{|c|}{$1 \mathrm{M}$} & \multicolumn{2}{|c|}{$4 \mathrm{M}$} & \multicolumn{2}{|c|}{$8 \mathrm{M}$} & \multicolumn{2}{|c|}{$12 \mathrm{M}$} \\
\hline & & & $\begin{array}{l}\text { strength } \\
\text { ft.lbs }\end{array}$ & $\begin{array}{c}\% \\
\text { change }\end{array}$ & $\begin{array}{c}\text { strength } \\
\text { ft.lbs }\end{array}$ & $\begin{array}{c}\% \\
\text { change }\end{array}$ & $\begin{array}{l}\text { strength } \\
\text { ft.lbs }\end{array}$ & $\begin{array}{c}\% \\
\text { change }\end{array}$ & $\begin{array}{c}\text { strength } \\
\text { ft.lbs }\end{array}$ & $\begin{array}{c}\% \\
\text { change }\end{array}$ \\
\hline ASRT & \multirow{4}{*}{$\begin{array}{l}\text { No } \\
\text { fiber }\end{array}$} & \multirow{4}{*}{0.36} & 0.35 & -3 & 0.46 & 28 & 0.38 & 6 & 0.42 & 17 \\
\hline ASFT & & & 0.3 & -17 & 0.37 & 3 & 0.38 & 6 & 0.38 & 6 \\
\hline SSRT & & & 0.35 & -3 & 0.44 & 22 & 0.44 & 22 & 0.44 & 22 \\
\hline SSFT & & & 0.39 & 8 & -0.35 & 3 & 0.41 & 14 & 0.48 & 33 \\
\hline
\end{tabular}

Note: AS: Alkaline solution, SS: Salt solution, RT: room temperature, FT: Freeze-thaw 
Table C. 8 Strength variations for impact test specimens subjected to aging for 1, 4, 8 and 12 months

\begin{tabular}{|c|c|c|c|c|c|c|c|c|c|}
\hline Impact & \multicolumn{9}{|c|}{ Alkaline solution room temperature } \\
\hline Layers & \multirow{2}{*}{$\begin{array}{c}\text { Base } \\
\text { test }\end{array}$} & \multicolumn{2}{|c|}{$1 \mathrm{M}$} & \multicolumn{2}{|c|}{$4 \mathrm{M}$} & \multicolumn{2}{|c|}{$8 \mathrm{M}$} & \multicolumn{2}{|c|}{$12 \mathrm{M}$} \\
\hline & & $\begin{array}{l}\text { strength } \\
\text { ft.lbs }\end{array}$ & $\begin{array}{c}\% \\
\text { change }\end{array}$ & $\begin{array}{l}\text { strength } \\
\text { ft.lbs }\end{array}$ & $\begin{array}{c}\% \\
\text { change }\end{array}$ & $\begin{array}{l}\text { strength } \\
\text { ft.lbs }\end{array}$ & $\begin{array}{c}\% \\
\text { change }\end{array}$ & $\begin{array}{l}\text { strength } \\
\text { ft.lbs }\end{array}$ & $\begin{array}{c}\% \\
\text { change }\end{array}$ \\
\hline No fiber & 0.36 & 0.35 & -3 & 0.46 & 28 & 0.38 & 6 & 0.42 & 17 \\
\hline 1-layer & 1.19 & 1.08 & -9.52 & 0.80 & -32.49 & 0.40 & -66.11 & 0.41 & -65.27 \\
\hline 3-layers & 2.21 & 1.68 & -24.02 & 1.76 & -20.40 & 0.60 & -73.01 & 0.60 & -72.71 \\
\hline 5-layers & 5.37 & 4.24 & -21.05 & 2.10 & -60.86 & 0.38 & -92.86 & 0.37 & -93.17 \\
\hline \multicolumn{10}{|c|}{ Alkaline solution under freeze-thaw } \\
\hline Layers & \multirow{2}{*}{$\begin{array}{c}\text { Base } \\
\text { test }\end{array}$} & \multicolumn{2}{|c|}{$1 \mathrm{M}$} & \multicolumn{2}{|c|}{$4 \mathrm{M}$} & \multicolumn{2}{|c|}{$8 \mathrm{M}$} & \multicolumn{2}{|c|}{$12 \mathrm{M}$} \\
\hline & & $\begin{array}{l}\text { strength } \\
\text { ft.lbs }\end{array}$ & $\begin{array}{c}\% \\
\text { change }\end{array}$ & $\begin{array}{l}\text { strength } \\
\text { ft.lbs }\end{array}$ & $\begin{array}{c}\% \\
\text { change }\end{array}$ & $\begin{array}{l}\text { strength } \\
\text { ft.lbs }\end{array}$ & $\begin{array}{c}\% \\
\text { change }\end{array}$ & $\begin{array}{l}\text { strength } \\
\text { ft.lbs }\end{array}$ & $\begin{array}{c}\% \\
\text { change }\end{array}$ \\
\hline No fiber & 0.36 & 0.3 & -17 & 0.37 & 3 & 0.38 & 6 & 0.38 & 6 \\
\hline 1-layer & 1.19 & 0.57 & -52 & 0.35 & -70.87 & 0.35 & -70.59 & 0.37 & -68.63 \\
\hline 3-layers & 2.21 & 1.43 & -35 & 0.79 & -64.12 & 0.37 & -83.42 & 0.42 & -81.15 \\
\hline 5-layers & 5.37 & 1.56 & -70 & 0.89 & -83.48 & 0.37 & -93.04 & 0.37 & -93.17 \\
\hline \multicolumn{10}{|c|}{ Salt solution room temperature } \\
\hline Layers & \multirow[b]{2}{*}{$\begin{array}{c}\text { Base } \\
\text { test }\end{array}$} & \multicolumn{2}{|c|}{$1 \mathrm{M}$} & \multicolumn{2}{|c|}{$4 \mathrm{M}$} & \multicolumn{2}{|c|}{$8 \mathrm{M}$} & \multicolumn{2}{|c|}{$12 \mathrm{M}$} \\
\hline & & $\begin{array}{l}\text { strength } \\
\text { ft.lbs }\end{array}$ & $\begin{array}{c}\% \\
\text { change }\end{array}$ & $\begin{array}{l}\text { strength } \\
\text { ft.lbs }\end{array}$ & $\begin{array}{c}\% \\
\text { change }\end{array}$ & $\begin{array}{l}\text { strength } \\
\text { ft.lbs }\end{array}$ & $\begin{array}{c}\% \\
\text { change }\end{array}$ & $\begin{array}{l}\text { strength } \\
\text { ft.lbs }\end{array}$ & $\begin{array}{c}\% \\
\text { change }\end{array}$ \\
\hline No fiber & 0.36 & 0.35 & -3 & 0.44 & 22 & 0.44 & 22 & 0.44 & 22 \\
\hline 1-layer & 1.19 & 1.77 & 48.74 & 1.19 & -0.28 & 1.04 & -12.32 & 1.16 & -2.24 \\
\hline 3-layers & 2.21 & 2.48 & 12.17 & 2.36 & 6.89 & 2.57 & 16.39 & 2.53 & 14.43 \\
\hline 5-layers & 5.37 & 4.49 & -16.39 & 2.94 & -45.21 & 2.95 & -44.96 & 2.93 & -45.33 \\
\hline \multicolumn{10}{|c|}{ Salt solution under freeze-thaw } \\
\hline Layers & \multirow[b]{2}{*}{$\begin{array}{c}\text { Base } \\
\text { test }\end{array}$} & \multicolumn{2}{|c|}{$1 \mathrm{M}$} & \multicolumn{2}{|c|}{$4 \mathrm{M}$} & \multicolumn{2}{|c|}{$8 \mathrm{M}$} & \multicolumn{2}{|c|}{$12 \mathrm{M}$} \\
\hline & & $\begin{array}{l}\text { strength } \\
\text { ft.lbs }\end{array}$ & $\begin{array}{c}\% \\
\text { change }\end{array}$ & $\begin{array}{l}\text { strength } \\
\text { ft.lbs }\end{array}$ & $\begin{array}{c}\% \\
\text { change }\end{array}$ & $\begin{array}{l}\text { strength } \\
\text { ft.lbs }\end{array}$ & $\begin{array}{c}\% \\
\text { change }\end{array}$ & $\begin{array}{l}\text { strength } \\
\text { ft.lbs }\end{array}$ & $\begin{array}{c}\% \\
\text { change }\end{array}$ \\
\hline No fiber & 0.36 & 0.39 & 8 & 0.35 & 3 & 0.41 & 14 & 0.48 & 33 \\
\hline 1-layer & 1.19 & 0.91 & -23.53 & 0.85 & -28.57 & 0.77 & -35.29 & 1.03 & -13.17 \\
\hline 3-layers & 2.21 & 2.47 & 11.71 & 2.16 & -2.31 & 2.20 & -0.35 & 2.27 & 2.52 \\
\hline 5-layers & 5.37 & 3.92 & -27.04 & 2.81 & -47.63 & 2.29 & -57.39 & 2.55 & -52.54 \\
\hline
\end{tabular}

Change in overall strength values of specimens made of recycled ABS polymers with $0,1,3$ and 5 layers of glass fabric due to 1, 4, 8 and 12 months of aging as compared to those without aging are presented (Table C.7 and C.8) 
Aging scheme: strength change under alkaline solution room temperature

Strength change with 0-layer: $-3 \%, 28 \%, 6 \%, 17 \%$

$$
\begin{aligned}
& \text { 1-layer: }-9.52 \%,-32.49 \%,-66.11 \%,-65.27 \% \\
& \text { 3-layers: }-24.02 \%, 20.4 \%,-73 \%,-72.71 \% \\
& \text { 5-layers: }-21.05 \%,-60.86 \%,-92.86 \%,-93.17 \%
\end{aligned}
$$

Aging scheme: strength change under alkaline solution under freeze-thaw

Strength change with 0-layer: $-17 \%, 3 \%, 6 \%, 6 \%$

$$
\begin{aligned}
& \text { 1-layer: }-52 \%,-70.87 .66 \%,-70.59 \%,-68.63 \% \\
& \text { 3-layers: }-35 \%,-64.12 \%,-83.42 \%,-81.15 \% \\
& \text { 5-layers: }-70 \%,-83.48 \%,-93.04 \%,-93.17 \%
\end{aligned}
$$

Aging scheme: strength change under salt solution room temperature

Strength change with 0-layer: $-3 \%, 22 \%, 22 \%, 22 \%$

$$
\begin{aligned}
& \text { 1-layer: } 48.74 \%,-0.28 \%,-12.32 \%,-2.24 \% \\
& \text { 3-layers: } 12.17 \%, 6.89 \%, 16.39 \%, 14.43 \% \\
& \text { 5-layers: }-16.39 \%,-45.21 \%,-44.96 \%,-45.33 \%
\end{aligned}
$$

Aging scheme: strength change under salt solution under freeze-thaw

Strength change with 0-layer: 8\%, 3\%, 14\%, 33\%

$$
\begin{aligned}
& \text { 1-layer: }-23.53 \%,-28.57 \%,-35.29 \%,-13.17 \% \\
& \text { 3-layers: } 11.71 \%,-2.31 \%,-0.35 \%, 2.52 \% \\
& \text { 5-layers: }-27.29 \%,-47.63 \%,-57.39 \%,-52.54 \%
\end{aligned}
$$

\section{C.4.1 Bar graph for impact strength variation for aged specimens}

Strength variation in impact test specimens due to aging are represented in the form of bar graphchart in following sections 


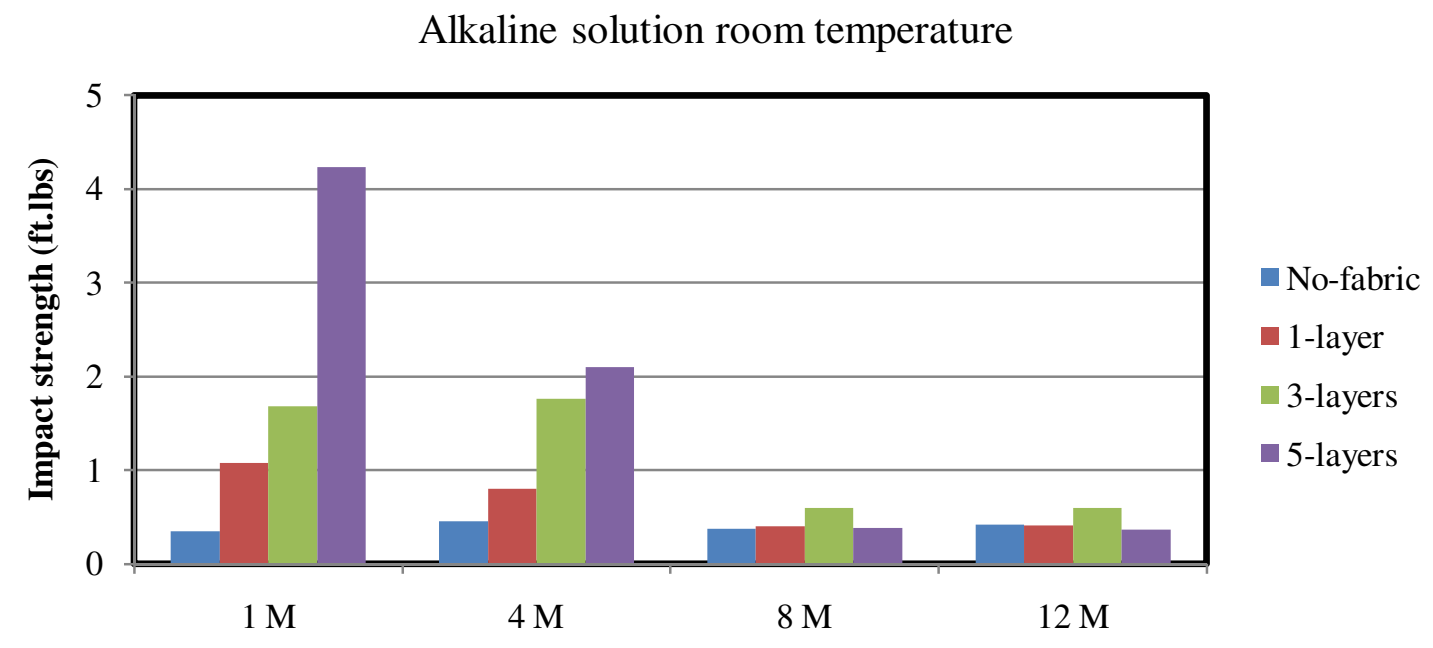

Figure C. 25 Strength reductions in alkaline solution at room temperature

The variation in impact strength of specimens with $0,1,3$ and 5 layers of glass fabric aged in alkaline solution at room temperature after 12 months were $17 \%,-65.27 \%,-72.17 \%$ and 93.17\%, respectively (Figures C.25 and C.26).

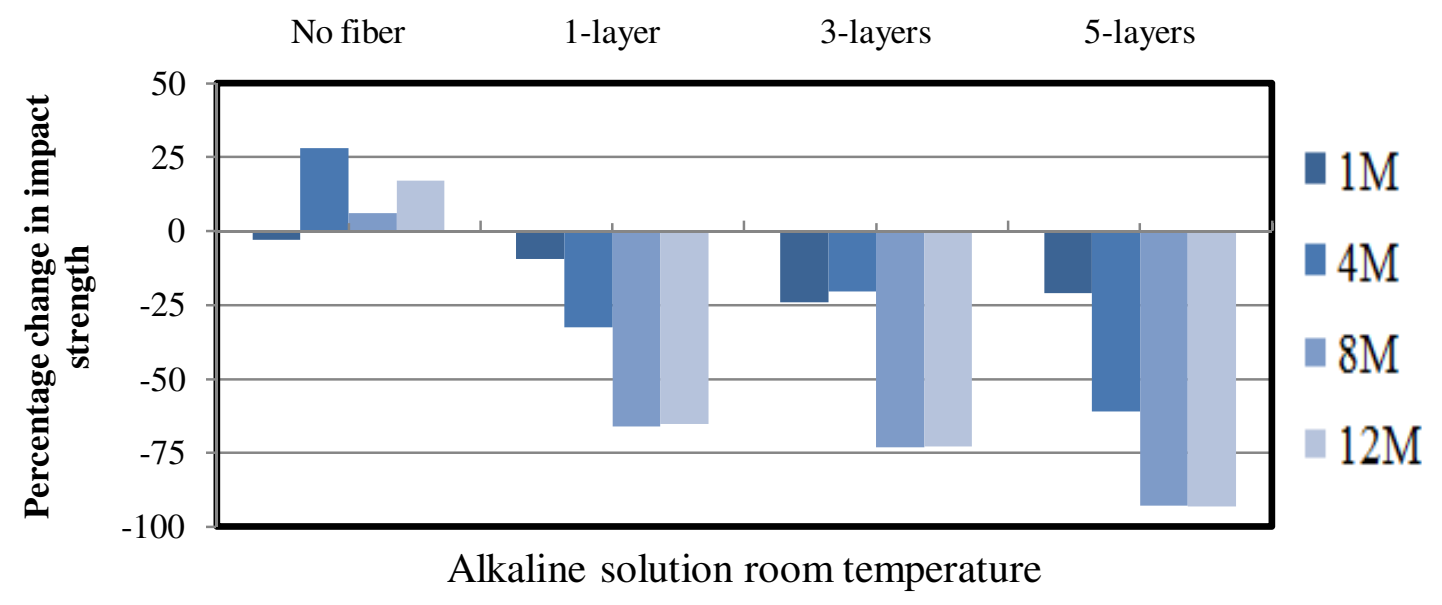

Figure C. 26 Percentage strength reductions in alkaline solution at room temperature 


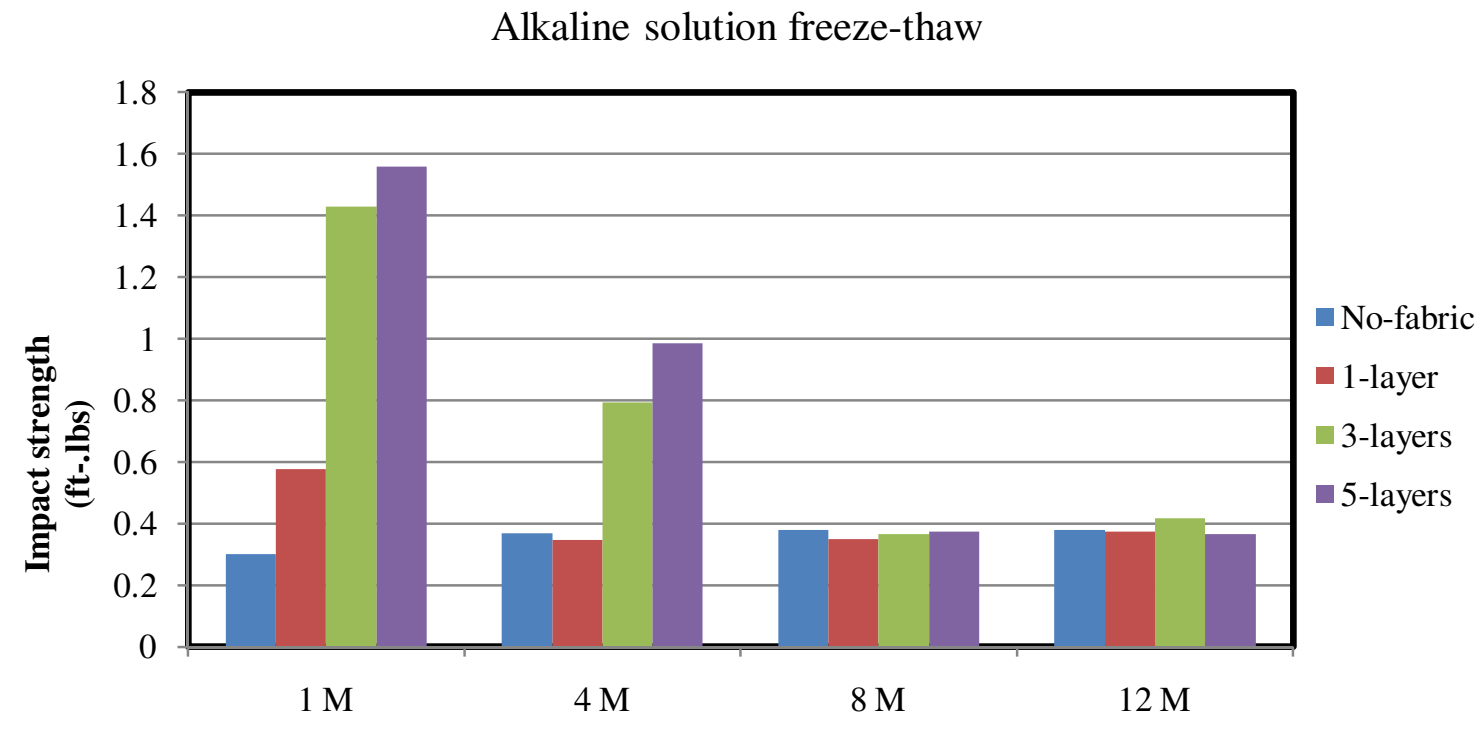

Figure C. 27 Strength reductions in alkaline solution under freeze-thaw

The variation in impact strength of specimens with $0,1,3$ and 5 layers of glass fabric aged in alkaline solution with freeze-thaw (environmental chamber) after 12 months were 6\%, -69\%,$81 \%$ and $-93 \%$, respectively (Figures C.27 and C.28).

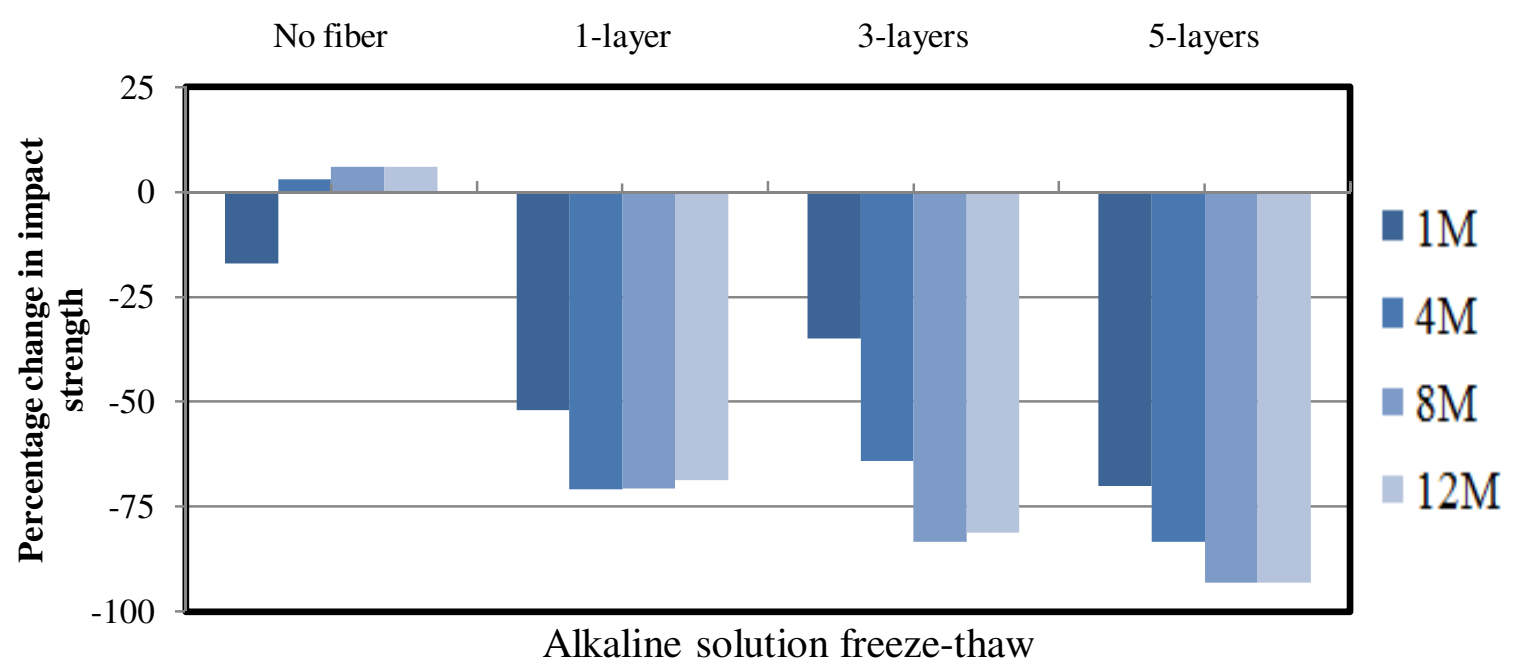

Figure C. 28 Percentage strength reductions in alkaline solution under freeze-thaw 


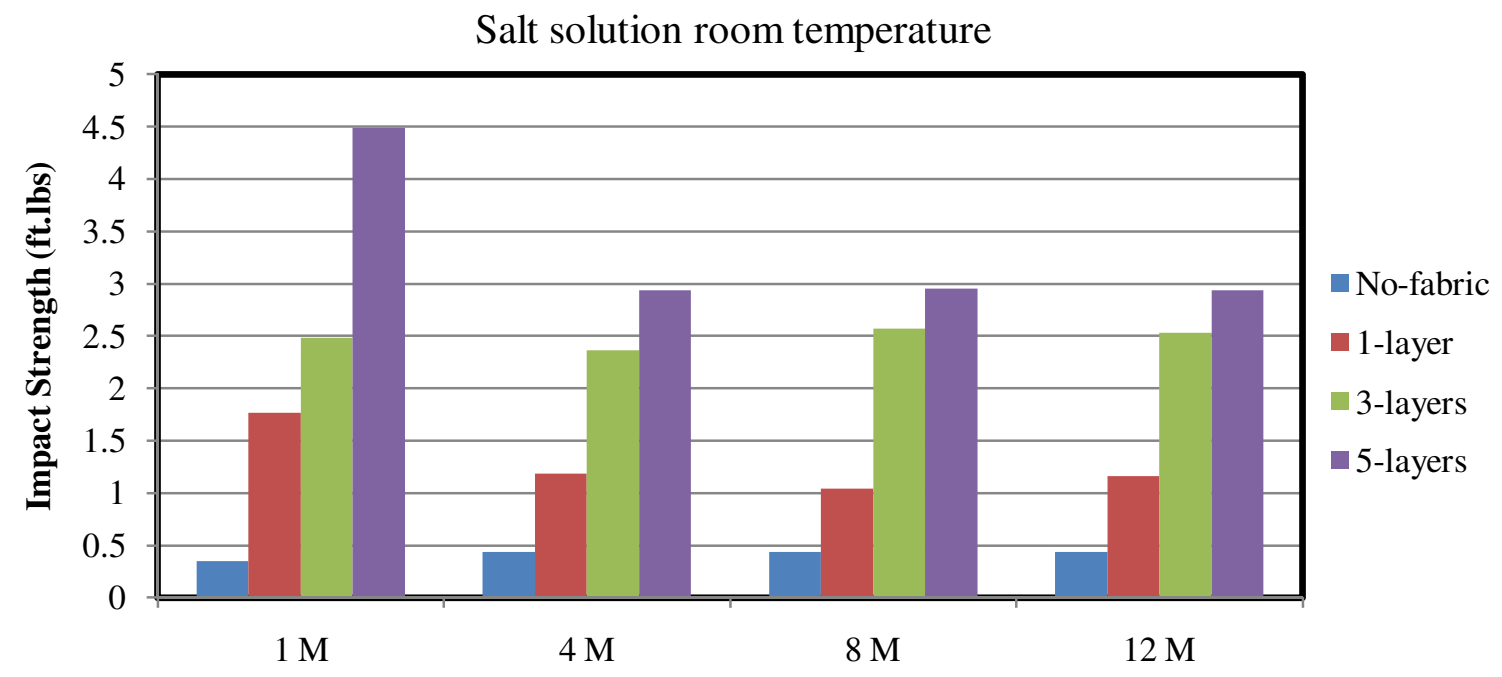

Figure C. 29 Strength reductions in salt solution at room temperature

The variation in impact strength of specimens with $0,1,3$ and 5 layers of glass fabric aged in salt solution at room temperature after 12 months were $22 \%,-2.24 \%,+14.43 \%$, and $-45.33 \%$, respectively (Figures C.29 and C.30).

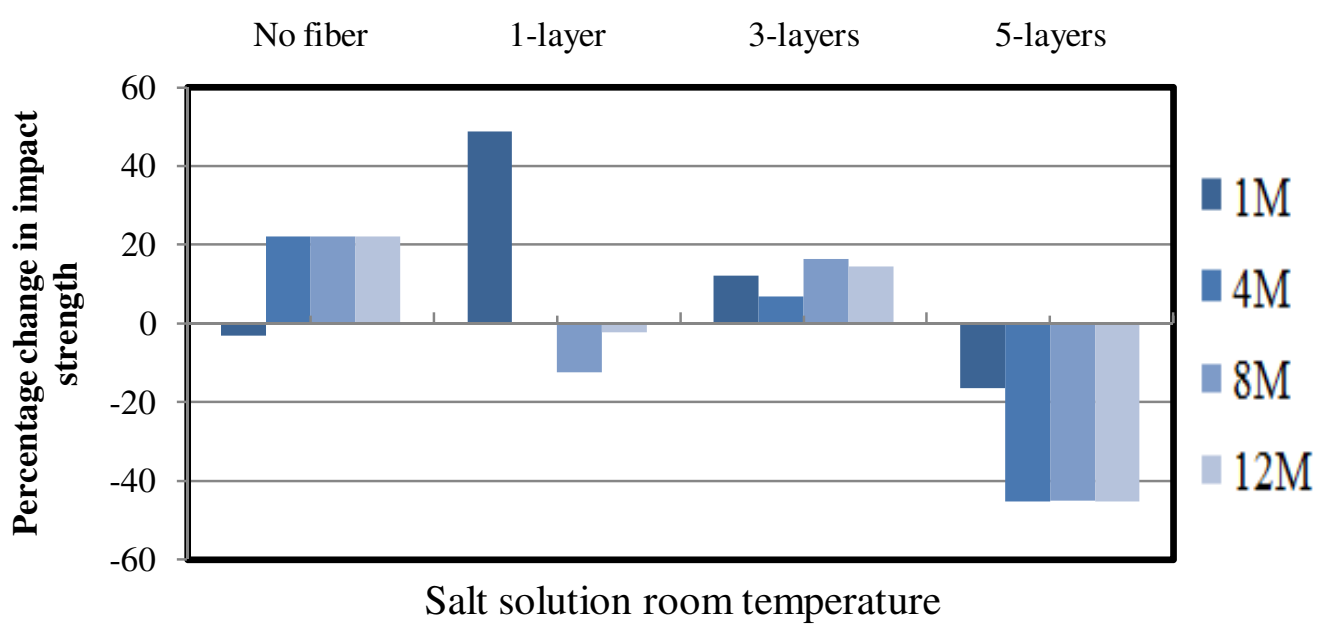

Figure C. 30 Percentage strength reductions in salt solution at room temperature 
Salt Solution freeze-thaw

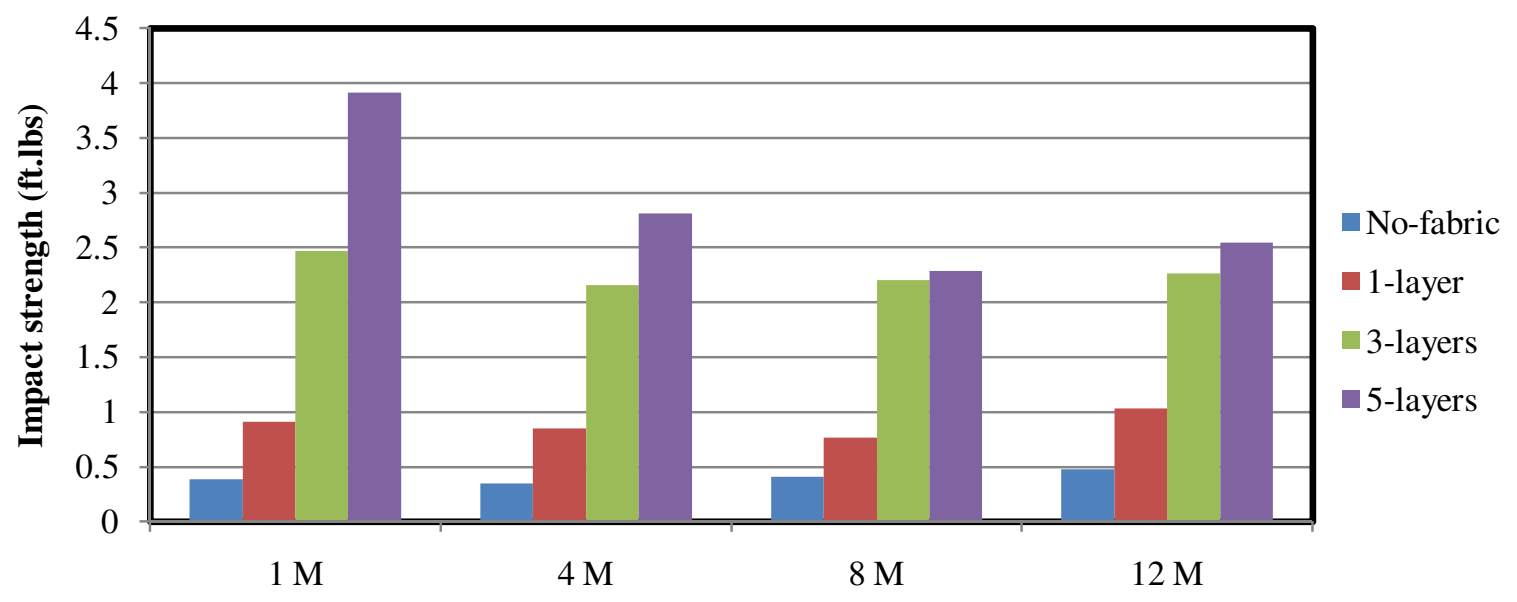

Figure C. 31 Strength reductions in salt solution under freeze-thaw

The variation in impact strength of specimens with $0,1,3$ and 5 layers of glass fabric aged in salt solution with freeze-thaw (environmental chamber) after 12 months were $+33 \%,-13.17 \%$, $+2.52 \%$ and $-52.54 \%$, respectively (Figures C.31 and C.32).

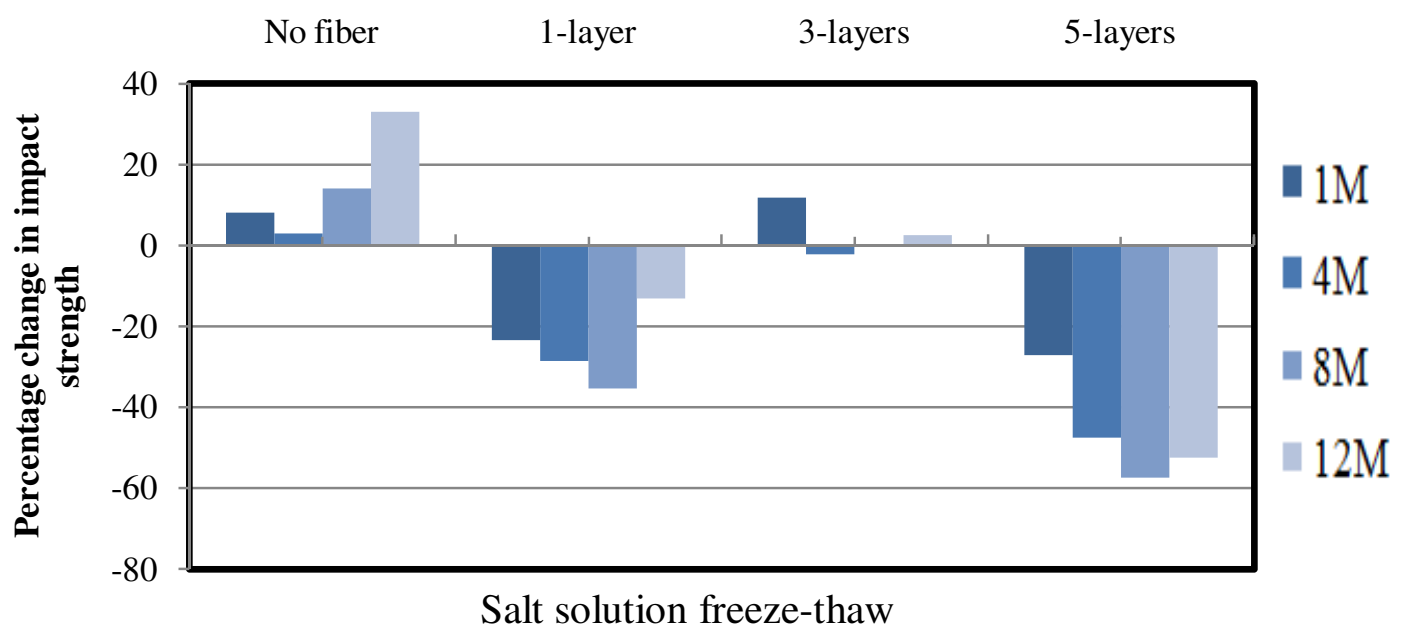

Figure C. 32 Percentage strength in salt solution under freeze-thaw 


\section{APPENDIX D:}

\section{D.1 Hand Lay-Up Method Sandwich Composites Thermoplastic/Thermoset}

\section{(TP/TS)}

Virgin ABS plates with 2 layers of glass fabric (7\% FVF) reinforcement were manufactured for TP/TS sandwich plates using compression molding process. Two layers of thermoset resin wet glass fabric were laid over ABS plate to form a (TP/TS) sandwich composite plate of vinyl ester (TS) and ABS (TP). Surface roughening of ABS plates was achieved using a DeWALT HeavyDuty 7"/ 9" large angle sander (Figure D.1). Surface roughening was achieved to better grip the thermoset over thermoplastic.

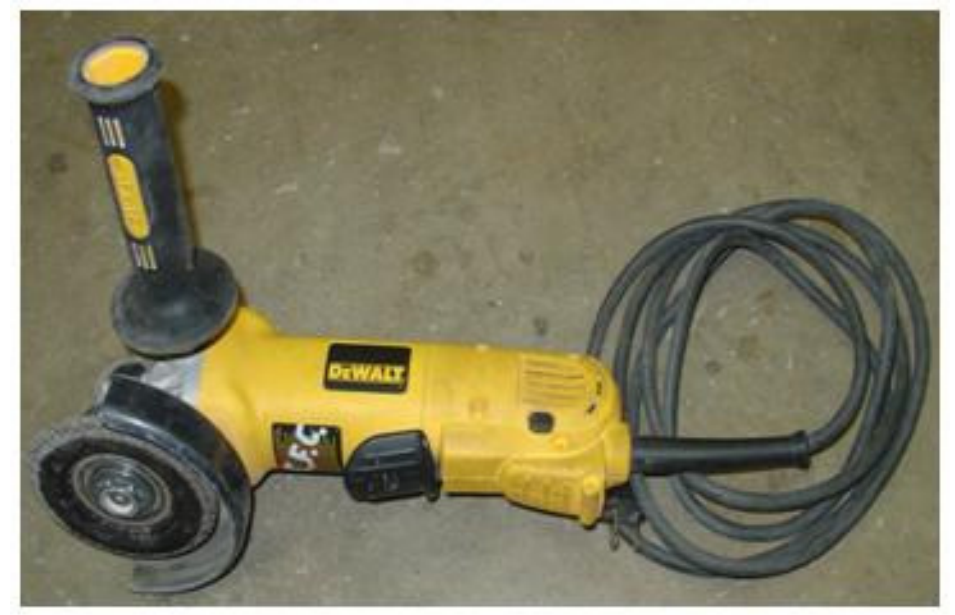

Figure D. 1 DeWALT Heavy-Duty 7"/ 9" Large Angle Sander

\section{D.1.1 Manufacturing procedure (TS/TP)}

1. Required size glass fabrics cut and was placed on an aluminum foil (Figure D.2 (a)). Vinyl ester resin (mixed with 2\% of Methyl Ethyl Ketone Peroxide as a curing agent) was poured on glass fabrics (Figure D.2 (b)) and was spread using 2" wide brush (Figure D.2 (c)). 
2. This vinyl-ester wet glass fabric layers were laid over roughened/un-roughened ABS plate (Figure D.2 (e) and (f)).

3. Proper brushing over vinyl-ester wet glass fabric layer was carried out to remove the entrapped air at the TP/TS interface (Figure D.2 (g)).

4. Finally, the plates were cured at room temperature (Figure D.2 (h)).

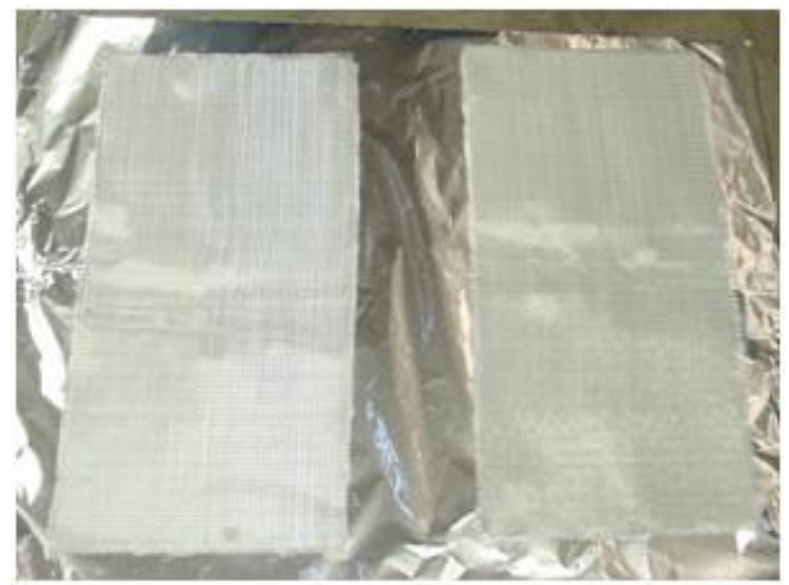

(a) Glass fiber sheets

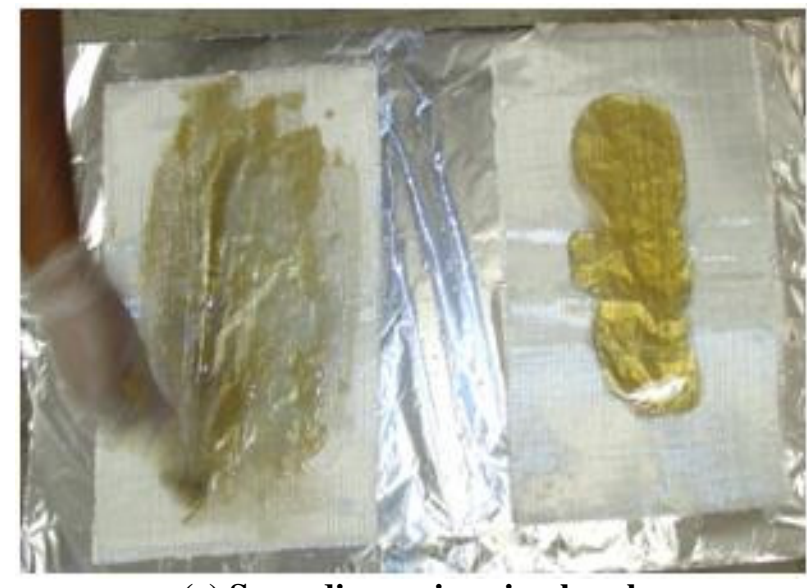

(c) Spreading resin using brush

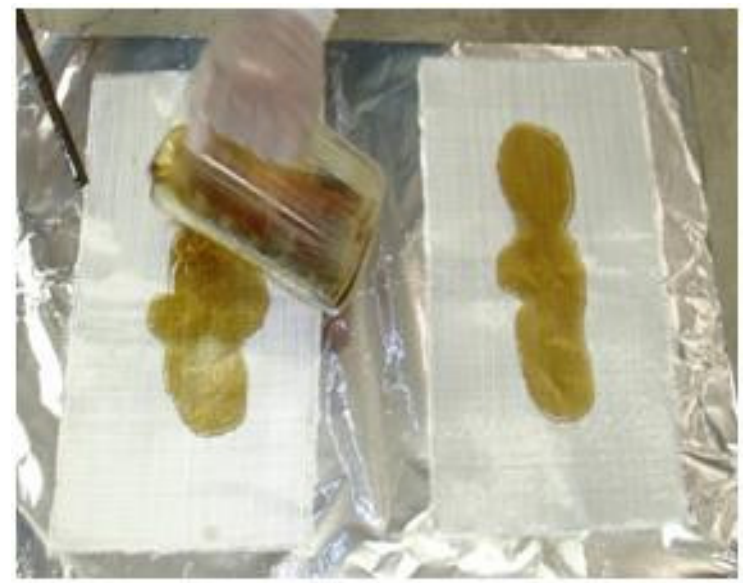

(b) Pouring of vinyl ester

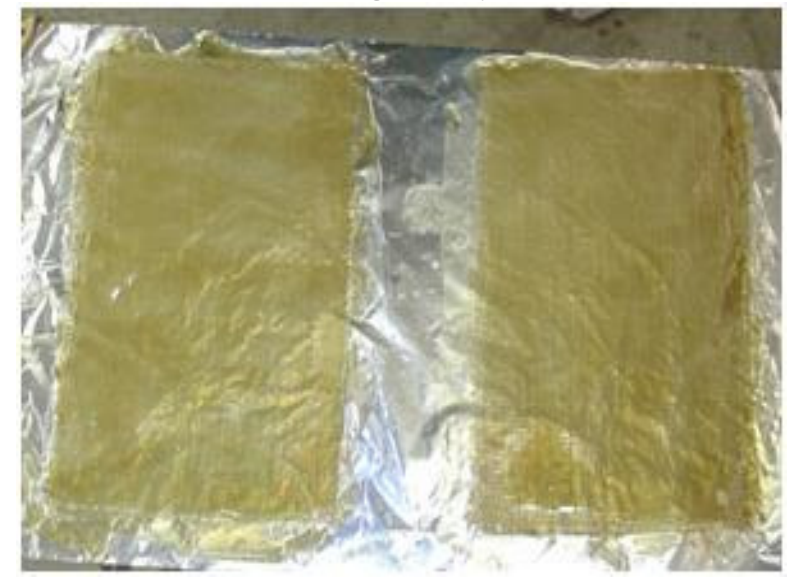

(d) Vinyl ester glass fibers are ready 


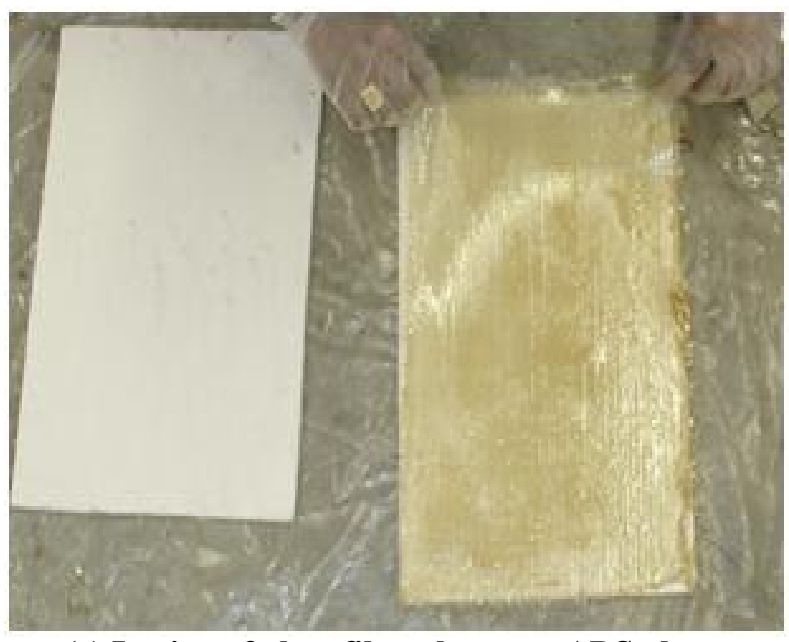

(e) Laying of glass fiber sheets on ABS plates

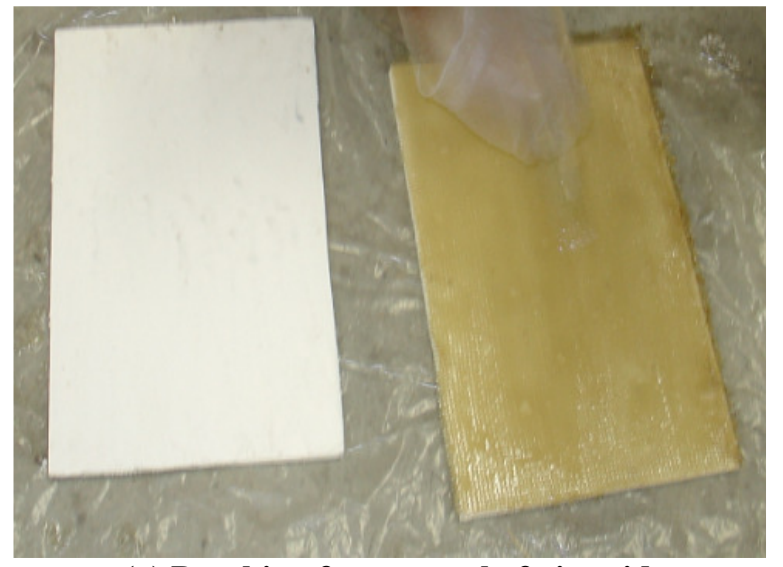

(g) Brushing for removal of air voids

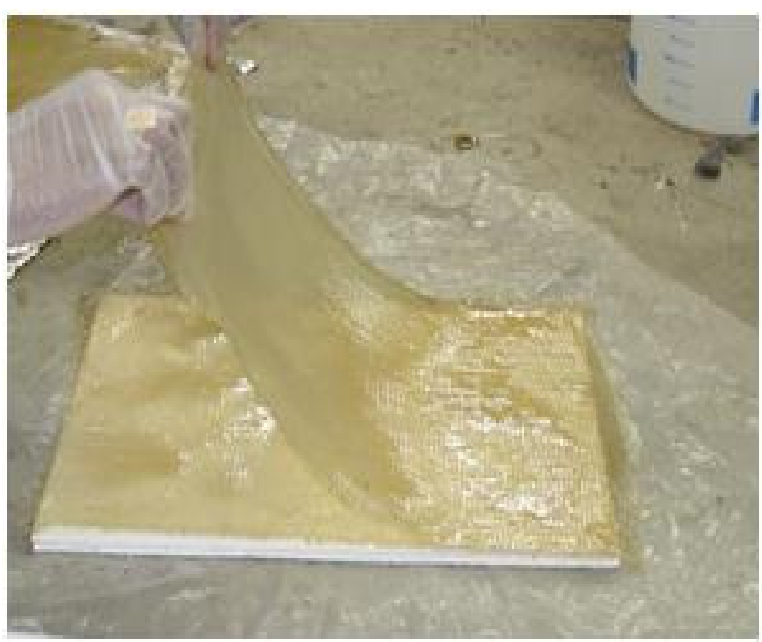

(f) Second layer of glass fiber on ABS plate

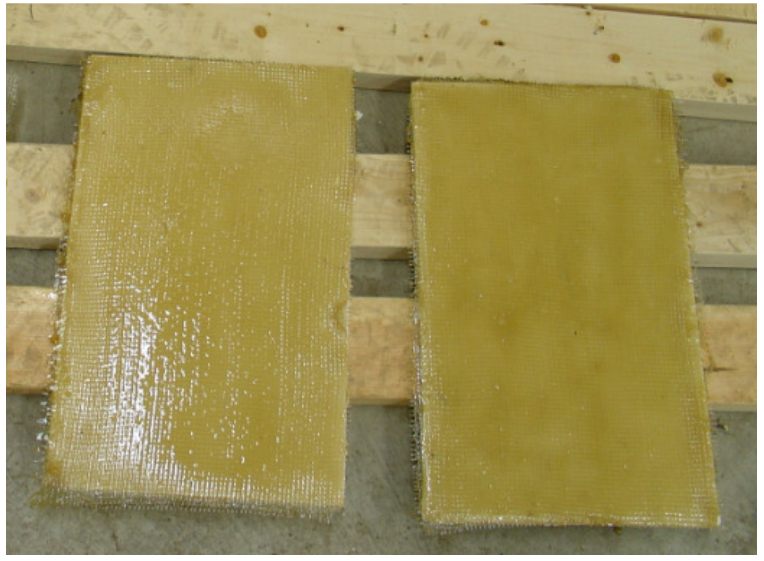

(h) Plates are cured at room temperature

Figure D. 2 Manufacturing of TP/TS composite sandwich plate

\section{D.1.2 Procedure for manufacturing thermoplastics/thermoset/thermoplastics (TP/TS/TP)}

1. Steps 1,2, and 3 from TS/TP procedure (section D.1) have to be repeated and an ABS plate was placed over vinyl-ester wet glass fabric side.

2. A weight of 3-4 lbs was placed over the TP plate as shown in Figure D.3 (a) and D.3 (b) which squeezes out extra resin from between ABS plates.

3. Finally, TP/TS/TP Sandwich composite plates were cured it at room temperature. 


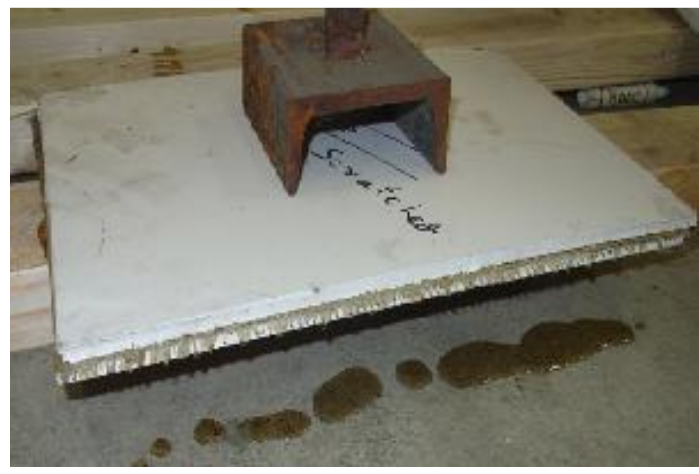

(a) Weight placed on plate to squeeze resin

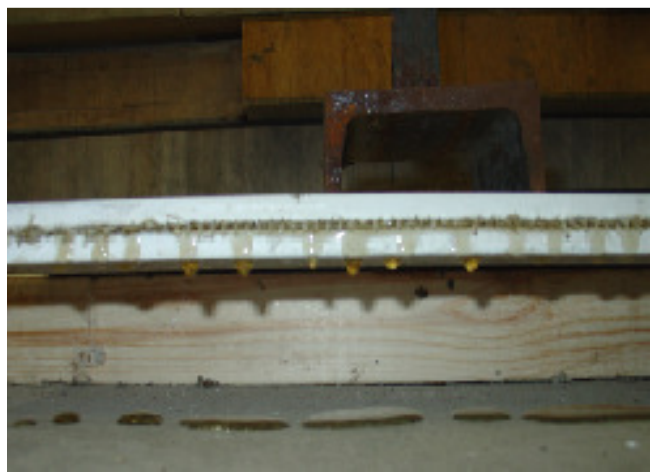

(b) Extra resin trickling down

Figure D. 3 Bonding of composite sandwich plate components (TP/TS/TP)

\section{D.1.3 Procedure for manufacturing thermoset/thermoplastics/thermoset (TS/TP/TS)}

1. Steps 1, 2, 3 and 4 have to be repeated from TS/TP procedure (complete curing of wet glass fabric layer on one side is mandatory for an over of another layer on the other side of the ABS plate).

2. A vinyl-ester wet glass fabric is laid on the other side of an ABS polymer plate and proper brushing ensured the removal of air voids.

3. The new vinyl-ester wet glass fabric layer side was cured at room temperature.

These plates were reinforced with extra fabrics at end zones (Figure D.4 (a), (b), (c) and (d)) to facilitate strengthening of gripping near end zones (tab area) during tension test.

\section{D.2 Bonding between Thermoplastic and Thermoset (TS/TP/TS) with End}

\section{Tabs}

The manufactured plates were machined to rectangular shape tension test specimens. Vinylester end tabs were manufactured for tension test specimens only (Figure D.4 (c) and (d)) to ensure the failure in gage length. However, several un-roughened specimens with poor bonding characteristics de-bonded due to vibration caused during machining. Followed by 
coupon specimen manufacturing and machining, different tests were carried out as applicable to ASTM standards.

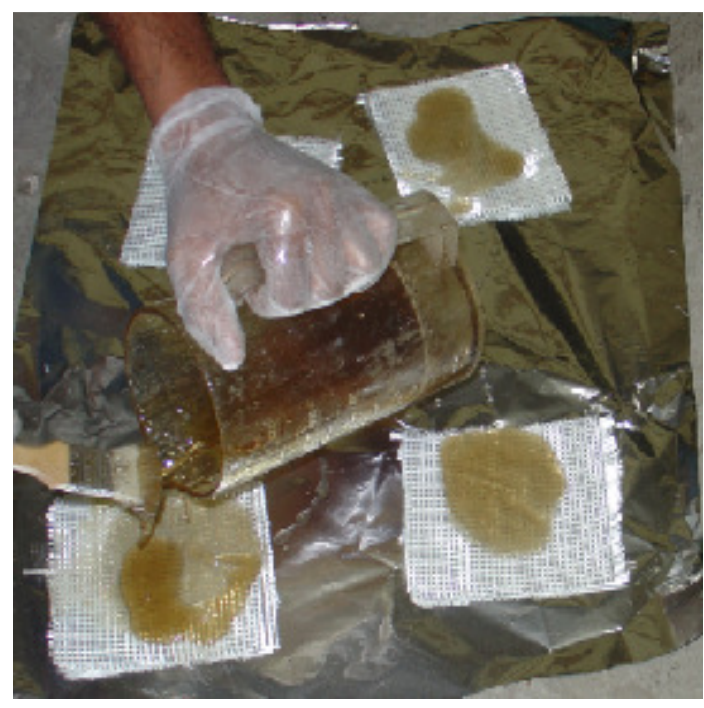

(a) Wetting glass fabrics with vinyl ester resin

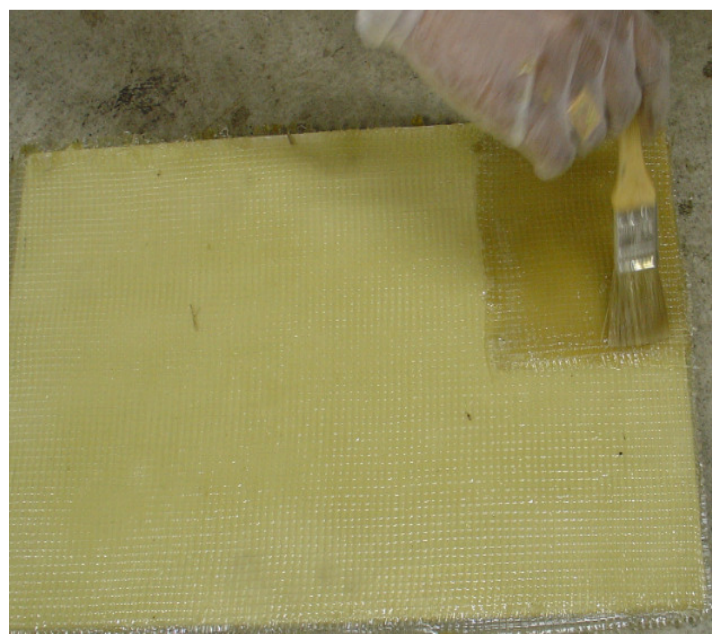

(c) Brushing for the removal of voids

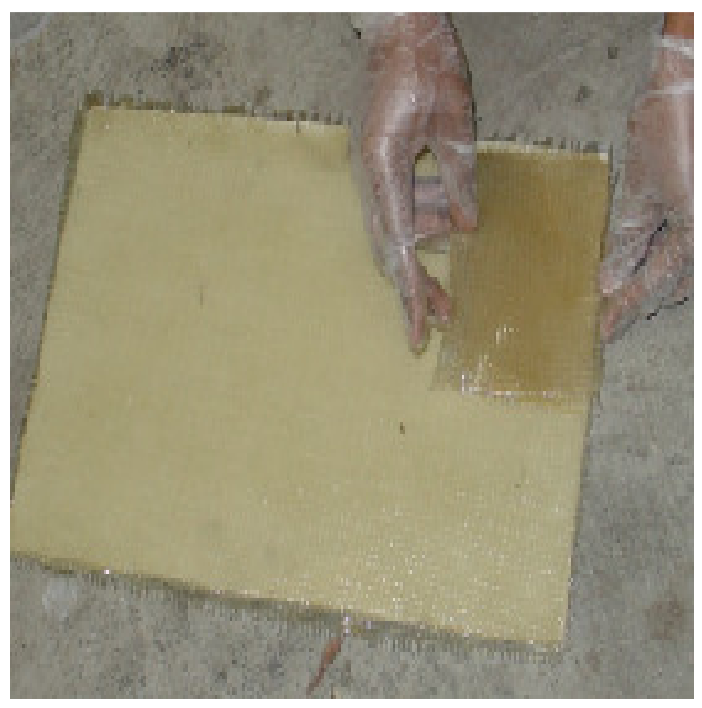

(b) Placing of glass fiber on plate

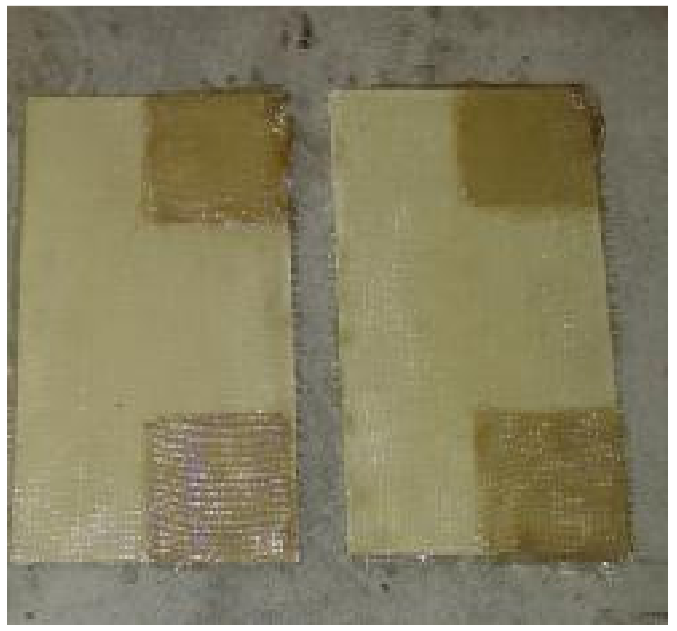

(d) Plates are ready with tabs on either side Figure D. 4 Application of tabs for sandwich specimens

\section{D.3 Specimen Manufacturing of Bond Test}

Procedure:

1. Two aluminum plates were covered with aluminum foil and were applied with demolding agent. 
2. 2 in. $x 0.75$ in area of rectangular shaped specimens was roughened (for bonding) using DeWALT Heavy-Duty 7"/ 9" large angle sander on one side end (area between black lines) (Figure D.5 (a)).

3. Aluminum plate and rectangular ABS specimens (with roughened side up) were arranged at same level on an aluminum plate (Figure D.5 (b)).

4. A layer of resin wet glass fabric with vinyl-ester was laid partially over the roughened ABS specimens and partially over aluminum plate, followed by brushing for removal of air voids (Figure D.5 (c)).

5. Rectangular ABS specimens were laid over wet glass fabric sheet (with roughened surface downside), such that they were just above the previously laid ABS specimens (Figure D.5 (d)).

6. A gentle weight of 3-4 lbs was applied for proper bonding between the thermoplastic and thermoset (Figure D.5 (e)).

7. Finally, the whole setup was cured at a temperature of $160 \mathrm{~F}$ and specimens were machined from the manufactured plate (Figure D.5 (f)). 


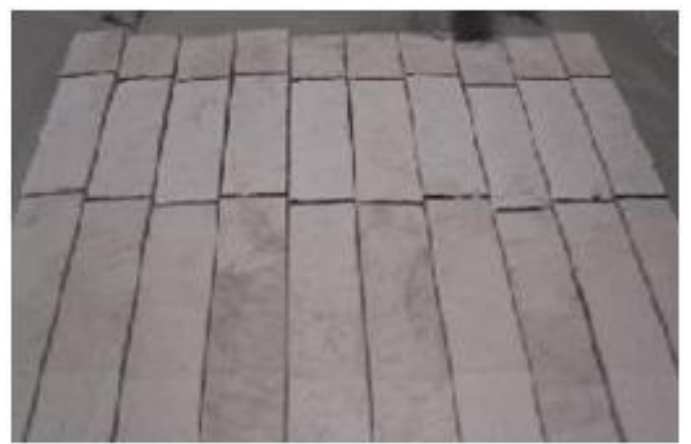

(a) Areas in the grip region was roughened

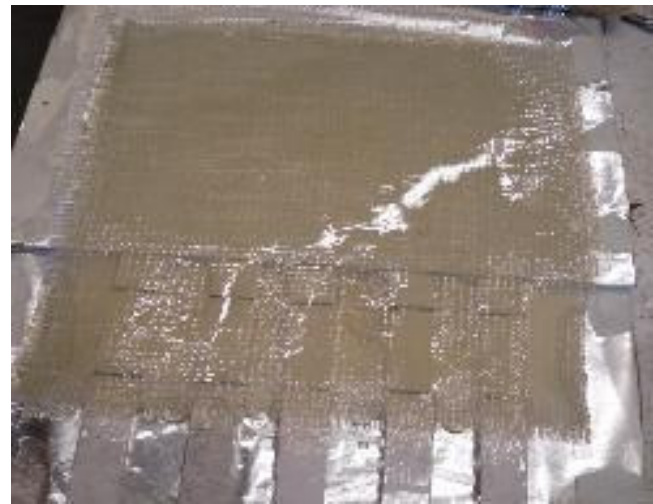

(c) Over lay of vinyl ester wet glass fabric

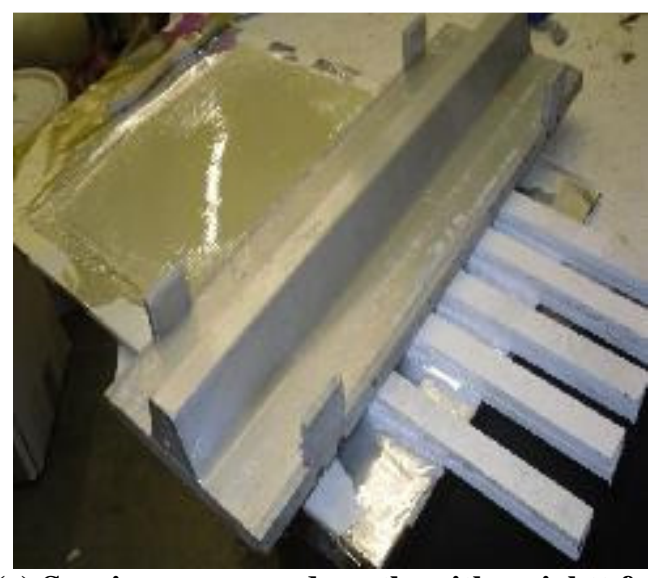

(e) Specimens pressed gently with weightt for proper bonding

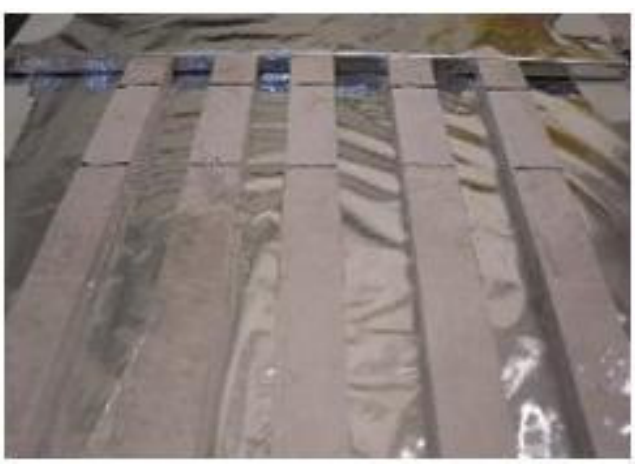

(b) Rectangular ABS specimens are arranged at the same level of aluminum plate

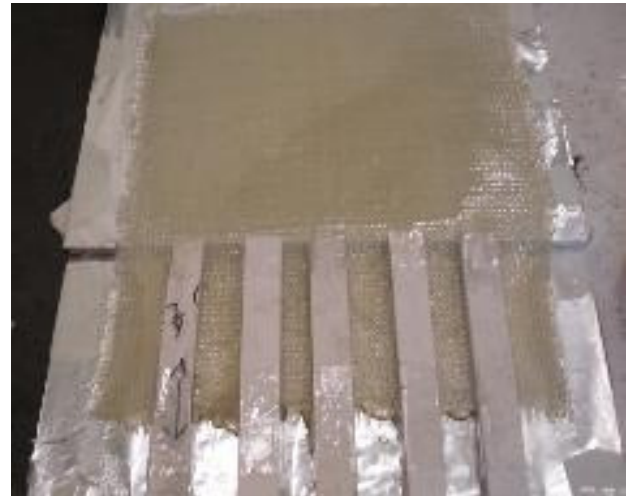

(d) Another set of ABS specimens just over the previously laid rectangular ABS specimens

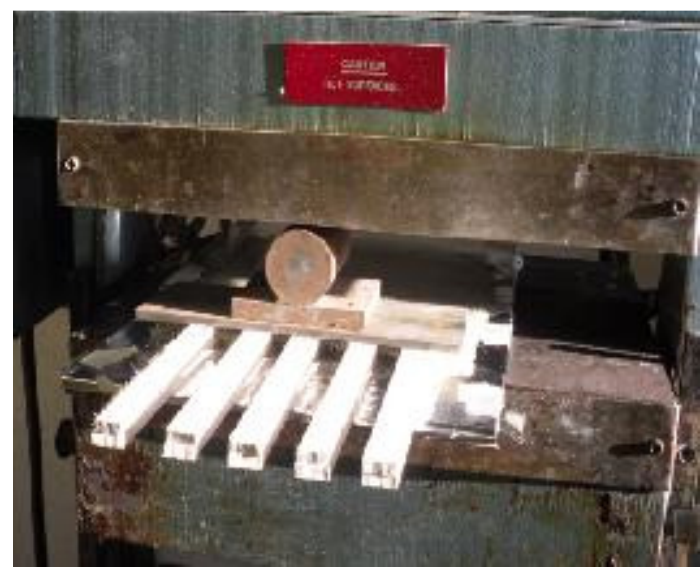

(f) Setup cured at a temperature of $160 \mathrm{~F}$

Figure D. 5 Manufacturing of specimens for bond test 


\section{Appendix E}

\section{Rule of Mixtures for non-aged Tension and Bending test results:}

$E_{c}=E_{f} x V_{f}+E_{m}\left(1-V_{f}\right)$

$\mathrm{E}_{\mathrm{f}}=10.5 \mathrm{msi}$.

Fiber Volume fraction $=4 \%, 7 \%$ and $12 \%$.

$\mathrm{E}_{\mathrm{m}}=0.31 \mathrm{msi}$.

$\mathrm{V}_{\mathrm{m}}=1-\mathrm{V}_{\mathrm{f}}$

For 4\% Fiber Volume Fraction:

$\mathrm{V}_{\mathrm{f}}=\mathrm{V}_{\mathrm{f}} / 2$ (for bi-directional, only $50 \%$ contributes in longitudinal direction)

$\mathrm{E}_{\mathrm{c}}=10.5 \times 0.02+0.31 \times(1-0.04)=0.5076 \mathrm{msi}$

For 4\% Fiber Volume Fraction:

$\mathrm{E}_{\mathrm{c}}=10.5 \times 0.035+0.31 \times(1-0.07)=0.655 \mathrm{msi}$

For 4\% Fiber Volume Fraction:

$E_{c}=10.5 \times 0.06+0.31 \times(1-0.12)=0.902 \mathrm{msi}$

Where

$\mathrm{E}_{\mathrm{c}}=$ Modulus of Composite

$E_{f}=$ Modulus of Fabric.

$\mathrm{E}_{\mathrm{m}}=0.31 \mathrm{msi}=$ Modulus of Matrix (experimental data).

$\mathrm{V}_{\mathrm{f}}=$ Volume fraction of Fabric.

$\mathrm{V}_{\mathrm{m}}=$ Volume fraction of Matrix. 